\title{
Taxonomic Revision of Natatolana (Crustacea: Isopoda: Cirolanidae)
}

\author{
STEPHEN J. KEABLE
}

Australian Museum, 6 College Street, Sydney NSW 2010, Australia

Stephen.Keable@austmus.gov.au

\begin{abstract}
Natatolana Bruce, 1981 is one of the most speciose, widespread and abundant isopod genera occurring in marine environments. Species in the genus are ecologically important as scavengers and occasionally have a negative impact on commercial fisheries by feeding on catches restrained in traps, nets or on lines. The study of Natatolana species is hampered by difficulties in identification, inadequate descriptions and a lack of overall taxonomic revision. In this study, taxonomic, biogeographical and ecological information is reviewed for all 72 species of Natatolana now recognized worldwide. A revised generic diagnosis, a key to species, and diagnoses and synonymies for all species are presented. Phylogenetic relationships of the genus and species are discussed. Thirteen new species are described, 10 from Australia: N. brucei n.sp., N. buzwilsoni n.sp., N. debrae n.sp., N. femina n.sp., N. flexura n.sp., $N$. helenae n.sp., $N$. lilliput n.sp., N. rusteni n.sp., $N$. sinuosa n.sp., and $N$. zebra n.sp., and three from New Zealand: N. aotearoa n.sp., N. honu n.sp., and $N$. paranarica n.sp. Redescriptions or new illustrations are provided for an additional seven species. Lectotypes are designated for three species. Justification for placement of $N$. lurur and $N$. wullunya as junior synonyms of $N$. arcicauda and N. nammuldi, respectively, is presented.
\end{abstract}

KeAble, StePhen J., 2006. Taxonomic revision of Natatolana (Crustacea: Isopoda: Cirolanidae). Records of the Australian Museum 58(2): 133-244.

\section{Contents}

Materials and methods 138

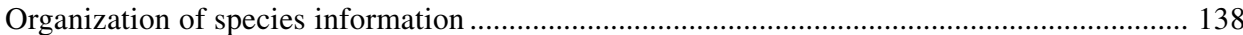

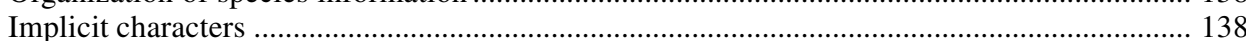

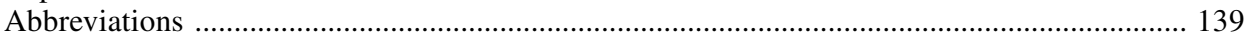

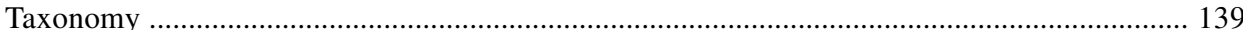

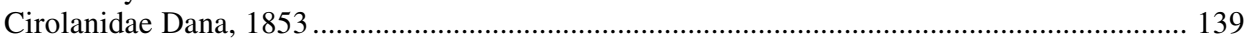

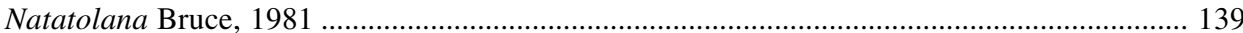

Key to species of Natatolana

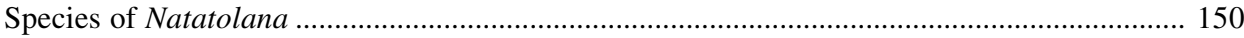

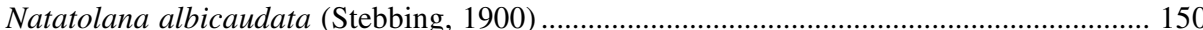

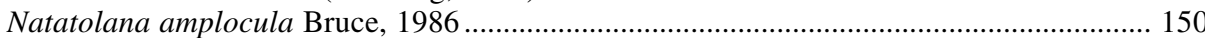

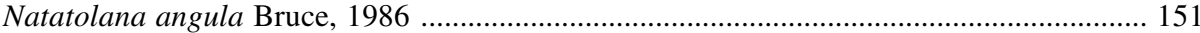

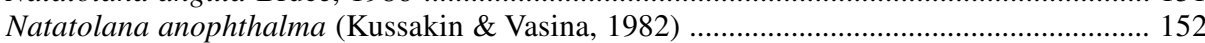

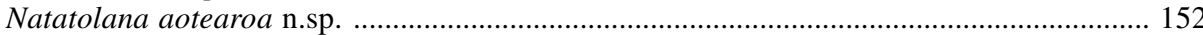

Natatolana arcicauda (Holdich, Harrison \& Bruce, 1981) .................................................. 155 


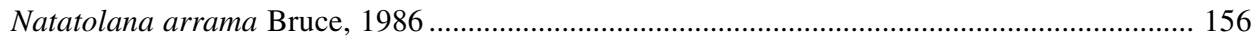

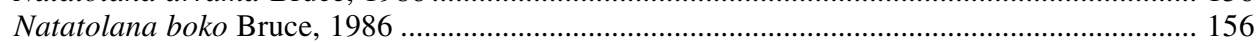

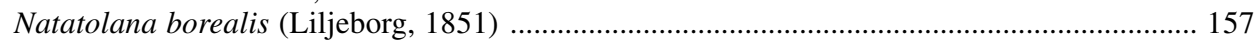

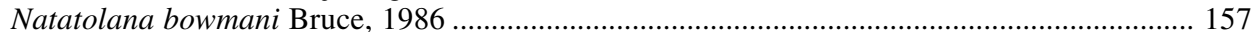

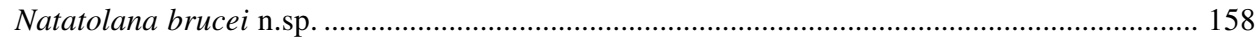

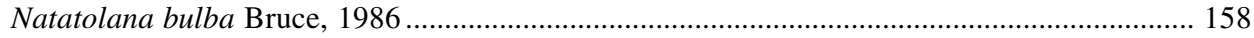

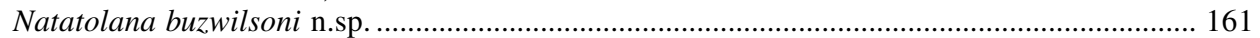

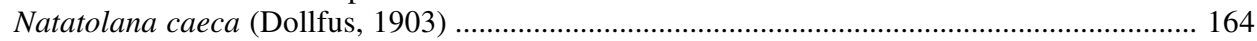

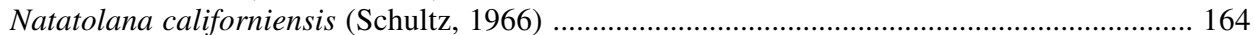

Natatolana carlenae Brusca, Wetzer \& France, 1995 .......................................................... 165

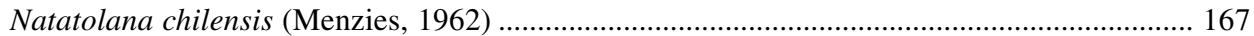

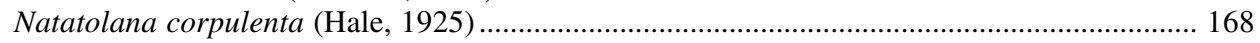

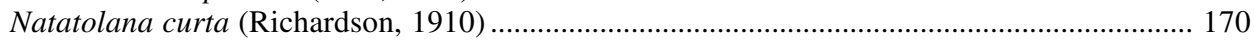

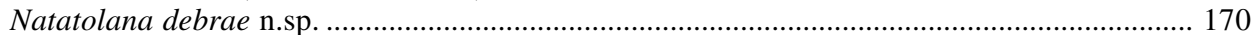

Natatolana endota Bruce, 1986 ......................................................................................... 174

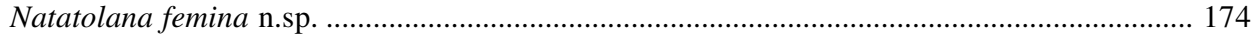

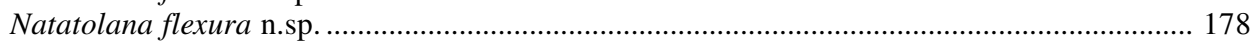

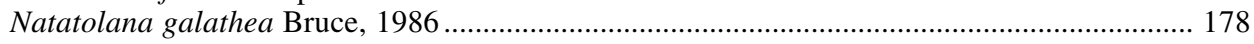

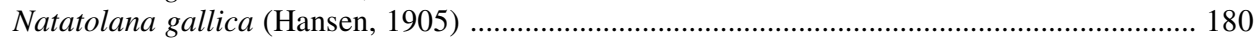

Natatolana gorung Bruce, 1986 .......................................................................................... 182

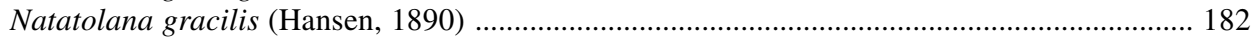

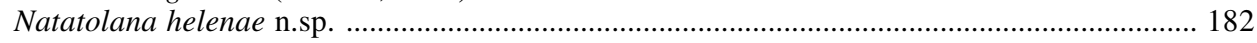

Natatolana hirtipes (Milne Edwards, 1840) ....................................................................... 185

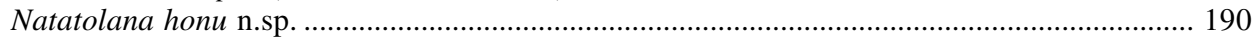

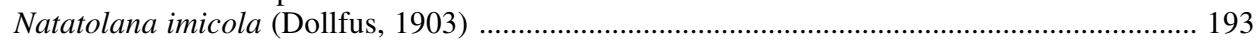

Natatolana insignis Hobbins \& Jones, 1993 .................................................................. 193

Natatolana intermedia (Vanhöffen, 1914) .......................................................................... 194

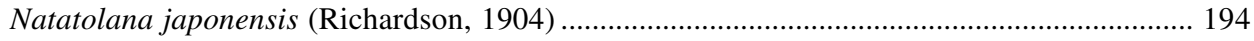

Natatolana kahiba Bruce, 1986 .............................................................................................. 195

Natatolana karkarook Bruce, 1986 .............................................................................. 195

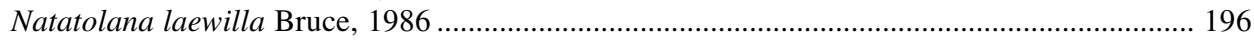

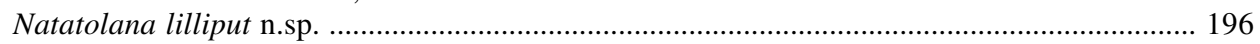

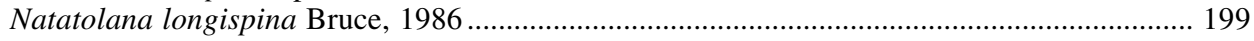

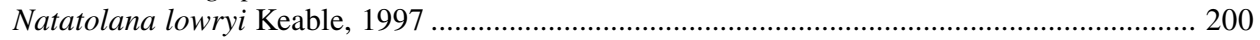

Natatolana luticola (Holdich, Harrison \& Bruce, 1981) ........................................................ 200

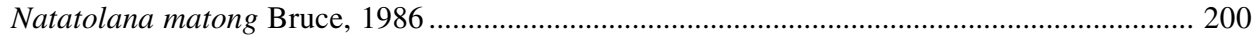

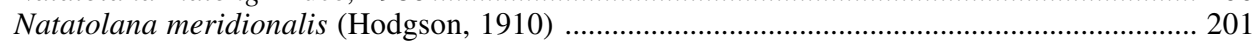

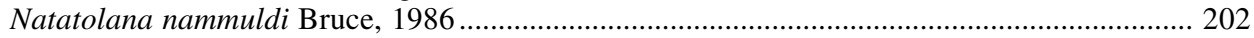

Natatolana narica (Bowman, 1971) ......................................................................................... 203

Natatolana natalensis (Barnard, 1940) …........................................................................... 203

Natatolana natalis (Menzies \& George, 1972) ...................................................................... 207

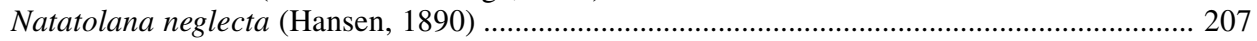

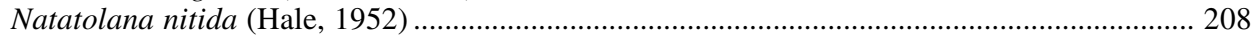

Natatolana nukumbutho Bruce \& Olesen, 1995 ......................................................................... 208

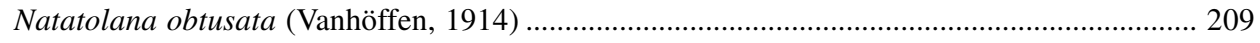

Natatolana oculata (Vanhöffen, 1914) ........................................................................................ 209

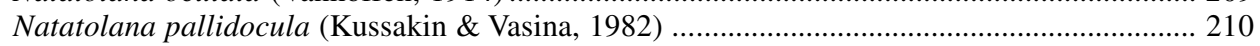

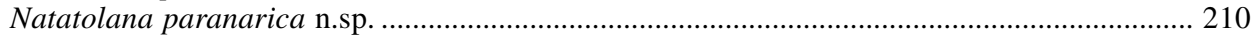

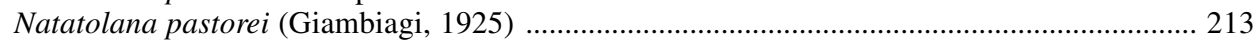

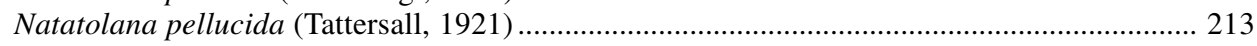

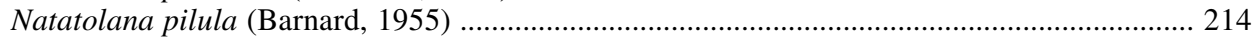

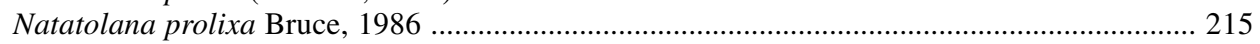

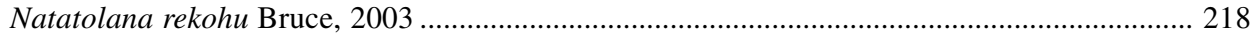

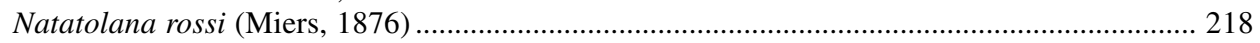

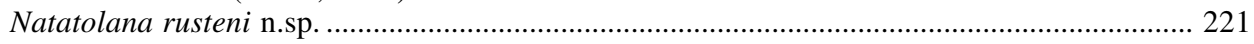

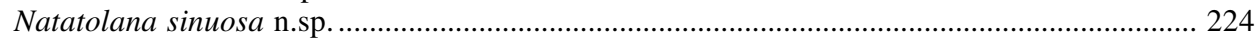

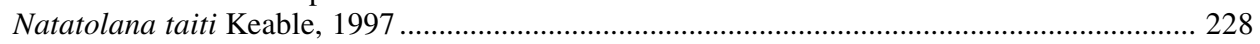

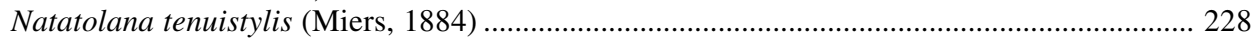

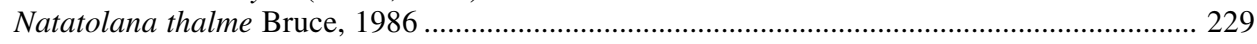

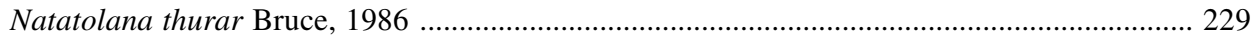

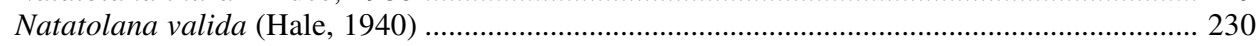

Natatolana variguberna (Holdich, Harrison \& Bruce, 1981) ...................................................... 230

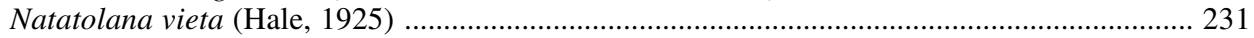

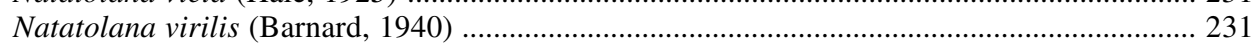

Natatolana woodjonesi (Hale, 1924) ................................................................................ 235

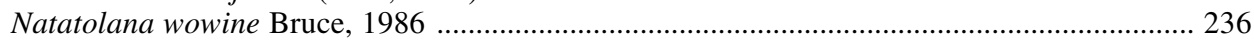

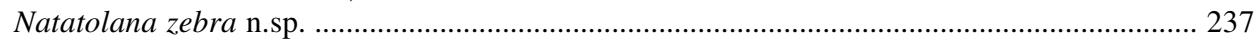

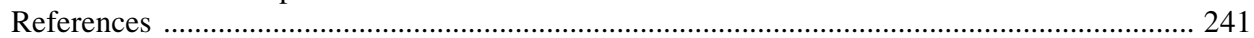




\section{Introduction}

Members of the family Cirolanidae are among the most abundant and speciose isopods of shallow marine environments as well as occurring in estuarine and freshwater habitats (Bruce, 1993a; Kensley, 1998; Bruce et $a l ., 2002)$. The family consists of approximately 61 genera, of these the most diverse are Cirolana and Natatolana, each with more than 70 nominal taxa, accounting for c. $36 \%$ of the known species in the family between them (Kensley et al., 1996 onwards; this study).

Distribution, diversity and natural history. Natatolana is the most widespread genus in the family with species found across the range of latitudes and in all oceans other than the Arctic Ocean (Fig. 1). This genus is also more diverse in temperate and cold temperate waters than other cirolanid genera (Bruce, 1986) and apparently has its greatest diversity in the southwest Pacific (Bruce, 2003; Fig. $1)$. The high diversity in this region may reflect a bias in study (e.g., Bruce, 1986; Keable, 1997; Bruce \& Olesen, 1995; Bruce, 2003; this study) relative to areas such as the coasts of Africa and South America but is valid when a comparison is made to areas where revisionary work has been undertaken, such as the North Atlantic and the tropical East Pacific (Brusca et al., 1995; Keable \& Bruce, 1997).

All species of Natatolana are restricted to marine, intertidal or subtidal environments; $N$. natalis has been collected from depths of c. 3,000 m while other species have been obtained from surface plankton (e.g., N. amplocula) or found stranded in pools on sand flats (e.g., N. karkarook). Specimens examined in this study, which could not be identified to species because of their poor condition, indicate that the genus occurs to depths of c. 6,000 $\mathrm{m}$ in the PeruChile trench (USNM 120961).The majority of species, however, are found at depths of less than 1,000 m.

Many species of Natatolana play an important role in ecosystems as scavengers (Keable, 1995, 1997; Ramsay et al., 1997; Bozzano \& Sarda, 2002; Castro et al., 2005) with their response to carrion thought to be chemosensory, involving sensilla on the antennules and antennae (Wong \& Moore, 1995; Kaïm-Malka et al., 1998). This feeding strategy represents a potentially important mechanism for the dispersal of radioactive waste or other pollutants in the marine environment (Carvalho \& Fowler, 1985). Species of the genus are also pests of commercial fisheries because they will feed on catches restrained in traps, nets or on lines (Hale, 1940; Bird, 1981; Bruce, 1986; Berrow, 1994; Mizzan, 1995). Natatolana woodjonesi has also been reported to attack and attempt to feed on SCUBA divers, causing superficial injuries (Edmonds, 1989).

Observations indicate the setose pereopods, which are an important taxonomic feature of the genus, are not used for swimming as previously suggested (Bruce, 1981) but provide protection for the pleopods during burrowing (Wägele \& Bruce, 1989; see also Wetzer et al., 1987; Keable, 1992; Taylor \& Moore, 1995). Individuals are capable of

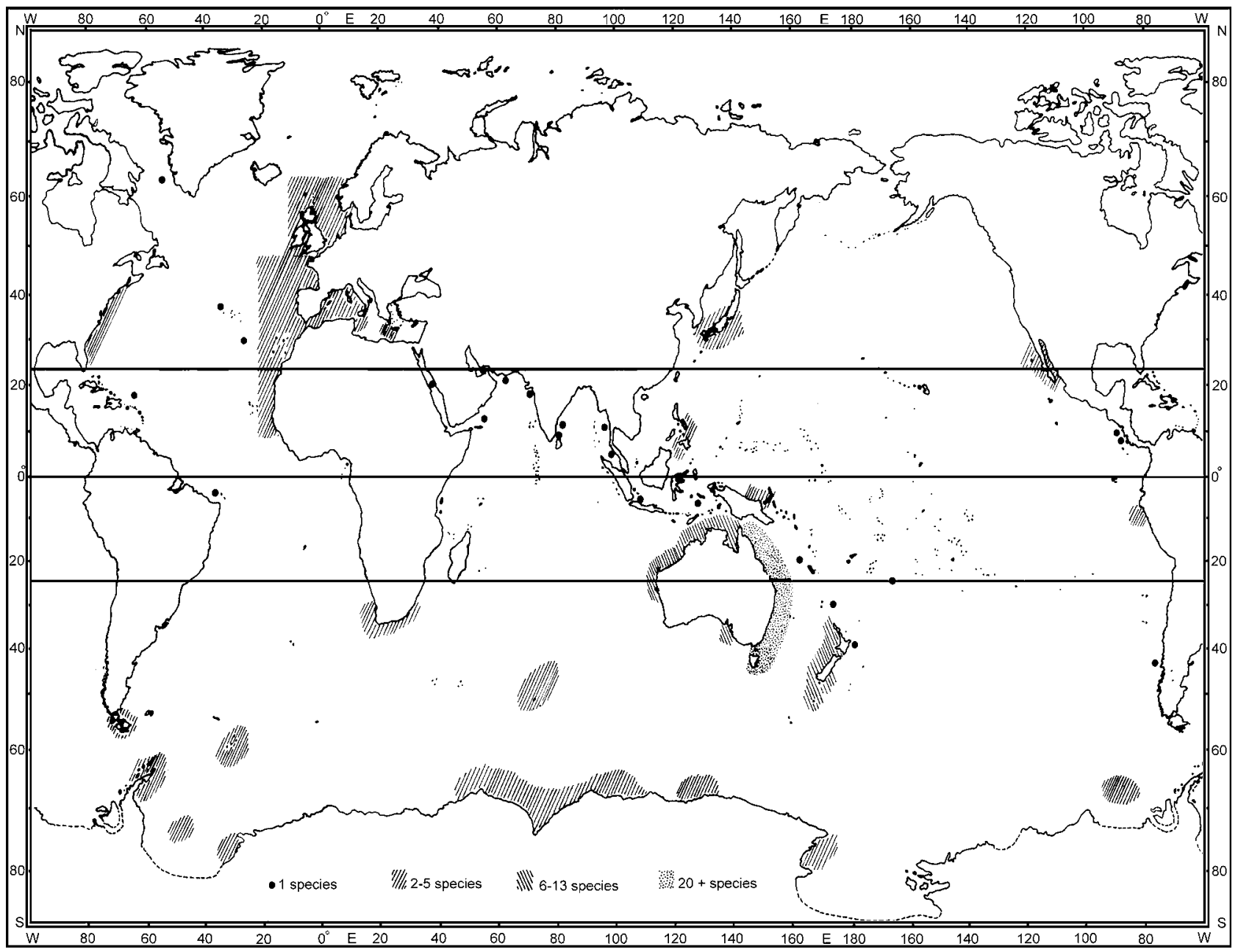

Fig. 1. World map indicating the distribution and diversity of described species of Natatolana. 

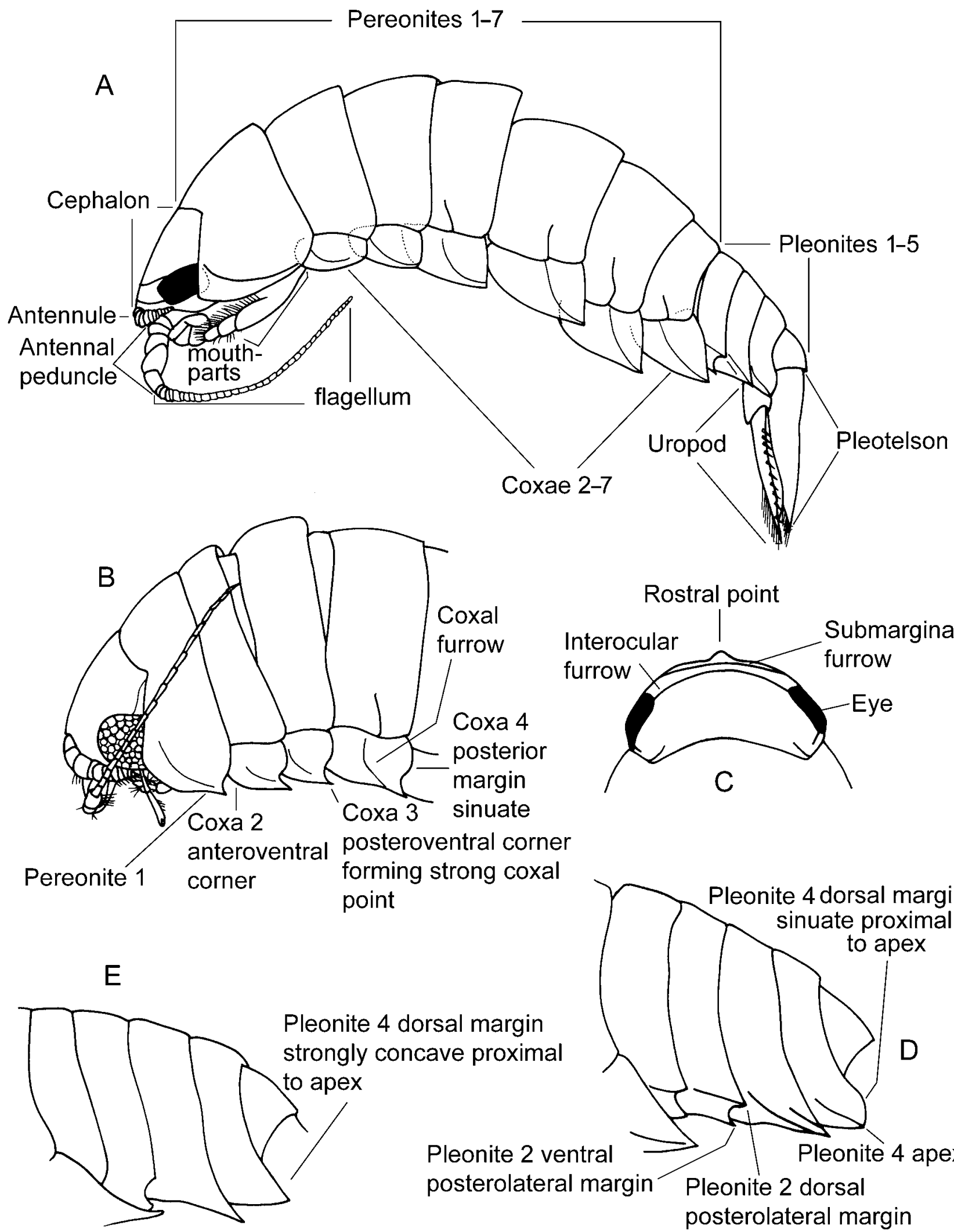

\section{Pereonite 1 corner \\ point}

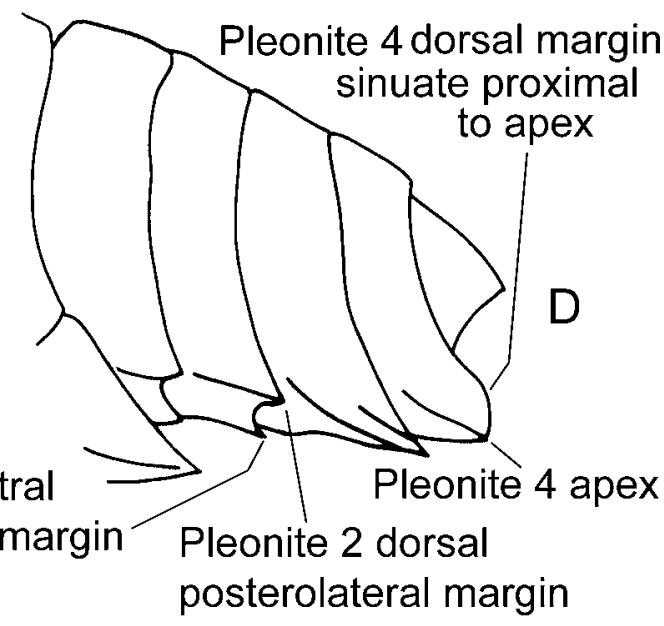

Fig. 2. Cirolanid characters referred to in text. $(A)$ Lateral view of whole animal indicating basic body parts (pereopods occurring ventrally excluded). $(B)$ Lateral view of anterior of body indicating terminology for coxae. $(C)$ Dorsal view of cephalon. $(D)$ Lateral view of pleonites indicating terminology. $(E)$ Lateral view of pleonites showing pleonite 4 with a strongly concave dorsal margin proximal to apex. 
swimming, however, by beating their pleopods (Wägele \& Bruce, 1989; Keable, 1992; Macquart-Moulin \& Kaïm-Malka, 1994; Taylor \& Moore, 1995; Wong \& Moore, 1995).

Scavenging species, such as Natatolana tenuistylis, are known to be restricted in distribution to sediments (Keable, 1992, 1995, this study) and Bruce (1986) considered that continental shelf sediments are the major habitat for species of Natatolana. At least one species ( $N$. albicaudata), however, does not appear to feed as a scavenger and has been collected from coral rock and rubble rather than sediments (Bruce, 1995a).

Composition and taxonomic revision prior to this study. Natatolana was established by Bruce (1981) during redescription and rediagnosis of Cirolana Leach, 1818. Thirty-three species were assigned to Natatolana, all of which had previously been described and included in Cirolana. Prior to the study of Bruce (1981), Hansen (1890, 1905) had recognized resemblances among some of these species based on characters such as the elongate frontal lamina and large number of plumose setae on the posterior three pereopods (especially pereopod 7). The relationship of Natatolana to other genera was discussed by Bruce
(1986), Botosaneanu et al. (1986), Wetzer et al. (1987), Wägele (1989) and Kensley \& Schotte (1989) (see generic remarks).

The cirolanid isopod fauna of Australia was reviewed by Bruce (1986), providing redescriptions or new records of 10 previously described species and descriptions of 21 new species of Natatolana. Both Hansen (1905, p. 346) and Bruce (1986) noted the similarities among the species included in Natatolana, and the difficulty in making accurate identifications. Characters that are regarded as especially important for species recognition were discussed by Bruce (1986, p. 10). A revised list of the species of Natatolana was also included by Bruce (1986), with the addition of new species this totalled 56 species.

Subsequent publications providing redescriptions, new distribution records, new synonymies or describing new species of Natatolana include those of Brandt (1988), Kensley (1989), Kensley \& Schotte (1989), Müller (1989), Wägele \& Bruce (1989), Nunomura (1991), Hobbins \& Jones (1993), Hutchings et al. (1993), Bruce (1995a), Bruce \& Olesen (1995), Brusca et al. (1995), Keable (1995, 1996a, 1997), Mizzan (1995), Keable \& Bruce (1997) and Bruce (2003). Saito et al. (2000) list the species $N$. albicauda (Nunomura, 1985) but this taxon (originally described in
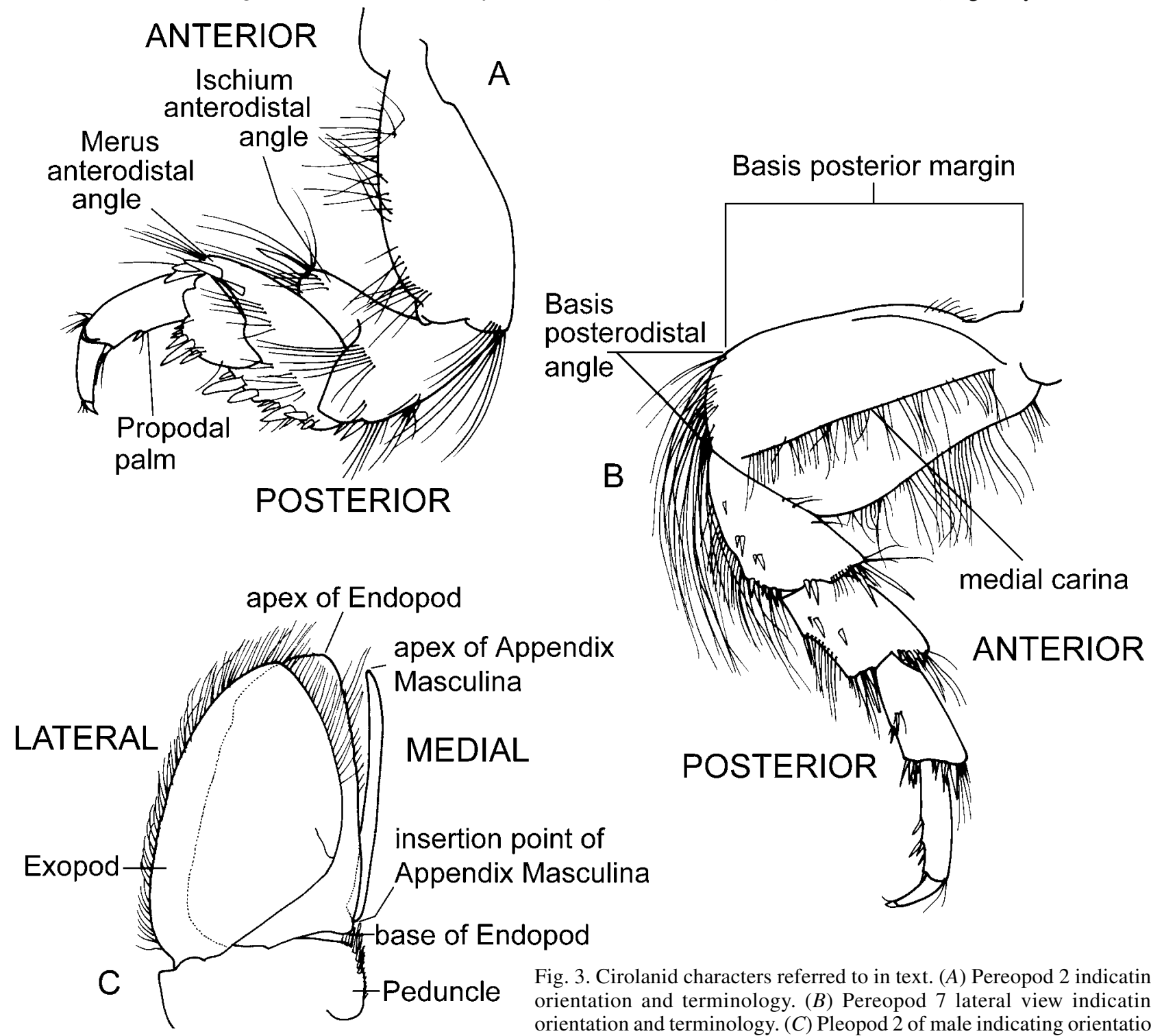

Fig. 3. Cirolanid characters referred to in text. (A) Pereopod 2 indicating orientation and terminology. (B) Pereopod 7 lateral view indicating orientation and terminology. (C) Pleopod 2 of male indicating orientation and terminology. 


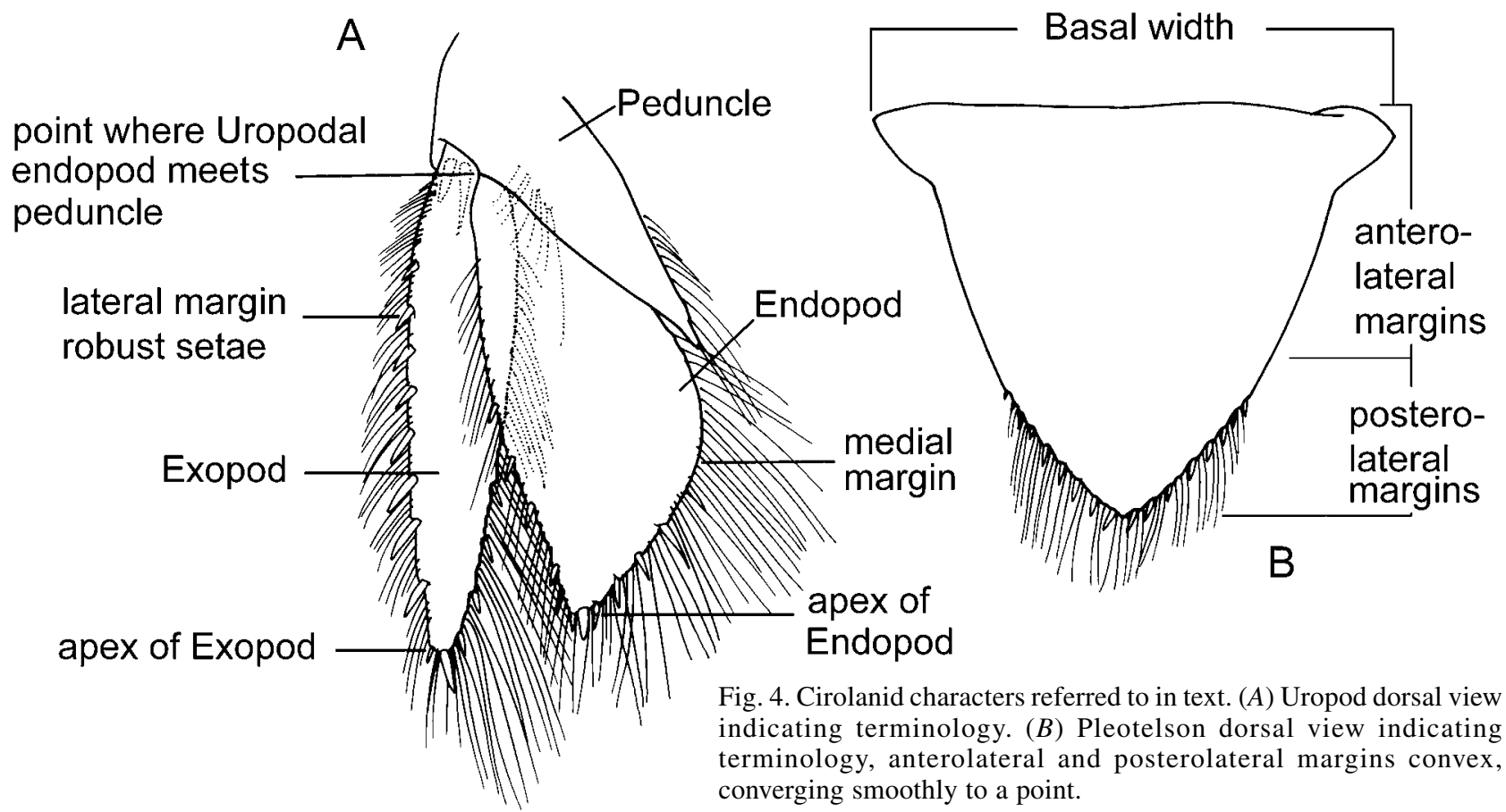

Cirolana) is a junior synonym of Dolicholana elongata (see Keable, 1999). Therefore, prior to this study, 62 described species of Natatolana were recognized.

Objective. Identification and study of species of Natatolana is hampered by the inadequacy of many of the existing descriptions and lack of a revisionary work which summarises existing knowledge for all species. This study addresses these problems by providing or reviewing taxonomic, biogeographical and ecological information for all 72 species of Natatolana now recognized. Redescriptions are presented for poorly known species where adequate material is available. New species from Australia and New Zealand which were recognized during the course of the study are described.

\section{Materials and methods}

Terminology and conventions. The anatomical terminology and the conventions regarding orientation of appendages follows that of Bruce $(1986,1993 b)$ and outlined in Figs. 2-4, with modifications to terminology noted by Keable (1996a, 1997) and Keable \& Bruce (1997). Practices for the examination and illustration of specimens are as outlined by Keable (1997). In the illustrations setules are indicated on the setae on which they were observed except for plumose setae on the proximal posterior pereopod segments and margins of the pleopod rami, pleotelson and uropods. The diagnoses and descriptions should be consulted for information of the distribution of these setae on these body parts. The relative extent of the antenna along the body noted in the species diagnoses was measured by flattening this appendage along the ventral margin of the body of the specimens examined. New species names are formed as nouns in apposition.

Electronic database. Morphological information recorded for the species diagnoses and descriptions, as well as information regarding the type material, sexual dimorphism, size range, character variation, distribution and ecology, has been recorded using the program DELTA (Dallwitz, 1980;
Watson et al., 1989; Dallwitz et al., 1993). The edited copy provided here has been generated from this database. Data files from the database are available on request from the author.

\section{Organization of species information}

Type material and material examined. Type material examined is indicated under that heading. Other specimens examined for these species is noted under the heading "Material examined". Collection information additional to the type locality or absent in the original description of the species is indicated by use of square brackets under the heading "Type locality". In the descriptions of new species collection information that differs for the paratypes, from that of the holotype (i.e., as noted under type locality), is provided under the heading "Type material". In these descriptions the heading "Additional material" is used to indicate material excluded from the type series because it does not come from the type locality and/or was only identified after completion of the species descriptions.

Generally, the gender and number of specimens is not included for those collection lots for which there is abundant material. In other cases, the initial number before the registration number indicates the number of specimens in each lot. For material recorded from Australia, the state where the material is recorded from is given but not the country. A large amount of material used in this study has come from baited trap samples collected during the Scavengers of Eastern Australian Seas (SEAS) project directed by Dr J. Lowry (Crustacea Section, Australian Museum). To avoid repetition, collection data for this project is provided in summarized form only. The full data for this study is available via the Australian Museum specimen database.

\section{Implicit characters}

To avoid repetition of character states that apply to most but not all species of Natatolana, unless indicated otherwise, the following character states are implicit throughout the species diagnoses and descriptions presented here. 
Diagnosis. Eyes: well developed; length less than $2 \times$ height. Labrum: smooth, without laminar projection. Antenna: flagellum digitate processes absent in males. Coxal plates: pereonite 1 , coxa 2 posterior margins straight or slightly convex. Coxa 2 with anteroventral corner rounded. Pleonite 2: ventral posterolateral margin acute, formed into short process. Pleonite 4: posterodorsal margin sinuate, convex proximal to meeting ventrolateral margin at apex. Pereopods 1-6: males with the RS on the merus of pereopods $1-3$, and carpus of pereopods $4-6$, shorter than the propodus. Pereopod 3: ischium anterodistal angle produced subequal to that of pereopods 1-2. Pereopods 5-7: propodus long, but on pereopod 5 less than $2 \times$ the length of that of pereopod 7. Uropods: endopod lateral margin without prominent excision. Exopod lateral margin with RS.

Additional descriptive characters. Cephalon. Rostral point present, not prominent; submarginal cephalic furrow well developed, runs entire length of anterior margin. Antennule: short, not reaching pereonite 1 ; peduncle colinear; flagellum with aesthetascs present. Antenna: peduncular article 5 longer than article 4 and all other articles.

Mandible. Incisor broad. Molar process with RS present on margin. Palp article 2 with numerous SS. Maxillule: medial lobe lateral margin with a well-developed protuberance. Maxilla: lateral and middle lobe slender; medial lobe short and broad. Maxilliped: palp medial margin RS absent, SS along most of the length of articles 2-5, article 5 serrate setae present; lateral margin SS along most of the length of articles 2-5, PS absent.

Pleonites. 1-5 equally visible along dorsal margin. Pleonites 1-2: posterolateral margins produced, but not into distinct spiniform processes. Pleonite 3: posterolateral margins produced; acute.

Pleotelson smooth, ornamentation and sculpting absent; posterolateral margins not conspicuously serrate; PS restricted to posterolateral margins.

Pereopods 1-3 propodus posterodistal angle with $1 \mathrm{RS}$ opposing dactylus. Pereopod 7: merus, carpus and propodus anterior margins without setae.

Pleopod 5 with proximal lobe of medial margin strongly produced.

Uropods. Peduncle medial margin strongly produced; exopod lanceolate.

Sexual dimorphism. Species of Natatolana exhibit little sexual dimorphism. All females differ from males in the primary sexual characters and do not have the pleopod 2 appendix masculina. Therefore, only differences other than these are recorded.

Distribution and ecology. Significant range extensions are underlined in the text. Ecological information is summarized where known but in most cases is limited to records of the species feeding as scavengers.

\section{Abbreviations}

Abbreviations of descriptive terms: $A 1$, antennule; $A 2$, antenna; $C E$, cephalon; $C L$, clypeal region; $F L$, frontal lamina; $M D$, mandible; $M P$, maxilliped; $M X 1$, maxillule; $M X 2$, maxilla; $n$, number of specimens; $P 1-7$, pereopods 1-7; PE, penes; $P L 1-5$, pleopods 1-5; PN, pleon; $P S$, plumose seta(e); $P T$, pleotelson; $R S$, robust seta(e); $S S$, slender seta(e); $U$, uropod.
AHF Allan Hancock Foundation, University of Southern California, USA;

AM The Australian Museum, Sydney;

BMNH The Natural History Museum, London, United Kingdom;

IOM Institut Océanographique Fondation Albert Ier Prince de Monaco;

LACM Natural History Museum of Los Angeles County, USA;

MNHN Muséum national d'Histoire Naturelle, Paris, France;

NIWA National Institute of Water \& Atmospheric Research, New Zealand;

NMNZ Museum of New Zealand Te Papa Tongarewa, Wellington;

NMV Museum Victoria, Melbourne, Australia;

NTM Northern Territory Museum of Arts and Sciences, Darwin, Australia;

PMBC Phuket Marine Biological Center, Reference Collection, Thailand;

QM Queensland Museum, Brisbane, Australia;

SAM South African Museum, Cape Town;

SAMA South Australian Museum, Adelaide;

SIF Senckenberg Institute, Frankfurt, Germany;

SMNH Swedish Museum of Natural History, Stockholm;

TM Tasmanian Museum and Art Gallery, Hobart, Australia;

TSM Toyama Science Museum, Japan;

USNM National Museum of National History, Smithsonian Institution, Washington, D.C., USA;

WAM Western Australian Museum, Perth.

ZIAS Zoological Institute of the Academy of Science, St. Petersburg, Russia;

ZMB Zoological Museum, Berlin, Germany;

ZMG Zoological Museum of Göttingen, Germany;

ZMUA Zoological Museum, University of Amsterdam, Netherlands;

ZMUC Zoologisk Museum, University of Copenhagen, Denmark;

Taxonomy

\section{Cirolanidae Dana, 1853}

For a recent synonymy and emendations see Bruce (1986) and Brusca et al. (1995).

\section{Natatolana Bruce, 1981}

Natatolana Bruce, 1981: 957.-1986: 52.-Brusca \& Iverson, 1985: 37.-Botosaneanu et al., 1986: 412.-Wetzer et al., 1987: 2.Brandt, 1988: 102.-Kensley \& Schotte, 1989: 139.-Brusca $e t$ al., 1995: 74.-Yu \& Li, 2001: 262.

Type species. Cirolana hirtipes Milne Edwards, 1840, by original designation [not subsequent designation as stated by Brusca et al. (1995)].

Diagnosis. Cephalon: width between 50-60\% of pereonite 1 ; moderately to strongly enclosed laterally by pereonite 1 ; anterior margin smoothly rounded, or with rostral point, without smooth medial indentation; rostrum not prominent when present. Frontal lamina: forming an angle of c. $45^{\circ}$ or less with clypeus; not fused to cephalon; elongate, length c. 3-10x basal width; ventral surface flat, not projecting anteroventrally from posterior. Clypeus: anterior margin abutting frontal lamina, ventral surface not projecting relative to frontal lamina. Antennule: colinear (most species), or geniculate (article 2 at right angles to article 1) (N. vieta). Peduncular articles 1-3 not fused; article 3 well developed, 
longer than articles 1-2 or subequal to article 1. Accessory flagellum absent. Primary flagellum shorter than or subequal to peduncle; without callynophore. Antenna: not sexually dimorphic (most species), or sexually dimorphic; when dimorphic males with longer flagellae than females $(N$. vieta), or with digitate processes on flagellar articles $(N$. insignis). Peduncle of 5 articles; articles 1 and 2 shortest, subequal; article 4 subequal to article 3 ; article 5 longer than article 4 and all other articles, or subequal to article 4 .

Mandible: molar well developed; medial surface smooth, without SS; RS present or absent on margins, numerous when present. Incisor broad, wider than narrowest part of mandible, or narrow, subequal to narrowest part of mandible; serrate; not quadridentate on left mandible. Lacinia mobilis absent. Setal row with numerous RS; intermediate SS absent. Palp 3-articulate; inserted slightly anterior to midlength, opposite molar; article 3 distally narrow. Maxilla: lateral lobe and middle lobe subequal; medial lobe short and broad; lateral lobe with 2-12 SS; middle and medial lobes with numerous setae. Maxilliped: palp medial margin with SS on more than half the length of articles 2-5; lateral margin with SS or PS along most of the length of articles 2-5; article 3 with distal margin width greater than proximal margin of article 4 ; article 4 with distal margin width greater than proximal margin of article 5 . Endite with (most species) or without coupling hooks ( $N$. endota, $N$. karkarook, N. prolixa, N. buzwilsoni).

Pereon: dorsal surfaces without setae; with $(N$. amplocula, $N$. hirtipes) or without indistinct tubercles (most species); with ( $N$. vieta) or without wrinkle like furrows (most species); pereonite 1 longer than pereonite 2. Coxae: not forming sternal plates.

Pleonites: five unfused segments present; all equally visible along dorsal margin (most species), or pleonite 1 partially or completely concealed by pereonite 7 ( N. angula, N. boko, $N$. curta, $N$. hirtipes, $N$. imicola, $N$. intermedia, $N$. natalis, $N$. neglecta, $N$. obtusata, $N$. pilula, $N$. tenuistylis, $N$. valida, $N$. wowine, N. brucei, N. helenae, N. aotearoa). Pleonite 3: epimera with lateral row of setae absent; posteroventral excision absent; enclosing or not enclosing pleonite 4. Pleonite 5: posterolateral margins encompassed by pleonite 4 .

Pleotelson: dorsal surface with anterodorsal depression present or absent, otherwise smooth, setae, tubercles, pits and ridges absent; RS present or absent on margins; PS present or absent, when present moderately abundant, restricted to posterolateral margins, or sparse, restricted to apex; marginal teeth-like serrations absent.

Pereopods 1-7: dactylus with secondary unguis present or absent; secondary unguis not large or strongly sclerotized when present. Pereopods 1-3: ischium anterodistal angle produced subequally or noticeably reduced on pereopod 3 . Merus anterodistal angle produced subequally. Dactylus shorter than propodus. Pereopod 1: merus anterodistal angle produced to posterodistal extent of carpus or beyond. Pereopod 7: basis noticeably broader in distal half compared to proximal half; anterior margin with long PS along entire length; medial carina with PS and SS along most of length of article; posterodistal angle with long PS present. Ischium anterior margin with PS and SS present or absent, PS sparse when present and only occurring distally; posterior margin with PS and SS present. Merus anterior margin SS present or absent, PS absent; posterior margin with PS and SS present or absent, PS sparse when present.
Penes: present or absent (vasa deferentia opening flush to surface of sternite 7); when present short and flattened, or long and tubular.

Pleopods: peduncle respiratory branchiae absent; accessory lobe reduced, without complex folding. Endopods 1-4 with PS on most of margins, 5 with only a few or no PS on margins; 1-4 without elongate laterally curving lobe arising from proximomedial angle. Exopods 1-4 without slender accessory lamella at posterior proximolateral angle. Pleopod 1: not operculate; peduncle length shorter than breadth; exopod and endopod broad, or only endopod narrow; exopod margin rounded, broad at apex; endopod width greater than $0.5 \times$ width of exopod. Pleopod 2 appendix masculina: arising basally or sub-basally; shorter or longer than endopod; broad, width equal to or greater than half pleopod peduncle length, or slender.

Uropods: inserted ventrolaterally on pleotelson; extending subequal to or beyond pleotelson, or not extending beyond pleotelson. Peduncle moderately or strongly produced along medial margin of endopod. Endopod and exopod margins with RS present or absent; PS on most of margin length; apices entire, not bifid or sub-bifid, with at least 2 RS. Endopod lateral margin with or without prominent lateral excision; without distinct pit.

Remarks. Kensley \& Schotte (1989) placed Natatolana in the subfamily Conilerinae, based on the classification outlined by Botosaneanu et al. (1986). The subfamily divisions of the Cirolanidae, however, appear to be weakly defined and require revision through a phylogenetic analysis of the entire family, as suggested by Brusca et al. (1995) and Bruce (1995b). Natatolana is difficult to incorporate in phylogenetic analyses because of its diversity (Riseman $\&$ Brusca, 2002) and because no unique apomorphies have been proposed that define it (Wetzer et al., 1987). The approach of using an exemplar for the genus presents difficulties because of polymorphism across the species. For example, Brandt \& Poore (2003) use $N$. woodjonesi as a representative species in analysing suborder and superfamily relationships and characters. They score the pleopod 5 endopod as lacking setae whereas they are present in small numbers in several other species of Natatolana (Brandt, 1988, fig. 50; Brusca et al., 1995; Keable, 1996b; this study, e.g., Fig. 28). It is an objective of this study to address some of these issues by clarifying character distribution within the genus and species identification.

Examination of specimens and descriptions of all species of Natatolana indicates that a putative synapomorphy that can unambiguously define the genus as a monophyletic group is the setation pattern on pereopod 7. This pattern entails the presence of long plumose setae on the length of the anterior margin and at the posterodistal angle of the basis, and the lack of plumose setae on the length of the anterior margin of the ischium. The plumose setae at the posterodistal angle of the basis are as long or longer than the ischium. This setation pattern is unique among the known taxa of the Cirolanidae (although it may occur in Sintorolana, a genus known only from a juvenile specimen in which pereopod 7 is missing). A similar setation pattern occurs in Dolicholana elongata but in this species plumose setae are present along the entire length of the anterior margin of the ischium and on the posterior margin of the merus. Of the species placed in Natatolana, plumose setae 

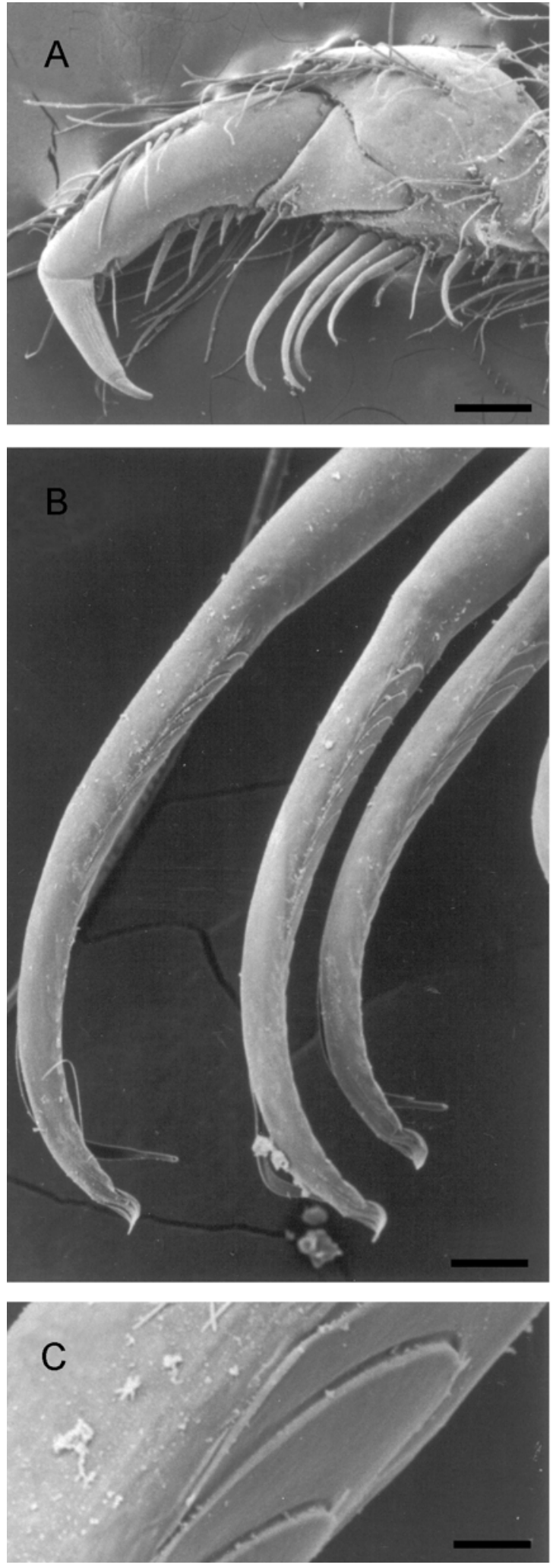
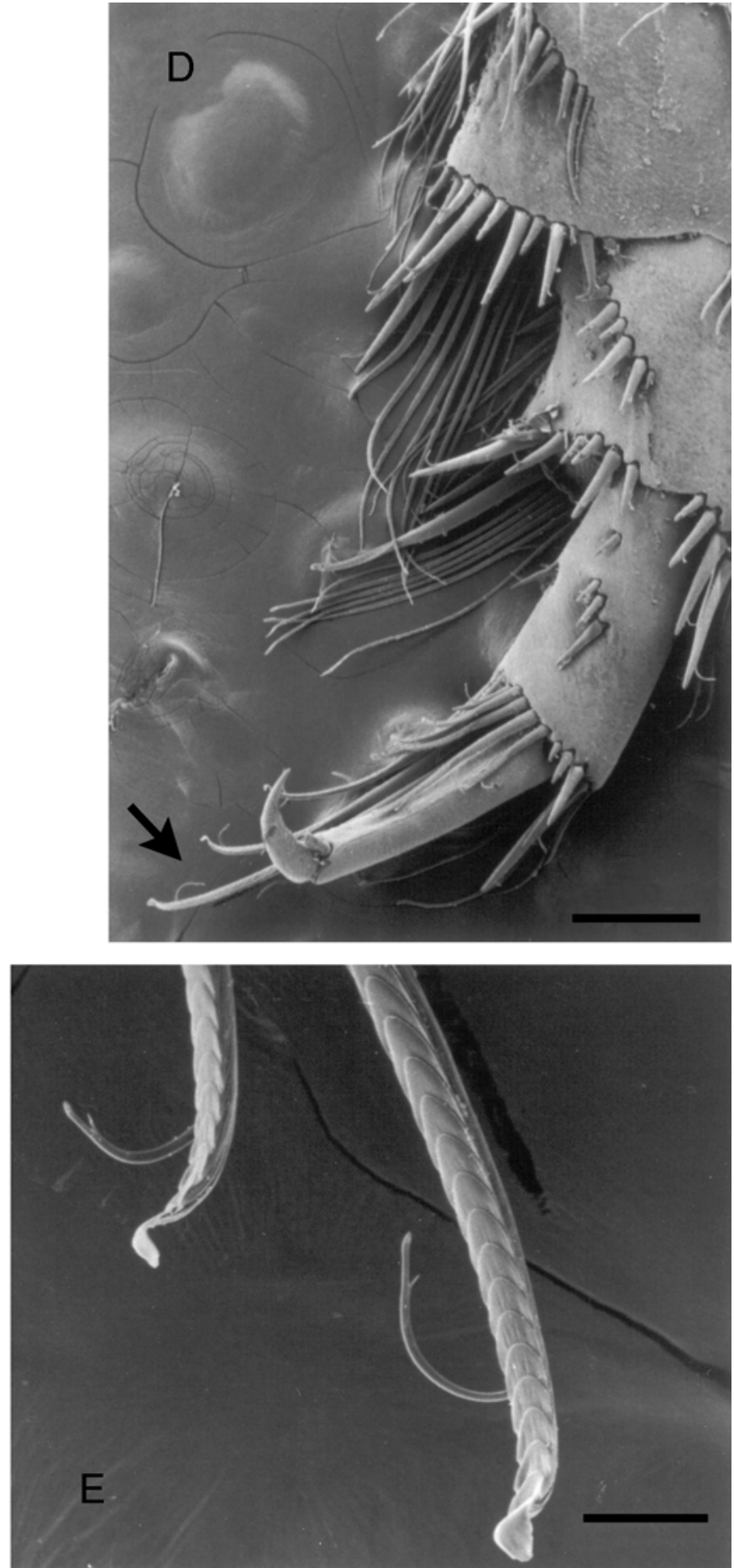

Plate 1. Elongate robust setae on male of Natatolana corpulenta AM $\mathrm{P} 48075$, a-c pereopod 1 merus, d-e pereopod 5 carpus $(A)$ whole article, scale $=25 \mu \mathrm{m} ;(B)$ enlargement of setae, scale $=50 \mu \mathrm{m} ;(C)$ enlargement of setae showing sculpting, scale $=50 \mu \mathrm{m} ;(D)$ whole article, scale $=200$ $\mu \mathrm{m} ;(E)$ enlargement of setae showing sculpting, scale $=50 \mu \mathrm{m}$. on the posterior margin of the ischium of pereopod 7 have only been observed in N. angula, $N$. karkarook, $N$. narica and $N$. tenuistylis. In these taxa these setae are sparse and do not extend all the way along this margin. In $D$. elongata plumose setae, however, are abundant and occur all the way along the margin. Only $N$. boko and $N$. tenuistylis are known to have plumose setae on the posterior margin of the merus of pereopod 7. Species of Dolicholana also differ from those of Natatolana in the characters noted below (Keable, 1999).

Other putative synapomorphies that may define Natatolana as a monophyletic group include: the smooth medial surface of the mandibular molar lacking slender setae (see Keable, 1996b; Keable, 1999); the short antennule in which the flagellum is shorter than, or subequal in length to the peduncle with articles broader than longer; and the narrow frontal lamina lacking a posteroventral projection. 
Comparison of these additional synapomorphies to characters occurring in other genera suggest, however, that they are not unique and further analysis is necessary before their phylogenetic significance can be fully evaluated.

The composition, relationships and phylogenetic significance of the four existing informal groups (the $N$. albicaudata, N. pellucida, N. valida and N. woodjonesi groups-Bruce, 1986; Wägele \& Bruce, 1989) within Natatolana are unclear because characters used in defining them may not be shared by all members of the group and/ or may be shared by species excluded from the group. For example, ambiguous characters used in defining these groups include:

- entire or complete coxal furrows-these occur in species placed in both the N. albicaudata and $N$. pellucida groups;

- pereopod 2 lacking robust setae on the palm of the propodus - this is a condition that occurs in all species included in both the N. pellucida and N. woodjonesi groups;

- pereopod 7 basis narrow with margins straight - this state occurs in the $N$. pellucida group and is indistinguishable from the state described for the $N$. valida group (pereopod 7 basis narrow, broadening distally, margins nearly straight).

Furthermore, conflicting statements have been made regarding the composition of the informal groups within Natatolana and some of the characters used in formulating them. For example, $N$. rossi and $N$. hirtipes have been included in the $N$. valida group, which is characterized by having "coxal plates with furrows feeble or absent", despite $N$. rossi and $N$. hirtipes being differentiated from $N$. matong on the grounds that they have "distinct" or "conspicuous" coxal furrows (Bruce, 1986, p. 97). Also, many species do not readily fall into these groups (Bruce, 1986; Bruce \& Olesen, 1995; this study).

A robust phylogenetic analysis of Natatolana is, therefore, required to determine the utility of these groups. A relevant character that has not been highlighted previously is the development of long, modified, robust setae on the posterior margins of the merus of pereopods 1-3 and on the distal margin of the carpus of pereopods 4-6 (Plate 1). These specialized setae are only known to occur on males of the species Bruce (1986) placed in the $N$. pellucida group (N. pellucida, N. corpulenta, N. galathea, N. laewilla, $N$. longispina) and $N$. debrae n.sp., $N$. sinuosa n.sp. and $N$. zebra n.sp. This and other characters included in the species diagnoses presented here, however, were used in a phylogenetic analysis by Keable (1996) that was inconclusive (being both ambiguous and partially resolved) regarding species relationships within Natatolana. The main conclusions of this analysis were that morphological characters are difficult to use because of problems in defining enough character state transitions to resolve relationships. This was viewed as being possibly the result of a strong adaptation to the benthic/scavenging niche, resulting in a conservative morphology, and/or particular speciation processes. Consequently, study of functional morphology of species of Natatolana to further resolve morphological character states and use of molecular techniques to clarify patterns of speciation within the genus were suggested to aid progress in determining species relationships.

Material examined during this study indicates the need to place Natatolana lurur Bruce, 1986 and N. wullunya Bruce, 1986 in synonymy with $N$. arcicauda Holdich, Harrison \& Bruce, 1981, and N. nammuldi Bruce, 1986, respectively. Therefore, 59 previously described species are recognized and, with the addition of 13 species described here, the total number of species now in the genus is 72 .

\section{Key to species of Natatolana}

Although some species can be identified using only female specimens, the key is written under the assumption that a fully adult male specimen is being used. Male specimens are preferable for identification because they have additional diagnostic characters (e.g., penes, appendix masculina) not found in females.

Due to uncertainty regarding many character states in N. anophthalma and N. pallidocula, they are not included in the key. Couplets to which they may key (based on their descriptions) are indicated using symbols $\dagger$ and $\ddagger$ respectively. Comparisons of these species to those identified in the marked couplets are given at the end of the key.

Diagnostic characters are highlighted in bold text in some of the longer couplets which utilize additional characters to aid in identification.

1 Uropod endopod, lateral margin with prominent deep excision (e.g., Fig. 30)

Uropod endopod, lateral margin without prominent excision

2 Coxae, all with furrows present; pleotelson with 4-6 robust setae on posterolateral margins; penes absent in males, vas deferens opening flush with the surface of sternite 7 N. variguberna

Coxae 2-5 without furrows; pleotelson with 10-14 robust setae on posterolateral margins; penes present in males N. honu n.sp.

3 (a) Pleotelson with distinct dorsal depression (e.g., Fig. 47) 4

(b) Pleotelson without distinct dorsal depression; pereopod 7, basis with the distance between the medial carina and the anterior margin less than between medial carina and the posterior margin 
- (c) Pleotelson without distinct dorsal depression; pereopod 7, basis with the distance between the medial carina and the anterior margin greater than between medial carina and the posterior margin

4 Antennule, peduncular articles 1-2 geniculate; antennal flagellum extending at least to pleon N. vieta

Antennule, peduncular articles 1-2 colinear; antennal flagellum not extending to pleon

5 Pereopod 3, propodal palm with robust setae; penes absent in males, vas deferens opening flush with the surface of sternite 7

Pereopod 3, propodal palm without robust setae; penes present in males

6 Pleotelson, apex strongly produced, posterolateral margins straight or concave and noticeably less convex than anterolateral margins (e.g., Fig. 47) .

_ Pleotelson, apex not strongly produced, posterolateral margins convex and joining smoothly with anterolateral margins (e.g., Fig. 53)

7 Coxa 2, anteroventral corner produced into an acute tooth (Fig. 13) $\ddagger N$. corpulenta

- Coxa 2, anteroventral corner rounded 8

8 Pereonite 1 and coxa 2 with sinuate posterior margins, posteroventral corners developed into acute coxal points (e.g., Fig. 45)

_ Pereonite 1 and coxa 2 with straight or slightly convex posterior margins, posteroventral corners rounded $\ddagger N$. femina n.sp.

9 Pereonite 1 and coxa 2 with the posteroventral corners developed into strong coxal points (Fig. 45)

Pereonite 1 and coxa 2 with the posteroventral corners developed into weak coxal points (Fig. 14)

10 Pleotelson, posterolateral margins with 2 robust setae; uropod endopod, lateral margin slightly concave with a prominent notch (Fig. 22) $\dagger N$. flexura $\mathrm{n} . \mathrm{sp}$ Pleotelson, posterolateral margins with 8 or more robust setae; uropod endopod, lateral margin convex without a prominent notch

11 Eyes vestigial, ommatidia indistinct and weakly pigmented; coxae, all with furrows or some without furrows; coxa 2, posteroventral corner strongly rounded so that posterior margin appears shorter than anterior margin $\dagger$ N. laewilla

- Eyes well developed, ommatidia distinct and strongly pigmented; coxae, all with furrows; coxa 2, posteroventral corner not strongly rounded

12 Pereonite 1 and coxa 2 with sinuate posterior margins, posteroventral corners developed into acute coxal points (e.g., Fig. 45)

_ Pereonite 1 and coxa 2 with straight or convex posterior margins, posteroventral corners slightly rounded (e.g., Fig. 51)

13 Pereopod 5, propodus elongate (twice length of pereopod 7 propodus) (Figs. 52-53) N. zebra n.sp.

— Pereopod 5, propodus short (less than twice length of pereopod 7 propodus) (e.g., Figs. 26-27).

14 Pleotelson width at posterior third greater than half basal width, posteroventral margins strongly convex; uropod endopod relatively broad, width greater than half length of lateral margin. 
- Pleotelson width at posterior third less than half basal width, posteroventral margins weakly convex; uropod endopod relatively narrow, width less than half length of lateral margin N. pellucida

15 Antennal flagellum longer than body 16

Antennal flagellum shorter than body

16 Pleotelson, margins straight, robust setae present N. endota

Pleotelson, margins sinuate, robust setae absent N. prolixa

17 Pleotelson, margins without robust setae $\dagger 18$

Pleotelson, margins with robust setae 19

18 Pleotelson, posterolateral margins concave and meeting at a narrowly rounded apex; appendix masculina, apex bluntly rounded

Pleotelson, posterolateral margins convex and meeting at a truncate apex; appendix masculina, apex with digitate process

19 Males with penes; interocular furrow incomplete or absent; coxal furrows present on all coxae; pereopods 2 and 3, propodal palms with robust setae

_ Males without penes; interocular furrow complete, incomplete or absent; coxal furrows present on all, some or none of the coxae; pereopods 2 and 3 , propodal palms with or without robust setae

20 Pleonite 4, posterodorsal margin strongly concave proximal to meeting ventrolateral margin at apex (e.g., Fig. 5)

Pleonite 4, posterodorsal margin sinuate, convex proximal to meeting ventrolateral margin at apex (e.g., Fig. 25)

21 Eyes rounded, length less than twice height; appendix masculina in males straight or only very slightly curved laterally (e.g., Fig. 27)

Eyes elongate, length approximately twice height; appendix

masculina in males strongly curved or twisted laterally

22 Pleonite 2, dorsal posterolateral margin strongly projecting posterior to ventral posterolateral margin; appendix masculina, apex bluntly rounded

_ Pleonite 2, dorsal posterolateral margin projecting subequal to ventral posterolateral margin; appendix masculina, apex tapered to finely acute point

N. pastorei

23 Eyes with light pink pigment (fading with preservation), approximately 9 vertical and 10 horizontal ommatidia; pleotelson, apex not strongly produced, posterolateral margins convex and joining smoothly with anterolateral margins; pereopod 7, basis posterior margin with sparse setae proximally and distally or with setae completely absent

N. meridionalis

Eyes with dark red or black pigment (generally not fading with preservation), c. 17 vertical and 12 horizontal ommatidia; pleotelson, apex strongly produced, posterolateral margins concave and distinctly angled to anterolateral margins; pereopod 7, basis posterior margin with relatively dense setae present on entire length

N. oculata

24 Coxa 2, anteroventral corner produced into an acute tooth (e.g., Fig. 13); pleotelson, anterolateral margins straight, angled to posterolateral margins N. nitida

Coxa 2, anteroventral corner rounded; pleotelson, anterolateral margins convex and joining smoothly with posterolateral margins 
25 Eyes well developed, ommatidia distinct, with dark pigment (generally not fading with preservation); pleotelson posterolateral margins straight, distinctly angled to anterolateral margins

Eyes vestigial, ommatidia indistinct, lacking pigment (possibly

fading with preservation); pleotelson posterolateral margins

convex, joining smoothly with anterolateral margins

26 Adults of small size, c. $8 \mathrm{~mm}$ in length; appendix masculina slender and strongly curved laterally ** N. gracilis

Adults of large size, to over $25 \mathrm{~mm}$ in length; appendix masculina broad and distinctly twisted

27 Appendix masculina slender, margins smooth, apex bluntly rounded.

- Appendix masculina broad, margins with a distinct notch or projection near apex

28 Appendix masculina strongly curved laterally $\dagger N$. californiensis Appendix masculina slightly curved laterally N. bowmani

29 (a) Appendix masculina, apex rounded and proximal margin of distal notch blunt; pleotelson usually with 12 or less robust setae; pereopods 1-2 propodal palm with fewer than 5, 3 robust setae respectively; uropod exopod lateral margin with fewer than 8 robust setae

N. imicola

(b) Appendix masculina, apex rounded and proximal margin of distal notch blunt; pleotelson usually with 12 or more robust setae; pereopods 1-2 propodal palm with 5,3 or more robust setae respectively; uropod exopod lateral margin with 8 or more robust setae N. rekohu

(c) Appendix masculina, apex acute and proximal margin of distal notch with an acute projection N. natalis

30 Eyes elongate, length approximately twice height; pereopods 2 and 3, propodal palms with robust setae; pleotelson, posterolateral margins with at least 10 robust setae

Eyes short, length approximately equal to height, or vestigial; pereopods 2 and 3, propodal palms with or without robust setae; pleotelson, posterolateral margins with more than or less than 10 robust setae

31 Appendix masculina broad, margins strongly curved laterally, apex truncate (Fig. 50) $\ddagger N$. virilis

Appendix masculina slender, margins straight or slightly curved laterally, apex bluntly rounded (e.g., Fig. 28)

32 Appendix masculina distinctly shorter than endopod N. nukumbutho Appendix masculina subequal to, or longer than, endopod length.

33 Frontal lamina, apex strongly expanded (broader than posterior margin)

Frontal lamina, apex weakly expanded (width equal to, or narrower than, posterior margin) N. valida

34 Pleonite 4, posterodorsal margins strongly sinuate, distinctly convex proximal to meeting ventrolateral margin at apex

_ Pleonite 4, posterodorsal margins weakly sinuate, indistinctly convex proximal to meeting ventrolateral margin at apex N. matong

35 Coxal furrows present on all coxae 36

Coxal furrows present on anterior coxae only N. carlenae 
36 Eyes, anterior margin angled, sloping posteriorly from dorsal margin to ventral margin; interocular furrow smoothly convex (Fig. 25)

Eyes, anterior margin convex; interocular furrow produced anteromedially (Fig. 41)

37 Pleonite 4, posterodorsal margin strongly concave proximal to meeting ventrolateral margin at apex (e.g., Fig. 5); interocular furrow complete (e.g., Fig. 5)

Pleonite 4, posterodorsal margin sinuate, convex proximal to meeting ventrolateral margin at apex (e.g., Fig. 25); interocular furrow complete or incomplete

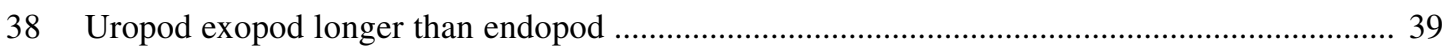

Uropod exopod distinctly shorter than endopod .....

39 Pleotelson, posterolateral margins broadly rounded, approximately parallel to basal margin at apex; uropod endopod, medial margin sinuate

_ Pleotelson, posterolateral margins convex, not parallel to basal margin at apex; uropod endopod, medial margin smoothly convex N. paranarica $\mathrm{n} . \mathrm{sp}$.

40 Frontal lamina, lateral margins straight and parallel; pereopod 3, ischium anterodistal angle extending subequal to that of pereopods 1 and 2 (e.g., Fig. 26) . N. thurar

_ Frontal lamina, lateral margins straight and narrowing anteriorly; pereopod 3, ischium anterodistal angle distinctly less extended than that of pereopod 1 and 2 (Fig. 6) N. aotearoa n.sp.

41 (a) Eyes well developed, ommatidia distinct; interocular furrow developed into a distinct ridge; uropod exopod length subequal to endopod

(b) Eyes vestigial, ommatidia indistinct; interocular furrow developed into a distinct ridge; uropod exopod length distinctly shorter than endopod.....

(c) Eyes well developed with distinct ommatidia; interocular furrow not developed into a distinct ridge; uropod exopod length distinctly shorter than endopod....

42 Interocular furrow complete; pleotelson, anterolateral margins convex and joining smoothly with posterolateral margins; pereopod 3, ischium distinctly less extended than that of pereopods 1 and 2 (e.g., Fig. 6)

_ Interocular furrow incomplete, anteriorly deflected; pleotelson, anterolateral margins straight and distinctly angled to anterolateral margins; pereopod 3, ischium extended subequal to that of pereopods 1 and 2 (e.g., Fig. 26) $\dagger N$. gorung

43 Maxilliped, palp lateral margin with plumose setae on articles 25; pleotelson, apex truncate (forming a line parallel with basal margin)

N. helenae n.sp.

Maxilliped, palp lateral margin with slender setae on articles 2-5; pleotelson, apex forming an angle or rounded

44 Uropod endopod broadly rounded distally, medial margin extending posterior to endopod apex; pleotelson, posterolateral margins broadly rounded (convex and smoothly continuous with anterolateral margins approximately parallel to basal margin at apex); pereopods 2 and 3, propodal palms with robust setae.

Uropod endopod lanceolate, medial margin not extending posterior to endopod apex; pleotelson, posterolateral margins broadly rounded or not broadly rounded; pereopods 2 and 3 , propodal palms with or without robust setae. 
45 Antennal flagellum of males with digitate processes at anterolateral margin of articles; uropod endopod, lateral margin with distinct notch

Antennal flagellum of males without digitate processes; uropod endopod, lateral margin without distinct notch

46 Maxilliped, endite without coupling hooks; maxillule, endopod with simple robust setae lacking setules N. buzwilsoni $\mathrm{n} . \mathrm{sp}$.

_ Maxilliped, endite with coupling hooks; maxillule, endopod with pappose robust setae

47 Interocular furrow complete N. amplocula

Interocular furrow incomplete N. curta

48 Labrum with acute laminar projection N. karkarook

Labrum smooth

49 Antenna at least $0.5 \times$ as long as the body; pleonite 2, ventral posterolateral margin strongly projecting posteriorly to dorsal posterolateral margin; pleonite 4, posterodorsal margin strongly sinuate meeting ventral margin at a small point

Antenna less than $0.5 \times$ as long as the body; pleonite 2 , ventral posterolateral margin projecting subequally, or anteriorly, to dorsal posterolateral margin; pleonite 4, posterodorsal margin sinuate but not meeting ventral margin at a small point

50 Appendix masculina, apex with acute projection; interocular furrow incomplete; coxal furrows distinct on all coxae, never discontinuous; pleotelson, posterolateral margins with fewer than 8 robust setae; pereopod 7, basis posterior margin with setae present; uropod exopod, lateral margin with robust setae present.....

_ Appendix masculina, apex with projection forming a Y shape or bluntly rounded; interocular furrow complete, incomplete or absent; coxal furrows distinct on all or only some coxae, sometimes discontinuous; pleotelson with fewer or more than 8 robust setae; pereopod 7, basis posterior margin with setae present or absent; uropod exopod, lateral margin with robust setae present or absent

51 Coxal furrows extending completely across coxae 4-7; pleotelson, posterolateral margins convex and joining smoothly with anterolateral margins; pereopod 7 , basis posterior margin with dense setae along entire length N. gallica

- Coxal furrows extending only about 50 to $75 \%$ of the way across coxae 4-7; pleotelson, posterolateral margins straight or only slightly convex and noticeably angled to anterolateral margins; pereopod 7, basis posterior margin with sparse setae

52 Pereopods 2 and 3, propodal palms with robust setae

Pereopods 2 and 3, propodal palms without robust setae 57

53 Appendix masculina, lateral margin projecting, apex formed into a Y shaped process; interocular furrow incomplete; coxal furrows distinct on anterior coxae only; pereopod 7, basis posterior margin with setae present on entire length

N. borealis

Appendix masculina, margins smooth, apex bluntly rounded not forming a $Y$ shaped process; interocular furrow complete, incomplete or absent; coxal furrows distinct on anterior coxae only, or on anterior and posterior coxae; pereopod 7, basis posterior margin with setae restricted to proximal half or absent 
54 Appendix masculina strongly curved laterally, forming semicircle; interocular furrow absent; pleotelson, posterolateral margins straight and distinctly angled to anterolateral margins.

N. gracilis $* *$

Appendix masculina straight or only slightly curved laterally; interocular furrow complete or incomplete; pleotelson, posterolateral margins straight and distinctly angled to anterolateral margins, or convex and joining smoothly with anterolateral margins

55 Coxal furrows distinct, continuous on all coxae; basis of pereopod 7 broad, width greater than $0.5 \times$ length, posterior margin without setae

Coxal furrows indistinct, discontinuous or absent on coxae 4,5 and 6; basis of pereopod 7 narrow, width less than $0.5 \times$ length, posterior margin with setae on proximal quarter N. arcicauda

56 Interocular furrow complete N. albicaudata Interocular furrow incomplete N. chilensis

57 Pleotelson, posterolateral margins straight and meeting at angular apex

Pleotelson, posterolateral margins convex or concave

58 Pleotelson, posterolateral margins distinctly angled to anterolateral margins; antennal peduncular article 4 without a row of long slender setae along entire posterolateral margin

Pleotelson, posterolateral margins joining smoothly with anterolateral margins; antennal peduncular article 4 with a row of long slender setae along entire posterolateral margin N. lowryi

59 Pleotelson, posterolateral margins meeting at an acute angle; pereopod 7, basis with anterior margin distinctly sinuate (distance between anterior margin and medial carina greater than between posterior margin and medial carina) and posterior margin with setae along entire length

Pleotelson, posterolateral margins meeting at an obtuse angle; pereopod 7, basis with anterior margin slightly convex (distance between anterior margin and medial carina less than between posterior margin and medial carina) and posterior margin without setae N. neglecta

60 Pleotelson, posterolateral margins concave N. brucei $\mathrm{n} . \mathrm{sp}$.

Pleotelson, posterolateral margins convex

61 Interocular furrow complete and pleotelson with at least 8 robust setae on margins N. angula

_ Interocular furrow complete and pleotelson with less than 8 robust setae on margins, or interocular furrow incomplete and pleotelson with a maximum of 8 robust setae on margins

62 Frontal lamina, lateral margins straight and narrowing anteriorly; pleotelson posterolateral margins with 4 robust setae; uropod exopod lateral margin with robust setae absent

_ Frontal lamina, lateral margins medially constricted; pleotelson posterolateral margins with 4 or more robust setae; uropod exopod lateral margin with robust setae present or absent.

63 Uropod exopod less than $80 \%$ length of endopod

Uropod exopod greater than $85 \%$ length of endopod

64 Uropod exopod, lateral margin with robust setae present 
65 Antennal flagellum with more than 19 articles extending to the posterior of pereonite 3

Antennal flagellum with less than 19 articles, not extending beyond pereonite 2

66 (a) Interocular furrow complete; pleotelson length less than basal width, posterolateral margins usually with 4 robust setae

N. lilliput $\mathrm{n} . \mathrm{sp}$.

(b) Interocular furrow incomplete; pleotelson length less than basal width, posterolateral margins usually with 4 robust setae

N. kahiba

(c) Interocular furrow incomplete; pleotelson length greater than basal width, posterolateral margins usually with 6 robust setae

N. rusteni $\mathrm{n} . \mathrm{sp}$.

67 Appendix masculina, apex falcate; antenna reaching to posterior of pereonite 3 ; pleonite 4 , posterodorsal margin broadly rounded, apex not angled; uropod endopod, apex rounded

- Appendix masculina, apex bluntly rounded; antenna reaching to posterior of pereonite 2; pleonite 4, posterodorsal margin rounded, apex angled; uropod endopod, apex acute.

68 Pleotelson, apex distinctly produced, margins usually with 4 (occasionally with 6) robust setae; uropod endopod, lateral margin angled at midpoint with each half approximately straight

N. woodjonesi

Pleotelson, apex indistinctly produced, margins usually with 8

(occasionally with 6) robust setae; uropod endopod, lateral margin

slightly sinuate in larger specimens

N. nammuldi

* Although no adult males of Natatolana femina are known, based on the presence of other characters in female specimens, fully adult males are predicted to have penes.

** Because of uncertainty regarding the presence or absence of penes in N. gracilis, it is included twice in the key.

Couplet 5 Natatolana pallidocula has more angled posterolateral margins of the pleotelson than $N$. natalensis. In $N$. anophthalma the eyes are vestigial or absent, whereas they are well developed in N. natalensis.

Couplet 7 Natatolana pallidocula has rectangular eyes with 14 ommatidia in the horizontal row, whereas $N$. corpulenta has oval eyes with c. 5 ommatidia in the horizontal row (see remarks for $N$. corpulenta).

Couplet 8 Natatolana pallidocula has rectangular eyes with 14 ommatidia in the horizontal row, whereas $N$. femina has oval eyes with c. 5 ommatidia in the horizontal row.

Couplet 10 Natatolana anophthalma apparently lacks robust setae on the pleotelson posterolateral margins (although they may have rubbed off), and the prominent notch on the uropod endopod lateral margin, which are present in $N$. flexura.

Couplet 11 Natatolana anophthalma apparently lacks robust setae on the pleotelson posterolateral margins (although they may have rubbed off), whereas they are present in $N$. laewilla. Examination of the holotype of $N$. anophthalma is needed to determine further differences to $N$. laewilla but these may include complete coxal furrows on all coxae in $N$. anophthalma.

Couplet 17 Natatolana anophthalma apparently lacks robust setae on the pleotelson posterolateral margins (although they may have rubbed off) but can be separated from $N$. boko and N. pilula by the smoothly convex posterolateral margins of the pleotelson meeting at a point.

Couplet 20 Natatolana pallidocula can be separated from all species identified from couplet 20 by its elongate eye, concave posterodorsal margin of pleonite 4 , angular posterior pleotelson margins and straight appendix masculina.

Couplet 28 Examination of the holotype of $N$. anophthalma is needed to distinguish it from $N$. californiensis although $N$. anophthalma is described as lacking robust setae on the pleotelson.

Couplet 31 Natatolana pallidocula apparently has the pleotelson with a more acute apex than in any of the species identified from couplet 31 .

Couplet 42 Natatolana pallidocula apparently has well-developed coxal furrows on all coxae, while these are absent on at least some coxae in both $N$. caeca and $N$. gorung. 


\section{Species of Natatolana}

\section{Natatolana albicaudata (Stebbing, 1900)}

Cirolana albicaudata Stebbing, 1900: 631, pl. 1xviiB.-Nierstrasz, 1931: 152.

Cirolana albicaudata var. japonica Thielemann, 1910: 8, figs. 1-4.-Nierstrasz, 1931: 152.

Cirolana albicauda japonica.-Iwasa, 1965: 14, 18.

Natatolana albicaudata.-Bruce, 1981: 958.-1986: 71, figs. 46, 47.-1995a: 409 figs. 19F,G.-Brusca et al., 1995: 79.-Kensley, 2001: 230.-Bruce et al., 2002: 148.

Natatolana albicaudata japonica.-Saito et al., 2000: 64.

Not Cirolana albicaudata.-Barnard, 1936: 152, fig. 2a-c [misidentification $=$ Natatolana insignis Hobbins \& Jones, 1993] .

Not Cirolana albicaudata.-Richardson, 1910: 5 [mis-identification $=$ Natatolana amplocula Bruce, 1986].

Type material. Syntypes: $4 \hat{\jmath} \widehat{\jmath}, 3.8-5.3 \mathrm{~mm}, 2 q q, 3.9,4.2$ mm, 5 mancas, 2.0-3.8 mm, BMNH 1906.4.19:44-54 (examined). - Type locality: Barawon, Blanche Bay, New Britain [Papua New Guinea, c. $\left.6^{\circ} \mathrm{S} 150^{\circ} \mathrm{E}\right]$.

Material examined. Queensland: series from Lizard Island, Qld., 14²4'S 145²8'E, N. Preston: manca, QM W18917, 30 Dec. 1986; + , QM W18912, 9 Nov. 1987, stn 2; manca, QM W18913, 4 Dec. 1987, stn 2; manca, QM W18910, 30 Oct. 1987, stn 1. New Caledonia: + , ZMUC CRU137, $23^{\circ} 32^{\prime}$ 'S $167^{\circ} 36^{\prime} \mathrm{E}$, surface, Dana Station 3604, 24 Nov. 1928.

Diagnosis. Interocular furrow: well developed, extending across the cephalon; smoothly convex. Frontal lamina: lateral margins straight, parallel. Antenna: c. $0.4 \times$ as long as body, reaching to between the posterior of pereonite 2 and 4 (In the original description it is illustrated as extending to posterior of pereonite 4 and described as about half the length of the body. This agrees with the syntype specimens examined here. The redescription of Bruce [1986] states that it extends to the anterior of pereonite 3 but is variable and may extend to pereonite 5). Coxal plates: furrows strongly developed, on coxae 2-7. Pleonite 4: apex forming a broad acute point. Pleotelson: broad, length $0.84 \times$ basal width; anterodorsal depression absent; anterolateral margins convex; posterolateral margins convex; apex not produced, lateral margins converging smoothly to a point; with 7-10 RS (the original description and figures indicate 8, Bruce's (1986) redescription gives 9 or 10 and his figures show 7). Pereopod 2: propodus with $2 \mathrm{RS}$ on palm. Pereopod 3: propodus with $1 \mathrm{RS}$ on palm. Pereopods 5-7: propodus long, on pereopod 5 greatly elongate, $2 \times$ that of pereopod 7 . Pereopod 7: basis broad, width $0.6 \times$ length; distance between anterior margin and medial carina less than between posterior margin and medial carina; posterior margin with setae completely absent along entire length. Penes: absent. Pleopod 2 appendix masculina: just shorter than endopod, $0.94 \times$ length of endopod; slender; margins very slightly curved laterally; apex not at angle to adjacent margins, bluntly rounded. Uropods: exopod short, $0.78 \times$ the length of the endopod.

Size. The largest syntype specimen is $5.3 \mathrm{~mm}$, Bruce (1986) recorded specimens to $8.9 \mathrm{~mm}$.

Remarks. Bruce $(1986$, p.53, 74) noted that Natatolana albicaudata, N. amplocula and $N$. curta share a number of similarities but that $N$. albicaudata can be distinguished from all other species in the genus by a combination of characters. These include having chromatophores, conspicuously elongated dactyls, a slender propodus on pereopods 4-6, and other characters dealing with the frontal lamina, pereopods, pleotelson and uropods, coxal furrowing and pleon shape that were not elaborated on. Both $N$. curta and $N$. amplocula were originally known only from single specimens. Comparison of the types and additional specimens of all three species indicates that the characters used by Bruce (1986) to differentiate them are difficult to apply. Type specimens of $N$. albicaudata, however, differ from those of $N$. amplocula and $N$. curta most noticeably in having a less rounded uropod endopod and pleotelson. It also appears to be a smaller species in which indistinct tubercles do not form on the dorsal surface of the pereonites of males and has fewer robust setae on the uropod exopod. Further collections of $N$. albicaudata, N. amplocula and $N$. curta from their type localities would help confirm this, especially as the type material of $N$. albicaudata is in poor condition, and Bruce (1986) indicated that in material he identified, which is larger than the type material, the apices of the pleotelson and uropods are far more distinctly rounded.

Richardson (1910) identified material from the Philippines as both Natatolana albicaudata and N. curta but did not indicate differences between these species. Examination of the material Richardson identified as $N$. albicaudata indicates it is most similar to N. amplocula.

The specimens reported here from Lizard Island and New Caledonia are only tentatively identified because of the difficulties in differentiating this species (noted above) and because the material consists of a limited series of females and juveniles.

Distribution and ecology. Records are restricted here to Japan (Thielemann, 1910; Iwasa, 1965), northwestern and northeastern Australia (Bruce, 1986), Indonesia (Nierstrasz, 1931), Papua New Guinea (Stebbing, 1900; Bruce, 1995a), and New Caledonia. This range is tentative given the similarities with N. amplocula and N. curta. Hayward et al. (1999, 2001) report $N$. albicaudata from New Zealand but Bruce (2003) considered this a probable misidentification. From surface plankton to a depth of $250 \mathrm{~m}$ (Thielemann, 1910).

Natatolana albicaudata is not a scavenger. Bruce (1995a) has briefly discussed the ecology of this species, noting that it has not been collected in Madang Lagoon using baited traps but does occur there. It has also been collected from coral rock and rubble rather than particulate substrata.

\section{Natatolana amplocula Bruce, 1986}

Natatolana amplocula Bruce, 1986: 74, fig. 48.-Brusca et al., 1995: 79.-Bruce et al., 2002: 149.

Cirolana albicaudata.-Richardson, 1910: 5 [mis-identification, not $N$. albicaudata Stebbing, 1900].

Type material. Holotype: female, $13.2 \mathrm{~mm}$, ZMUC CRU1691 (examined). $\bullet$ Type locality: south of Kei Islands, $5^{\circ} 34^{\prime} \mathrm{S} 132^{\circ} 26^{\prime} \mathrm{E}$.

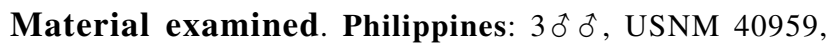
Tomindao Island anchorage, electric light, Albatross Expedition,

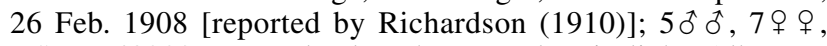
USNM 40988, Java Island anchorage, electric light, Albatross Expedition, 14 Dec. 1908 [reported by Richardson (1910)]; 3 ㅇ $~$, ZMUC CRU118, Tubajon Bay, Dinagat, $10^{\circ} 20^{\prime} \mathrm{N} 125^{\circ} 32^{\prime} \mathrm{E}$, corals, 40 m, 16 Jul. 1951, Galathea Station 414. Indonesia: $\widehat{0}$, ZMUC CRU128, Banda Sea, $6^{\circ} 37^{\prime} \mathrm{N} 122^{\circ} 24^{\prime} \mathrm{E}$, planktonic, 3 April 1929, Dana stn 3684; 57, ZMUC CRU127, off Java, $6^{\circ} 41.5^{\prime}$ 'S $105^{\circ} 19.5^{\prime}$ E, planktonic-surface, 3 Sep. 1929, Dana stn 3808. Australia, Northern Territory: $\widehat{\delta}$, NTM Cr005812, New Year 
Island, $10^{\circ} 55^{\prime} \mathrm{S} 133^{\circ} 01^{\prime} \mathrm{E}, 5 \mathrm{~m}$. Queensland: $\delta^{\circ},+$, manca, AM P47471, Shadwell Reef, $11^{\circ} 27.66^{\prime} \mathrm{S} 143^{\circ} 46.63$ 'E, nightlight, surface over $20 \mathrm{~m}$ depth, H. Larson, J. Leis, M. McGrouther, 12 Jan. 1993, QLD-646; series from west of Carter Reef, $14^{\circ} 33$ 'S $145^{\circ} 35^{\prime} \mathrm{E}$, surface over $30 \mathrm{~m}$ (neuston and vertical tows), J. Leis $\&$ party, RV Sunbird, 4-7 Mar. 1983: $2 \hat{\widehat{o}}$ ô, 4 우 ㅇ, AM P47472; 2 오, 3 mancas, AM P47473; $\widehat{0}, 5$ 우, AM P47474; $q$, AM P47475; ㅇ, QM W18911, Lizard Island, $14^{\circ} 40^{\prime} \mathrm{S} 145^{\circ} 28^{\prime} \mathrm{E}, \mathrm{N}$. Preston, 12 Nov. 1986, stn 1; ô, AM P47476, off East Fitzroy Reef, $23^{\circ} 34.92^{\prime} \mathrm{S} 152^{\circ} 11.76$ 'E, $58 \mathrm{~m}, 16-17$ Jun. 1993, SEAS

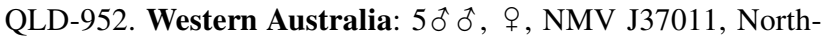
West Shelf between Port Hedland and Dampier, $18^{\circ} 45^{\prime} \mathrm{S} 118^{\circ} 24^{\prime} \mathrm{E}$, trawl, 142 m, G.C.B. Poore \& H.M. Lew-Ton, 5 Jun. 1983. Southwest Pacific Ocean: $2 q 9$, AM P47477, Elizabeth Reef, Tasman Sea, $29^{\circ} 55^{\prime} \mathrm{S} 159^{\circ} 05^{\prime} \mathrm{E}$, hand net at surface, attracted to light at night, A. Gill \& J.K. Lowry on RV Flamingo Bay, 12 Dec. 1987, site 42; $\widehat{0}$, + , AM P41150, Taupo Seamount, Tasman Sea, $33^{\circ} 16.85^{\prime} \mathrm{S} 156^{\circ} 09.15^{\prime} \mathrm{E}$, limestone and sand bottom, 244 m, 1.2 m sled, J.K. Lowry et al. on RV Franklin, 2 May 1989, FRO589-8; 0 , damaged specimen, MNHN, New Caledonia, $19^{\circ} 07^{\prime} \mathrm{S} 163^{\circ} 22^{\prime} \mathrm{E}, 200 \mathrm{~m}$, MUSORSTOM 4, 14 Sep. 1985, stn 0151 ; $0^{\circ}$, MNHN, Chesterfield Islands, $22^{\circ} 47.7^{\prime} \mathrm{S} 159^{\circ} 23.7^{\prime} \mathrm{E}$, 360-390 m, MUSORSTOM 5, 11 Oct. 1986, stn 0299; $q, 2$ mancas, NMNZ, Raoul Island, Kermadec Islands, $28^{\circ} 50^{\prime} \mathrm{S}$ $177^{\circ} 48^{\prime} \mathrm{E}$, plankton net at surface over 268-332 m, RV James Cook, 17 Jun. 1976.

Diagnosis. Interocular furrow: well developed, extending across the cephalon; smoothly convex. Frontal lamina: lateral margins straight, narrowing posteriorly. Antenna: c. $0.4 \times$ as long as body, reaching to between the posterior of pereonite 3 and posterior of pereonite 4. Coxal plates: furrows strongly developed, on coxae 2-7. Pleonite 4: apex forming a broad acute point. Pleotelson: broad, length $0.74 \times$ basal width; anterodorsal depression absent; anterolateral margins convex; posterolateral margins broadly rounded; apex produced into a small point; with 6-12 RS. Pereopod 2: propodus with $2 \mathrm{RS}$ on palm. Pereopod 3: propodus with 2 RS on palm. Pereopod 7: basis broad, width $0.6 \times$ length; distance between anterior margin and medial carina less than between posterior margin and medial carina; posterior margin with setae completely absent along entire length. Penes: absent. Pleopod 2 appendix masculina: just shorter than endopod, 0.85-0.95× length of endopod; slender; margins bent slightly medially; apex not at angle to adjacent margins, bluntly rounded. Uropods: exopod short, $0.73 \times$ the length of the endopod; lateral margin convex.

Variation. The number of robust setae on the pleotelson is most often 8 but may range between 6 and 12 (6 in the holotype and specimens from Lizard Island, Queensland; eight in specimens from the Philippines [USNM 40988], Carter Reef and Shadwell Reef, Queensland; 10 in specimens from the Philippines [USNM 40959], Taupo Seamount and New Caledonia; 12 in specimens from northwestern Australia and the southwest Pacific [Elizabeth Reef, Raoul Island and Chesterfield Islands]. Indistinct tubercles are present on the dorsal surface of pereonites 1 and 3 in males from off Java, Indonesia, New Year Island, NT, Carter Reef and east Fitzroy Reef, Queensland, New Caledonia and Taupo Seamount. The antennae reach the posterior of pereonite 4 in the material from Carter Reef and Elizabeth Reef whereas in other material they extend approximately half way along pereonite 3 .

Sexual dimorphism. Males may develop indistinct tubercles on the dorsal surface of pereonites 1 and 3 .
Size. Adults to $13.2 \mathrm{~mm}$.

Remarks. Natatolana amplocula is most similar to $N$. albicaudata (see remarks for that species) and N. curta. Natatolana curta was described from a single specimen and has not been subsequently collected. The uropod endopod is less rounded in the holotype of N. amplocula, than in the holotype of $N$. curta but the specimen of $N$. curta is larger and may have had the distal lateral margins somewhat worn down. Other differences of the holotype of $N$. curta to that of $N$. amplocula follow with the state for N. amplocula in parentheses: interocular furrow incomplete (complete); dorsal posterolateral margin of pleonite 2 produced posterior to ventral posterolateral margin (subequal), 11 robust setae on the pleotelson margin (six); indistinct tubercles on the dorsal surface of pereonites 1 and 3 (absent-but this appears to be a sexually dimorphic character found only in mature males and the holotype of $N$. amplocula is female).

The specimens reported here are only tentatively identified as Natatolana amplocula because of the difficulties in differentiating this species as noted above. None of the specimens examined were as large as the holotype of $N$. curta and none had the uropod endopod as strongly rounded. In other respects, all of the material examined appeared to be intermediate between $N$. amplocula and $N$. curta because: all specimens have a complete interocular furrow; the number of robust setae on the pleotelson varies between 6-12; and the dorsal posterolateral margin of pleonite 2 is produced posterior to the ventral posterolateral margin. Furthermore, the holotype of $N$. curta is a male and has indistinct tubercles on the dorsal surface of pereonites 1 and 3 . In a number of samples examined here, similar tubercles were found on male specimens but never females. Because of the limited type material of $N$. amplocula the significance of these tubercles is unclear.

Distribution. Philippines, Indonesia, northwestern and northeastern Australia, southern Pacific Ocean as far west as the Kermadec Islands and as far south as Taupo Seamount. Recorded from surface plankton to a depth of $441 \mathrm{~m}$.

\section{Natatolana angula Bruce, 1986}

Natatolana angula Bruce, 1986: 106, fig. 73.-Springthorpe \& Lowry, 1994: 37.-Brusca et al., 1995: 79.-Keable, 1997: 255, fig. 1e.-Bruce et al., 2002: 149.

Natatolana cf. angula.-Keable, 1995: 43.

Type material. Holotype: đo, QM W9795. Paratypes: QM W9797-9800; AM P32380 (examined); USNM; NTM. • Type locality: Halifax Bay, Townsville, Queensland, Australia, $19^{\circ} 08^{\prime} \mathrm{S}$ $146^{\circ} 19^{\prime} \mathrm{E}$.

\section{Material examined. Listed by Keable (1997).}

Diagnosis. Interocular furrow: well developed, extending across the cephalon; smoothly convex. Frontal lamina: lateral margins medially constricted. Antenna: c. $0.4 \times$ as long as body, reaching to between the posterior of pereonite 3 and 4 (pereonite 2 according to Bruce (1986), however, in one paratype from AM P32380 it reaches to the posterior of pereonite 3 and in the other it reaches to one third of the way along pereonite 4). Coxal plates: furrows moderately developed, on all coxae. Pleonite 4: apex slightly rounded. Pleotelson: broad, length $0.76 \times$ basal width; anterodorsal 
depression absent; anterolateral margins almost straight and angling posteriorly toward the midline; posterolateral margins straight, markedly angled to anterolateral margins and meeting at an obtuse angle or convex (on paratypes the posterior margin appears straight); apex not produced, lateral margins converging smoothly to a point; with 8-12 RS. Pereopods 2-3: propodus without RS on palm. Pereopod 7: basis broad, width $0.58 \times$ length; distance between anterior margin and medial carina greater than between posterior margin and medial carina; posterior margin with setae along entire length. Penes: absent. Pleopod 2 appendix masculina: just shorter than endopod; margins very slightly curved laterally or straight; slender; apex not at angle to adjacent margins, bluntly rounded. Uropods: exopod slightly shorter than endopod, $0.87 \times$ the length of the endopod.

Size. Adults to $13.5 \mathrm{~mm}$.

Remarks. Identification, distribution, ecology and character variation for Natatolana angula is discussed by Keable (1997) who also re-illustrated the uropod.

Distribution and ecology. Australia: northern Western Australia, Darwin (Northern Territory), northern Queensland south to Gladstone. Hayward et al. (2001) report "Notatolana [sic] 'angula"' from New Zealand, this requires confirmation. Intertidal to $83 \mathrm{~m}$ depth. Scavenger.

\section{Natatolana anophthalma (Kussakin \& Vasina, 1982)}

Cirolana anophthalma Kussakin \& Vasina, 1982a: 263, figs. 3, 4.-1982b: 329, 336.

Natatolana anophthalma.-Bruce, 1986: 222.-?Kensley, 1989: 149.-Brusca et al., 1995: 79.

Natatolana anopthalma.-Kensley, 2001: 230 [lapsus].

Type material. Holotype: ô, $21.2 \mathrm{~mm}$, ZIAS No. 1/71 226 (not examined). - Type locality: Kerguelen Islands, $47^{\circ} 57^{\prime} \mathrm{S} 69^{\circ} 02^{\prime} \mathrm{E}, 175 \mathrm{~m}$.

Material examined. St. Paul and Amsterdam Islands, southern Indian Ocean, manca, USNM $25215838^{\circ} 24.4^{\prime}$ 'S 77³4.8'E, 14301600 m, previously determined by Kensley (1989).

Diagnosis. Details of the interocular furrow, labrum, coxa 2 , number of robust setae on the pleotelson, setation and size of the pereopod articles, penes, and setation of the uropod exopod are unknown. Eyes: vestigial or absent. Antenna: c. $0.3 \times$ as long as body, reaching to at least the posterior of pereonite 2. Coxal plates: furrows moderately developed, on all coxae. Pleonite 4: apex slightly rounded. Pleotelson: broad; anterolateral margins almost straight and angling posteriorly toward the midline; posterolateral margins convex; apex not produced, lateral margins converging smoothly to a point; RS present (not mentioned in original description but apparent in illustration). Pereopod 7: basis narrow. Pleopod 2 appendix masculina: extending subequal with tip of endopod; margins strongly curved laterally; slender; apex not at angle to adjacent margins, bluntly rounded (described as rounded but appears truncate in the original illustration). Uropods: exopod slightly shorter than endopod, $0.87 \times$ the length of the endopod.

\section{Sexual dimorphism. Unknown.}

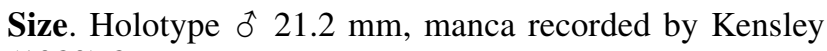
(1989) $8 \mathrm{~mm}$.
Remarks. An attempt to borrow the holotype of Natatolana anophthalma from the Zoological Institute of the Academy of Science, St. Petersburg, was unsuccessful. Other than the type material, the only record of this species is that of Kensley (1989) who recorded two specimens from St. Paul and Amsterdam Islands. Only one of these specimens, a manca, is now available. This specimen was examined but, because it is a juvenile, characters such as the shape of the appendix masculina and basis of pereopod 7 could not be observed and the identification of the species is considered here to be doubtful. Examination of the type material is needed to distinguish this species from a number of similar species such as $N$. californiensis.

Distribution. Kerguelen Islands (type locality, $175 \mathrm{~m}$ ); possibly also occurring at St. Paul and Amsterdam Islands, southern Indian Ocean (1430-1600 m).

\section{Natatolana aotearoa n.sp.}

Figs. 5-6

Type material. HOLOTYPE: $\delta, 19 \mathrm{~mm}$, NIWA 18748. PARATYPES: all from New Zealand: $q$, ZMUC CRU108, Milford Sound, 443 $34^{\prime} \mathrm{S}$ $167^{\circ} 48^{\prime} \mathrm{E}$, mud with sand and clay, $136 \mathrm{~m}$, Galathea Station 619, 19 Jan. 1952; + , $5 \overbrace{}^{\widehat{o}}$, NMNZ 9203, Akaroa Harbour entrance, c. $44^{\circ} \mathrm{S}$ $173^{\circ} \mathrm{E}$, black mud, $13-15 \mathrm{~m}$, RV Acheron, 20 Feb. 1979, BS 782; 3 우 우 NMNZ 9204, northwest of Manawatu River, $40^{\circ} 22.5^{\prime} \mathrm{S} 174^{\circ} 59.5^{\prime} \mathrm{E}, 86$ m, RV Acheron, 2 Mar. 1976, BS 495. Series from off the west coast of the South Island, dredge-anchor box, P.K. Probert: manca, NIWA 18750, $42^{\circ} 48.5^{\prime} \mathrm{S} 169^{\circ} 53.5^{\prime} \mathrm{E}$, silt-clay, $520 \mathrm{~m}, 20 \mathrm{Feb} .1982 ; 2$ mancas, NIWA $18751,41^{\circ} 25.5^{\prime} \mathrm{S} 171^{\circ} 10.3^{\prime} \mathrm{E}$, silt-clay, $172 \mathrm{~m}, 25 \mathrm{Feb} .1982$; manca, NIWA $18752,42^{\circ} 24.5^{\prime} \mathrm{S} 170^{\circ} 57.5^{\prime} \mathrm{E}$, sand-silt-clay, $133 \mathrm{~m}, 28$ Feb. 1982; ${ }^{\circ}$, manca, NIWA $18753,42^{\circ} 23.4^{\prime} \mathrm{S} 170^{\circ} 53.6^{\prime} \mathrm{E}$, sand-silt-clay, $167 \mathrm{~m}, 4$ Mar. 1982; đo, 2 mancas, NIWA $18754,42^{\circ} 57.7^{\prime} \mathrm{S} 170^{\circ} 12.4^{\prime} \mathrm{E}$, silt-clay, 109 m, 18 Feb. 1982; o, NIWA $18756,41^{\circ} 33.4^{\prime} \mathrm{S} 171^{\circ} 25^{\prime} \mathrm{E}$, sand-siltclay, $140 \mathrm{~m}, 25 \mathrm{Feb} .1982$; $ᄋ$, NIWA $18755,42^{\circ} 25.7^{\prime} \mathrm{S} 171^{\circ} 01.8^{\prime} \mathrm{E}$, sandsilt-clay, $87 \mathrm{~m}, 28 \mathrm{Feb}$. 1982. - Type locality: off west coast of South Island, New Zealand, $41^{\circ} 25.5^{\prime} \mathrm{S} 171^{\circ} 10.3^{\prime} \mathrm{E}$, silt-clay, $172 \mathrm{~m}$ [dredgeanchor box, P.K. Probert, 25 Feb. 1982].

Diagnosis. Eyes: vestigial. Interocular furrow: well developed, forming a ridge that extends across the cephalon; smoothly convex. Frontal lamina: lateral margins straight, narrowing anteriorly. Antenna: c. $0.4 \times$ as long as body, reaching to half way along pereonite 4. Coxal plates: furrows variously developed, strongly developed on coxae 2-3, absent on coxae 4-6, moderately developed on coxa 7. Pleonite 4: posterodorsal margin strongly concave proximal to meeting posteroventral margin at apex; apex forming a narrow acute point. Pleotelson: broad, length $0.86 \times$ basal width; anterodorsal depression absent; anterolateral margins convex; posterolateral margins convex; apex not produced, lateral margins converging smoothly to a point; with 6 RS. Pereopod 2: propodus with 2 RS on palm. Pereopod 3: ischium anterodistal angle produced, but not as produced as on pereopods 1 and 2, similar to pereopod 4. Propodus with $1 \mathrm{RS}$ on palm. Pereopod 7: basis of medium breadth, width $0.5 \times$ length; distance between anterior margin and medial carina less than between posterior margin and medial carina; posterior margin with setae on proximal third. Penes: absent. Pleopod 2 appendix masculina: extending subequal with tip of endopod, $1.01 \times$ length of endopod; margins very slightly curved laterally; slender; apex not at angle to adjacent margins, bluntly rounded. Uropods: exopod slightly shorter than endopod, $0.8 \times$ the length of the endopod. 


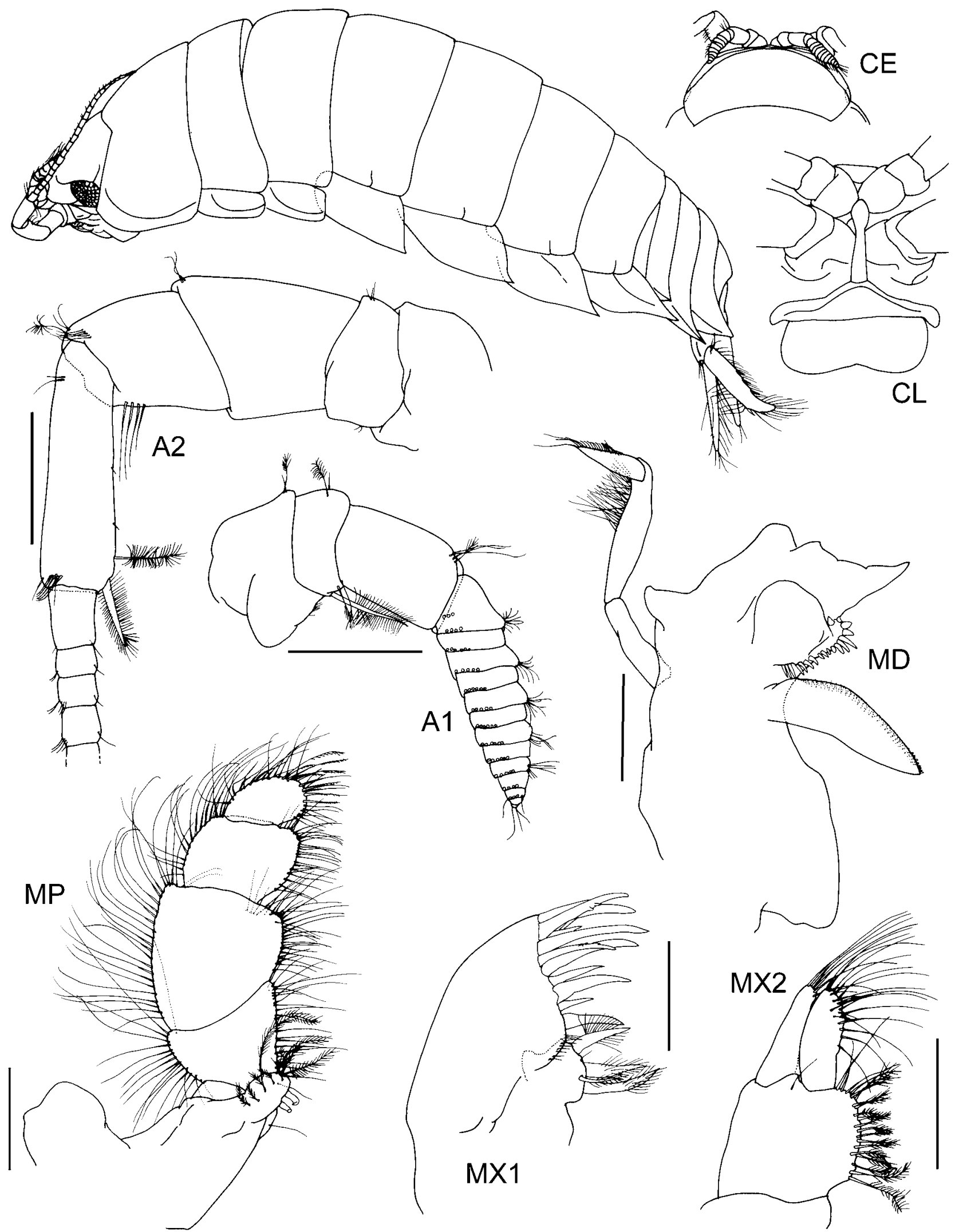

Fig. 5. Natatolana aotearoa, n.sp., holotype. Scales $=0.5 \mathrm{~mm}$.

Additional descriptive characters. Based on holotype. Body: length c. $2.6 \times$ width. Colour cream in alcohol. Chromatophores absent. Eyes: with 7 ommatidia in horizontal diameter; with 7 ommatidia in vertical diameter; round; colour white in alcohol. Frontal lamina: length c. $4.5 \times$ basal width; apex expanded, anterior margin rounded. Antennule: peduncular article 1 longer than article 2; article 2 with 1 large pappose seta; article 3 long, larger than article 1 or 2 but shorter than their combined lengths. Flagellum 13-articulate. Antenna: peduncular article 4 with 4 SS on posterolateral margin, 8 SS and 1 penicillate seta at anterodistal angle; article 5 with 2 pappose setae at posterodistal angle, 6 SS at anterodistal angle. Flagellum 27- 


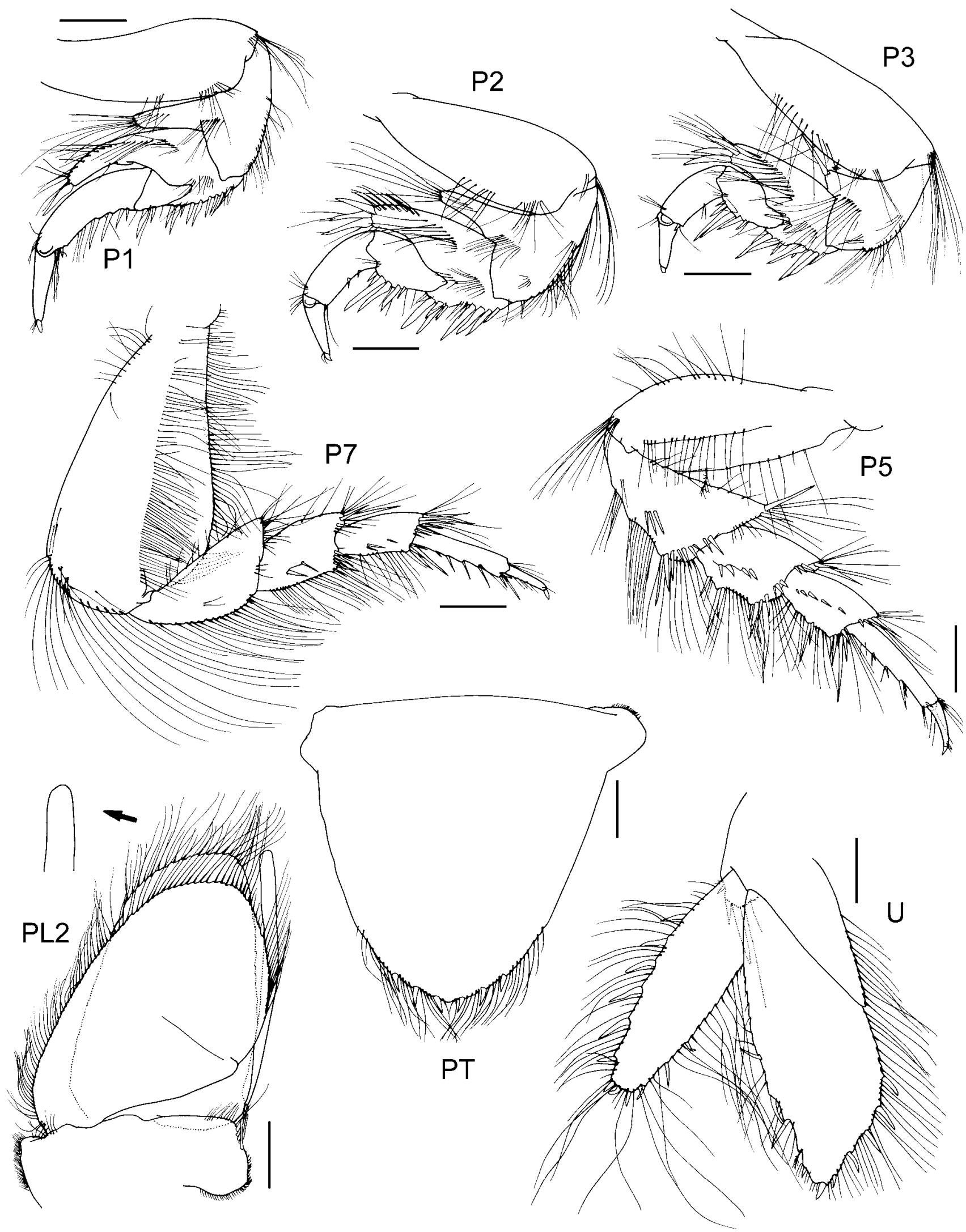

Fig. 6. Natatolana aotearoa, n.sp., holotype. Scales $=0.5 \mathrm{~mm}$.

articulate. Mandible: setal row with 19 RS. Maxillule: medial lobe with 3 large and 1 smaller robust pappose setae; lateral lobe with 13 RS on distal surface. Maxilla: lateral lobe with 6 SS; medial lobe with 5 SS and 17 PS; middle lobe with 20 SS. Maxilliped: endite with 2 coupling hooks, and 9 PS. Pereon: ornamentation consists of 1 strongly developed furrow on lateral margin of pereonite 1 and 1 short, medial furrow on lateral margins of pereonites 4-7; pereonite 1 longest, 4-6 subequal and longer than 2-3 and 7 which are subequal. Coxae: pereonite 1, coxa 2 with rounded posteroventral corners, coxa 3 with a square posteroventral corner, coxae 4-7 with increasingly produced, acute posteroventral corners. Pleonites: 
$1-5$ visible but 1 almost completely concealed along dorsal margin by pereonite 7. Pleonite 2: dorsal posterolateral margin clearly projecting posterior to ventral posterolateral margin. Pereopod 7: basis anterior margin sinuate; medial carina with PS along entire length; posterior margin convex, PS present. Ischium anterior margin with SS; posterior margin without RS, PS present. Merus anterior margin with SS; posterior margin without RS (2 submarginally), SS present. Carpus posterior margin without RS (3 submarginally), SS present. Propodus longer than carpus; posterior margin with $6 \mathrm{RS}, \mathrm{SS}$ present. Pleopod 2 appendix masculina: arising sub-basally. Pleopods 1-5: exopod suture strongly developed on pleopods $3-5$; endopod PS on most of margins of pleopods $1-4$, only a few setae on pleopod 5. Uropods: endopod lanceolate; medial margin convex, with 5 RS, PS along entire length; apex with 2 RS; lateral margin slightly sinuate, with 4 RS, PS on distal three-quarters. Exopod medial margin convex, with 4 RS, PS on distal three-quarters; apex acute, with $2 \mathrm{RS}$; lateral margin convex, with 6 RS, PS along entire length.

Size. Adults to c. $20 \mathrm{~mm}$.

Etymology. From the Māori for New Zealand, meaning land of the long white cloud or long bright land, in reference to the species distribution.

Remarks. Natatolana aotearoa is most similar to $N$. thurar. In both of these species the eyes have indistinct ommatidia that lack pigment, the interocular furrow is developed into a ridge and the posterodorsal margin of pleonite 4 is concave with the apex developed into a narrow acute point. Natatolana aotearoa, however, differs in having the ischium of pereopods 1-2 more produced, with distinctly concave anterodistal margins, and in having the ischium of pereopod 3 less produced. The apex of the frontal lamina is also less acute and the lateral margins not parallel as in $N$. thurar.

Distribution. New Zealand; known only from the west coast. At depths of 13-520 m.

\section{Natatolana arcicauda (Holdich, Harrison \& Bruce, 1981)}

Cirolana arcicauda Holdich et al., 1981: 563, fig. 14.

Natatolana lurur Bruce, 1986: 89, fig. 61.-Brusca et al., 1995: 80.-Kensley, 2001: 230.

Cirolana woodjonesi.-Hale, 1940: 288 (part) [mis-identification, not $N$. woodjonesi (Hale, 1924)].

Natatolana arcicauda.-Bruce, 1981: 958.-1986: 89, fig. 59.Brusca et al., 1995: 79.-Bruce et al., 2002: 149.

Type material of $N$. arcicauda. Holotype: female, $11.3 \mathrm{~mm}$, QM W6335 (examined). Paratypes: đo, 10.5 mm, QM W6336 (examined); $\widehat{0}$, but institution where deposited not stated, possibly in Nottingham University. $\bullet$ Type locality of $N$. arcicauda: Cleveland Bay, Townsville, Queensland, Australia [19 $\left.{ }^{\circ} 13^{\prime} \mathrm{S} 146^{\circ} 55^{\prime} \mathrm{E}\right]$.

Type material of $N$. lurur. Holotype:,$+ 15.8 \mathrm{~mm}$, WAM 4680. Paratype: WAM 20-80. All examined. - Type locality of $N$. lurur: northwest of Bluff Point, Geraldton, WA, Australia, $27^{\circ} 40^{\prime} \mathrm{S}$ $113^{\circ} 03^{\prime} \mathrm{E}, 150 \mathrm{~m}$.

Material examined. Queensland: 6, AM P47294, off Flynn Reef, $16^{\circ} 41.32^{\prime} \mathrm{S} 146^{\circ} 18.26^{\prime} \mathrm{E}, 100 \mathrm{~m}, 7-8 \mathrm{Jun} .1993$, SEAS QLD937; 5, AM P47295, due east of Mooloolaba, 26 $39.13^{\prime} \mathrm{S}$ $153^{\circ} 18.88^{\prime} \mathrm{E}, 51 \mathrm{~m}, 2-3$ Aug. 1994, SEAS QLD-1122. Western Australia: $3 \delta^{\dagger} \hat{0}, 5 \%+$, AM P47709, off Kimberley Plateau, c. $16^{\circ} 8.86^{\prime} \mathrm{S} 123^{\circ} 27.76^{\prime} \mathrm{E}$, baited trap, 20 m, F. Wells, 1994, stn 20.
Diagnosis. Interocular furrow: well developed, extending across the cephalon, or moderately developed, distinct but not extending across the cephalon; smoothly convex. Frontal lamina: lateral margins straight, parallel. Antenna: c. 0.36× as long as body, reaching to posterior of pereonite 3. Coxal plates: furrows variously developed, strongly developed on coxae 2, 3 and 7, absent on coxae 4, 5 and 6, or weakly developed on coxae 2-3 and strongly developed on coxa 7, or moderately developed on all coxae. Pleonite 4: apex slightly rounded. Pleotelson: broad, length $0.75 \times$ basal width; anterodorsal depression absent; anterolateral margins convex, or almost straight and angling posteriorly toward the midline; posterolateral margins broadly rounded, or straight, markedly angled to anterolateral margins and meeting at an obtuse angle; apex not produced, lateral margins converging smoothly to a point; with 8-10 RS. Pereopod 2: propodus with $3 \mathrm{RS}$ on palm. Pereopod 3: propodus with $1 \mathrm{RS}$ on palm. Pereopod 7: basis narrow, width $0.43-0.46 \times$ length; distance between anterior margin and medial carina less than between posterior margin and medial carina; posterior margin with setae on proximal third. Penes: absent. Pleopod 2 appendix masculina: extending subequal with tip of endopod; margins very slightly curved laterally; slender; apex not at angle to adjacent margins, bluntly rounded. Uropods: exopod slightly shorter than endopod, $0.83 \times$ the length of the endopod.

Variation. The holotype of Natatolana arcicauda has eight robust setae on the margin of the pleotelson and the holotype of $N$. lurur has 10 robust setae on this margin. Specimens from Kimberley Plateau on the northwest coast of Australia (AM P47709) and Flynn Reef off the northeast coast (AM P47294) have a range of eight to 10 robust setae on the pleotelson. All of the specimens examined, other than the holotype of $N$. arcicauda, have an angular pleotelson as described for this species by Bruce (1986). Specimens from east of Mooloolaba on the northeast Australian coast (AM P47295) have a complete interocular furrow and indistinct coxal furrows on all coxae.

Size. Adults 11.3-18.9 mm.

Remarks. Bruce (1986) discussed the differences between Natatolana lurur and $N$. thurar. Differences between $N$. lurur and $N$. arcicauda, however, were not discussed. Comparison of the original descriptions of $N$. arcicauda and $N$. lurur, and the additional description of $N$. arcicauda by Bruce (1986), indicate six possible significant distinctions between the two species. These are differences in the shape of the frontal lamina, development of the interocular furrow, length of the antennae combined with the number of articles in the antennal flagellum, the distribution of the coxal furrows, the shape of the pleotelson and the number of robust setae on the margins of the pleotelson. Examination of the holotypes of both species and of additional material, however, indicates that these differences are not profound. The reasons for this conclusion are discussed below.

While the frontal lamina of Natatolana arcicauda has been illustrated as having an angular apex (Bruce, 1986) it is actually rounded as in the type material of $N$. lurur. Similarly, the length of the antennae in the type material of $N$. lurur is incorrectly described. Instead of extending to the posterior of pereonite 2 and having 28 articles in the flagella, the antennae extend to the posterior of pereonite 3 and have between 21 and 25 articles in the flagella, (23 articles in N. arcicauda). Furthermore, although the furrows on coxae 2 and 3 of the holotype of $N$. arcicauda are not as 
well developed as those in the type material of $N$. lurur, they are still present. The interocular furrow is incomplete in the type material of $N$. arcicauda and complete in that of $N$. lurur. Comparison with additional material from near the type locality of N. arcicauda (AM P47294-5), however, suggests this is a variable character. Similarly, differences in the number of robust setae on the margins of the pleotelson appear to represent intra-specific rather than interspecific variation. The margins of the pleotelson of the holotype of $N$. arcicauda appear worn and damaged and Bruce (1986) has indicated that the shape of the pleotelson is variable and can resemble that described for $N$. lurur.

Additionally, the general agreement in alternative characters, such as the shape of the coxae and pleonites, and the shape and setation of the pereopods and uropods, suggest that the two nominal taxa are conspecific. Accordingly, Natatolana lurur is recognized as a junior subjective synonym of $N$. arcicauda as reported in Bruce et al. (2002).

Distribution and ecology. Australia, off Geraldton and Kimberley Plateau (Western Australia) and off Cairns to Mooloolaba (Queensland). At depths of 2.7-150 m. Scavenger.

\section{Natatolana arrama Bruce, 1986}

Natatolana arrama Bruce, 1986: 108, fig. 74.-Springthorpe \& Lowry, 1994: 38.-Brusca et al., 1995: 79.-Bruce et al., 2002: 149.

Type material. Holotype: + , $11.1 \mathrm{~mm}$, AM P30363. Paratype: AM P30362. All examined. - Type locality: south of Portland, Victoria, Australia, $38^{\circ} 52^{\prime} \mathrm{S} 141^{\circ} 50^{\prime} \mathrm{E}, 77 \mathrm{~m}$.

Material examined. New South Wales: 21, AM P47468, east of Coffs Harbour, $30^{\circ} 17.49^{\prime} \mathrm{S} 153^{\circ} 13.90^{\prime} \mathrm{E}, 45.4 \mathrm{~m}, 11-12 \mathrm{Aug}$. 1993, SEAS NSW-873; 30, AM P47469, off Providential Head, $34^{\circ} 44^{\prime}$ S $150^{\circ} 39^{\prime}$ E, baited trap, $45-50$ m, S. Keable, A. Parker \& J. Lowry, 14-15 Jan. 1991, PIO-107; 502, AM P44317, off Wollongong, $34^{\circ} 26.54^{\prime} \mathrm{S} 150^{\circ} 57.98^{\prime} \mathrm{E}, 50 \mathrm{~m}, 28 \mathrm{Mar}$. 1994, SEAS NSW-956. Tasmania: 175, AM P47470, about 800 m east of Point Geographe, Freycinet Peninsula, $42^{\circ} 17^{\prime} \mathrm{S} 148^{\circ} 18.8^{\prime} \mathrm{E}$, baited trap, 45 m, J.K. Lowry \& S.J. Keable, 30 April-1 May 1991, TAS-337.

Diagnosis. Interocular furrow: moderately developed, distinct but not extending across the cephalon. Frontal lamina: lateral margins straight, narrowing anteriorly. Antenna: c. $0.24 \times$ as long as body, reaching to posterior of pereonite 2. Coxal plates: furrows moderately developed, on all coxae. Pleonite 4: apex slightly rounded. Pleotelson: broad, length $0.93 \times$ basal width; anterodorsal depression absent; anterolateral margins convex; posterolateral margins convex; apex produced into a small point; with 4 RS. Pereopods 2-3: propodus without RS on palm. Pereopod 7: basis broad, width $0.68 \times$ length; distance between anterior margin and medial carina greater than between posterior margin and medial carina; posterior margin with setae along entire length. Penes: absent. Pleopod 2 appendix masculina: extending beyond tip of endopod; margins straight or very slightly curved laterally; slender; apex recurved, bent slightly medially, bluntly rounded. Uropods: exopod slightly shorter than endopod, $0.82 \times$ the length of the endopod; lateral margin without RS.

Size. Adults to c. $12.6 \mathrm{~mm}$.

Remarks. This is the first record of a male specimen of Natatolana arrama. Bruce (1986) appears to have illustrated and described pereopod 6 of this species rather than pereopod 7 as stated. The anterior margin of the basis of pereopod 7 is sinuate and the posterior margin convexnot both strongly convex as originally described.

Using the key provided by Bruce (1986) this species can only be reached if it is assumed in couplet 21 that it has six or more robust setae on the pleotelson, whereas it only has four. Natatolana arrama is most readily identified by the lack of robust setae on the uropod exopod lateral margin combined with straight lateral margins of the frontal lamina that converge anteriorly to form an unexpanded and acute apex.

Distribution and ecology. Australia: central New South Wales, off the east coast of Tasmania, Bass Strait (off Portland, Victoria, and Eucla, South Australia). At depths of 45-77 m. Scavenger.

\section{Natatolana boko Bruce, 1986}

Natatolana boko Bruce, 1986: 59, fig. 35, 36.-Springthorpe \& Lowry, 1994: 40.-Brusca et al., 1995: 79.-Bruce et al., 2002: 149.

Type material. Holotype: $\widehat{0}, 5.2 \mathrm{~mm}$, AM P32173. Paratype: AM P30382. All examined. - Type locality: east of Lady Musgrave Island, Queensland, Australia, $23^{\circ} 44^{\prime} \mathrm{S} 152^{\circ} 49^{\prime} \mathrm{E}, 357-384 \mathrm{~m}$.

Material examined. Tasmania: 15, NMV J18419-21, all off Freycinet Peninsula, $41^{\circ} 57.5^{\prime}-42^{\circ} 2.2^{\prime} \mathrm{S} 148^{\circ} 37.7^{\prime}-148^{\circ} 38.7^{\prime} \mathrm{E}$, sled, coarse shell or shelly sand, 400-800 m, M.F. Gomon et al., 27 Jul. 1986.

Diagnosis. Eyes: vestigial. Interocular furrow: well developed, extending across the cephalon (described by Bruce (1986) as submarginal furrow); smoothly convex. Frontal lamina: lateral margins straight, parallel. Antenna: c. $0.25-0.3 \times$ as long as body, reaching to posterior of pereonite 2. Coxal plates: furrows completely absent on all coxae. Pleonite 4: apex forming a broad acute point. Pleotelson: broad, length $0.67 \times$ basal width; anterodorsal depression absent (although described by Bruce (1986) as having a depression, this is not distinct and abrupt as in species such as N. pellucida); anterolateral margins convex; posterolateral margins concave; apex not produced, lateral margins converging smoothly to a point; RS absent. Pereopod 2: propodus with 0-2 RS on palm. Pereopod 3: propodus without RS on palm. Pereopods 5-7: propodus short and robust on each pereopod. Pereopod 7: basis broad, width $0.54 \times$ length; distance between anterior margin and medial carina less than between posterior margin and medial carina; posterior margin with sparse setae on proximal half. Penes: present (although the vas deferens are described as opening flush to the sternite surface by Bruce (1986), distinct penial processes are evident in the type material and other material examined). Pleopod 2 appendix masculina: extending subequal with tip of endopod, $1.03 \times$ length of endopod; slender; margins very slightly curved laterally; apex not at angle to adjacent margins, bluntly rounded. Uropods: exopod short, $0.6 \times$ the length of the endopod; lateral margin without RS.

Size. Adults to c. $5.2 \mathrm{~mm}$.

Remarks. Natatolana boko can be readily distinguished from other species by the sinuate lateral margins of the pleotelson and uropod endopod, both of which also lack robust setae.

Distribution. Australia: off Lady Musgrave Island, Queensland; Freycinet Peninsula, Tasmania. At depths of 357-800 m. 


\section{Natatolana borealis (Liljeborg, 1851)}

Synonymy in Keable \& Bruce, 1997: 659, figs. 1-4.

Type material. Syntypes: deposition of the original material was not indicated, $3 \hat{0} 0,5$ ? $9+9$ in the Zoological Museum, Lund University, Sweden, probably represent at least part of the original type series examined by Liljeborg (Keable \& Bruce, 1997). All examined. - Type locality: Kristiansund [as Christiansund, c. $63^{\circ} 23^{\prime} \mathrm{N} 7^{\circ} 45^{\prime} \mathrm{E}$ ] and Bergen [c. $60^{\circ} 23^{\prime} \mathrm{N} 5^{\circ} 20^{\prime} \mathrm{E}$ ], Norway.

Material examined. Listed by Keable \& Bruce (1997).

Diagnosis. Interocular furrow: moderately developed, distinct but not extending across the cephalon. Frontal lamina: lateral margins straight, parallel. Antenna: c. $0.4 \times$ as long as body, reaching to posterior of pereonite 4. Coxal plates: furrows variously developed, faint and incomplete on coxae 2 and 3 only. Pleonite 4: apex forming a broad acute point. Pleotelson: broad, length $0.96 \times$ basal width; anterodorsal depression absent; anterolateral margins convex; posterolateral margins convex; apex not produced, lateral margins converging smoothly to a point; with 6-8 RS. Pereopod 2: propodus with 4-6 RS on palm (4 large and 2 small). Pereopod 3: propodus with $3 \mathrm{RS}$ on palm. Pereopod 7: basis broad, width $0.57 \times$ length; distance between anterior margin and medial carina less than between posterior margin and medial carina; posterior margin with setae along entire length. Penes: absent. Pleopod 2 appendix masculina: just shorter than endopod, $0.87 \times$ length of endopod; margins straight or bent slightly medially; slender; apex not at angle to adjacent margins, with lateral projection forming a Y-shape with acute apex. Uropods: exopod slightly shorter than endopod, $0.87 \times$ the length of the endopod.

Variation. In smaller males (e.g., $22 \mathrm{~mm}$ ) the appendix masculina is shorter (e.g., $0.81 \times$ endopod) and the $\mathrm{Y}$ shaped process on the appendix masculina apex may be absent or only partially developed (Keable \& Bruce, 1997).

Size. Adults to c. $33 \mathrm{~mm}$.

Remarks. Keable \& Bruce (1997) redescribe Natatolana borealis and discuss its identification and character variation. This species can be readily recognized by the shape and setation of the uropods and pleotelson, and by the distinctive shape of the appendix masculina of adult males.

The material of Natatolana borealis reported from South Africa by Kensley $(1975,1978)$ is not $N$. borealis. Kensley (1975) noted the South African specimens have coxae with sinuate posterior margins, and a small notch at posteroventral corner where an acute coxal point is produced. Kensley suggested that this was a variation that may be due to the immaturity of the specimens. This does not seem to be the case, juvenile Natatolana usually resemble the adult very closely in these features (personal observation) and the coxae of smaller specimens identified by Keable \& Bruce (1997), as N. borealis, are similar to those of the adults. Also, one of the specimens reported by Kensley (1975) (SAM A-13556) has an apparently fully developed basis of pereopod 7 attached to the body and can therefore be considered to have reached adult size. A unusual feature of the South African specimens is that the carpus of pereopods 4-5 [figured as pereopod 6 by Kensley (1975)] is greatly elongated (c. 2 times as long as the merus and 1.5 times as long as the propodus). This is a unique character within Natatolana and indicates that these specimens represent an undescribed species. Unfortunately, the material is not in good enough condition to describe.

Distribution and ecology. Disjunct North Atlantic records-primarily recorded from northeastern Atlantic coasts between $70^{\circ}$ and $10^{\circ} \mathrm{N}$, westwards to about $22^{\circ} \mathrm{W}$ but also recorded from off South Carolina, USA (Keable \& Bruce, 1997; Johansen \& Brattegard, 1998). At depths of 5-1478 $\mathrm{m}$ with the depth range varying with locality (Keable \& Bruce, 1997; Johansen \& Brattegard, 1998).

Natatolana borealis is well documented as a scavenger, feeding on dead and dying fish (Keable \& Bruce, 1997). Ecological and physiological studies reporting this species, subsequent to those summarized by Keable \& Bruce (1997), include Johansen (1999, 2000a, 2000b), Johansen \& Brattegard (1998), Kaïm-Malka (1997), Kaïm-Malka et al. (1998), Bozzano \& Sarda (2002) and Castro et al. (2005).

\section{Natatolana bowmani Bruce, 1986}

Natatolana bowmani Bruce, 1986: 60, fig. 37.-Springthorpe \& Lowry, 1994: 40.-Brusca et al., 1995: 80.-Bruce et al., 2002: 150 .

Type material. Holotype: $\widehat{\jmath}, 13.8 \mathrm{~mm}$, AM P33555. Paratypes: AM P31573-P31576, P31905. All examined. • Type locality: east

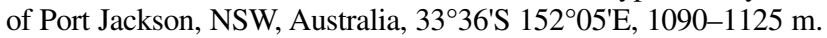

Material examined. New South Wales: 5, AM P47296, northeast of Coffs Harbour, 30 $10.94^{\prime} \mathrm{S} 153^{\circ} 32.27^{\prime} \mathrm{E}, 1000 \mathrm{~m}$, 11-12 Aug. 1993, SEAS NSW-862; 210, AM P44364, off Wollongong, $34^{\circ} 33.41^{\prime} \mathrm{S} 151^{\circ} 21.35^{\prime} \mathrm{E}, 1000 \mathrm{~m}, 6-7$ May 1993, SEAS NSW-788. Tasmania: 29, AM P47297, east of Fortescue Bay,

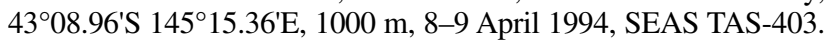

Diagnosis. Eyes: vestigial. Interocular furrow: moderately developed, distinct but not extending across the cephalon. Frontal lamina: lateral margins straight, parallel, or lateral margins concave but not medially constricted, broadening anteriorly. Antenna: c. $0.38 \times$ as long as body, reaching to slightly beyond the posterior of pereonite 3 to half way along pereonite 4. Coxal plates: furrows strongly developed, on all coxae. Pleonite 4: apex forming a broad acute point, or apex slightly rounded. Pleotelson: broad, length $0.82 \times$ basal width; anterodorsal depression absent; anterolateral margins convex; posterolateral margins convex; apex not produced, lateral margins converging smoothly to a point, or produced into a small point; with 4-8 RS. Pereopod 2: propodus with $1 \mathrm{RS}$ on palm. Pereopod 3: propodus with $1 \mathrm{RS}$ on palm. Pereopod 7: basis narrow, width $0.38 \times$ length; distance between anterior margin and medial carina less than between posterior margin and medial carina; posterior margin with setae on distal third. Penes: present. Pleopod 2 appendix masculina: extending beyond tip of endopod, $1.03 \times$ length of endopod; slender; margins very slightly curved laterally; apex not at angle to adjacent margins, bluntly rounded. Uropods: exopod slightly shorter than endopod, $0.8 \times$ the length of the endopod.

Sexual dimorphism. Females have the pereon slightly broader than males.

Size. Mancas to $5.8 \mathrm{~mm}$, males to $13.8 \mathrm{~mm}$; females to $14.0 \mathrm{~mm}$.

Remarks. Examination of the holotype of Natatolana bowmani indicates that the anterior apex of the frontal lamina is more angled than illustrated by Bruce (1986). The 
margins of the pleotelson of the holotype and some paratype material appear worn and damaged. On some of the paratypes and other specimens examined there are eight robust setae on the posterolateral margins of the pleotelson, not four as described by Bruce (1986). The vestigial eyes, presence of penes, shape of pleonite 4 and morphology of the appendix masculina are the most useful characters in differentiating $N$. bowmani from similar species.

Distribution and ecology. Australia: between Coffs Harbour and Port Kembla, New South Wales; and east coast of Tasmania. At depths of 880-1200 m. Scavenger.

\section{Natatolana brucei n.sp.}

Figs. 7-8

Type material. Holotype: $\delta^{\dagger}, 16.0 \mathrm{~mm}$, AM P47185. PARATYPES: 116, AM P38675; 0 ,,+ at BMNH, USNM, ZMUC. - Type locality: off Grotto Point, Port Jackson, NSW, Australia, $33^{\circ} 49.2^{\prime} \mathrm{S} 151^{\circ} 15.75^{\prime} \mathrm{E}$, [baited trap, unknown substrate, probably sediment], $10 \mathrm{~m}$, [S. Keable, J. Lowry \& D. Townsend, 16-17 Jul. 1988, Site 37].

Additional material. New South Wales: 9, AM P47199, off Grotto Point, Port Jackson, 33⒋ ${ }^{\circ}$ '05'S $151^{\circ} 15.8^{\prime} \mathrm{E}$, baited trap on sediment, 15 m, S. Keable \& J. Lowry, 8-9 May 1988, site 13; series from south of Sydney, Australian Museum/The Ecology Lab Pty. Ltd. Pioneer Consultation Project 1991, off Providential Head, $34^{\circ} 44^{\prime} \mathrm{S} 150^{\circ} 39^{\prime} \mathrm{E}$, baited traps, S. Keable, A. Parker \& J. Lowry on MV Krista, 14-15 Jan. 1991: AM P47202-47207; ㅇ, 25-30 m, PIO-101; o, 2 mancas, 25-30 m, PI0-103; ㅇ, $33 \mathrm{~m}$, PIO-116; off Bate Bay/Port Hacking, $34^{\circ} 07.00^{\prime S} 151^{\circ} 10.00^{\prime} \mathrm{E}$ : 4, 25-30 m, S2R1 shallow; ô, ๆ, manca, 25-30 m, S2R2 shallow; o, 35-40 m, S2R 2 medium; series from Twofold Bay, baited trap, J. Lowry \& S. Keable, 27-29 Nov. 1988: 9, AM P47200, between Whale Spit and Mungora Point, 37 $5.7^{\circ} \mathrm{S} 149^{\circ} 53.1^{\prime} \mathrm{E}$, unknown substrate, probably sediment, $8 \mathrm{~m}$, NSW-381; 2, AM P47201, between Lookout Point and Seahorse Shoals, 37 ${ }^{\circ}$ 5.6'S $149^{\circ} 56.6^{\prime} \mathrm{E}$, unknown substrate-probably sediment, 30 m, NSW-392.

Diagnosis. Interocular furrow: weakly developed, indistinct and not extending across the cephalon. Frontal lamina: lateral margins straight, parallel. Antenna: c. $0.3 \times$ as long as body, reaching to just beyond posterior of pereonite 3 . Coxal plates: furrows variously developed, strong and complete on coxae 2-3, 7, indistinct and incomplete on coxae 4-6. Pleonite 4: apex slightly rounded. Pleotelson: narrow, length $1.14 \times$ basal width; anterodorsal depression absent; anterolateral margins convex; posterolateral margins concave; apex produced into a large point; with 6 RS. Pereopods 2-3: propodus without RS on palm. Pereopod 7: basis broad, width $0.61 \times$ length; distance between anterior margin and medial carina greater than between posterior margin and medial carina; posterior margin with setae on proximal half. Penes: absent. Pleopod 2 appendix masculina: extending beyond tip of endopod, $1.04 \times$ length of endopod; margins very slightly curved laterally; slender; apex not at angle to adjacent margins, bluntly rounded. Uropods: exopod slightly shorter than endopod, $0.87 \times$ the length of the endopod.

Additional descriptive characters. Based on holotype. Body: length c. $3.3 \times$ width. Colour cream in alcohol. Chromatophores absent. Eyes: with 7 ommatidia in horizontal diameter; with 8 ommatidia in vertical diameter; ovate; colour tan in alcohol. Frontal lamina: length c. $6.8 \times$ basal width; apex not expanded, anterior margin rounded.
Antennule: peduncular article 1 longer than article 2; article 2 with 1 large pappose seta (broken); article 3 long, larger than article 1 or 2 but shorter than their combined lengths. Flagellum 12-articulate. Antenna: peduncular article 4 with $2 \mathrm{SS}$ and 1 penicillate seta medially on posterolateral margin, $2 \mathrm{SS}$ at posterodistal angle, $2 \mathrm{SS}$ at anterodistal angle; article 5 with 1 pappose and 1 PS at posterodistal angle, 3 SS and 1 penicillate seta at anterodistal angle. Flagellum 22articulate. Mandible: setal row with 14 RS. Maxillule: medial lobe with 3 large robust pappose setae and 3 SS; lateral lobe with $12 \mathrm{RS}$ on distal surface. Maxilla: lateral lobe with 6 SS; medial lobe with 5 SS and 9 PS; middle lobe with 12 SS. Maxilliped: endite with 2 coupling hooks, 1 SS and 6 PS. Pereon: ornamentation consists of 1 strongly developed furrow on lateral margin of pereonite 1 and 1 short, medial furrow on lateral margins of pereonites 4-6; pereonites 1, 4-6 subequal and longest, 2-3 and 7 subequal. Coxae: pereonite 1 and coxae 2-3 with rounded posteroventral corners, coxae 5-7 with sinuate posterior margins formed into moderately large coxal points. Pleonites: $1-5$ visible but 1 almost completely concealed along dorsal margin by pereonite 7. Pleonite 2: dorsal posterolateral margin subequal with ventral posterolateral margin. Pereopod 7: basis anterior margin sinuate; medial carina with PS and SS present (plumose setae on proximal third, slender setae on distal third); posterior margin convex, PS present. Ischium anterior margin with SS; posterior margin with 1 RS (submarginal), PS present. Merus posterior margin with 7 RS (and 4 submarginally), SS present. Carpus posterior margin with 6 RS (2 submarginally), SS absent. Propodus longer than carpus; posterior margin with $7 \mathrm{RS}$, SS absent. Pleopod 2 appendix masculina: arising sub-basally. Pleopods 1-5: exopod suture strongly developed on pleopods 3-5; endopod PS on most of margins on pleopods 1-4, absent on pleopod 5. Uropods: endopod lanceolate; medial margin convex, with 4 RS, PS along entire length; apex with 2 RS; lateral margin slightly sinuate, with $3 \mathrm{RS}$ and 1 penicillate seta, PS on distal three-quarters. Exopod medial margin convex, with 2 RS, PS along entire length; apex acute, with 2 RS; lateral margin convex, with 7 RS, PS along entire length.

Size. Adults to c. $16 \mathrm{~mm}$.

Etymology. Named after Dr Niel Bruce, in recognition of the help he has given me with this study.

Remarks. Natatolana brucei appears to be very similar to $N$. pallidocula but differs in having a round eye with fewer ommatidia, a rounded posteroventral margin on coxa 3 , a antennal flagellum with more articles, a longer appendix masculina and a broader pereopod 7 .

Distribution and ecology. Australia: New South Wales within Port Jackson and off the coast south of Port Jackson; Twofold Bay. At depths of 8-40 m. Scavenger.

\section{Natatolana bulba Bruce, 1986}

Natatolana bulba Bruce, 1986: 108, fig. 75.-Springthorpe \& Lowry, 1994: 41.-Brusca et al., 1995: 80.-Bruce et al., 2002: 150.

Type material. Holotype: $\widehat{\jmath}, 9.5 \mathrm{~mm}, \mathrm{AM}$ P32174. Paratypes: AM E4843. All examined. - Type locality: off North West Island, Capricorn Group, Southern Great Barrier Reef, Queensland, Australia, $23^{\circ} 17.5^{\prime} \mathrm{S} 151^{\circ} 42^{\prime} \mathrm{E}, 40 \mathrm{~m}$. 


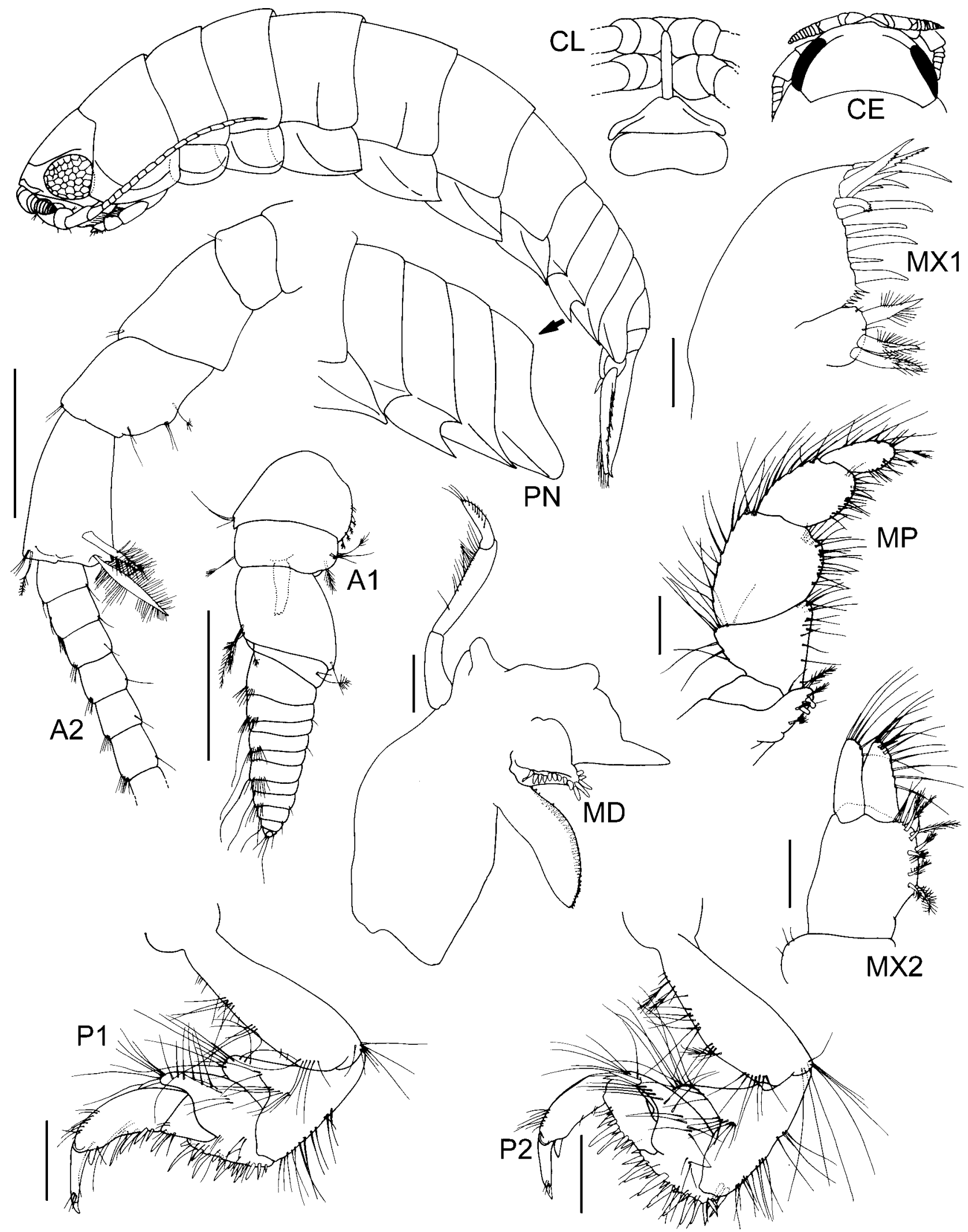

Fig. 7. Natatolana brucei, n.sp., holotype. Scales for A1, A2, P1, P2 = 0.5 mm. Scales for MD, MP, MX1, MX2 = $0.2 \mathrm{~mm}$.

Material examined. Queensland: series from off Flynn Reef: ơ, AM P47632, 16 ${ }^{\circ} 41.32$ 'S $146^{\circ} 18.26^{\prime} \mathrm{E}, 100 \mathrm{~m}, 6-7$ Jun. 1993, SEAS QLD-920; 4, AM P47633, 16²40.82'S 146² $18.81^{\prime} \mathrm{E}, 200$ m, 7-8 Jun. 1993, SEAS QLD-940; series from off East Fitzroy Reef; 22, AM P47634, 2332.53'S $152^{\circ} 16.45^{\prime} \mathrm{E}, 105 \mathrm{~m}, 16-17$ Jun. 1993, SEAS QLD-956; 3, AM P47635, 2330.46'S
152 $21.32^{\prime} \mathrm{E}, 300 \mathrm{~m}, 16-17$ Jun. 1993, SEAS QLD-960; 9, AM

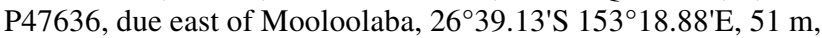
2-3 Aug. 1994, SEAS QLD-1122. New South Wales: series from northeast and east of Coffs Harbour; 21, AM P47637, 30 $15.86^{\prime} \mathrm{S}$ 1532⒈90'E, 92.7 m, 11-12 Aug. 1993, SEAS NSW-870; 6, AM P47638, $30^{\circ} 17.49^{\prime} \mathrm{S} 153^{\circ} 13.90^{\prime} \mathrm{E}, 45.4 \mathrm{~m}, 11-12$ Aug. 1993, 


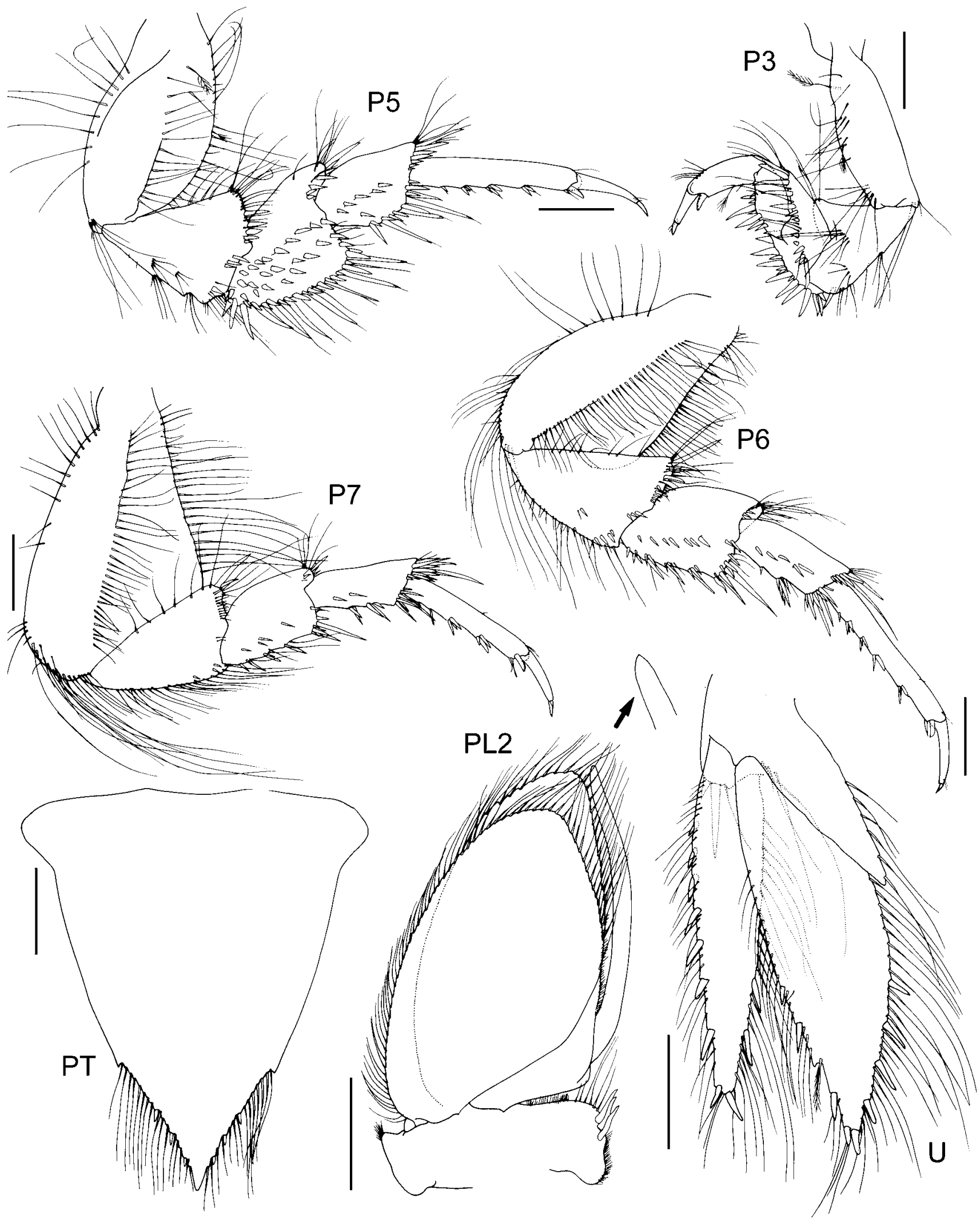

Fig. 8. Natatolana brucei n.sp., holotype. Scales $=0.5 \mathrm{~mm}$.

SEAS NSW-873; 62, AM P47639, 30²15.75'S 15321.98'E, 98 m, 12-13 Aug. 1993, SEAS NSW-885; 19, AM P47641, $30^{\circ} 12.97 ' \mathrm{~S} 153^{\circ} 29.23^{\prime} \mathrm{E}, 400 \mathrm{~m}, 8-9$ Sep. 1994, SEAS NSW994; many, AM P47640, $1.7 \mathrm{~km}$ east of Ramsgate, Botany Bay, $33^{\circ} 59.1^{\prime} \mathrm{S} 151^{\circ} 9.95 ' \mathrm{E}$, baited trap, $5 \mathrm{~m}, \mathrm{~S}$. Keable \& R. Springthorpe, 7-8 April 1992, FACSCAV-30; 6, AM P47642, Parriwi Point, Port Jackson, $33^{\circ} 48.5^{\prime} \mathrm{S} 151^{\circ} 14.8^{\prime} \mathrm{E}$, baited trap, sediment, 8 m, S. Keable \& J. Lowry, 23-24 Sep. 1988, site 49;

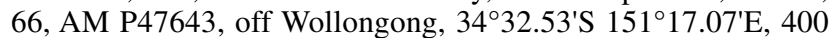
m, 6-7 May 1993, SEAS NSW-787. Tasmania: series from east

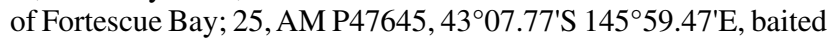
trap, 50 m, 17-18 April 1993, SEAS TAS-368; 8, AM P47648, $43^{\circ} 08.96$ 'S $145^{\circ} 15.36$ 'E, $1000 \mathrm{~m}, 17-18$ April 1993 , SEAS TAS383; 10, AM P38833, $43^{\circ} 07.77$ 'S $145^{\circ} 59.47$ 'E, 50 m, 8-9 April 
1994, SEAS TAS-386; 56, AM P47647, about 80 m outside Hannants Bight, north side of Cape Sorell, $42^{\circ} 11.5^{\prime} \mathrm{S} 145^{\circ} 11^{\prime} \mathrm{E}$, sand and detritus, 18 m, J. Lowry \& S. Keable, 26-27 April 1991, TAS-277.

Diagnosis. Interocular furrow: moderately developed, distinct but not extending across the cephalon or well developed, extending across the cephalon; smoothly convex. Frontal lamina: lateral margins medially constricted. Antenna: c. $0.25-0.3 \times$ as long as body, reaching to between the posterior of pereonite 2 and 3. Coxal plates: furrows moderately developed, on all coxae. Pleonite 4: apex forming a broad acute point. Pleotelson: broad, length 0.9 basal width; anterodorsal depression absent; anterolateral margins convex; posterolateral margins convex; apex produced into a small point; with 4-6 RS (4 in types). Pereopods 1-6: males with RS on the merus of pereopods $1-3$, and carpus of pereopods 4-6, shorter than the propodus. Pereopods 2-3: propodus without RS on palm. Pereopod 7: basis broad, width $0.6 \times$ length; distance between anterior margin and medial carina greater than between posterior margin and medial carina; posterior margin with setae along entire length. Penes: absent. Pleopod 2 appendix masculina: just shorter than endopod; margins very slightly curved laterally; slender; apex recurved, bent slightly medially, bluntly rounded. Uropods: exopod short, $0.75 \times$ the length of the endopod; lateral margin without RS.

Variation. All material noted here is tentatively identified as Natatolana bulba. Some of the material examined from Queensland (Flynn Reef: AM P47632, AM P47633; Fitzroy Reef: AM P47635), New South Wales (Botany Bay: AM P47641; Wollongong: AM P47643) and eastern Tasmania (AM P47648) have a narrower apex to the uropod endopod than the type specimens. Of these, those from Fitzroy Reef, Queensland (AM P47635) and Botany Bay, New South Wales (AM P47641) also have a complete interocular furrow. Specimens from Wollongong, New South Wales (AM P47643), however, have a narrow apex to the uropod endopod and a complete or an incomplete interocular furrow. Specimens from eastern Tasmania (AM P38833) have the apex of the uropod endopod intermediate between those of the type specimens and those from Wollongong, New South Wales (AM P47643). Specimens from New South Wales (Port Jackson: AM P47642), eastern Tasmania (AM P47645) and western Tasmania (AM P47647) have the antennae reaching to the posterior of pereonite 2 , not pereonite 3 as in the types. The sample from Mooloolaba, Queensland (AM P47636), however, contains specimens with antennae that reach to the posterior of pereonite 2 and also some in which the antennae reach to the posterior of pereonite 3. In the material from western Tasmania (AM $\mathrm{P} 47647$ ) there are a few specimens with five or six robust setae on the pleotelson rather than the usual four.

Size. Adults from $9.5 \mathrm{~mm}$ (male from type material) to 12.9 mm ( $q$ from type material) (Bruce, 1986). Specimens examined here from AM P47643 to c. $16 \mathrm{~mm}$.

Remarks. Natatolana bulba is extremely similar to $N$. kahiba, comparison of their type specimens revealed only two characters to differentiate them: the number of robust setae on the uropod exopod lateral margin (none in N. bulba; two or three in N. kahiba); and the relative lengths of the antennae (in $N$. bulba reaching to the posterior of pereonite $3,0.3-0.35 \times$ as long as the body with c. 18 flagellar articles; in N. kahiba reaching between pereonite 1 and 2, 0.2-0.25x as long as the body, with 12-15 flagella articles). Specimens without robust setae on the uropod exopod lateral margin but with short antennae corresponding to those found in $N$. kahiba were identified as N. bulba as noted in "variation". Allozyme analysis comparing specimens with this morphology, with that of $N$. kahiba, shows that recognition of separate species is warranted (Keable, 1996b).

The most distinctive feature of Natatolana bulba is the lack of robust setae on the lateral margin of the uropod exopod. Similar species recorded here, which may also lack these setae, include $N$. arrama, $N$. nammuldi and $N$. wowine. These species can be most readily separated from $N$. bulba by the shapes of the frontal lamina, appendix masculina, posterolateral margins of pleonite 4 , and the uropods and the number of robust setae on the pleotelson.

Using the key provided by Bruce (1986) Natatolana bulba can only be reached if it is assumed in couplet 21 that it has six or more robust setae on the pleotelson, whereas the type specimens only have four.

Distribution and ecology. Australia: Queensland, New South Wales, and Tasmania. At depths of 5-1000 m. Scavenger.

\section{Natatolana buzwilsoni n.sp.}

Figs. 9-10

Type material. HolotyPe: $\widehat{\delta}, 14 \mathrm{~mm}$, AM P47241. PARATYPES: All North-West Shelf, WA, collected CSIRO; 우, AM P47242, 19²9.9'S $118^{\circ} 52.0^{\prime} \mathrm{E}, 37 \mathrm{~m}, 24$ Oct. 1983, 05-D1-S; đิ, AM P47243, $19^{\circ} 04.4^{\prime} \mathrm{S} 118^{\circ} 47.5^{\prime} \mathrm{E}, 82-83 \mathrm{~m}, 16$ Feb. 1983, 01B6-S; ô, AM P47244, 19²9.9'S $118^{\circ} 52^{\prime} \mathrm{E}, 38 \mathrm{~m}, 25$ Oct. 1993, 05-D9-S. - Type locality: North-West Shelf, WA, Australia, $19^{\circ} 56.9^{\prime} \mathrm{S} 117^{\circ} 53.7^{\prime} \mathrm{E}, 42-43 \mathrm{~m}$, [22 May 1983, 02-B2-S].

Diagnosis. Interocular furrow: weakly developed, indistinct and not extending across the cephalon. Frontal lamina: lateral margins straight, parallel. Antenna: c. $0.3 \times$ as long as body, reaching to posterior of pereonite 3. Coxal plates: furrows moderately developed, on all coxae. Pleonite 2: ventral posterolateral margin not produced. Pleonite 4: apex rounded. Pleotelson: broad, length $0.71 \times$ basal width; anterodorsal depression absent; anterolateral margins convex; posterolateral margins broadly rounded; apex not produced, lateral margins converging smoothly to a point; with 5 RS. Pereopod 2: propodus with 3 RS on palm. Pereopod 3: propodus with 2 RS on palm. Pereopods 5-7: propodus short and robust on each pereopod. Pereopod 7: basis broad, width $0.53 \times$ length; distance between anterior margin and medial carina less than between posterior margin and medial carina; posterior margin with setae on proximal half. Penes: absent. Pleopod 2 appendix masculina: extending subequal with tip of endopod, $1.01 \times$ length of endopod; margins very slightly curved laterally; slender; apex not at angle to adjacent margins, acute. Uropods: exopod short, $0.78 \times$ the length of the endopod.

Additional descriptive characters. Based on holotype. Body: length c. $3.2 \times$ width. Colour cream-white in alcohol. Chromatophores absent. Eyes: with 10 ommatidia in horizontal diameter; with 10 ommatidia in vertical diameter; round; without pigment in alcohol. Frontal lamina: length c. $3.2 \times$ basal width; apex expanded, anterior margin angled. Antennule: short, just reaching pereonite 1. Peduncular article 1 longer than article 2; article 2 with 1 large pappose 


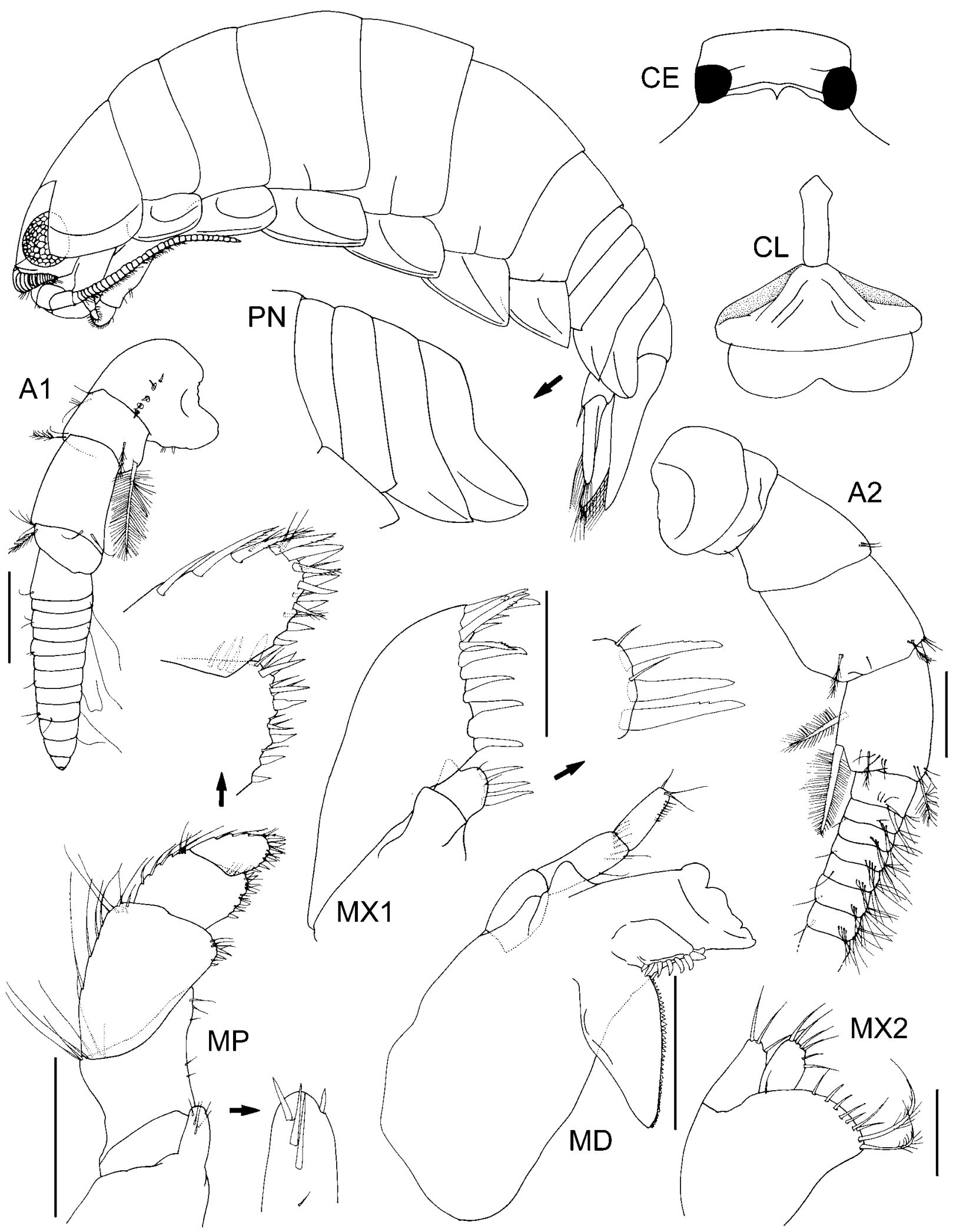

Fig. 9. Natatolana buzwilsoni $\mathrm{n} . \mathrm{sp}$., holotype. Scales $=0.5 \mathrm{~mm}$.

seta; article 3 short, subequal to article 1. Flagellum 13articulate. Antenna: peduncular article 4 with short penicillate and SS at distal margin; article 5 subequal in length to article 4, with 2 pappose setae on posterolateral margin, short penicillate and SS along distal margin. Flagellum 35-articulate. Mandible: incisor narrow, with posterior tooth not strongly developed; setal row with 8 RS. Maxillule: medial lobe with 3 large RS; lateral lobe with 11 RS on distal surface. Maxilla: lateral lobe broad, with $3 \mathrm{SS}$; medial lobe with $7 \mathrm{SS}$ and 2 PS; middle lobe reduced, with 6 SS. Maxilliped: palp medial margin RS present. Endite with coupling hooks absent, 4 SS present. Pereon: 

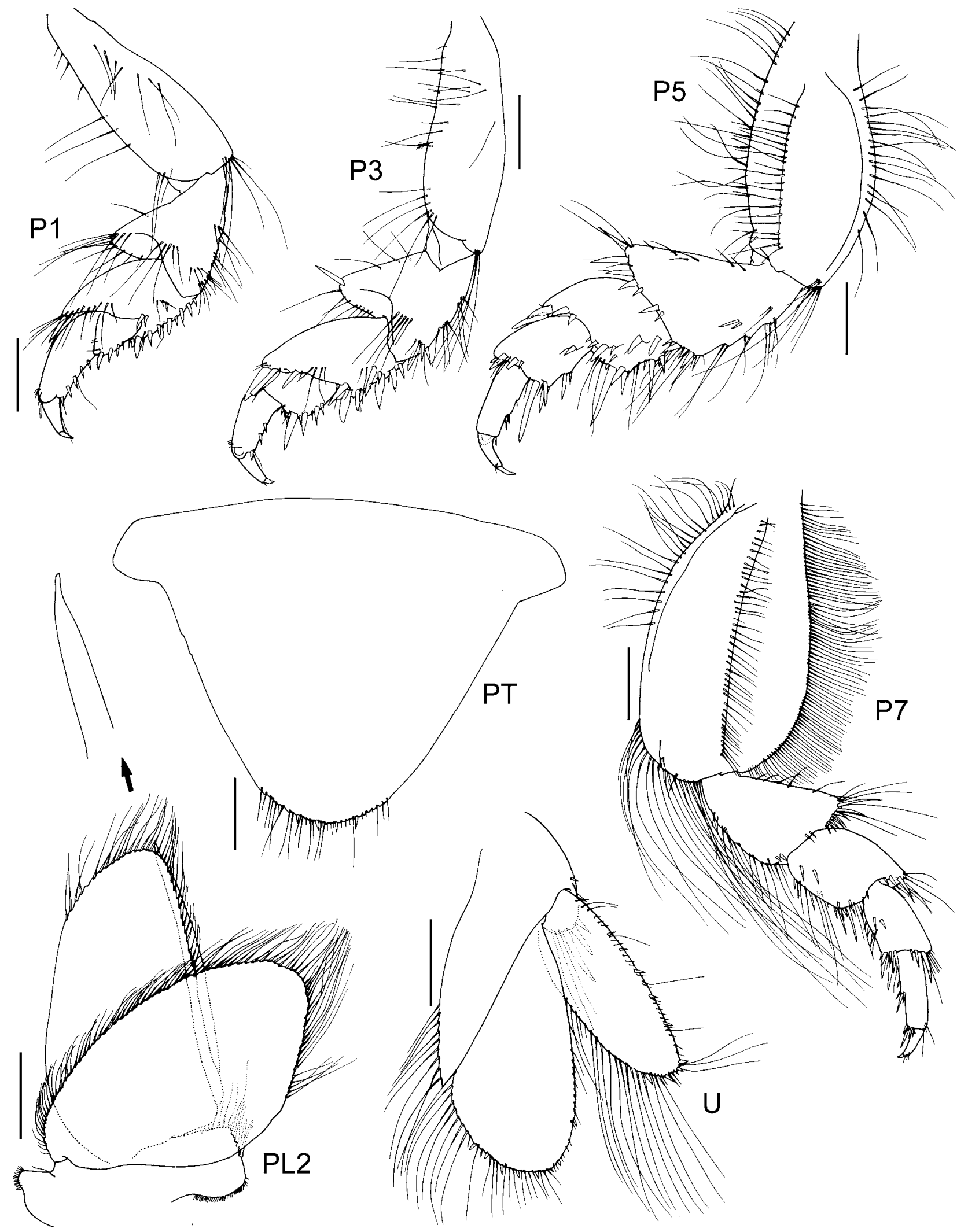

Fig. 10. Natatolana buzwilsoni n.sp., holotype. Scales $=0.5 \mathrm{~mm}$, except MX2 $=0.2 \mathrm{~mm}$.

ornamentation consists of 1 strongly developed furrow on lateral margin of pereonite 1 ; pereonites $1,4-6$ subequal and longest, 2-3 and 7 subequal. Coxae: pereonite 1, coxae 2-3 with rounded posteroventral corners, coxae 4-7 with increasingly produced, broad, acute posteroventral corners. Pleonite 2: dorsal posterolateral margin clearly projecting posterior to ventral posterolateral margin. Pereopod 7: basis anterior margin slightly convex; medial carina with SS; posterior margin convex, PS present. Ischium width subequal to length; anterior margin with SS; posterior margin without RS, SS present. Merus posterior margin with 3 RS (and 2 submarginal RS), SS present. Carpus posterior 
margin with 5 RS, 1 SS. Propodus subequal to carpus; posterior margin with 4 RS, SS. Pleopod 2 appendix masculina: arising sub-basally. Pleopods 1-5: exopod suture strongly developed on pleopods 3-5; endopod PS on most of margins of pleopods $1-4$, only a few setae on pleopod 5 . Uropods: endopod subcircular; medial margin rounded, with 5 RS, PS along entire length; apex with $2 \mathrm{RS}$; lateral margin slightly convex, curving in slightly before apex, with $1 \mathrm{RS}$, PS on distal half. Exopod ovate; medial margin convex, with 2 RS, PS on distal two-thirds; apex rounded, with 2 $\mathrm{RS}$; lateral margin convex, with $5 \mathrm{RS}$, PS along entire length.

Variation. The holotype has five robust setae on the pleotelson as does one of the male paratypes. The other male paratype has six robust setae and the female paratype has four robust setae here.

Size. Adults to c. $14 \mathrm{~mm}$.

Etymology. Named after Dr George (Buz) Wilson, in recognition of the help he has given me with this study.

Remarks. The mouthparts of Natatolana buzwilsoni are unusual; the narrow incisor of the mandible and lack of coupling hooks on the maxilliped endite occur in N. endota, $N$. prolixa and $N$. karkarook. Natatolana helenae also has a narrow mandible incisor. A reduction of the lateral lobe and middle lobe of the maxilla is also found in N. karkarook. The lack of setules on the robust setae of the maxillule medial lobe is a unique character state within the genus. The robust setae on the medial margin of the maxilliped palp are also unlike those found in other species.

Natatolana buzwilsoni is superficially similar to $N$. pilula but differs in numerous characters, most noticeably in having a broadly rounded pleotelson with robust setae, rather than a truncate pleotelson lacking robust setae. The apex of the appendix masculina is also distinct in the two species, being tapered to an acute point in N. buzwilsoni, whereas in N. pilula it forms a minute digitiform process.

Distribution. Australia: known only from the North-West Shelf of Western Australia. At depths of 37-83 m.

\section{Natatolana caeca (Dollfus, 1903)}

Synonymy in Keable \& Bruce, 1997: 671, figs. 5-7.

Type material. Syntypes: all IOM; 138 specimens, 360188 , Station 318; 2 specimens, 36 0189, Station 506; 5 specimens, 36 0184, Station 769; 5 specimens, 36 0185, Station 1048; 2 specimens, 36 0186, Station 1.100. All examined. $\cdot$ Type locality: all Méditerranée, (Campagnes de l'Hirondelle et de la Princesse Alice, $38^{\circ} 37^{\prime} \mathrm{N} 13^{\circ} 5^{\prime} \mathrm{E}, 1210 \mathrm{~m}$, [Station 318]; 43 ${ }^{\circ} 36^{\prime} \mathrm{N} 5^{\circ} 17^{\prime} \mathrm{E}$, $1503 \mathrm{~m}$, [Station 506]; 43⒉ $28^{\prime} \mathrm{N} 5^{\circ} 25^{\prime} \mathrm{E}, 2368 \mathrm{~m}$, [Station 769]; $41^{\circ} 47^{\prime} \mathrm{N} 4^{\circ} 54^{\prime} \mathrm{E}, 2276 \mathrm{~m}$, [Station 1048]; 430. $02^{\prime} \mathrm{N} 6^{\circ} 22^{\prime} \mathrm{E}, 2500$ $\mathrm{m}$, [Station 1.100]).

\section{Material examined. Listed by Keable \& Bruce (1997).}

Diagnosis. Eyes: absent. Interocular furrow: well developed, forming a ridge that extends across the cephalon; smoothly convex. Frontal lamina: lateral margins straight, narrowing anteriorly. Antenna: c. $0.25 \times$ as long as body, reaching to posterior of pereonite 2. Coxal plates: furrows completely absent on all coxae. Pleonite 4: apex rounded. Pleotelson: broad, length $0.98 \times$ basal width; anterodorsal depression absent; anterolateral margins convex; posterolateral margins convex; apex not produced, lateral margins converging smoothly to a point; with 8 RS. Pereopods 1-6: males with RS on the merus of pereopods $1-3$, and carpus of pereopods 4-6, shorter than the propodus. Pereopod 2: propodus with 2 RS on palm. Pereopod 3: ischium anterodistal angle produced, but not as produced as on pereopods 1 and 2, similar to pereopod 4. Propodus with 2 RS on palm. Pereopod 7: basis narrow, width $0.46 \times$ length; distance between anterior margin and medial carina less than between posterior margin and medial carina; posterior margin with setae completely absent along entire length. Penes: absent. Pleopod 2 appendix masculina: extending beyond tip of endopod, $1.07 \times$ length of endopod; margins very slightly curved laterally; slender; apex not at angle to adjacent margins, bluntly rounded. Uropods: exopod slightly shorter than endopod, $0.81 \times$ the length of the endopod.

Size. Adults to $15 \mathrm{~mm}$.

Remarks. Keable \& Bruce (1997) redescribe Natatolana caeca and discuss its identification and character variation. The reduced anterodistal angle of the ischium of pereopod 3 and absence of eyes are particularly useful characters for identifying this species.

Distribution. Material recorded by Keable \& Bruce (1997) and the records of Hansen (1890) and Monod (1930) are from the northeast Atlantic between c. $18^{\circ}$ to $50^{\circ} \mathrm{N}$ and $6^{\circ}$ to $17^{\circ} \mathrm{W}$. Only the type material has been recorded from the Mediterranean Sea. Most records are from the vicinity of about $1000 \mathrm{~m}$ depth, but the type specimens come from a maximum depth of $2500 \mathrm{~m}$ and a reliable minimum depth of $486 \mathrm{~m}$ is recorded by Keable \& Bruce (1997).

\section{Natatolana californiensis (Schultz, 1966)}

Cirolana californiensis Schultz, 1966: 14, pl. 8.-1969: 178, fig. 276.-Brusca \& Ninos, 1978: 379, figs. 1-7.

Cirolana deminuta Menzies \& George, 1972: 19, figs. 12-13.Brusca \& Ninos, 1978: 379.-Bruce, 1986: 218.

Natatolana californiensis.-Bruce, 1981: 958.-1986: 218, 222.Brusca \& Iverson, 1985: 37, fig. 11E.-Brusca et al., 1995: 84, figs. 65A, 66, 67.-Espinosa-Pérez \& Hendrickx, 2001: 48.

Type material of $\boldsymbol{N}$. californiensis. Holotype: male (not female as originally recorded), $8.0 \mathrm{~mm}$, LACM 60.88.4, AHF Type No. 6048 (Brusca et al., 1995). Paratypes: 2 (apparently 1 lost as Schultz (1966) indicated 3 specimens in addition to the holotype), LACM 60.76.3, AHF Cat. No. 952-1 San Clemente Island, Tanner Canyon, $54.8 \mathrm{~km} .250^{\circ} \mathrm{T}$ from China Point Light, Channel Islands, Los Angeles County, California, USA, $32^{\circ} 37.87^{\prime} \mathrm{N} 118^{\circ} 58.70^{\prime} \mathrm{W}$, 792 m, RV Velero IV, Sta. 6833-60, 29 Jan. 1960 (Wetzer et al., 1991; Brusca et al., 1995). None examined. - Type locality of $N$. californiensis: Coronado Canyon, southern California, USA. Originally cited as $32^{\circ} 37^{\prime} 54^{\prime \prime} \mathrm{N} 118^{\circ} 55^{\prime} 40^{\prime \prime} \mathrm{W}, 812 \mathrm{~m}$, [Velero IV station 6851 ] but emended to $32^{\circ} 30.70^{\prime} \mathrm{N} 117^{\circ} 21.62^{\prime} \mathrm{W}, 8.6 \mathrm{~km}$, $322.5^{\circ} \mathrm{T}$ from North Coronado Island, San Diego County, on green mud, 794 m, [Velero IV Sta. 6851-60, 1 Feb. 1960] (Wetzer et al.; Brusca et al., 1995).

Type material of $N$. deminuta. Holotype: $q$, $17 \mathrm{~mm}$, USNM 121749 (examined). - Type locality of $N$. deminuta: Peru-Chile Trench, $7^{\circ} 58^{\prime} \mathrm{S} 80^{\circ} 37^{\prime} \mathrm{W}, 1005-1124 \mathrm{~m}$, [Anton Bruun Station 88].

Material examined. USA: 33, USNM 113588, SW of San Clemente Island, California, $32^{\circ} 41.6^{\prime} \mathrm{N} 118^{\circ} 41^{\prime} \mathrm{W}$, Hagfish trap, Hubbs, Newman et al., 26-27 Sep. 1965, Agassiz stn MV 65.III.35.

Diagnosis. Eyes: absent or vestigial (there can be a small patch indicating vestigial ommatidia). Interocular furrow: 
moderately developed, distinct but not extending across the cephalon; smoothly convex. Frontal lamina: lateral margins straight, narrowing anteriorly. Antenna: c. $0.45 \times$ as long as body, reaching to approximately half way along pereonite 4. Coxal plates: furrows moderately developed on coxae 2-4 and strongly developed on coxae 5-7. Pleonite 4: apex forming a broad acute point or rounded (mostly produced into a broad acute point but in a few specimens it is worn into a rounded shape). Pleotelson: broad, length $0.77-0.88 \times$ basal width; anterodorsal depression absent (but with shallow paired submedian depressions near base that do not form a distinct and abrupt depression as in species such as $N$. pellucida); anterolateral margins convex; posterolateral margins convex; apex not produced, lateral margins converging smoothly to a point; with 6-10 RS. Pereopod 2: propodus with 1-3 RS on palm. Pereopod 3: propodus with 1-3 RS on palm. Pereopods 5-7: propodus long, on pereopod 5 greatly elongate, $2 \times$ that of pereopod 7. Pereopod 7: basis narrow, width $0.35-0.47 \times$ length; distance between anterior margin and medial carina less than between posterior margin and medial carina; posterior margin with setae along entire length (Brusca et al. (1995) do not show setae on this margin. Their illustration, however, is a lateral view (no medial carina shown). In the material examined here, the short slender setae occurring along the length of this margin are difficult to see and would not be apparent in a lateral view). Penes: present. Pleopod 2 appendix masculina: extending beyond tip of endopod, 1.09x length of endopod; margins very strongly curved laterally; slender; apex not at angle to adjacent margins, bluntly rounded. Uropods: exopod slightly shorter than endopod, $0.86 \times$ the length of the endopod.

Variation. Brusca \& Ninos (1978) recorded a range of 1021 articles for the antennal flagellum, Brusca et al. (1995) give a range of 10-22. In the smallest subadult examined here there is at least 17 articles. Possibly the figure of 10 articles was based on the illustration of $C$. deminuta by Menzies \& George (1972), which is erroneous.

Size. Adults to $13.4 \mathrm{~mm}$.

Remarks. Schultz (1966) did not illustrate an interocular furrow for Natatolana californiensis. In the material examined, however, a distinct, incomplete interocular furrow is apparent. Brusca \& Ninos (1978) synonymized $N$. deminuta with $N$. californiensis. The holotype of $N$. deminuta has the apex of the pleotelson more produced than that described for $N$. californiensis and appears to have had 12-14 robust setae on the pleotelson, many of which have been broken off. Brusca \& Ninos (1978) recorded the range of robust setae on the pleotelson of $N$. californiensis as six to 12 but this was modified by Brusca et al. (1995) as six to 10. The illustration of Brusca et al. (1995) shows eight robust setae on the pleotelson margins of the holotype of $N$. californiensis. Of the material examined here, the most common number of robust setae on the pleotelson is eight although some specimens have nine. The material of $N$. californiensis examined here and the holotype of $N$. deminuta both have a broad acute posterolateral margin on pleonite 4. It is, however, somewhat narrower and less rounded in the holotype of $N$. deminuta. The holotype of $N$. californiensis lacks setae on the endopod of pleopod 5 (Brusca et al., 1995), but these are present on the holotype of $N$. deminuta (pers. obsv.). Given these differences, and the distance between the type locality of $N$. deminuta and records of $N$. californiensis, they may not be synonyms. The holotype of $N$. deminuta, however, is in poor condition and, because it is a female, diagnostic characters, such as the shape of the appendix masculina or presence of penes, cannot be assessed. Therefore, further material from the proximity of the type locality of $N$. deminuta is needed to resolve the question of whether it represents a valid species of Natatolana or a synonym of $N$. californiensis.

Distribution and ecology. Natatolana californiensis has been recorded from the west coast of North, Central and South America. The species has mostly been recorded from southern California and Mexico, with a single record from Costa-Rica (Brusca et al., 1995; Espinosa-Pérez \& Hendrickx, 2001). The holotype of Natatolana deminuta that Brusca \& Ninos (1978) synonymized with $N$. californiensis was collected from the Peru-Chile Trench. Brusca \& Ninos (1978) indicated that most specimens are collected at depths of 700-2000 m, although a few specimens have been collected from depths as shallow as $40 \mathrm{~m}$ and $250 \mathrm{~m}$. Alternatively, Brusca et al. (1995) cite the distribution as including depths of 792-1250 m. Scavenger (some of the material examined in this study was from a hag fish trap and was therefore presumably scavenging on bait or the catch in the trap).

\section{Natatolana carlenae Brusca, Wetzer \& France, 1995}

Natatolana carlenae Brusca et al., 1995: 84, figs. 65B, 68-70.Espinosa-Pérez \& Hendrickx, 2001: 48.

Natatolana carlanae.-Espinosa-Pérez, \& Hendrickx, 1997: 39 [lapsus].

Type material. Holotype: $\widehat{\delta}$, USNM 252731 (not examined). Paratypes: $5 \hat{\delta} \delta$ and $\phi+\varphi$ from type locality, USNM 252732 (not examined); numerous additional paratypes from Mexico, Baja California and several from Costa Rica and Panama in USNM and LACM of which $2 q q$, manca, USNM 252742, Los Angeles Bay, Baja California, Mexico, Gulf of California, $59 \mathrm{~m}$, Velero III Station 701-37 examined. - Type locality: Tiburon Island, Sonora, Gulf of California, Mexico, [c. $29^{\circ} \mathrm{N} 112^{\circ} 30^{\prime} \mathrm{W}$ ], on muddy sand, 73-101 m, [Sta. No. 563-36, USNM acc. no. 139772, 10 Mar. 1936].

Diagnosis. Eyes: well developed; elongate, length c. $2 \times$ height. Interocular furrow: well developed, extending across the cephalon; smoothly convex. Frontal lamina: lateral margins concave but not medially constricted, narrowing toward apex. Antenna: c. $0.35-0.4 \times$ as long as body, reaching to posterior of pereonite 3. Coxal plates: furrows variously developed, weakly developed and incomplete on anterior coxae, absent on coxa 6 and incomplete on coxa 7 . Pleonite 4: apex forming a broad acute point. Pleotelson: broad, length $0.82 \times$ basal width; anterodorsal depression absent (with a pair of shallow submedian depressions near base that do not form a distinct and abrupt depression as in species such as N. pellucida); anterolateral margins almost straight and angling posteriorly toward the midline, or convex; posterolateral margins convex; apex not produced, lateral margins converging smoothly to a point; with 10-14 RS (holotype illustrated as having 12, material examined with 12). Pereopod 2: propodus with $2 \mathrm{RS}$ on palm. Pereopod 3: propodus with $1 \mathrm{RS}$ on palm. Pereopod 7: basis broad, width $0.55 \times$ length; distance between anterior margin and medial carina less than between posterior margin and 


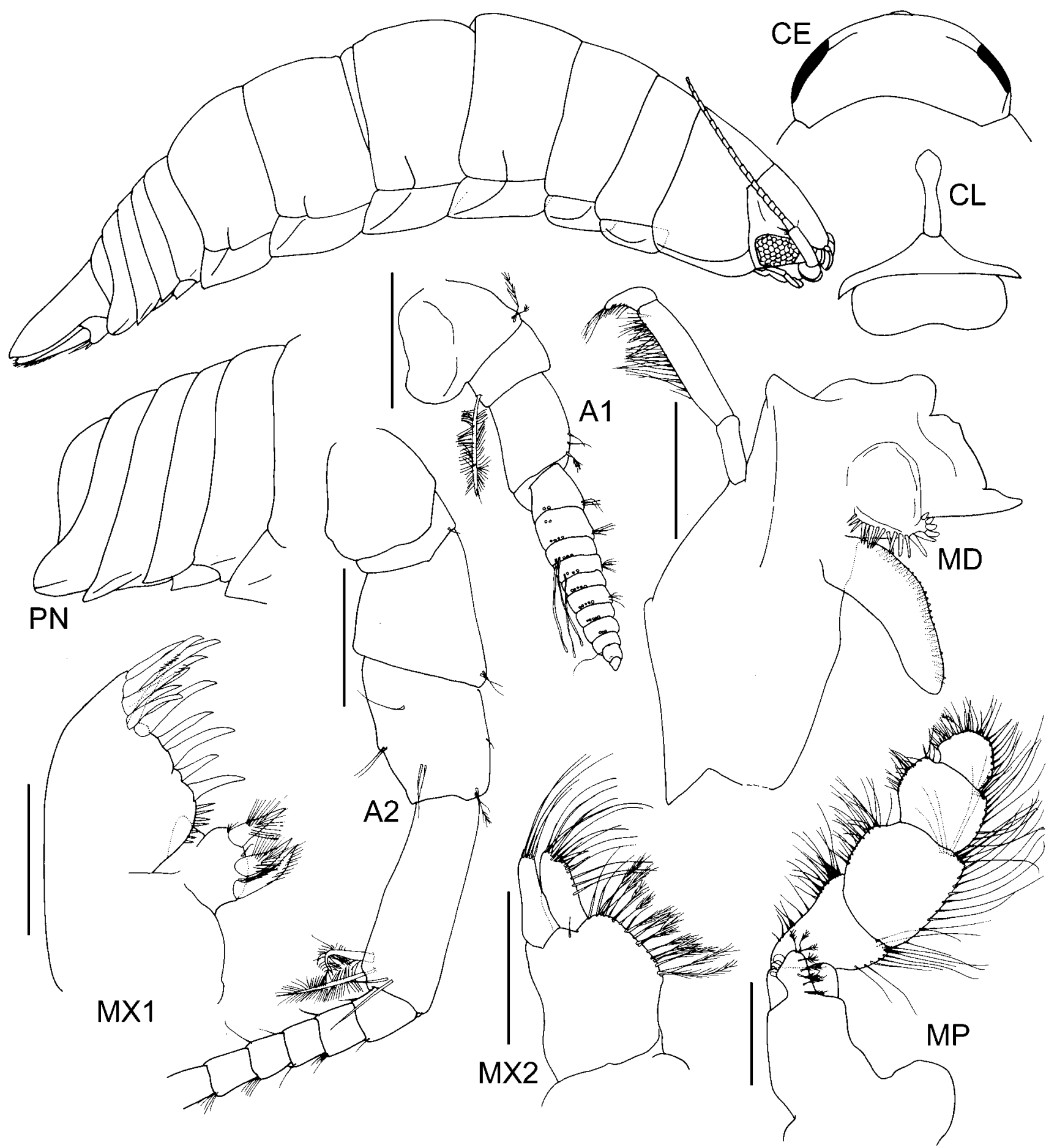

Fig. 11. Natatolana chilensis, male paratype SMNH 3182. All scales $=0.5 \mathrm{~mm}$.

medial carina; posterior margin with setae proximally and distally but not medially. Penes: absent. Pleopod 2 appendix masculina: extending subequal with tip of endopod, $1 \times$ length of endopod; margins very slightly curved laterally; slender; apex not at angle to adjacent margins, bluntly rounded. Uropods: exopod subequal to endopod, $0.94 \times$ the length of the endopod.

Size. Adults to $16.8 \mathrm{~mm}$.
Remarks. Natatolana carlenae is very similar to $N$. nukumbutho but differs in having coxal furrows only on the anterior coxae, pereopod 7 with a slightly broader basis and pleonite 4 with slightly broader posterolateral margins.

Distribution. North/Central America: northwest Baja California (Pacific), the Gulf of California, Costa Rica, and Panama. At depths of 9-1168 m but mostly recorded from depths of 9-165 m, rarely from 247-1168 m. 


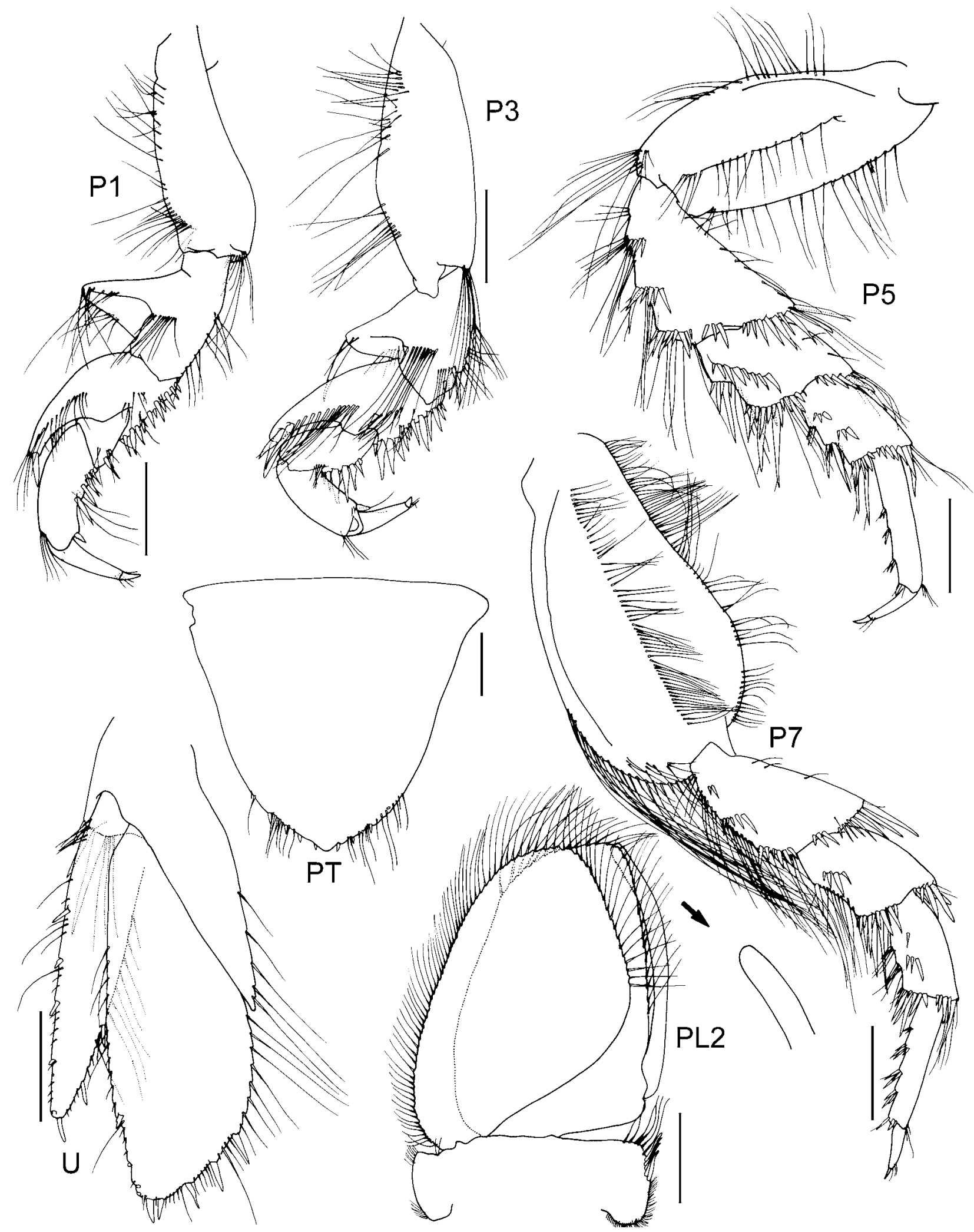

Fig. 12. Natatolana chilensis, male paratype SMNH 3182. All scales $=0.5 \mathrm{~mm}$.

Natatolana chilensis (Menzies, 1962)

Figs. 11-12

Cirolana chilensis Menzies, 1962: 122, fig. 39 A-E.-Carvacho, 1977: 40.-Ríos et al., 2003: 6.

Natatolana chilensis.-Bruce, 1981: 958.-1986: 222.-Brusca et al., 1995: 80.
Type material. Holotype: $\widehat{\jmath}, 19.6 \mathrm{~mm}, \mathrm{SMNH} 3181$; allotype, ㅇ, $22.4 \mathrm{~mm}$, SMNH 3181. Paratypes: 46 specimens, SMNH 3182. All examined. - Type locality: the bay east of the church on Isla Quellín, Seno Reloncaví, Southern Chile, 41 $52^{\prime} 30^{\prime \prime S} 72^{\circ} 53^{\prime} 50^{\prime \prime} \mathrm{W}, 25 \mathrm{~m}$, [Lund University Chile Expedition 1948-49, Station M 39]. 
Diagnosis. Interocular furrow: moderately developed, distinct but not extending across the cephalon. Frontal lamina: lateral margins medially constricted. Antenna: c. $0.34 \times$ as long as body, reaching to posterior of pereonite 3 . Coxal plates: furrows strongly developed, on all coxae. Pleonite 4: apex rounded. Pleotelson: broad, length 0.87x basal width; anterodorsal depression absent; anterolateral margins almost straight and angling posteriorly toward the midline; posterolateral margins convex; apex produced into a small point; with 8-10 RS. Pereopod 2: propodus with 3 RS on palm. Pereopod 3: propodus with $1 \mathrm{RS}$ on palm. Pereopod 7: basis broad, width $0.54 \times$ length; distance between anterior margin and medial carina less than between posterior margin and medial carina; posterior margin with setae completely absent along entire length. Penes: absent (area around openings slightly raised but not forming flexible processes). Pleopod 2 appendix masculina: extending subequal with tip of endopod, $0.97 \times$ length of endopod; margins very slightly curved laterally; slender; apex not at angle to adjacent margins, bluntly rounded. Uropods: exopod slightly shorter than endopod, $0.82 \times$ the length of the endopod.

Additional descriptive characters. Based on paratype, male, $20 \mathrm{~mm}$. Body: length c. 3.41× width. Colour cream in alcohol. Chromatophores present, or absent (there appear to be minute traces of chromatophores); small; red/brown/ grey in alcohol; scattered over body. Eyes: with 8 ommatidia in horizontal diameter; with 7 ommatidia in vertical diameter; ovate; colour red/brown in alcohol. Frontal lamina: length c. $4.8 \times$ basal width; apex expanded, anterior margin angled. Antennule: peduncular article 1 longer than article 2; article 2 with 1 large pappose seta; article 3 short, subequal to article 1. Flagellum 11-articulate. Antenna: peduncular article 4 with several SS posteromedially, 1 PS and 1 penicillate seta at anterodistal angle; article 5 with 2 PS and 2 pappose setae at posterodistal angle. Flagellum 26-articulate. Mandible: setal row with 18 RS. Maxillule: medial lobe with 3 large and 1 smaller robust pappose setae; lateral lobe with $13 \mathrm{RS}$ on distal surface. Maxilla: lateral lobe with $5 \mathrm{SS}$; medial lobe with $7 \mathrm{SS}$ and 14 PS; middle lobe with 15 SS. Maxilliped: endite with 3 coupling hooks, and 8 PS. Pereon: ornamentation consists of 1 strongly developed furrow on lateral margin of pereonite 1 and 1 short, medial furrow on lateral margins of pereonites 4-7; pereonites 1 and 5-6 subequal in length and longest, 4 and 7 subequal and longer than 2-3 which are subequal. Coxae: pereonite 1, coxae 2-3 with rounded posteroventral corners, coxae 4-7 with produced, broad, acute posteroventral corners. Pleonite 2: dorsal posterolateral margin subequal with ventral posterolateral margin. Pereopod 7: basis anterior margin sinuate; medial carina with PS and SS present (plumose setae sparse, a few proximally and distally, slender setae along entire length); posterior margin convex. Ischium anterior margin with SS (sparse); posterior margin with 7 RS, PS and SS present. Merus posterior margin with 5 RS, SS present. Carpus posterior margin with 4 RS (and 4 submarginally), SS present. Propodus longer than carpus; posterior margin with $12 \mathrm{RS}$, SS absent. Pleopod 2 appendix masculina: arising sub-basally. Pleopods 1-5: exopod suture feebly developed (complete but very faint) on pleopods $3-$ 5 ; endopod PS on most of margins of pleopods 1-4, only a few setae on pleopod 5. Uropods: endopod lanceolate; medial margin convex, with 5 RS, PS along entire length; apex with 2 RS; lateral margin slightly convex, with 3 RS,
PS on distal two-thirds. Exopod medial margin convex, with 2 RS, PS along entire length; apex acute, with 2 RS; lateral margin convex, with 4-6 RS, PS on distal three-quarters.

Variation. Ten paratype specimens were examined for variation in the number of robust setae occurring on the margins of the pleotelson. Of these $20 \%$ have $10,10 \%$ have nine and $70 \%$ have eight.

Size. Adults to c. $22.4 \mathrm{~mm}$.

Remarks. The dorsal view illustration of Natatolana chilensis by Menzies (1962) is misleading showing far more articles than are present in the antennal flagellum.

This species is similar to a number of others, including Natatolana woodjonesi as noted by Menzies (1962). The incomplete interocular furrow, complete coxal furrows on all coxae, absence of penes, sinuate posterodorsal margin of pleonite 4, convex posterolateral margins of the pleotelson converging smoothly to a point with eight to 10 robust setae, and presence of robust setae on the propodal palm of pereopods 2 and 3, are, however, sufficient characters to distinguish $N$. chilensis from all other species in the genus.

Distribution. Chile: several localities. In depths of 12-60 m.

\section{Natatolana corpulenta (Hale, 1925)}

\section{Fig. 13}

Cirolana corpulenta Hale, 1925: 134, fig. 3 (part).-1929: 248, fig. 239.-Nierstrasz, 1931: 157.-Poore et al., 1975: 33.

Natatolana corpulenta.-Bruce, 1981: 958.-1986: 79, figs. 51, 53 (part).-Brusca et al., 1995: 80.-Bruce et al., 2002: 150.

Not Cirolana corpulenta.-Hale, 1940: 289 [mis-identification = Natatolana longispina Bruce, 1986; Natatolana sinuosa $\mathrm{n} . \mathrm{sp}$.$] .$

Type material. Holotype: + , SAMA, C275. Paratypes: 35 specimens, SAMA C276; 9 , SAMA C277. All examined. • Type locality: Port Willunga, South Australia, Australia, [35¹6'S $\left.138^{\circ} 28^{\prime} \mathrm{E}\right]$.

Material examined. New South Wales: manca, AM P23040, 500 m east of Merewether Beach, $32^{\circ} 57 ' \mathrm{~S} 151^{\circ} 45^{\prime} \mathrm{E}$, Shipek [grab] collection transect, 15 m, AM Hunter District Water Board Survey, 30 Nov. 1975 (reported by Bruce [1986]); series from off Grotto Point, Port Jackson, baited trap; 434, AM P47464, 3349.05'S $151^{\circ} 15.8^{\prime} \mathrm{E}$, on sediment, $15 \mathrm{~m}$, S. Keable \& J. Lowry, 8-9 May

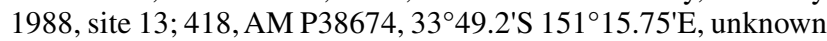
substrate, probably sediment, $10 \mathrm{~m}$, S. Keable, J. Lowry \& D. Townsend, 16-17 Jul. 1988, Site 37; 1, AM P47645, 3349.2'S $151^{\circ} 15.55^{\prime} \mathrm{E}$, baited trap on sediment a few metres from rocky shore, 3 m, S. Keable, J. Lowry \& D. Townsend, 16-17 Jul. 1988, site 38. Tasmania: series from off St Helens Point, c. $41^{\circ} 17.3^{\prime} \mathrm{S}$ $148^{\circ} 21^{\prime} \mathrm{E}$ (except as noted), baited trap, J. Lowry, S. Keable \& C. McCormick, 13-16 April 1991; 64, AM P47456, sandy bottom, 15 m, TAS-124; 70, AM P47457, sandy bottom, 5 m, TAS-125; 229, AM P47458, sandy bottom, 10 m, TAS-126; 13 mancas, AM P47459, off rocks at northern end, sandy bottom, $15 \mathrm{~m}$, TAS139; 1, AM P47462, inside breakwater, Blanche Point, Georges Bay, $41^{\circ} 17.05^{\prime} \mathrm{S} 148^{\circ} 19.9^{\prime} \mathrm{E}$, sand bottom, $12 \mathrm{~m}$, TAS-161; 50, AM P47460, in the cove off Beerbarrel Beach, $41^{\circ} 17.2^{\prime} \mathrm{S}$ $148^{\circ} 21.3^{\prime} \mathrm{E}$, sandy bottom, $10 \mathrm{~m}$, TAS-127; 1, AM P47461, off Binalong Beach, Binalong Bay, $41^{\circ} 14.7$ 'S $148^{\circ} 17.6^{\prime} \mathrm{E}$, on sand, $8 \mathrm{~m}$, TAS-144; 2, AM P47463, about $25 \mathrm{~m}$ off middle of breakwater, Pilot Bay, $42^{\circ} 12.4$ 'S $145^{\circ} 12.4^{\prime} \mathrm{E}$, baited trap, unknown substrate, probably sand, 6 m, J. Lowry \& S. Keable, 26-27 April 1991, TAS-286. 


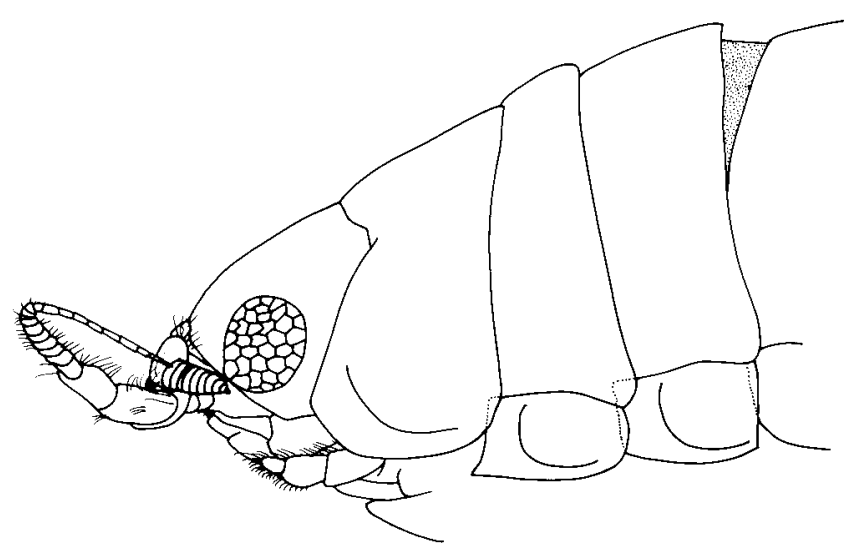

Fig. 13. Natatolana corpulenta, female, 19 mm, AM P47458.

Diagnosis. Interocular furrow: absent. Frontal lamina: lateral margins straight, parallel. Antenna: c. $0.27 \times$ as long as body, reaching to just beyond the posterior margin of pereonite 2. Coxal plates: furrows strongly developed, on all coxae. Coxa 2 with anteroventral corner produced into an acute tooth. Pleonite 4: posterodorsal margin strongly concave proximal to meeting posteroventral margin at apex; apex forming a broad acute point. Pleotelson: broad, length $0.7 \times$ basal width; anterodorsal depression present; anterolateral margins almost straight and angling posteriorly toward the midline, or convex; posterolateral margins concave; apex produced into a large point; with 10-12 RS. Pereopods 1-6: males with conspicuous elongated RS subequal to propodus on the merus of pereopods $1-3$ and extending from the carpus to dactylus of pereopods 4-6. Pereopods 2-3: propodus without RS on palm. Pereopod 7: basis narrow, width $0.47 \times$ length; distance between anterior margin and medial carina less than between posterior margin and medial carina; posterior margin with setae on distal half or along entire length. Penes: present. Pleopod 2 appendix masculina: extending beyond tip of endopod, $1.14 \times$ length of endopod; slender; margins very slightly curved laterally; apex recurved, bent slightly medially, bluntly rounded or acute. Uropods: exopod subequal to endopod, $0.99 \times$ the length of the endopod.

Variation. The female specimen described by Bruce (1986) from Point Leo, Victoria has only 10 robust setae on the pleotelson, not 12 as in the holotype. The male, $7.2 \mathrm{~mm}$, from Stockton Beach, New South Wales, illustrated by Bruce (1986) has an acute apex on the appendix masculina whereas in a male, $15 \mathrm{~mm}$, examined here from Tasmania (AM P47458) the apex was bluntly rounded. The material from New South Wales examined by Bruce (1986) has been re-examined (see remarks), most of it is not Natatolana corpulenta. Unfortunately it cannot be determined if the male illustrated by Bruce (1986) is among these specimens.

Sexual dimorphism. Females lack the conspicuously elongated robust setae present on the merus of pereopods 1-3 and on the carpus of pereopods 4-6 of adult males.

Size. Adults to c. $12 \mathrm{~mm}$.
Remarks. Natatolana corpulenta can be most easily separated from similar species by the presence of an acute produced tooth on the anteroventral corner of coxa 2 . This tooth was illustrated and described in the holotype female of $N$. corpulenta but not emphasized (Hale, 1925) and was omitted in the redescription of the species by Bruce (1986). Natatolana nitida is the only other species of Natatolana, examined in this study, which has a similar tooth, although it is indicated in the illustrations of N. pallidocula and $N$. anophthalma.

Natatolana corpulenta has been confused with a number of other species. Hale (1940) stated that prior to his record, of a female specimen of $N$. corpulenta from Tasmania, only one other specimen (the type female) had been recorded. This is erroneous as Hale (1925) mentioned a single specimen from the body cavity of a Port Jackson shark collected at Brighton. Hale (1925) also stated that a small series of mostly immature specimens was obtained at Port Willunga. These additional specimens are registered in the collections of the South Australian Museum (C277 and C276 respectively) as paratypes of $N$. corpulenta. The specimen from the Port Jackson shark is a female of $N$. debrae n.sp. Of the 35 specimens from Port Willunga (SAMA C276), 29 are $N$. corpulenta and six are N. sinuosa n.sp. The female specimen recorded by Hale (1940) from Elliott Cove (as Eliott Cove), West Coast, Tasmania is held at the Australian Museum (E6757). This specimen is $N$. longispina not $N$. corpulenta. Hale (1940) also mentioned specimens sent to him from New South Wales by T.C. Roughley. These specimens are $N$. sinuosa not $N$. corpulenta. Three species are present in the material recorded by Bruce (1986) from the Australian Museum Hunter District Water Board Survey series, collected near Newcastle, NSW (P23034-40, P23042, P23047). The specimens from off Stockton Beach are N. sinuosa, those from off Belmont Beach are a mixture of $N$. longispina and $N$. sinuosa, and the specimen off Dudley Beach is $N$. sinuosa. Only the manca specimen from off Merewether Beach is $N$. corpulenta.

Apart from the tooth on coxa 2, Natatolana corpulenta can be separated from most other species of Natatolana by the shape and setation of the pleotelson which is similar to that illustrated by Bruce (1986). The concave posterolateral margins, with c. 12 robust setae and strongly produced acute apex are distinctive.

Natatolana pallidocula, known only from the holotype (not examined), appears to be extremely similar to $N$. corpulenta. Many important characters, such as the presence or absence of penes in males, have not been recorded for $N$. pallidocula. The description given by Kussakin \& Vasina (1982a) indicates that $N$. pallidocula differs from $N$. corpulenta in having rectangular eyes with 14 ommatidia in the horizontal row (not oval with five ommatidia in the horizontal row), lacking conspicuously elongated robust setae on pereopods 1-6 in males and in having the appendix masculina of the male pleopod 2 slightly shorter than the endopod. The male characters, however, are only fully developed in mature specimens and the holotype of $N$. pallidocula could be immature.

Distribution and ecology. Australia: central New South Wales, Victoria, Tasmania, and South Australia. At depths of 3-15 m. Scavenger. 


\section{Natatolana curta (Richardson, 1910)}

Cirolana curta Richardson, 1910: 7, fig. 6.-Nierstrasz, 1931: 156. Natatolana curta.-Bruce, 1981: 958.-1986: 53, 74, 222.-Brusca et al., 1995: 80.

Type material. Holotype: $\widehat{\delta}, 18 \mathrm{~mm}$, USNM 41013 (examined). - Type locality: between Jolo and Tawi Tawi, Dammi Island, [Philippines, $5^{\circ} 48^{\prime} \mathrm{N} 120^{\circ} 36 ' \mathrm{E}$ ], $441 \mathrm{~m}$, [Albatross Station 5565].

Diagnosis. Interocular furrow: moderately developed, distinct but not extending across the cephalon. Frontal lamina: lateral margins straight, narrowing posteriorly. Antenna: c. $0.39 \times$ as long as body, reaching to between the posterior of pereonite 3 and one-quarter of the way along pereonite 4. Coxal plates: furrows strongly developed, clearer on anterior coxae than posterior but all complete, on all coxae. Pleonite 4: apex forming a broad acute point. Pleotelson: broad, length $0.71 \times$ basal width; anterodorsal depression absent; anterolateral margins convex; posterolateral margins broadly rounded; apex not produced, lateral margins converging smoothly to a point; with 11 RS. Pereopod 2: propodus with 4 RS on palm. Pereopod 3: propodus with 3 RS on palm. Pereopod 7: basis broad, width 0.6× length; distance between anterior margin and medial carina less than between posterior margin and medial carina; posterior margin with setae completely absent along entire length. Penes: absent. Pleopod 2 appendix masculina: just shorter than endopod, $0.92 \times$ length of endopod; margins very slightly curved laterally; slender; apex not at angle to adjacent margins, bluntly rounded. Uropods: exopod short, $0.68 \times$ the length of the endopod.

Sexual dimorphism. Unknown, but the male holotype has indistinct tubercules on the dorsal surface of pereonites 1 and 3 that may be absent in females.

Size. Adults to $18 \mathrm{~mm}$.

Remarks. A description of the penes and appendix masculina of Natatolana curta have not previously been given. Natatolana curta is most similar to N. albicaudata and $N$. amplocula, see remarks for these species.

Distribution. Philippines. At depths of $441 \mathrm{~m}$.

\section{Natatolana debrae n.sp.}

Figs. 14-16

Cirolana corpulenta.-Hale, 1925: 134 fig. 3 (part) [misidentification, not Natatolana corpulenta (Hale, 1925)].

Type material. HolotyPe: $\delta, 9$ mm, AM P31604. PARATYPes: q, $16 \mathrm{~mm}$, $q, 6.5 \mathrm{~mm}$, manca, $6 \mathrm{~mm}$, AM P47245. • Type locality: Henley Beach, Adelaide, South Australia, Australia, $38^{\circ} 56^{\prime} \mathrm{S}$ $138^{\circ} 31^{\prime} \mathrm{E}$, low tide sand bar $20 \mathrm{~m}$ off shore, fine sand and shell, [J.K. Lowry, 29 Dec. 1976].

Additional material. South Australia, paratype female of Natatolana corpulenta, SAMA C277, Brighton [presumably Gulf St Vincent, $\left.35^{\circ} 01^{\prime} \mathrm{S} 138^{\circ} 31^{\prime} \mathrm{E}\right]$, from body cavity of Heterodontus phillipi, H. Collyer.

Diagnosis. Interocular furrow: absent. Frontal lamina: lateral margins medially constricted. Antenna: c. $0.46 \times$ as long as body, reaching to posterior of pereonite 4. Coxal plates: furrows moderately developed, on all coxae. Pereonite 1, coxa 2 posterior margins sinuate, posteroventral corners developed into weak coxal points. Pleonite 4: posterodorsal margin strongly concave proximal to meeting posteroventral margin at apex; apex forming a broad acute point. Pleotelson: broad, length $0.9 \times$ basal width; anterodorsal depression present; anterolateral margins convex; posterolateral margins concave; apex produced into a large point; with 10 RS. Pereopods 1-6: males with conspicuous elongated RS subequal to propodus on the merus of pereopods 1-3 and extending from the carpus to dactylus of pereopods 4-6. Pereopods 2-3: propodus without RS on palm. Pereopod 7: basis narrow, width $0.42 \times$ length; distance between anterior margin and medial carina less than between posterior margin and medial carina; posterior margin with setae along entire length. Penes: present. Pleopod 2 appendix masculina: extending beyond tip of endopod, $1.05 \times$ length of endopod; margins sinuate; slender; apex not at angle to adjacent margins, bluntly rounded. Uropods: exopod subequal to endopod, $0.93 \times$ the length of the endopod; lateral margin with RS.

Additional descriptive characters. Based on holotype. Body: length c. $2.11 \times$ width. Colour cream-yellow in alcohol. Chromatophores absent. Eyes: with 5 ommatidia in horizontal diameter; with 8 ommatidia in vertical diameter; ovate; colour brown in alcohol. Frontal lamina: length c. $3.8 \times$ basal width; apex expanded, anterior margin angled. Antennule: peduncular article 1 longer than article 2; article 2 with 1 large pappose seta; article 3 short, subequal to article 1. Flagellum 10-articulate. Antenna: peduncular article 4 with 5 SS medially on posterolateral margin, 4 SS on distal margin, $3 \mathrm{SS}$ and 1 penicillate seta at anterodistal angle; article 5 with 2 conspicuous pappose setae and $1 \mathrm{SS}$ at posterodistal angle, $3 \mathrm{SS}$ on distal margin and $2 \mathrm{SS}$ at anterodistal angle. Flagellum 20-articulate. Mandible: setal row with 16 RS. Maxillule: medial lobe with 3 large robust pappose setae and $2 \mathrm{SS}$; lateral lobe with $12 \mathrm{RS}$ on distal surface. Maxilla: lateral lobe with 4 SS; medial lobe with 6 SS and 9 PS; middle lobe with 11 SS. Maxilliped: endite with 2 coupling hooks, and 7 PS. Pereon: ornamentation consists of 1 strongly developed furrow on lateral margin of pereonite 1; pereonite 1 longest, 4-6 subequal and longer than 2-3 and 7 which are subequal. Coxae: coxal points weakly developed on posteroventral corners of pereonite 1 and all coxae. Pleonite 2: dorsal posterolateral margin subequal with ventral posterolateral margin. Pereopod 7: basis anterior margin slightly convex; medial carina with PS along entire length; posterior margin convex, SS present. Ischium anterior margin with SS; posterior margin with 1 RS (and 2 submarginally), PS present. Merus anterior margin with SS; posterior margin with 1 RS (submarginal), SS present. Carpus anterior margin with $1 \mathrm{SS}$; posterior margin with 3 RS (and 1 submarginally), SS absent. Propodus subequal to carpus; posterior margin with $3 \mathrm{RS}$, SS absent. Penes: forming well separated flattened lobes. Pleopod 2 appendix masculina: arising basally. Pleopods 1-5: exopod suture strongly developed on pleopods 3-5; endopod PS on most of margins of pleopods 1-4, only a few setae on pleopod 5. Uropods: endopod triangular; medial margin slightly convex and obtusely angled proximal to peduncle, with 5 RS, PS along entire length; apex with 2 RS; lateral margin slightly convex, with 4 RS and 1 penicillate seta, PS along entire length. Exopod medial margin convex, with 3 RS, PS along entire length; apex acute, with 2 RS; lateral margin convex, with 8 RS, PS along entire length. 


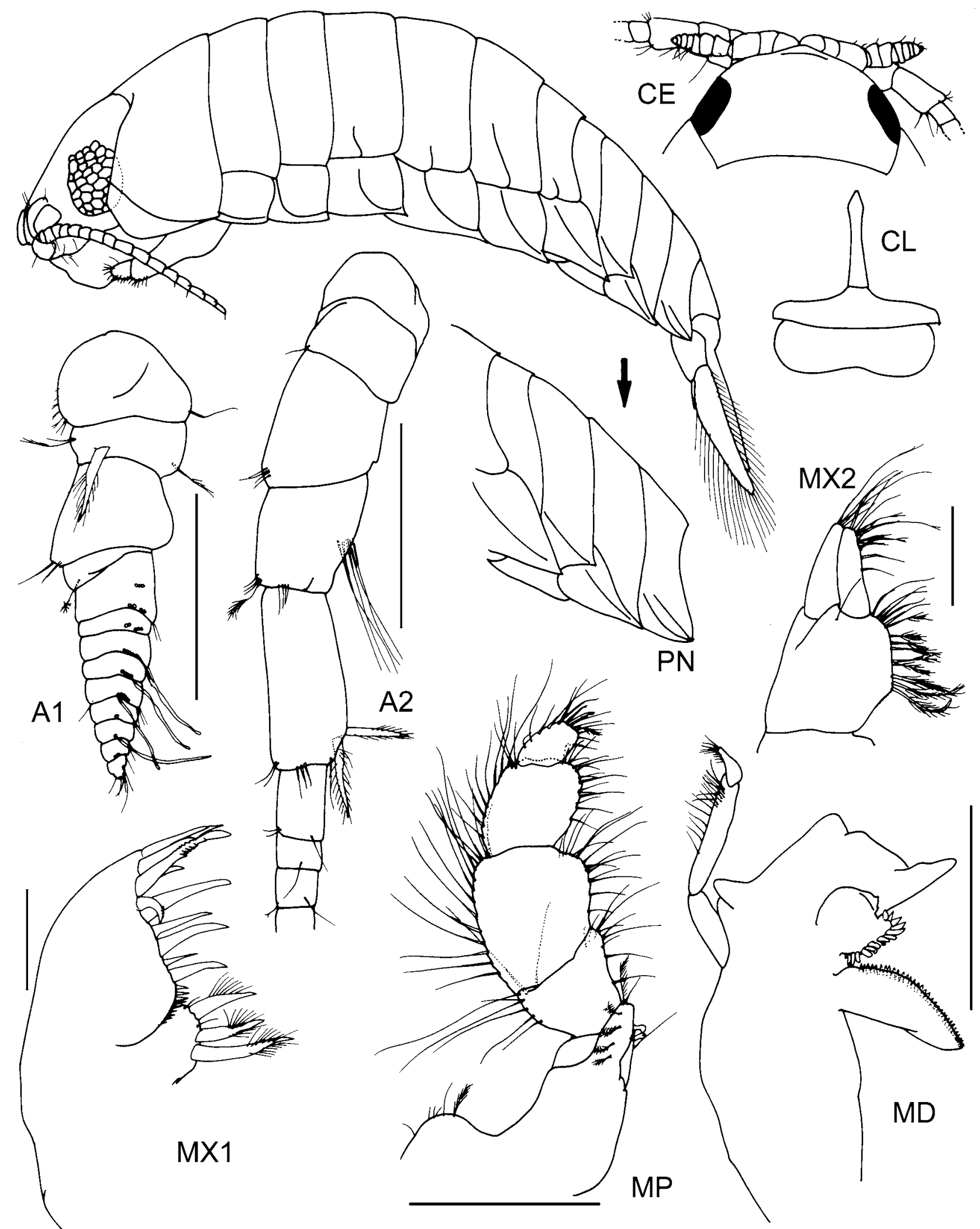

Fig. 14. Natatolana debrae n.sp., holotype. Scales $=0.5 \mathrm{~mm}$, except MX1, MX2 $=0.2 \mathrm{~mm}$.

Variation. The right uropod endopod of the holotype has two robust seta on the apex and four robust setae on the medial margin.

Sexual dimorphism. Females lack the conspicuously elongated robust setae present on the merus of pereopods $1-3$ and the carpus of pereopods $4-6$ of adult males.
Size. Adults to c. $16 \mathrm{~mm}$.

Etymology. Named after my wife Debra, in recognition of the help she has given me during this and other projects.

Remarks. The specimen of Natatolana corpulenta recorded by Hale (1925) from the body cavity of a Port Jackson shark 

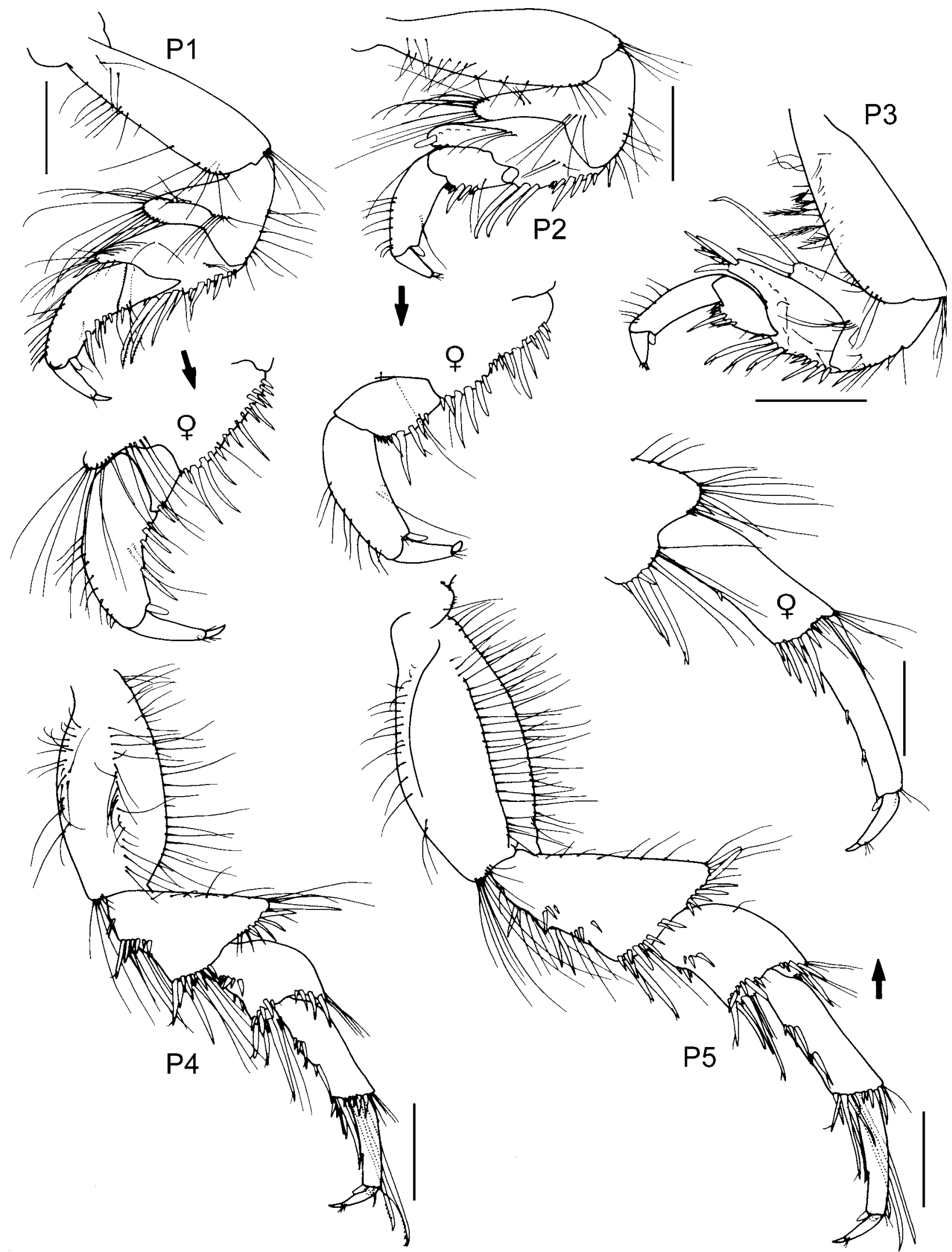

Fig. 15. Natatolana debrae n.sp., holotype, except; female = paratype female, AM P47245. Scales $=0.5 \mathrm{~mm}$.

collected by $\mathrm{H}$. Collyer at Brighton is registered in SAMA collections (C277) as a paratype of $N$. corpulenta but is actually a specimen of $N$. debrae.

Natatolana debrae is most similar to $N$. corpulenta, $N$. femina $\mathrm{n}$.sp. and $N$. sinuosa $\mathrm{n}$.sp. Natatolana debrae differs from $N$. corpulenta in lacking an acute produced tooth on the anteroventral corner of coxa 2 ; in having sinuate posterior margins developed into weak coxal points on the posteroventral corners of pereonite 1 and coxae $2-3$; and in having longer antennae. Natatolana sinuosa and N. femina 


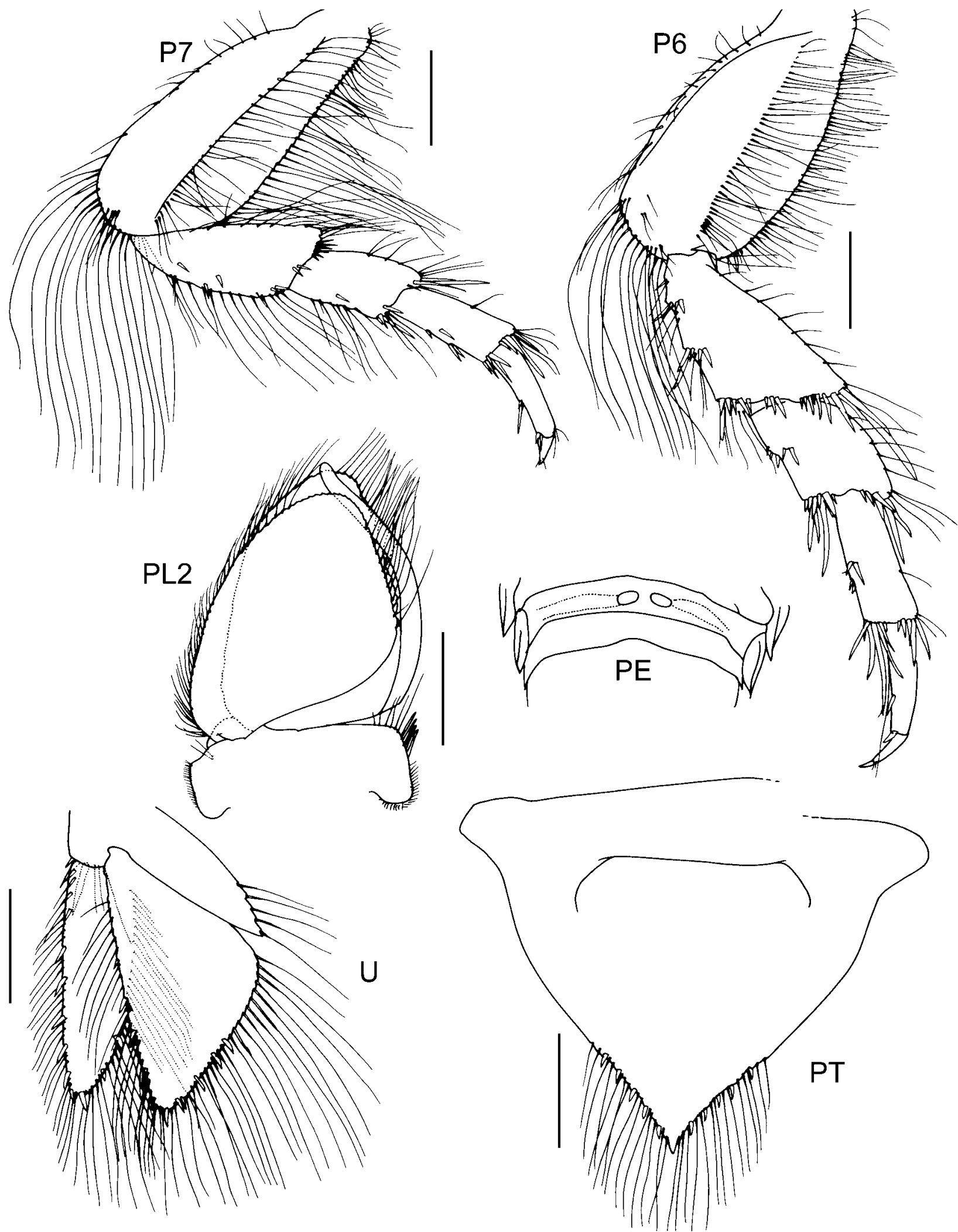

Fig. 16. Natatolana debrae n.sp., holotype. Scales $=0.5 \mathrm{~mm}$, except MX1, MX2 $=0.2 \mathrm{~mm}$.

can be readily distinguished from $N$. debrae by the development of coxal points on the posteroventral corners of pereonite 1 and coxa 2-3 (much stronger in $N$. sinuosa and rounded in N. femina).
Distribution and ecology. Australia: known only from Gulf St Vincent, South Australia. Apparently intertidal and subtidal. Scavenger (specimens have been recorded from the body cavity of a Port Jackson shark). 


\section{Natatolana endota Bruce, 1986}

Natatolana endota Bruce, 1986: 63, figs. 38, 39.-Springthorpe \& Lowry, 1994: 44.-Brusca et al., 1995: 80.-Bruce et al., 2002: 150 .

Type material. Holotype: đ̊, 12.8 mm, AM P32172 (examined). Paratypes: AM P10693, P10689 (examined); TM G1505 (not examined). - Type locality: off Sow and Pigs Shoal, Port Jackson, NSW, Australia, $33^{\circ} 20^{\prime} \mathrm{S} 151^{\circ} 16^{\prime} \mathrm{E}, 10 \mathrm{~m}$.

Diagnosis. Interocular furrow: moderately developed, distinct but not extending across the cephalon. Frontal lamina: lateral margins straight, parallel. Antenna: c. $1.3 \times$ as long as body, reaching to beyond pleotelson. Coxal plates: furrows variously developed, indistinct furrows on coxae 2-4 only. Pleonite 2: ventral posterolateral margin acute, formed into long curved process. Pleonite 4: posterodorsal margin strongly concave proximal to meeting posteroventral margin at apex; apex forming a narrow acute point. Pleotelson: broad, length $0.76 \times$ basal width; anterodorsal depression absent; anterolateral margins almost straight and angling posteriorly toward the midline; posterolateral margins straight, contiguous with anterolateral margins; apex narrowly rounded; with 4 RS. Pereopods 1-6: males with the RS on the merus of pereopods 1-3, and carpus of pereopods 4-6 shorter, than the propodus. Pereopod 2: propodus with $8 \mathrm{RS}$ on palm. Pereopod 3: propodus with 8 RS on palm. Pereopod 7: basis of medium breadth, width $0.52 \times$ length; distance between anterior margin and medial carina less than between posterior margin and medial carina; posterior margin with setae on proximal half. Penes: present (although Bruce (1986) describes the vas deferens as opening flush to the surface of the sternite). Pleopod 2 appendix masculina: extending subequal with tip of endopod, $1 \times$ length of endopod; slender; margins very slightly curved laterally; apex not at angle to adjacent margins, acute. Uropods: exopod subequal to endopod, $1 \times$ the length of the endopod.

Size. Adults to $13.9 \mathrm{~mm}$.

Remarks. The antennular flagellum of Natatolana endota was described by Bruce (1986) as being longer than the peduncle but the illustration provided and examination of specimens indicates that it is shorter. Natatolana endota is readily distinguished from other species in having antennae that reach beyond the pleotelson and a pleotelson with straight lateral margins that converge to a narrowly rounded apex that has four robust setae.

Distribution. Australia: Port Jackson, New South Wales; northern Tasmania At depths of 9-23 m.

\section{Natatolana femina n.sp.}

Figs. 17-19

Type material. Holotype: $q, 12.5 \mathrm{~mm}$, AM P47232. PARATYPES: $\widehat{o}^{\lambda}, 10 \mathrm{~mm}$, AM P47233, same data as for holotype except off the rocks on the north end of Maurouard Beach, $41^{\circ} 17.3^{\prime} \mathrm{S} 148^{\circ} 21.3^{\prime} \mathrm{E}, 15 \mathrm{~m}$, TAS- $124 ; 7$ specimens, TM, same data as holotype. - Type locality: in the corner off the northern end of Maurouard Beach, St Helens Point, Tasmania, Australia, $41^{\circ} 17.3^{\prime} \mathrm{S} 148^{\circ} 20.9^{\prime} \mathrm{E}$, [baited trap], sandy bottom, $5 \mathrm{~m}$, [J. Lowry, S. Keable \& C. McCormick, 13-14 April 1991, TAS-125].

Additional material. Tasmania: 18 mancas, AM P47234, off rocks at the northern end of Maurouard Beach, $41^{\circ} 17.3^{\prime} \mathrm{S}$ $148^{\circ} 21^{\prime} \mathrm{E}, 10 \mathrm{~m}$, TAS-126; 6 mancas, AM P47235, same data as holotype except in the cove off Beerbarrel Beach, $41^{\circ} 17.2^{\prime} \mathrm{S}$ $148^{\circ} 21.3^{\prime} \mathrm{E}, 10 \mathrm{~m}$, TAS-127; 29 mancas, AM P47236, same data as holotype except off Binalong Beach, Binalong Bay, $41^{\circ} 14.7^{\prime} \mathrm{S}$ $148^{\circ} 17.6^{\prime} \mathrm{E}, 8 \mathrm{~m}, 14-15$ April 1991, TAS-144.

Diagnosis. Interocular furrow: absent. Frontal lamina: lateral margins concave but not medially constricted, narrowing toward apex. Antenna: c. $0.3 \times$ as long as body, reaching to posterior of pereonite 3 . Coxal plates: furrows weakly developed, on all coxae. Pleonite 4: posterodorsal margin strongly concave proximal to meeting posteroventral margin at apex; apex forming a broad acute point. Pleotelson: broad, length $0.87 \times$ basal width; anterodorsal depression present; anterolateral margins convex; posterolateral margins concave; apex produced into a large point; with 12-15 RS. Pereopods 1-6: males with the RS on the merus of pereopods $1-3$, and carpus of pereopods 4-6, shorter than the propodus (but fully mature males not known). Pereopods 2-3: propodus without RS on palm. Pereopod 7: basis broad, width $0.57 \times$ length; distance between anterior margin and medial carina less than between posterior margin and medial carina; posterior margin with setae along entire length. Penes: absent, vasa deferentia opening flush to surface of sternite 7 (but fully mature males not known). Pleopod 2 appendix masculina: just shorter than endopod, $0.88 \times$ length of endopod; margins very slightly curved laterally; slender; apex not at angle to adjacent margins, bluntly rounded (but fully mature males not known). Uropods: exopod subequal to endopod, $0.98 \times$ the length of the endopod.

Additional descriptive characters. Based on holotype. Body: length c. $2.7 \times$ width. Colour translucent white to yellow in alcohol. Chromatophores present; both large and small; grey in alcohol; restricted to lateral margins of pereonites, pleonites and coxae, fairly sparse and faint, fading after preservation. Cephalon: submarginal cephalic furrow absent. Eyes: with 5 ommatidia in horizontal diameter; with 9 ommatidia in vertical diameter; ovate; colour red-brown in alcohol. Frontal lamina: length c. 3.85x basal width; apex expanded, anterior margin angled. Antennule: peduncular article 1 and article 2 subequal in length; article 2 with several small penicillate setae on lateral margins and 1 large pappose seta on medial anterolateral margin; article 3 long, larger than article 1 or 2 but shorter than their combined lengths. Flagellum 14-articulate. Antenna: peduncular article 4 with numerous long SS on posterolateral margin, several short SS and 1 penicillate seta at anterodistal angle; article 5 with 2 pappose setae and 4 SS at posterodistal angle, 4 SS at anterodistal angle. Flagellum 27-articulate. Mandible: setal row with 19 RS. Maxillule: medial lobe with 3 large and 1 smaller robust pappose setae and 2 small SS; lateral lobe with 13 RS on distal surface. Maxilla: lateral lobe with 4 SS; medial lobe with 3 SS and 17 PS; middle lobe with 17 long SS on outer row and 4 short SS on inner row. Maxilliped: endite with 2 coupling hooks, 5 PS and 2 SS. Pereon: ornamentation consists of 1 weakly developed furrow on lateral margin of pereonite 1; pereonites 1 and 5-6 subequal in length and longest, 4 and 7 subequal and longer than 2-3 which are subequal. Coxae: pereonite 1, coxae $2-4$ with rounded posteroventral corners, coxae 5-6 with sinuate posterior margins developed into small coxal points, coxa 7 with a produced, broad, acute posteroventral corner. Pleonite 2: dorsal posterolateral margin subequal with ventral 


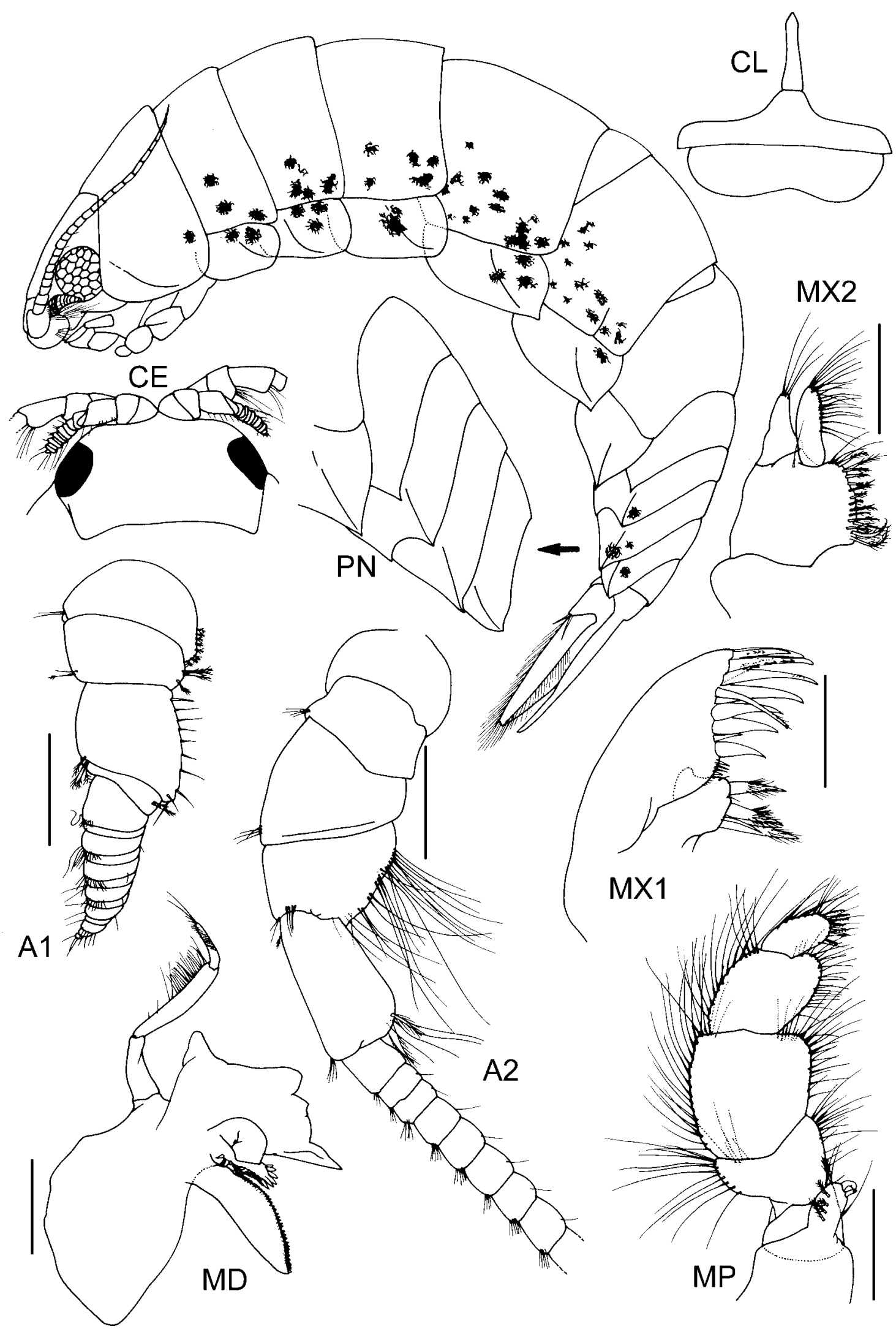

Fig. 17. Natatolana femina n.sp., holotype. Scales $=0.5 \mathrm{~mm}$.

posterolateral margin. Pereopod 7: basis anterior margin slightly convex; medial carina with PS along entire length; posterior margin convex, SS present. Ischium anterior margin with SS; posterior margin with groups of RS present, PS present. Merus anterior margin with SS; posterior margin with 5 RS (1 proximal and 1 group of 4 medially), SS present. Carpus anterior margin with SS; posterior margin with 6 RS, SS absent. Propodus subequal to carpus; posterior margin with 5 RS, SS absent. Pleopods 1-5: exopod suture strongly developed on pleopods 3-5; endopod PS on most 

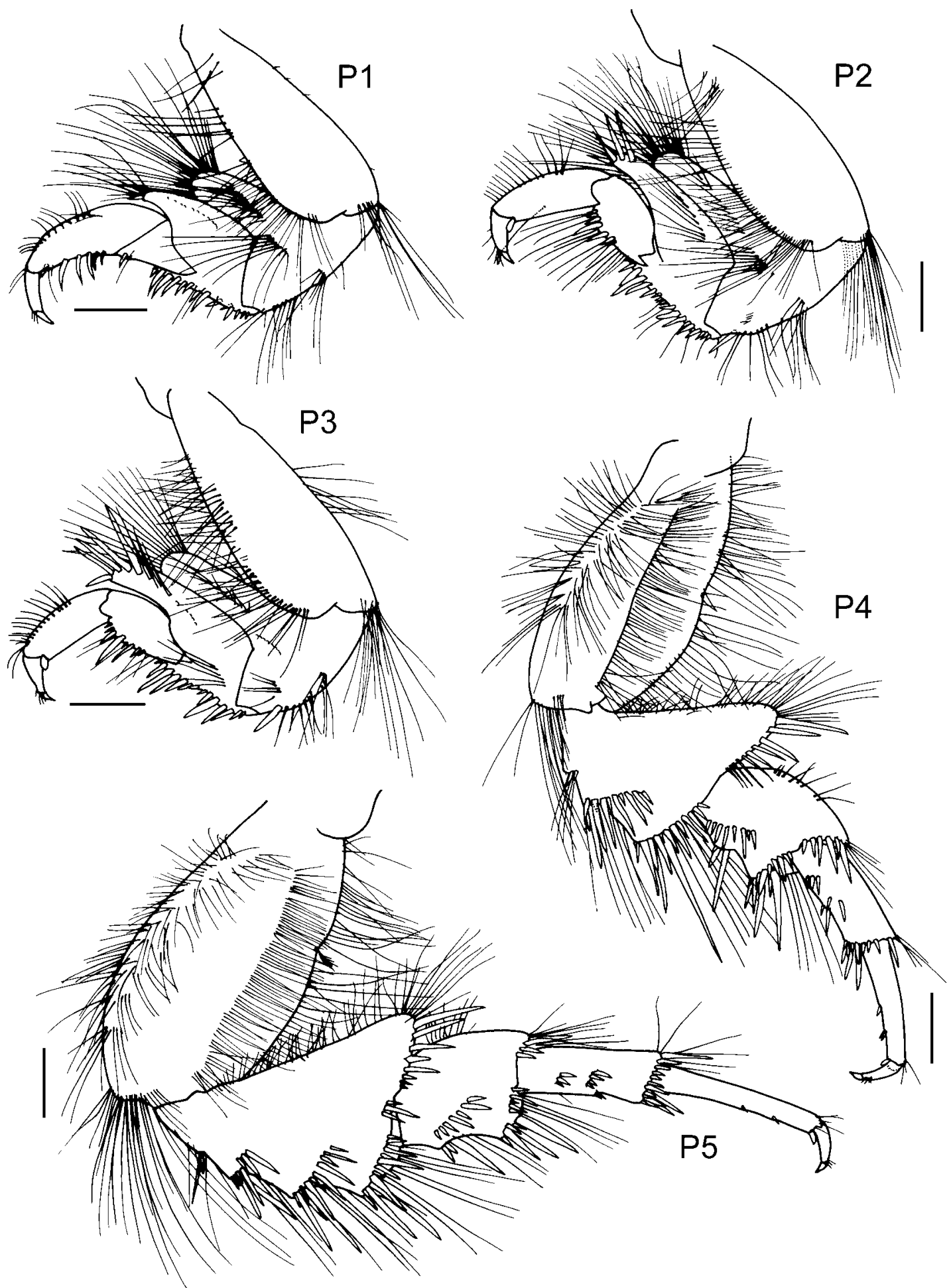

Fig. 18. Natatolana femina n.sp., holotype. Scales $=0.5 \mathrm{~mm}$.

of margins on pleopods 1-4, absent on pleopod 5. Uropods: endopod triangular; medial margin convex, with $3 \mathrm{RS}$, PS along entire length; apex with 2 RS; lateral margin straight, with 3 RS, PS along entire length. Exopod medial margin convex, with 4 RS, PS along entire length; apex acute, with $2 \mathrm{RS}$; lateral margin convex, with $8 \mathrm{RS}$, PS along entire length.

Supplementary description of male. Based on paratype, 10 mm, AM P47233, not fully mature. Pleopod 2 appendix masculina: arising basally.
Variation. The number of robust setae occurring on the pleotelson is variable, the holotype has 15 . Among the seven paratype specimens examined in the Tasmanian Museum, three have 14, two have 13, one has 12 and one is damaged.

Sexual dimorphism. In the material examined there was only one male present, this specimen was not fully mature and sexual dimorphism could not be adequately assessed. In mature males of species that may be closely related, however, conspicuously elongate robust setae develop on the carpus of pereopods 1-3 and on the merus of pereopods 4-6. 


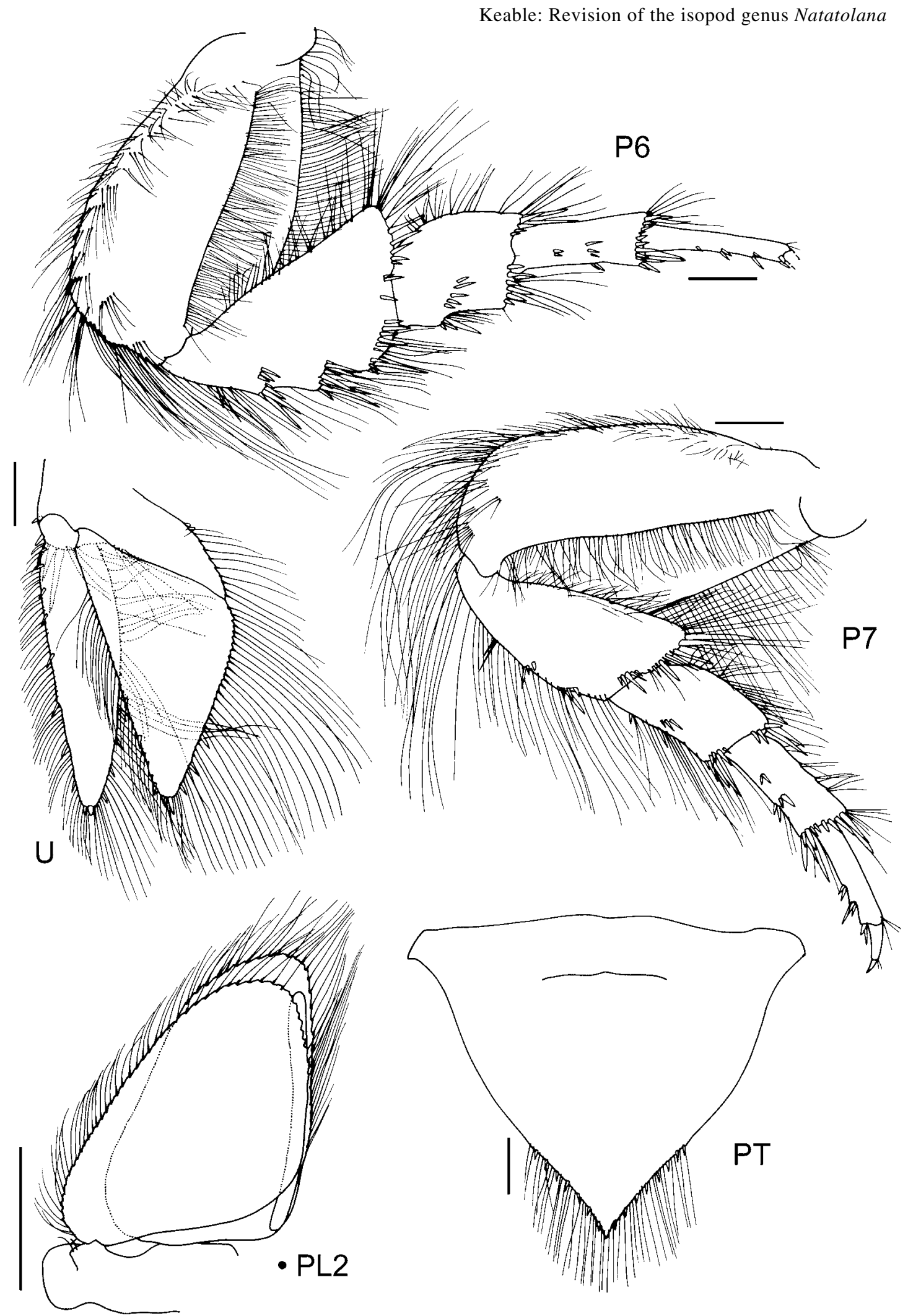

Fig. 19. Natatolana femina n.sp., holotype, except; $\bullet$ PL2 $=$ paratype male (immature). Scales $=0.5 \mathrm{~mm}$.

Size. Adults to $25 \mathrm{~mm}$.

Etymology. From the Latin "femine" (the female) in reference to the absence of mature males in the material examined.

Remarks. No fully mature males of Natatolana femina are known. Therefore, whether the males develop conspicuously long robust setae on the pereopods as in similar species such as $N$. corpulenta is unclear. Furthermore, the appendix masculina and penes are probably not fully developed in the specimen described here.

Natatolana femina is most similar to $N$. natalensis but differs from that species in having the posterolateral margins of the pleotelson concave (not convex) and in lacking robust setae on the propodal palm of pereopods 2-3. Natatolana pellucida, $N$. sinuosa n.sp., $N$. debrae n.sp., $N$. corpulenta 
and N. pallidocula are also similar. Natatolana pellucida differs from $N$. femina in having the posterior margins of coxa 3-4 sinuate, forming weak coxal points at the posteroventral corners of these coxae and because the posterolateral margins of the pleotelson are convex. Natatolana sinuosa and $N$. debrae differ from $N$. femina because pereonite 1 and coxae 2-7 have sinuate posterior margins that form strong coxal points at their posteroventral corners in these species. Natatolana corpulenta has the anteroventral corner of coxa 2 produced into an acute tooth whereas it is rounded in N. femina. Natatolana pallidocula has rectangular eyes with 14 ommatidia in the horizontal row whereas in N. femina the eyes are rounded with only 5 ommatidia in the horizontal row.

Distribution and ecology. Australia: northeast coast of Tasmania At depths of 5-15 m. Scavenger.

\section{Natatolana flexura n.sp.}

Figs. 20-22

Type material. HOLOTYPE: đ̊, 6 mm, AM P47222. PARATYPES: All off Wollongong, NSW, baited trap, 100 m, P. Freewater, S. Keable \& W. Vader, May 1993; 35 specimens (mancas and $q$ $q$ ), AM P47223, $34^{\circ} 28.15^{\prime} \mathrm{S} 151^{\circ} 02.37^{\prime} \mathrm{E}, 15.5^{\circ} \mathrm{C}$, SEAS NSW-778;

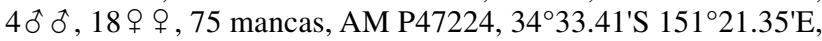
SEAS NSW-796. - Type locality: east of Fortescue Bay, north of Hippolyte Rocks, Tasmania, Australia, $43^{\circ} 06.70 ' \mathrm{~S} 148^{\circ} 03.45^{\prime} \mathrm{E}$, [baited trap], $100 \mathrm{~m},\left[15.8^{\circ} \mathrm{C}, \mathrm{J}\right.$. Lowry \& P. Freewater, $16-17$ April 1993, SEAS TAS-355].

Diagnosis. Interocular furrow: weakly developed, indistinct and not extending across the cephalon. Frontal lamina: lateral margins concave but not medially constricted, narrowing toward apex. Antenna: c. $0.3 \times$ as long as body, reaching to posterior of pereonite 2. Coxal plates: furrows strongly developed, on all coxae. Pleonite 4: apex forming a broad acute point. Pleotelson: broad, length $0.82 \times$ basal width; anterodorsal depression present; anterolateral margins almost straight and angling posteriorly toward the midline; posterolateral margins convex; apex not produced, lateral margins converging smoothly to a point; with 2 RS. Pereopods 2-3: propodus without RS on palm. Pereopod 7: basis narrow, width $0.4 \times$ length; distance between anterior margin and medial carina less than between posterior margin and medial carina; posterior margin with setae on distal half. Penes: present. Pleopod 2 appendix masculina: extending subequal with tip of endopod, $1.07 \times$ length of endopod; margins strongly or very strongly curved laterally; broad; apex not at angle to adjacent margins, broadly rounded with a slight depression at tip. Uropods: exopod slightly shorter than endopod, $0.81 \times$ the length of the endopod.

Additional descriptive characters. Based on holotype. Body: length c. $2.7 \times$ width. Colour translucent white with a yellow tinge in alcohol. Chromatophores present; small; yellow to brown in freshly preserved material, fading completely after a short time in preservative; on all sections of the body but concentrated on posterior segments. Eyes: with 8 ommatidia in horizontal diameter; with 8 ommatidia in vertical diameter; round; colour red in freshly preserved material, turning to tan after a short time in preservative. Frontal lamina: length c. $4 \times$ basal width; apex expanded, anterior margin angled. Antennule: peduncular article 1 longer than article 2; article 2 with 1 large pappose seta and $2 \mathrm{SS}$ at posterodistal angle, $1 \mathrm{PS}$ and 1 penicillate seta at anterodistal angle; article 3 long, larger than article 1 or 2 but shorter than their combined lengths. Flagellum 10articulate. Antenna: peduncular article 4 with $3 \mathrm{SS}$ on medial surface, 2 SS and 1 penicillate seta at anterodistal angle; article 5 with 2 large pappose setae at posterodistal angle. Flagellum 16-articulate. Mandible: setal row with 18 RS. Maxillule: medial lobe with 3 large and 1 smaller robust pappose setae; lateral lobe with $13 \mathrm{RS}$ on distal surface. Maxilla: lateral lobe with 4 SS; medial lobe with 5 SS and 6 PS; middle lobe with 7 long SS on outer row and 2 long SS on inner row. Maxilliped: endite with 1 coupling hook, and 3 PS. Pereon: ornamentation consists of 1 strongly developed furrow on lateral margin of pereonite 1 ; pereonites 1, 4-5 subequal and longest, 2-3 and 6 subequal and longer than 7. Coxae: pereonite 1, coxae 2-3 posteroventral corners rounded, coxae 4-7 with increasingly produced, broad, acute posteroventral corners. Pleonite 2: dorsal posterolateral margin subequal with ventral posterolateral margin. Pleotelson: posterolateral margins conspicuously serrate. Pereopod 7: basis anterior margin slightly convex; medial carina with SS; posterior margin convex, PS present. Ischium anterior margin with non-RS absent; posterior margin without RS, PS present. Merus posterior margin with $3 \mathrm{RS}$, non-RS absent. Carpus posterior margin with 3 RS, SS absent. Propodus longer than carpus; posterior margin with $5 \mathrm{RS}, \mathrm{SS}$ absent. Penes: forming well separated flattened lobes. Pleopod 2 appendix masculina: arising basally. Pleopods 1-5: exopod suture feebly developed on pleopods 3-5; endopod PS on most of margins of pleopods $1-4$, only a few setae on pleopod 5. Uropods: endopod triangular; medial margin convex, with 3 RS, PS along entire length; apex with 2 RS; lateral margin slightly concave with a prominent notch, with $1 \mathrm{RS}$ and 1 prominent penicillate seta in notch, PS along entire length (but absent from distal section of notch). Exopod medial margin convex, with 2 RS, PS along entire length; apex acute, with 2 RS; lateral margin convex, with $4 \mathrm{RS}$, PS along entire length.

Variation. The paratype males do not have the appendix maculina as strongly curved laterally as in the holotype.

Size. Adults to c. $6 \mathrm{~mm}$.

Etymology. From the Latin "flecto" (to bend or curve) in reference to the shape of the pleopod 2 appendix masculina.

Remarks. Natatolana flexura can be distinguished from all other species in the genus by the presence of an anterodorsal depression on the pleotelson, the low number of robust setae on the margins of the pleotelson and the shape of the lateral margins of the uropod endopod.

Distribution and ecology. Australia: east of Fortescue Bay, north of Hippolyte Rocks, Tasmania; off Wollongong, New South Wales. At depths of $100 \mathrm{~m}$. Scavenger.

\section{Natatolana galathea Bruce, 1986}

Natatolana galathea Bruce, 1986: 86, fig. 58.-Brusca et al., 1995: 80.-Bruce et al., 2002: 150.

Type material. Holotype: $\uparrow$, ZMUC CRU1692 (examined). • Type locality: Gulf of Carpentaria, Australia, $10^{\circ} 37^{\prime} \mathrm{S} 139^{\circ} 19^{\prime} \mathrm{E}$.

Material examined. Western Australia: series from NorthWest Shelf, CSIRO 1983, sled, AM P47135-47138: ơ, 1956.7'S $117^{\circ} 53.6^{\prime} \mathrm{E}, 41 \mathrm{~m}, 05-\mathrm{B} 2-\mathrm{S} ; 20^{\star} \sigma^{\star}$, ovigerous + , $19^{\circ} 56.4^{\prime} \mathrm{S}$ $117^{\circ} 53.9^{\prime} \mathrm{E}, 44 \mathrm{~m}, 03-\mathrm{B} 2-\mathrm{S}$; $0 \hat{0}, 5$ 우 (1 ovigerous), manca, 


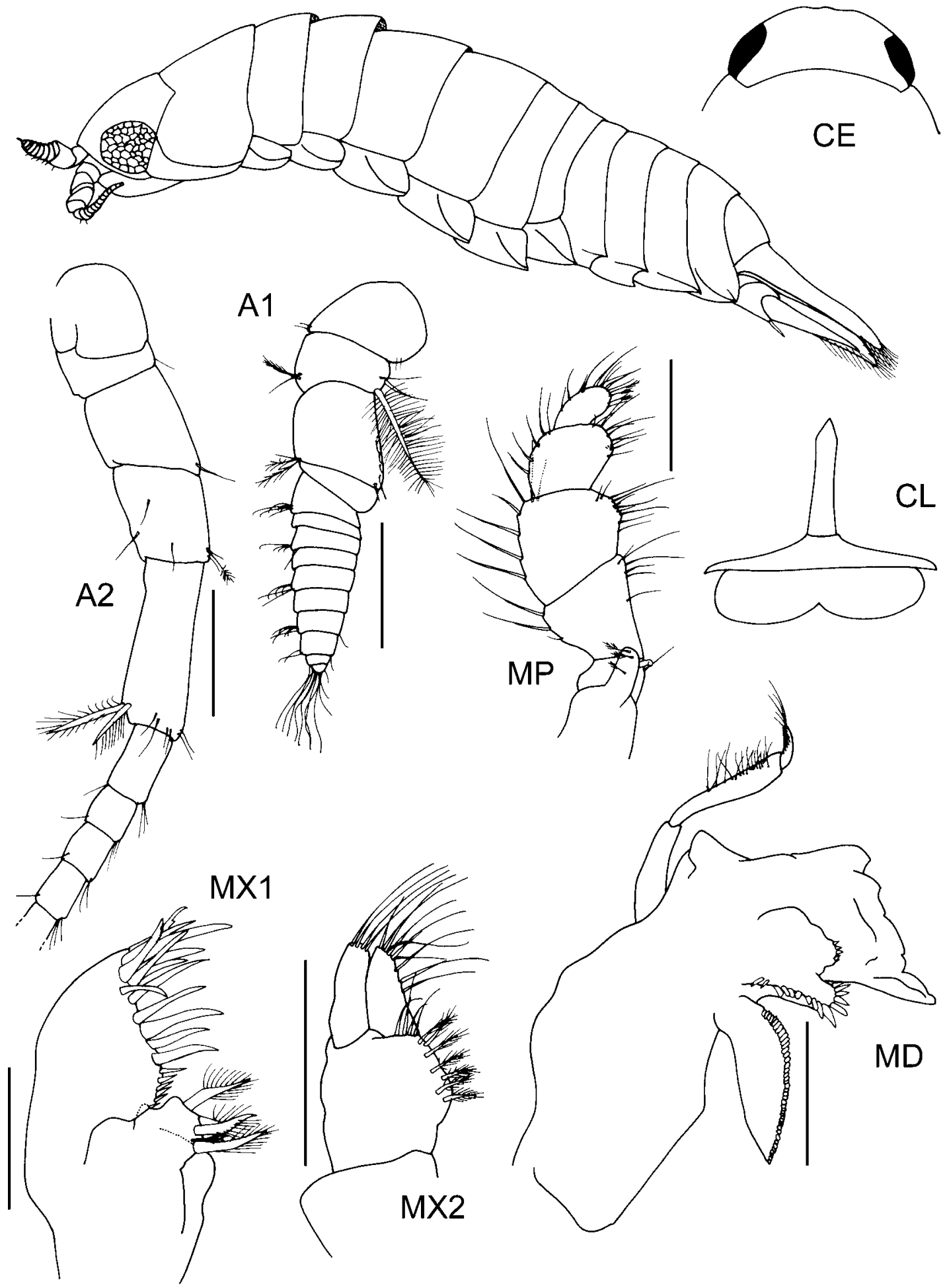

Fig. 20. Natatolana flexura n.sp., holotype. Scales $=0.2 \mathrm{~mm}$.

$19^{\circ} 56.9^{\prime} \mathrm{S} 117^{\circ} 53.7^{\prime} \mathrm{E}, 42-43 \mathrm{~m}, 02-\mathrm{B} 2-\mathrm{S} ;$;, $1^{\circ} 59^{\prime} \mathrm{S} 117^{\circ} 51.4^{\prime} \mathrm{E}$, 42m, 01-B1-S.

Diagnosis. Interocular furrow: moderately developed, distinct but not extending across the cephalon. Frontal lamina: lateral margins straight, narrowing anteriorly. Antenna: c. $0.35 \times$ as long as body, reaching to between posterior of pereonite 3 and 4 (not to pereonite 2 as originally described). Coxal plates: furrows strongly developed, on all coxae. Pleonite 4: apex slightly rounded. Pleotelson: broad, length $0.7 \times$ basal width; anterodorsal depression present; anterolateral margins almost straight and angling posteriorly toward the midline, or convex; posterolateral margins convex; apex not produced, lateral margins converging smoothly to a point, or produced into a small point; with $8 \mathrm{RS}$. Pereopods 1-6: males with conspicuous elongated RS subequal to propodus on the merus of pereopods 1-3 and extending from the carpus to dactylus of pereopods 4-6. Pereopods 2-3: propodus without RS on palm. Pereopod 7: basis narrow, width $0.45 \times$ length; distance between anterior margin and medial carina 


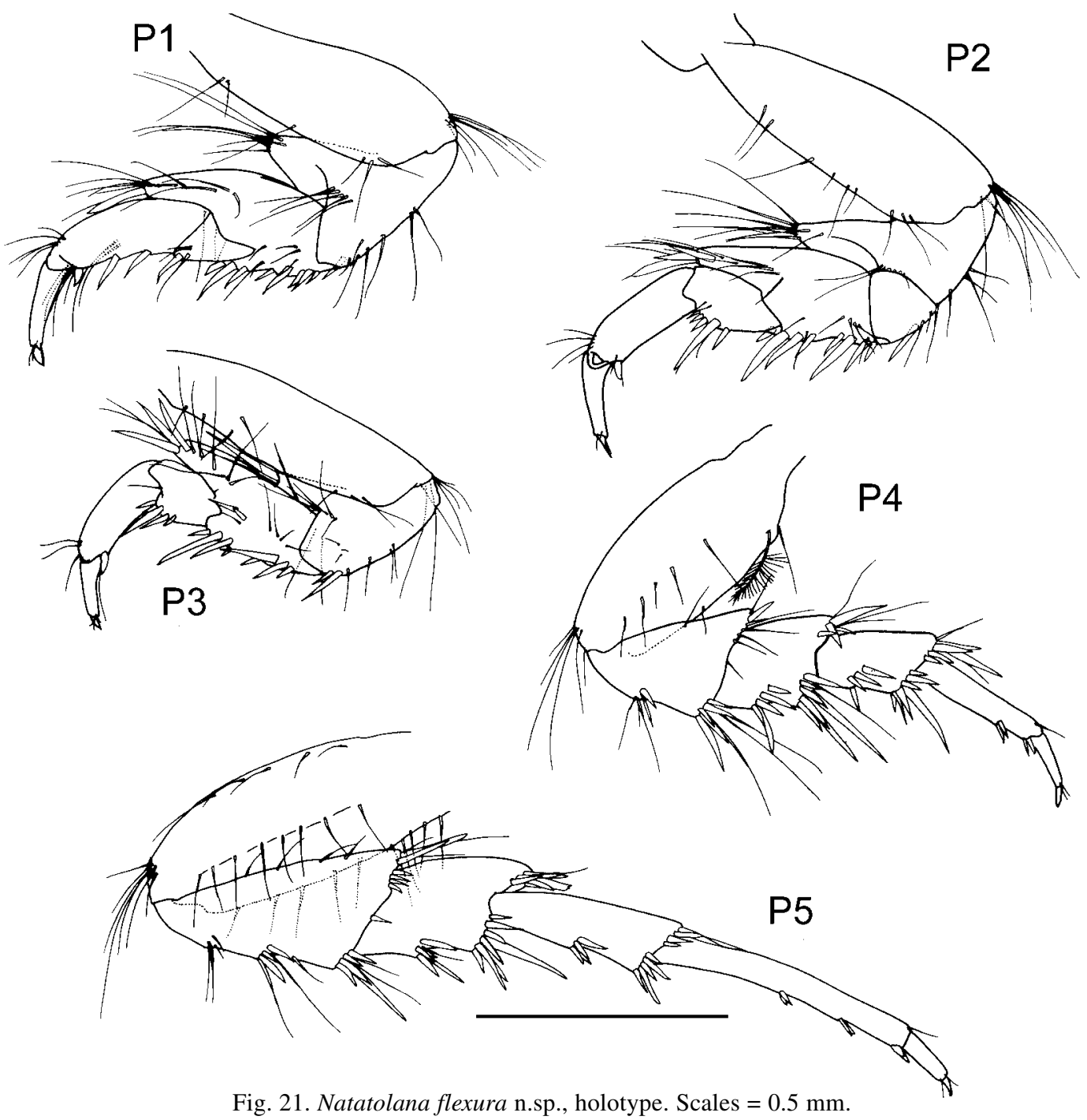

less than between posterior margin and medial carina; posterior margin with setae along entire length. Penes: present. Pleopod 2 appendix masculina: extending subequal with tip of endopod, $1 \times$ length of endopod; margins strongly curved laterally; slender; apex not at angle to adjacent margins, bluntly rounded. Uropods: exopod slightly shorter than endopod, $0.85 \times$ the length of the endopod.

Sexual dimorphism. Males may have slightly longer antennae, extending to the posterior of pereonite 4 . Females lack the conspicuously elongated robust setae present on the merus of pereopods $1-3$ and on the carpus of pereopods 4-6 of adult males.

Size. Adults to c. $7 \mathrm{~mm}$.

Remarks. This is the first record of a male specimen of Natatolana galathea. This species is most similar to $N$. pellucida and can be identified by examination of the characters discussed in remarks for that species.

Distribution. Australia: northwestern Western Australia; Gulf of Carpentaria. At depths of 41-57 m.

\section{Natatolana gallica (Hansen, 1905)}

Synonymy in Keable \& Bruce, 1997: 677, figs. 8-10. Additional listings and records of this species are those of Castelló \& Carballo (2001, p. 231).

Type material. Syntypes: 157 specimens, ZMUC CRU147 (examined). - Type locality: Roscoff [France, c. $48^{\circ} 42^{\prime} \mathrm{N} 4^{\circ} 0^{\prime} \mathrm{W}$, although Hansen (1905) also cites Guernsey and Jersey as possible type localities and indicates the specimens are from the collections of the maritime station of Roscoff].

Material examined. Listed by Keable \& Bruce (1997).

Diagnosis. Interocular furrow: moderately developed, distinct but not extending across the cephalon. Frontal lamina: lateral margins medially constricted. Antenna: c. $0.27 \times$ as long as body, reaching to approximately one third of the way along pereonite 3. Coxal plates: furrows moderately developed, on all coxae. Pleonite 4: apex slightly rounded. Pleotelson: broad, length $0.95 \times$ basal width; anterodorsal depression absent; anterolateral margins convex; posterolateral margins convex; apex not produced, lateral margins converging smoothly to a point; with 3-5 RS. Pereopod 2: propodus with 0-1 RS on palm. Pereopod 3: ischium anterodistal angle produced, but not as produced as on pereopods 1 and 2, similar to pereopod 4. Propodus 


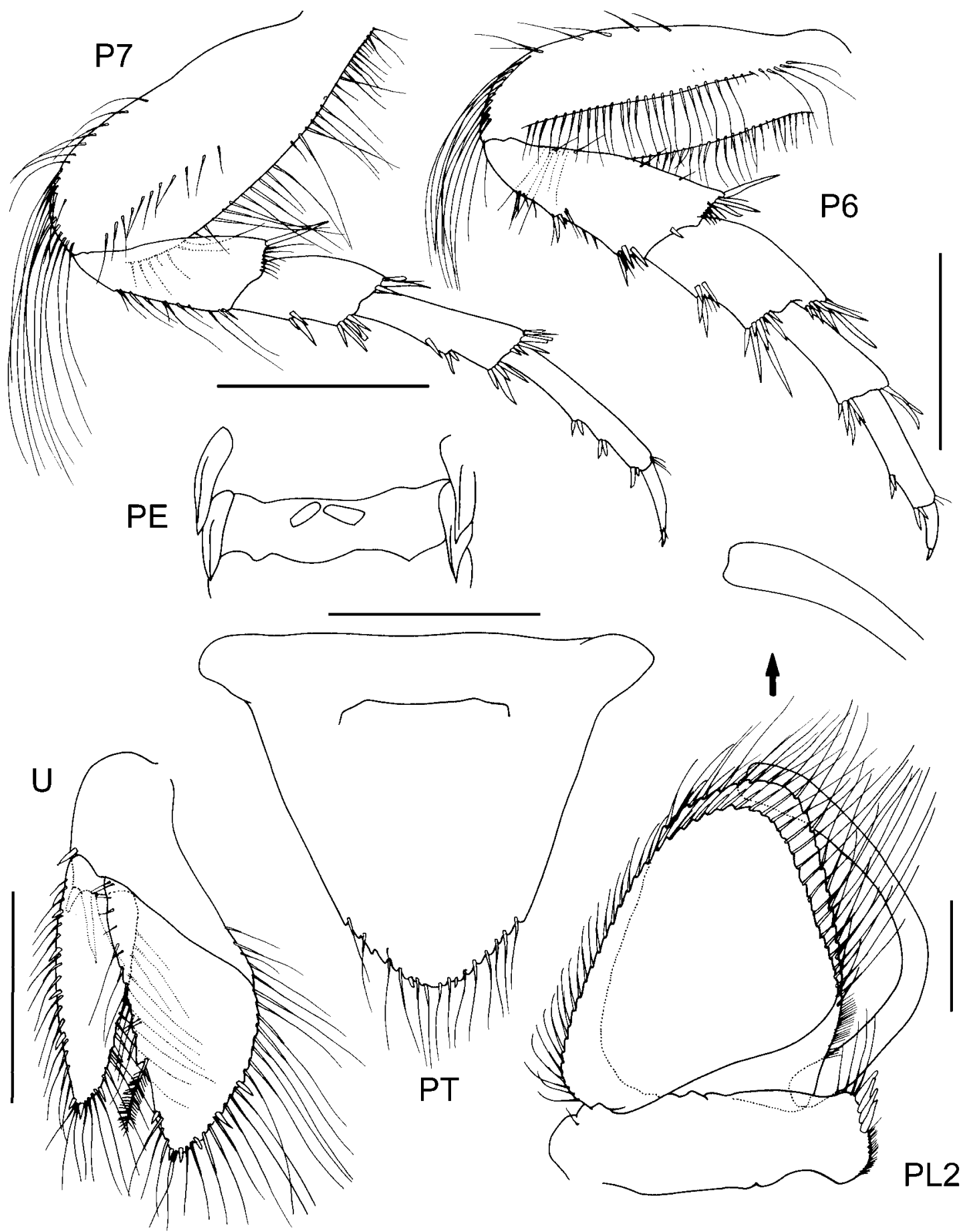

Fig. 22. Natatolana flexura $\mathrm{n} . \mathrm{sp}$., holotype. Scales $=0.5 \mathrm{~mm}$, except PL2 $=0.2 \mathrm{~mm}$.

with $0-1$ RS on palm. Pereopod 7: basis broad, width $0.65 \times$ length; distance between anterior margin and medial carina greater than between posterior margin and medial carina; posterior margin with dense setae along entire length. Penes: absent, vasa deferentia opening flush to surface of sternite 7 (area around openings slightly raised but not forming flexible processes). Pleopod 2 appendix masculina: extending beyond tip of endopod, $1.05 \times$ length of endopod; margins very slightly curved laterally; slender; apex not at angle to adjacent margins, with a distinct acute projection. Uropods: exopod slightly shorter than endopod, $0.88 \times$ the length of the endopod.

Size. To c. $25 \mathrm{~mm}$.
Remarks. Natatolana gallica was redescribed by Keable \& Bruce (1997). It is most similar to $N$. thalme but differs noticeably from that species in having the posterolateral margin of the pleotelson convex and smoothly continuous with the anterolateral margins (angled to the anterolateral margins in $N$. thalme), more strongly developed coxal furrows, dense setae along the length of the posterior margin of the basis of pereopod 7 (sparse in $N$. thalme) and in often having robust setae on the palm of the propodus of pereopods 2 and 3 (absent in N. thalme).

Distribution. Atlantic coasts of Europe and northern Africa. At depths of 8-210 m (Keable \& Bruce, 1997; Castelló \& Carballo, 2001). 


\section{Natatolana gorung Bruce, 1986}

Natatolana gorung Bruce, 1986: 66, figs. 42, 43.-Springthorpe \& Lowry, 1994: 46.-Brusca et al., 1995: 80.-Bruce et al., 2002: 150 .

Type material. Holotype: $\widehat{\jmath}, 14.5 \mathrm{~mm}$, NMV J1340 (not examined). Paratype: AM P24324 (examined). - Type locality: Port Phillip Bay, Victoria, Australia, $38^{\circ} 19^{\prime} \mathrm{S} 144^{\circ} 47^{\prime} \mathrm{E}$.

Material examined. New South Wales: 3 adults, manca, AM P38673, Middle of Spring Cove, North Harbour, Port Jackson, baited trap, 15 m, S. Keable, D. Townsend, J. Lowry, 16-17 Jul. 1988; series from Bate Bay, Pioneer Cement/The Ecology Lab. EIS Study, AM P47277-47281, baited trap, 1991: 100 specimens, S1R1 E deep; 3 specimens, S1R1 deep; 30 specimens, S2R1 deep; 97 specimens (2 vials), S1R2 E deep; same study off Providential Head, 62 m; series from Jervis Bay, CSIRO Baseline Studies, P. Hutchings et al. AM, corer, AM P47271-47276; 1 specimen, site 4\#5, 25 May, 1990; 1 specimen, site 4\#2, 5 Jun. 1990; 5 mancas, site 6\#3, Aug. 1989; manca, site 6\#2, 5 Jun. 1989; manca, site 4\#2, Jun. 1989; manca, site 6, Aug. 1989.

Diagnosis. Eyes: vestigial. Interocular furrow: well developed, forming a ridge that runs across the cephalon and deflects anteriorly towards the midpoint. Frontal lamina: lateral margins straight, parallel. Antenna: c. $0.25 \times$ as long as body, reaching to posterior of pereonite 1. Coxal plates: furrows variously developed, strongly developed on pereonite 1 and coxae 2-3, absent on coxae 4-6, weakly developed on coxa 7. Pleonite 4: apex forming a broad acute point. Pleotelson: broad, length $0.83 \times$ basal width; anterodorsal depression absent; anterolateral margins almost straight and angling posteriorly toward the midline; posterolateral margins straight, markedly angled to anterolateral margins and meeting at an obtuse angle; apex not produced, lateral margins converging smoothly to a point; with 10-12 RS. Pereopod 2: propodus with $2 \mathrm{RS}$ on palm. Pereopod 3: propodus without RS on palm. Pereopod 7: basis broad, width $0.55 \times$ length; distance between anterior margin and medial carina less than between posterior margin and medial carina; posterior margin with setae proximally and distally but not medially. Penes: absent. Pleopod 2 appendix masculina: extending subequal with tip of endopod, 0.96× length of endopod; slender; margins straight; apex bent laterally slightly, bluntly rounded. Uropods: exopod short, $0.75 \times$ the length of the endopod.

Size. Adults to $18.6 \mathrm{~mm}$.

Remarks. The incomplete interocular furrow formed into a distinct ridge is sufficient to distinguish Natatolana gorung from all other species in the genus.

Distribution and ecology. Australia: New South Wales: Port Jackson; off Sydney; Jervis Bay. Victoria: Port Phillip Bay. To depths of $66 \mathrm{~m}$. Scavenger.

\section{Natatolana gracilis (Hansen, 1890)}

Synonymy in Keable \& Bruce, 1997: 682, figs. 11-12.

Type material. Holotype: $\widehat{o}, 8 \mathrm{~mm}$, ZMUC CRU152 (examined). $\bullet$ Type locality: the only type specimen was without location data but Hansen (1890) indicates that there is a high probability that it was collected at St Thomas, Virgin Islands [c. $\left.18^{\circ} 20^{\prime} \mathrm{N} 64^{\circ} 55^{\prime} \mathrm{W}\right]$.

Diagnosis. Eyes: well developed (Hansen (1890) describes the eyes as large with a few large ommatidia, these have faded in the holotype and are now barely apparent). Interocular furrow: absent. Frontal lamina: lateral margins concave but not medially constricted, narrowing toward apex. Antenna: c. $0.4-0.5 \times$ as long as body, reaching to posterior of pereonite 4. Coxal plates: furrows moderately developed, on all coxae. Pleonite 4: apex slightly rounded. Pleotelson: broad, length $0.87 \times$ basal width; anterodorsal depression absent (although the anterior margin is thickened, and there is a smooth curve to a depression, this is not equivalent to the distinct and abrupt depression found in species such as $N$. pellucida); anterolateral margins almost straight and angling posteriorly toward the midline; posterolateral margins straight, markedly angled to anterolateral margins and meeting at an obtuse angle; apex produced into a small point; with 7-8 RS. Pereopod 2: propodus with 4 RS on palm (illustrated by Hansen (1890), pereopod 2 propodus now missing from holotype). Pereopod 3: propodus with $3 \mathrm{RS}$ on palm. Pereopod 7: basis narrow, width $0.38 \times$ length; distance between anterior margin and medial carina less than between posterior margin and medial carina; posterior margin with setae completely absent along entire length. Penes: unknown (the only specimen that can be identified with certainty is damaged and fragile, there appear to be 2 flattened lobes present, these may be penes but because of the fragile nature of the specimen these could not be examined closely enough to conclude that they were penes). Pleopod 2 appendix masculina: extending beyond tip of endopod, $1.07 \times$ length of endopod; margins very strongly curved laterally; slender; apex not at angle to adjacent margins, bluntly rounded. Uropods: exopod slightly shorter than endopod, $0.8 \times$ the length of the endopod.

Sexual dimorphism. Based on the record of Koening (1972), females apparently differ from males only in the primary sexual characters and do not have the pleopod 2 appendix masculina. The possibility of further sexual dimorphism, however, is uncertain until samples from the type locality, containing both sexes, have been examined.

Size. Only measured specimen reported is $8 \mathrm{~mm}$.

Remarks. The most distinctive feature of Natatolana gracilis is the shape of the male appendix masculina. The holotype is the only male specimen that has been reported and is, therefore, the only specimen that can be attributed to the species with certainty. Further specimens from the vicinity of the type locality are needed in order to expand upon the redescription of Keable \& Bruce (1997).

Distribution. The type locality is uncertain but is probably St Thomas, U.S. Virgin Islands. Also reported from northern Brazil at depths of 7-85 m (Koening, 1972; Pires-Vanin, 1998) but this requires verification (Keable \& Bruce, 1997).

\section{Natatolana helenae n.sp.}

Figs. 23-24

Type material. Holotype: $\delta^{\star}, 14 \mathrm{~mm}, \mathrm{QM}$ W18851. • Type locality: Gulf of Carpentaria, Australia, $10^{\circ} 41.4^{\prime} \mathrm{S} 141^{\circ} 51.6^{\prime} \mathrm{E}$, [grab], 10 m, [CSIRO Southern Surveyor, 29 Nov. 1991, stn 62].

Diagnosis. Interocular furrow: absent. Frontal lamina: lateral margins straight, narrowing anteriorly. Antenna: c. $0.8 \times$ as long as body, reaching to posterior of pereonite 6 . Coxal plates: furrows moderately developed, on all coxae. 


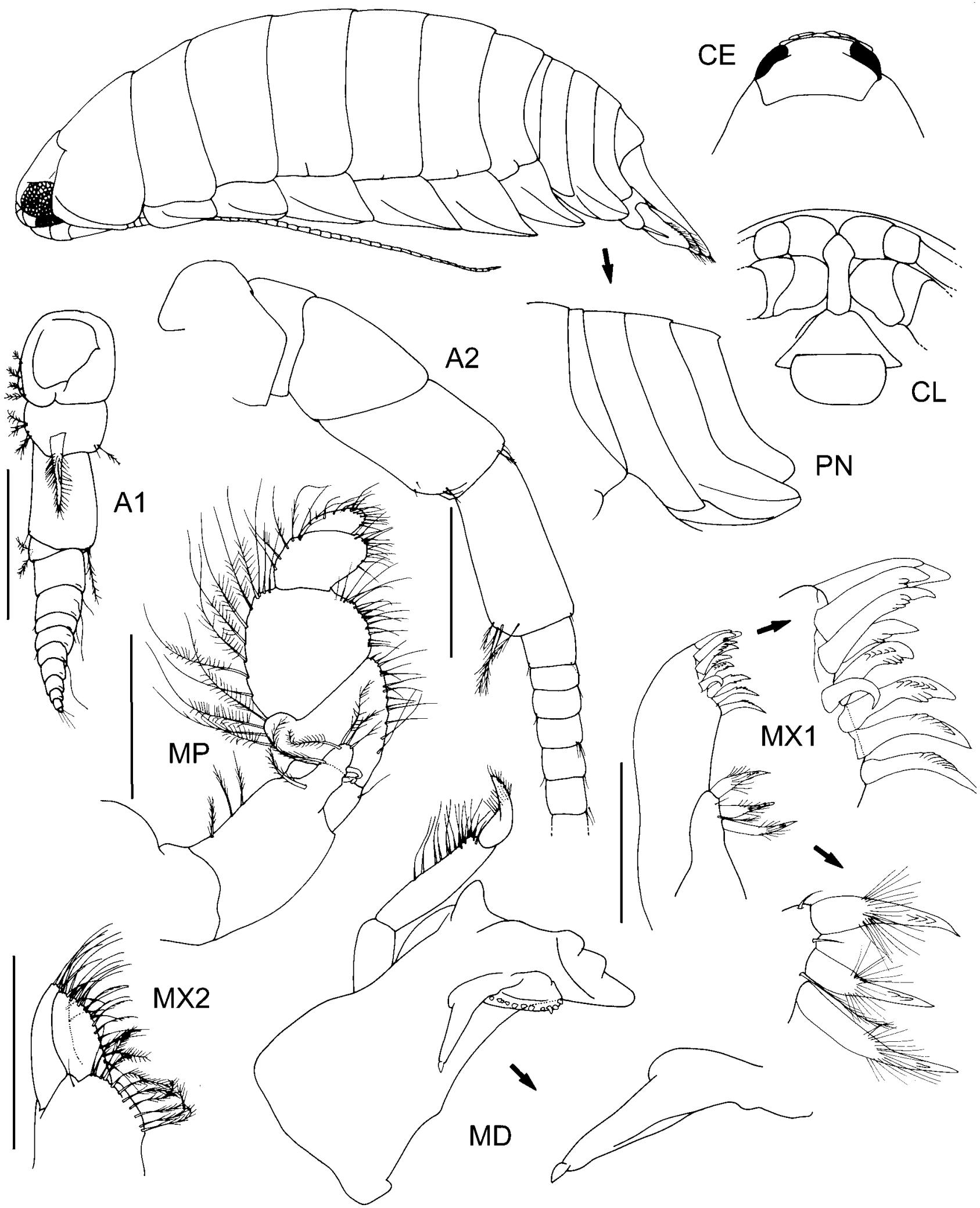

Fig. 23. Natatolana helenae n.sp., holotype. Scales $=0.5 \mathrm{~mm}$.

Pleonite 2: ventral posterolateral margin not produced. Pleonite 4: apex slightly rounded. Pleotelson: broad, length $0.67 \times$ basal width; anterodorsal depression absent; anterolateral margins almost straight and angling posteriorly toward the midline; posterolateral margins straight, contiguous with anterolateral margins; apex truncate with a serrate margin; with 8 RS. Pereopod 2: propodus without
RS on palm. Pereopod 3: ischium anterodistal angle produced subequal to pereopod 2, both more produced than pereopod 1 ischium. Propodus without RS on palm. Pereopods 5-7: propodus short and robust on each pereopod. Pereopod 7: basis broad, width $0.61 \times$ length; distance between anterior margin and medial carina less than between posterior margin and medial carina; posterior 


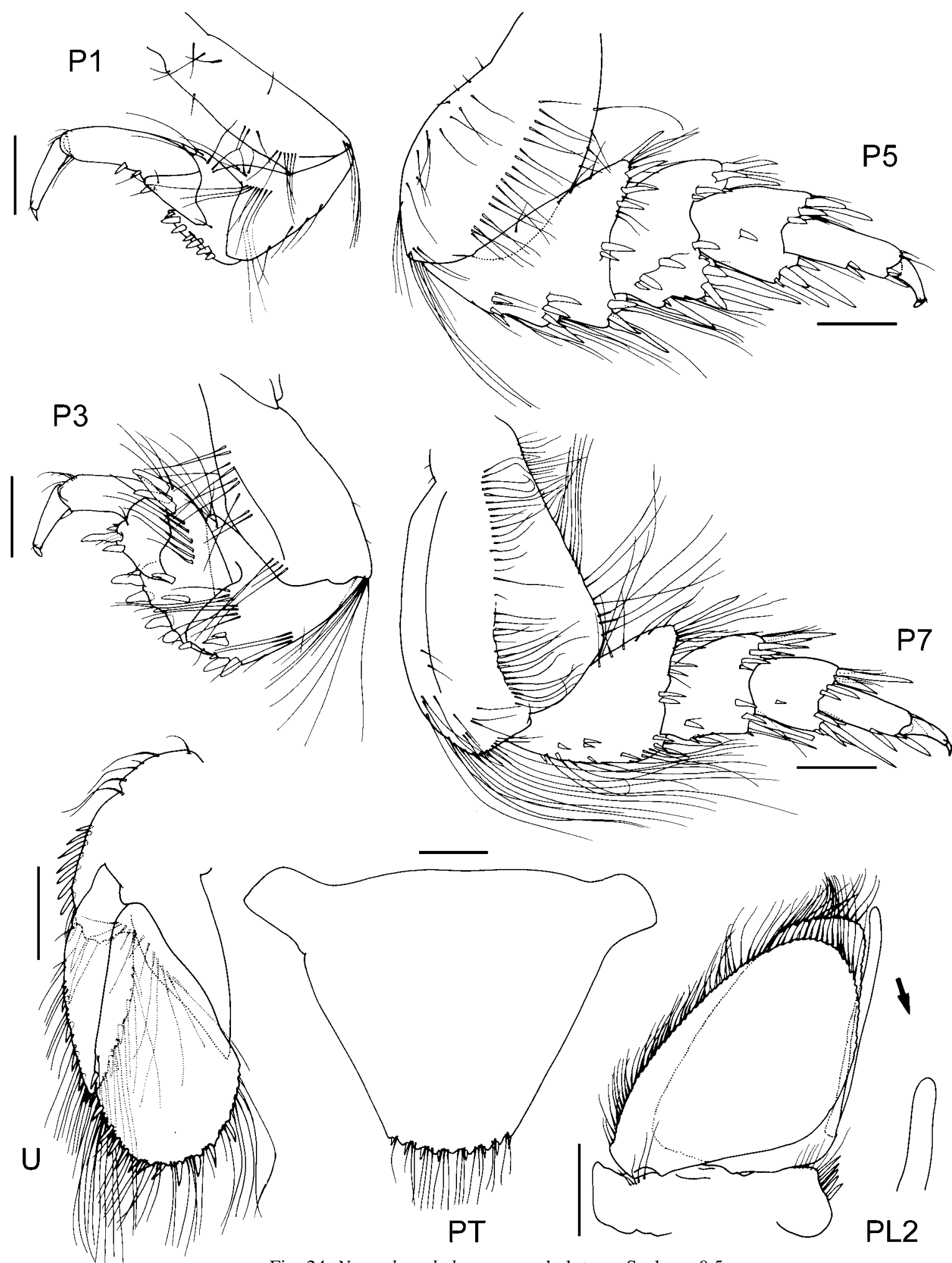

Fig. 24. Natatolana helenae n.sp., holotype. Scales $=0.5 \mathrm{~mm}$.

margin with setae completely absent along entire length. Penes: absent. Pleopod 2 appendix masculina: extending beyond tip of endopod, $1.08 \times$ length of endopod; margins straight; slender; apex bent laterally slightly, bluntly rounded. Uropods: exopod short, $0.73 \times$ the length of the endopod.

Additional descriptive characters. Based on holotype. Body: length c. $2.35 \times$ width. Colour cream in alcohol. Chromatophores absent. Eyes: with 9 ommatidia in horizontal diameter; with 6 ommatidia in vertical diameter; ovate; colour tan in alcohol. Frontal lamina: length c. $3 \times$ basal width; apex expanded, anterior margin angled. Antennule: short, just reaching pereonite 1. Peduncular article 1 longer than article 2 ; article 2 with 1 large pappose seta medially and several penicillate setae on margins; article 3 short, subequal to article 1. Flagellum 10-articulate. Antenna: peduncular article 4 with 4 short SS at posterodistal angle, 1 penicillate and 1 short SS at anterodistal angle; 
article 5 with 3 pappose setae and 1 SS at posterodistal angle. Flagellum 47-articulate. Mandible: molar RS absent on margins; incisor narrow, with posterior tooth not strongly developed; setal row with 11 RS. Maxillule: medial lobe with 3 large and 1 smaller robust pappose setae (larger setae with serrations), lateral margin with protuberance absent; lateral lobe with $11 \mathrm{RS}$ on distal surface. Maxilla: lateral lobe with 8 SS (2 are uniserrate and 3 are biserrate); medial lobe with 3 SS and 9 PS; middle lobe with 18 SS, 7 of which are serrate. Maxilliped: palp lateral margin with PS on most of the length of articles 2-5; article 5 serrate setae absent. Endite with 2 coupling hooks, and 6 PS. Pereon: ornamentation consists of 1 strongly developed furrow on lateral margin of pereonite 1 and 1 short, medial furrow on lateral margins of pereonites 4-7; pereonite 1 longest, 2-5 subequal, 6-7 progressively shorter. Coxae: pereonite 1, coxae 2-3 with rounded posteroventral corners, coxae 4-6 with increasingly produced, broad, acute posteroventral corners, coxa 7 posterior margin distinctly concave and posteroventral corner produced into a narrow acute point. Pleonite 2: dorsal posterolateral margin clearly projecting posterior to ventral posterolateral margin. Pleonite 3: rounded. Pleotelson: PS restricted to apex. Pereopod 1: propodus posterodistal angle without RS opposing dactylus. Pereopod 7: basis anterior margin slightly convex; medial carina with PS along entire length; posterior margin convex. Ischium broad, width greater than length; anterior margin with SS; posterior margin with 5 RS (and 3 submarginally), PS present. Merus posterior margin with $2 \mathrm{RS}$ (and 1 submarginally), SS present. Carpus posterior margin without RS, SS absent. Propodus subequal to carpus; posterior margin with 2 RS, SS absent. Pleopod 2 appendix masculina: arising sub-basally. Pleopods 1-5: exopod suture strongly developed on pleopods 3-5; endopod PS on most of margins on pleopods 1-4, absent on pleopod 5. Uropods: endopod subcircular; medial margin rounded, with 4 RS, PS along entire length; apex with 3 RS; lateral margin straight for proximal two thirds, convex at distal third, with $5 \mathrm{RS}$ and 1 penicillate seta, PS on distal third. Exopod medial margin convex, with 3 RS, PS on distal three-quarters; apex acute, with 3 RS; lateral margin convex, with 4 RS, PS on distal two-thirds.

Size. Adults to $14 \mathrm{~mm}$.

Etymology. Named after Ms Helen Stoddart, in recognition of the help she has given me in this and other studies.

Remarks. Natatolana helenae is distinguished from all others species in the genus by the truncate, serrate pleotelson. The lack of robust setae on the mandible molar, the presence of plumose setae on the lateral margins of the maxilliped palp, the serrations on the pappose setae of the medial lobe of the maxillule and the absence of a robust seta at the posterodistal angle of the pereopod 1 propodus, are also unique characters within the genus.

Distribution. Australia: known only from Gulf of Carpentaria. In a depth of $10 \mathrm{~m}$.

\section{Natatolana hirtipes (Milne Edwards, 1840)}

Figs. 25-28

Cirolana hirtipes Milne Edwards, 1840: 236, pl. 31, figs. 25, 26.Milne Edwards, 1836-49 [exact publication date unknown, see Sherborn (1922), subsequent to Milne Edwards (1840)]: pl. 67, figs. 6-6i.-Hansen, 1890: 326, pl.1, figs. 2-2g.Stebbing, 1910: 421.-Tattersall, 1913: 880.-Vanhöffen, 1914: 501, fig. 38.-?Barnard, 1936: 150.-Kensley, 1975: 39.-1978: 67, fig. 27 E-F.-Huber, 1992: 58.

Natatolana hirtipes.-Bruce, 1981: 957, 958.-1986: 53, 97, 222.Brusca et al., 1995: 80.-Kensley, 2001: 230.

Not Cirolana hirtipes.-Heller, 1866: 742.-Stalio, 1877: 1375.Stossich, 1880: 224 [mis-identification = Natatolana neglecta (Hansen, 1890)].

Not Cirolana hirtipes.-Goss, 1855: 133.-White, 1857.-Lo Bianco, 1903: 258 [mis-identification = Natatolana borealis (Liljeborg, 1851)].

Not Cirolana hirtipes.-Filhol, 1885: 445, 449, pl. 53 fig. 6.Nierstrasz, 1931: 158.-Hurley, 1961: 267 [mis-identification = Natatolana rossi (Miers, 1876)].

Type material. Lectotype: designated here, ô, $24 \mathrm{~mm}, \mathrm{MNHN}$ Is. 96. Paralectotype: $+, 27 \mathrm{~mm}, \mathrm{MNHN}$ Is. 96. All examined. • Type locality: Cape of Good Hope (as Cap de Bonne-Esperance),

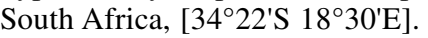

Material examined. South Africa: $\widehat{o}, 18 \mathrm{~mm}, ~ \uparrow, 12 \mathrm{~mm}$ and manca, 10 mm, SAM-A14579, False Bay, FAL 587 G-E; 11 ô, 6 우 오, ZMUC CRU160, Table Bay, Swedish South African Expedition, 1935, Zool. Inst. Lund. (Prof. O. Carlgren) ded. 1-71937; đ̊, ZMUC CRU161, Table Bay [as Tafel Bay], Strandgaard, Studiesaml [teaching collection], ded. 1890, 23-5-1890.

Diagnosis. Eyes: well developed; elongate, length c. $2 \times$ height. Interocular furrow: well developed, extending across the cephalon; smoothly convex. Frontal lamina: lateral margins medially constricted. Antenna: c. $0.4 \times$ as long as body, reaching to just beyond the posterior of pereonite 3 (i.e., about $1 / 4$ of the way along pereonite 4 ) or the posterior of pereonite 4. Coxal plates: furrows strongly developed, on all coxae. Pleonite 4: apex slightly rounded. Pleotelson: broad, length $0.82 \times$ basal width; anterodorsal depression absent; anterolateral margins convex (in type material), or almost straight and angling posteriorly toward midline; posterolateral margins convex (in type material), or straight, markedly angled to anterolateral margins and meeting at an obtuse angle; apex not produced, lateral margins converging smoothly to a point; with $12-19$ RS (18 in lectotype). Pereopod 2: propodus with $1 \mathrm{RS}$ on palm. Pereopod 3: propodus with $1 \mathrm{RS}$ on palm. Pereopod 7: basis broad, width $0.54 \times$ length; distance between anterior margin and medial carina less than between posterior margin and medial carina; posterior margin with setae on proximal quarter. Penes: absent. Pleopod 2 appendix masculina: extending subequal with tip of endopod, $0.98 \times$ length of endopod; margins very slightly curved laterally; slender; apex not at angle to adjacent margins, bluntly rounded. Uropods: exopod subequal to endopod, $0.98 \times$ the length of the endopod.

Additional descriptive characters. Based on the type material, the female paralectotype was used for the whole animal illustration and was checked against the male lectotype that had been slightly squashed, the lectotype was used for all dissected parts. Body: length c. $3 \times$ width. Colour translucent cream-white in alcohol. Chromatophores absent. Eyes: with 


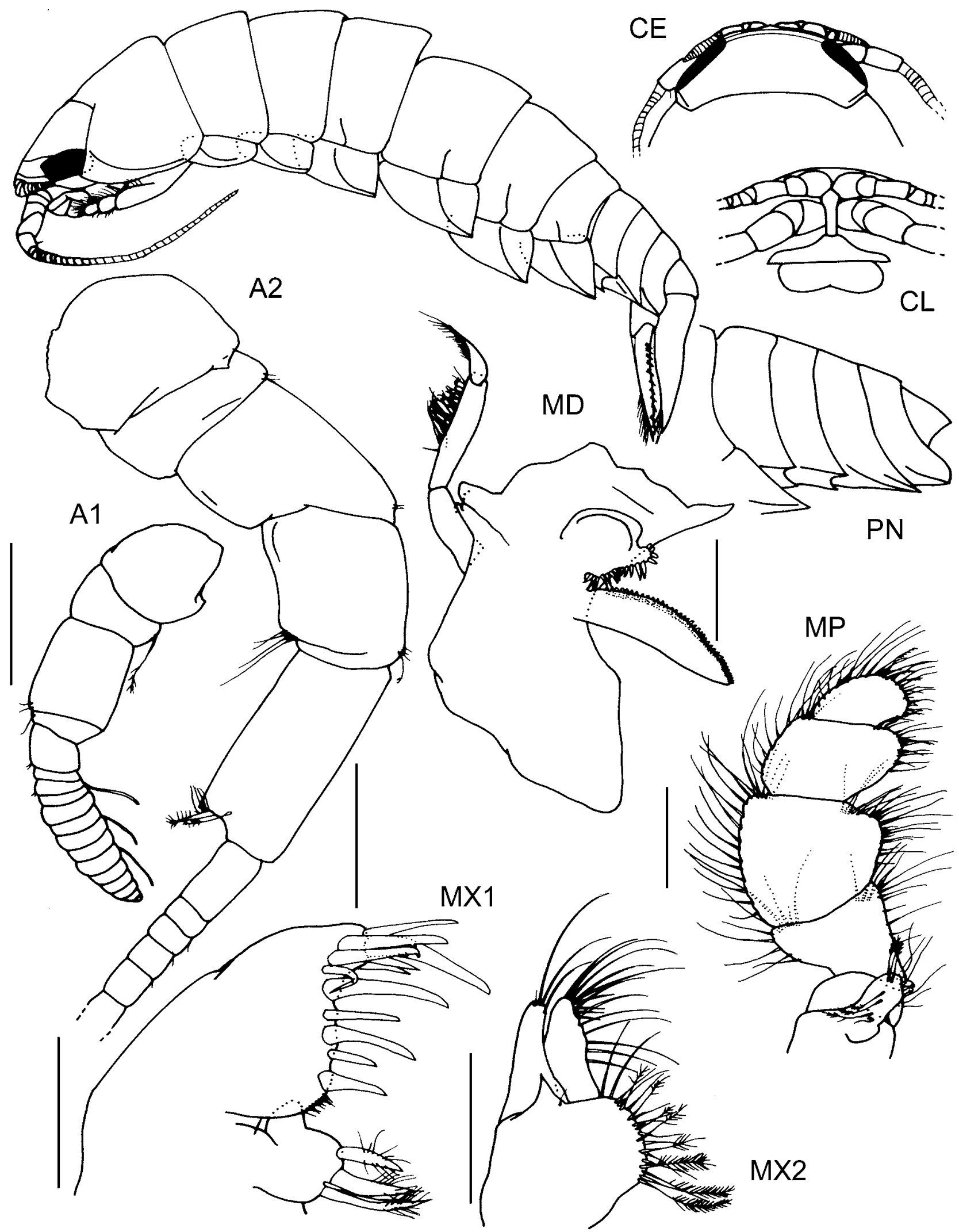

Fig. 25. Natatolana hirtipes. Whole animal = paralectotype female, all other parts $=$ lectotype male. Scales $=0.5 \mathrm{~mm}$.

14 ommatidia in horizontal diameter; with 10 ommatidia in vertical diameter; rectangular; colour tan in alcohol. Frontal lamina: length c. $4 \times$ basal width; apex expanded, anterior margin angled. Antennule: peduncular article 1 longer than article 2; article 2 with 1 long narrow pappose seta; article 3 short, subequal to article 1. Flagellum 14-articulate. Antenna: peduncular article 4 with $4 \mathrm{SS}$ at posterodistal angle and 1 penicillate seta at anterodistal angle; article 5 with 1 pappose seta and 1 penicillate seta at posterodistal angle. Flagellum 35-articulate. Mandible: setal row with 17 RS. Maxillule: medial lobe with 3 large and 1 smaller robust pappose setae; lateral lobe with $12 \mathrm{RS}$ on distal surface. Maxilla: lateral lobe 


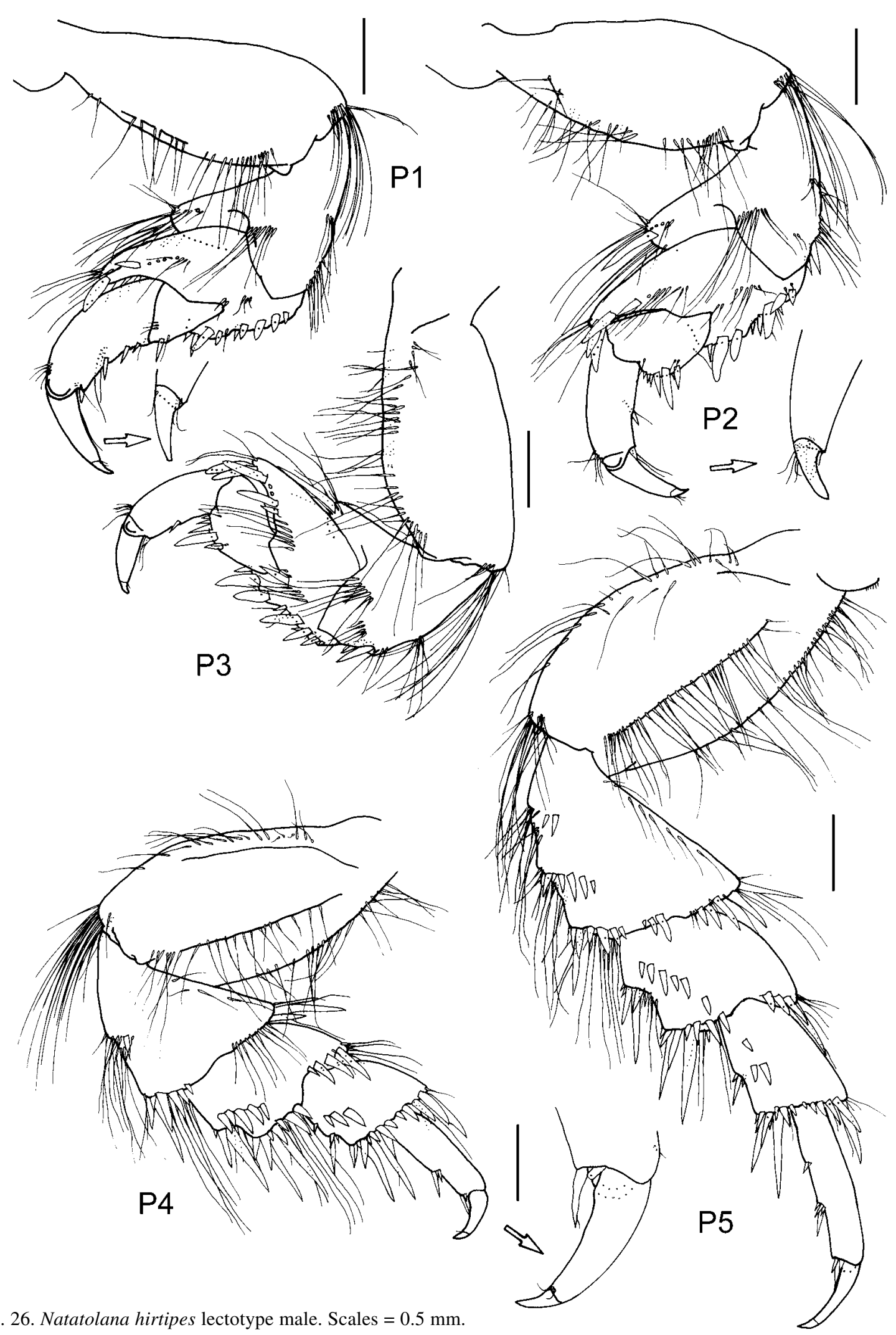

with 4 SS (one of which is broken); medial lobe with 11 SS and 9 PS; middle lobe with 16 SS. Maxilliped: endite with 2 coupling hooks, and 7 PS. Pereon: ornamentation consists of 1 strongly developed furrow on the lateral margin of pereonite 1 and 1 short, medial furrow on the lateral margins of pereonites 4-7; pereonites 1 and 5 subequal in length and longest, 2-4 and 6 subequal and longer than 7. Coxae: pereonite 1, coxae 2-3 with rounded posteroventral corners, coxae 4-7 with increasingly produced, broad, acute posteroventral corners. Pleonite 2: dorsal posterolateral margin subequal with ventral posterolateral margin. Pereopod 7: basis anterior margin sinuate; medial carina with PS and SS present; posterior margin 


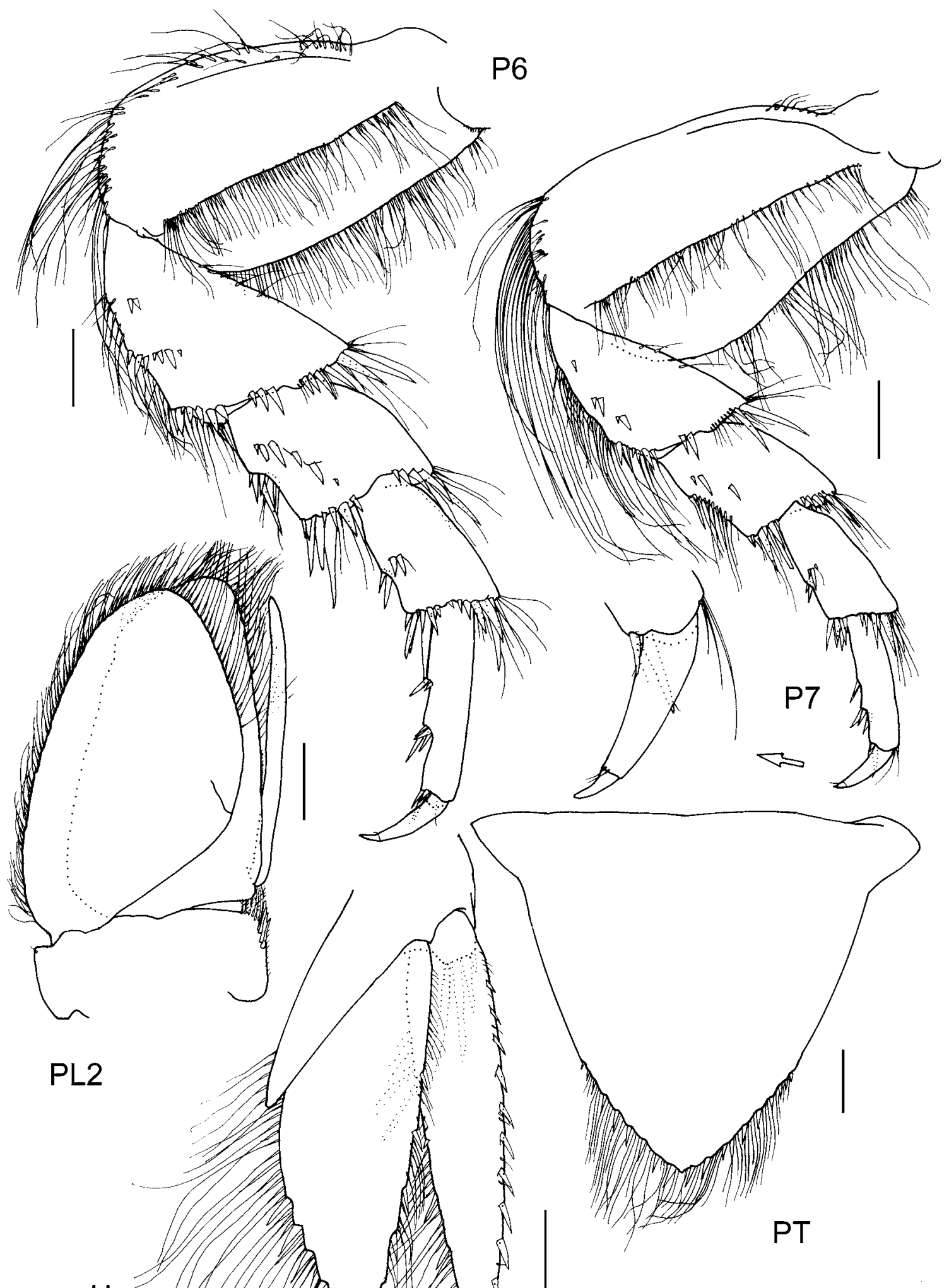

Fig. 27. Natatolana hirtipes, lectotype male. Scales $=0.5 \mathrm{~mm}$.

basally. Pleopods 1-5: exopod suture strongly developed on pleopods 3-5; endopod PS on most of margins of pleopods 14, only a few setae on pleopod 5. Uropods: endopod lanceolate;

convex, posterior margin PS present. Ischium anterior margin with SS (sparse); posterior margin with 5 RS (submarginal), PS and SS present. Merus posterior margin with 3 RS (submarginal), SS present. Carpus posterior margin with 4 RS, SS absent. Propodus subequal to carpus; posterior margin with 5 RS, SS absent. Pleopod 2 appendix masculina: arising submedial margin convex, with 5 RS, PS along entire length; apex with 2 RS; lateral margin slightly convex, with 6 RS, PS along entire length. Exopod medial margin convex, with 3 RS, PS on distal three-quarters; apex acute, with 2 RS; lateral margin convex, with $10 \mathrm{RS}$, PS along entire length (although most have been broken or been rubbed off). 

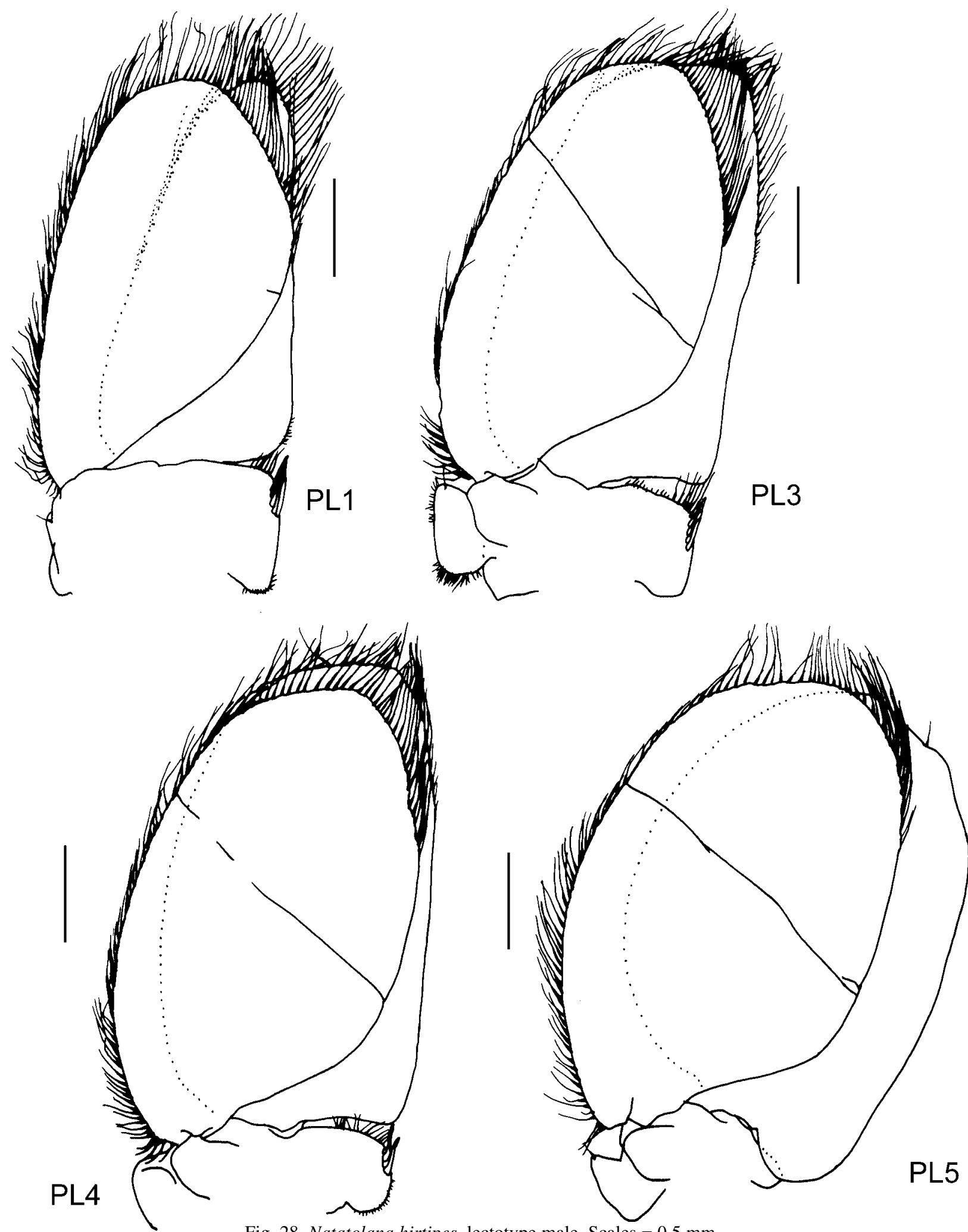

Fig. 28. Natatolana hirtipes, lectotype male. Scales $=0.5 \mathrm{~mm}$.

Variation. The male lectotype has pleonite 1 clearly visible between pereonite 7 and pleonite 2 , in the female paralectotype pleonite 1 is just visible. The male, female and manca specimens from False Bay (SAM A-14579) all have pleonite 1 just visible. On these non-type specimens the antennae reach the posterior of pereonite 4 (not just beyond the posterior of pereonite 3 as in the types) and smaller specimens have fewer articles in the antennal flagellum. Seventeen specimens from Table Bay (ZMUC CRU160) were also examined for variations in the numbers of robust setae occurring on the pleotelson and uropods. These robust setae are quite long in Natatolana hirtipes and appear to be readily dislodged from the animals, resulting in considerable variation between specimens as the setae regenerate. Also, robust setal counts on the pleotelson and uropods often varied from one side of a specimen to the 
other. These counts showed no correlation with the size of the animal, small specimens occasionally having more setae than large specimens. The male lectotype has 18 robust setae on the pleotelson. Variations in the number of robust setae present, were as follows: on the pleotelson, ranged from 12-19 (average 14, 40\%); on the uropod endopod medial margin, ranged from 4-6 (average 5, 59\%); on the uropod endopod apex 2 were present (or sockets indicated their presence) in all specimens; on the uropod endopod lateral margin, ranged from 5-8 (average 7, 35\%); on the uropod exopod medial margin ranged from 1-4 (average 3, 53\%); on the uropod exopod apex 2 were present (or sockets indicated their presence) in all specimens; on the uropod exopod lateral margin, ranged from 8-14 (average 10, 29\%). The specimens examined from Table Bay (ZMUC CRU160, ZMUC CRU161) all have 5 pleonites clearly visible. Males in ZMUC CRU160 all have two indistinct tubercles dorsally on the surface of pereonite 2, however, these are not discernible in the type material. Some specimens in ZMUC CRU160 also have the pleotelson margins straighter and more angular than in the type material. Hansen (1890) described the specimen ZMUC (CRU161) (20 mm in length) from Table Bay, this specimen has 18 robust setae on the pleotelson and an antennal flagellum with 35 articles but is otherwise indistinguishable from the lectotype of $N$. hirtipes.

Sexual dimorphism. Large males (greater than $24 \mathrm{~mm}$ ) may have two closely spaced, indistinct tubercles, medially on the dorsal surface of pereonite 2 .

Size. Hansen (1890) and Kensley (1978) record lengths of $20 \mathrm{~mm}$. Milne Edwards (1840) states a length of 1 pouce, i.e., $25 \mathrm{~mm}$. The paralectotype female (newly measured) is c. $27 \mathrm{~mm}$. A manca of $10 \mathrm{~mm}$ and a female of $12 \mathrm{~mm}$ were also examined here.

Remarks. Because Natatolana hirtipes is the type species of the genus and, as it shows some variation and may be difficult to separate from other species the male syntype is illustrated, redescribed and designated as a lectotype. The purpose of this is to avoid future taxonomic confusion in applying the generic name and identifying the species. The female syntype becomes a paralectotype.

The type specimens of Natatolana hirtipes match the few features discernible in the brief original description and two illustrations of Milne Edwards (1840). Figure 26 of Milne Edwards is misleading, however, showing the antennal peduncle as longer than the flagellum. This is not the case, the flagellum was probably foreshortened in the original illustration.

Natatolana hirtipes is extremely similar to $N$. rossi in most features, as noted by Chilton (1909). Consistent differences between $N$. hirtipes and $N$. rossi include a smoothly convex interocular furrow (medially produced in $N$. rossi), a angled anterior margin to the eye (convex in $N$. rossi), a convex ventral margin to the cephalon (concave in $N$. rossi) and a slightly more sinuate anterior margin of the basis of pereopod 7 in $N$. hirtipes.

Natatolana hirtipes is also similar to N. matong. The development of the coxal furrows does not reliably separate the two species as suggested by Bruce (1986). The shape of pleonite 4 is, however, consistently different, $N$. hirtipes having a more sinuate posterodorsal margin. The interocular furrow is smoothly convex and the basis of pereopod 7 basis is also broader in $N$. hirtipes.
Distribution and ecology. South Africa: Luderitz to East London. Intertidal to $200 \mathrm{~m}$ depth (Kensley 1978; Bruce 1986). Hansen $(1890,1905)$ assigned earlier records from the Adriatic Sea to Natatolana neglecta and from the Mediterranean Sea to $N$. borealis. The records of $N$. hirtipes by Filhol (1885), also listed by Nierstrasz (1931) and Hurley (1961), from Cook Strait, New Zealand, were considered to be a mis-identification of $N$. rossi by Barnard (1936) who additionally noted that the two species are very similar. Barnard (1936) also recorded a female specimen, $13.5 \mathrm{~mm}$, from the Strait of Hormuz (as Strait of Ormuz), Persian Gulf, and an immature specimen, $8.5 \mathrm{~mm}$, from west of Mangalore, southwest India. He also doubtfully recorded a male specimen of $6 \mathrm{~mm}$ from off Southern Myanmar (Burma). These records have not been included in the distribution reported by Kensley (1978) or Bruce (1986) and the material was not examined in this study.

Vanhöffen (1914) reported specimens from Simonstown that were apparently scavenging, along with ostracods, on fish caught in nets.

\section{Natatolana honu n.sp.}

Figs. 29-30

Type material. Holotype: $\widehat{\jmath}, 11 \mathrm{~mm}$, NIWA 18745. PARATYPES: all off the west coast of the North Island, New Zealand: $\delta$, 4 우 으, manca, NIWA $18746,38^{\circ} 30^{\prime} \mathrm{S} 172^{\circ} 24^{\prime} \mathrm{E}$,

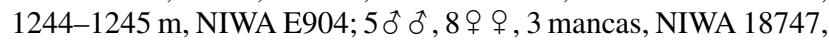
$35^{\circ} 20^{\prime} \mathrm{S} 172^{\circ} 15^{\prime} \mathrm{E}, 1286-1313 \mathrm{~m}$, NIWA E881. - Type locality: off the west coast of the South Island, New Zealand, 42 $23.7^{\circ} \mathrm{S}$ $169^{\circ} 11.8^{\prime} \mathrm{E}$, [anchor-box dredge], sand-silt-clay, $1120 \mathrm{~m}$, [P.K. Probert, 22 Feb. 1982].

Diagnosis. Eyes: vestigial. Interocular furrow: well developed, extending across the cephalon or weakly developed, indistinct and not extending across the cephalon; smoothly convex. Frontal lamina: lateral margins straight, narrowing anteriorly. Antenna: c. $0.36 \times$ as long as body, reaching to posterior of pereonite 3. Coxal plates: furrows variously developed, absent on coxae 2-5, weakly developed on coxae 6-7. Pleonite 4: apex forming a broad acute point. Pleotelson: broad, length $0.98 \times$ basal width; anterodorsal depression absent (there is a slight depression but it is not as distinct and abrupt as the depression found in species such as N. pellucida); anterolateral margins convex; posterolateral margins convex; apex not produced, lateral margins converging smoothly to a point; with 10-14 RS. Pereopod 2: propodus with 1 RS on palm. Pereopod 3: propodus without RS on palm. Pereopod 7: basis narrow, width $0.33 \times$ length; distance between anterior margin and medial carina less than between posterior margin and medial carina; posterior margin with setae on distal half. Penes: present. Pleopod 2 appendix masculina: just shorter than endopod, $0.96 \times$ length of endopod; margins very strongly curved laterally; slender; apex not at angle to adjacent margins, bluntly rounded. Uropods: endopod lateral margin with prominent excision. Exopod short, $0.77 \times$ the length of the endopod.

Additional descriptive characters. Based on holotype. Body: length c. $2.95 \times$ width. Colour translucent white in alcohol. Chromatophores absent. Eyes: with c. 6 ommatidia in horizontal diameter; with 6 ommatidia in vertical diameter; round; without pigment, ommatidia indistinct in alcohol. Frontal lamina: length c. $3.75 \times$ basal width; apex expanded, anterior margin angled. Antennule: peduncular article 1 longer than article 2 ; article 2 with 1 large pappose 


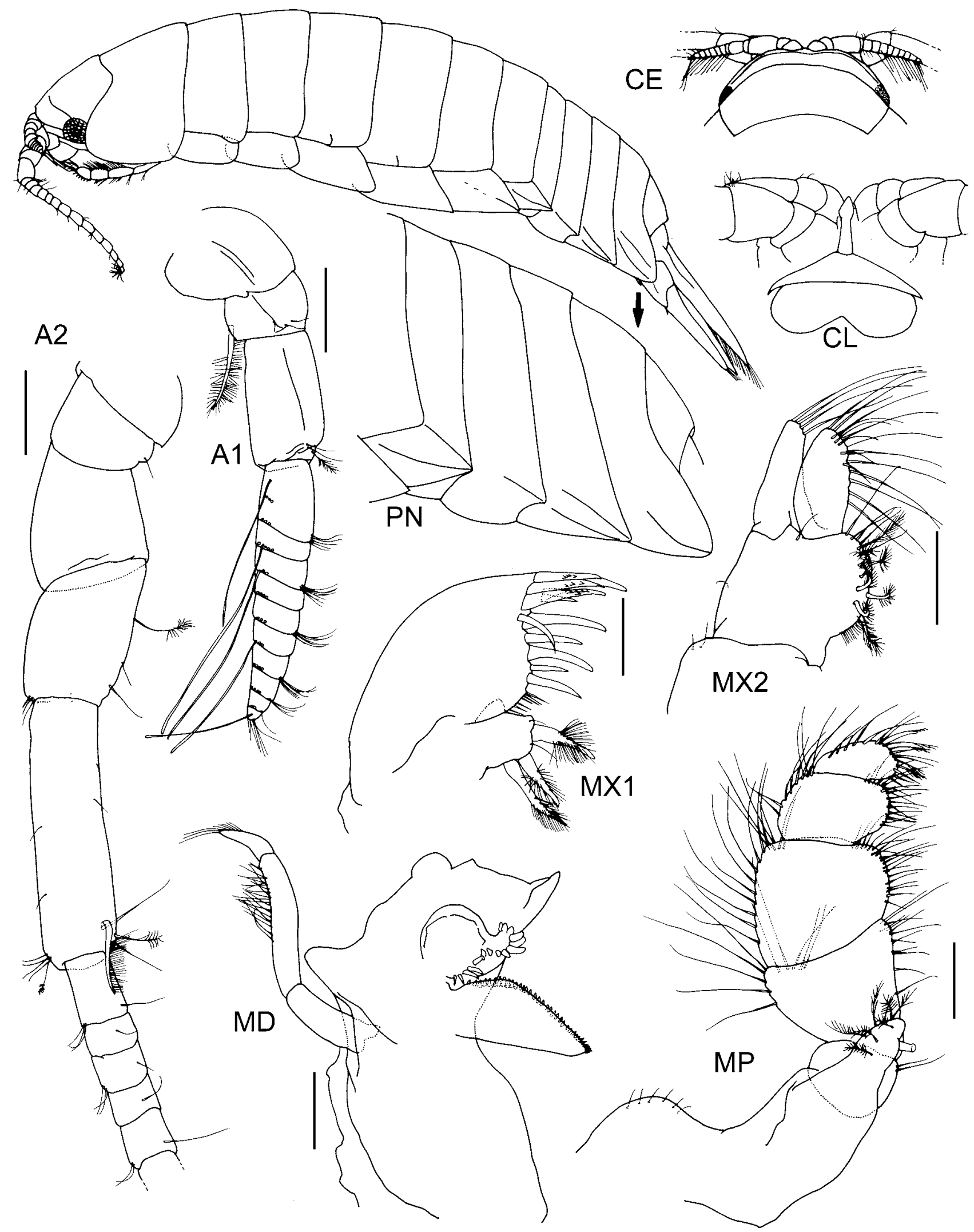

Fig. 29. Natatolana honu, n.sp., holotype. Scales $=0.2 \mathrm{~mm}$.

seta; article 3 very long, subequal to or longer than the combined lengths of articles 1 and 2. Flagellum 10articulate. Antenna: peduncular article 4 with 1 penicillate seta and $2 \mathrm{SS}$ on posterior margin, $3 \mathrm{SS}$ at anterodistal angle; article 5 with 1 pappose, 1 penicillate and $2 \mathrm{SS}$ at posterodistal angle, $4 \mathrm{SS}$ and 1 penicillate seta at anterodistal angle. Flagellum 21-articulate. Mandible: setal row with 15 RS. Maxillule: medial lobe with 3 large robust pappose setae; lateral lobe with 13 RS on distal surface. Maxilla: lateral lobe with 4 SS; medial lobe with 6 SS and 9 PS; middle lobe with 1 medial row of $5 \mathrm{SS}, 1$ lateral row of 11 SS. Maxilliped: endite with 1 coupling hook, 7 PS and 1 


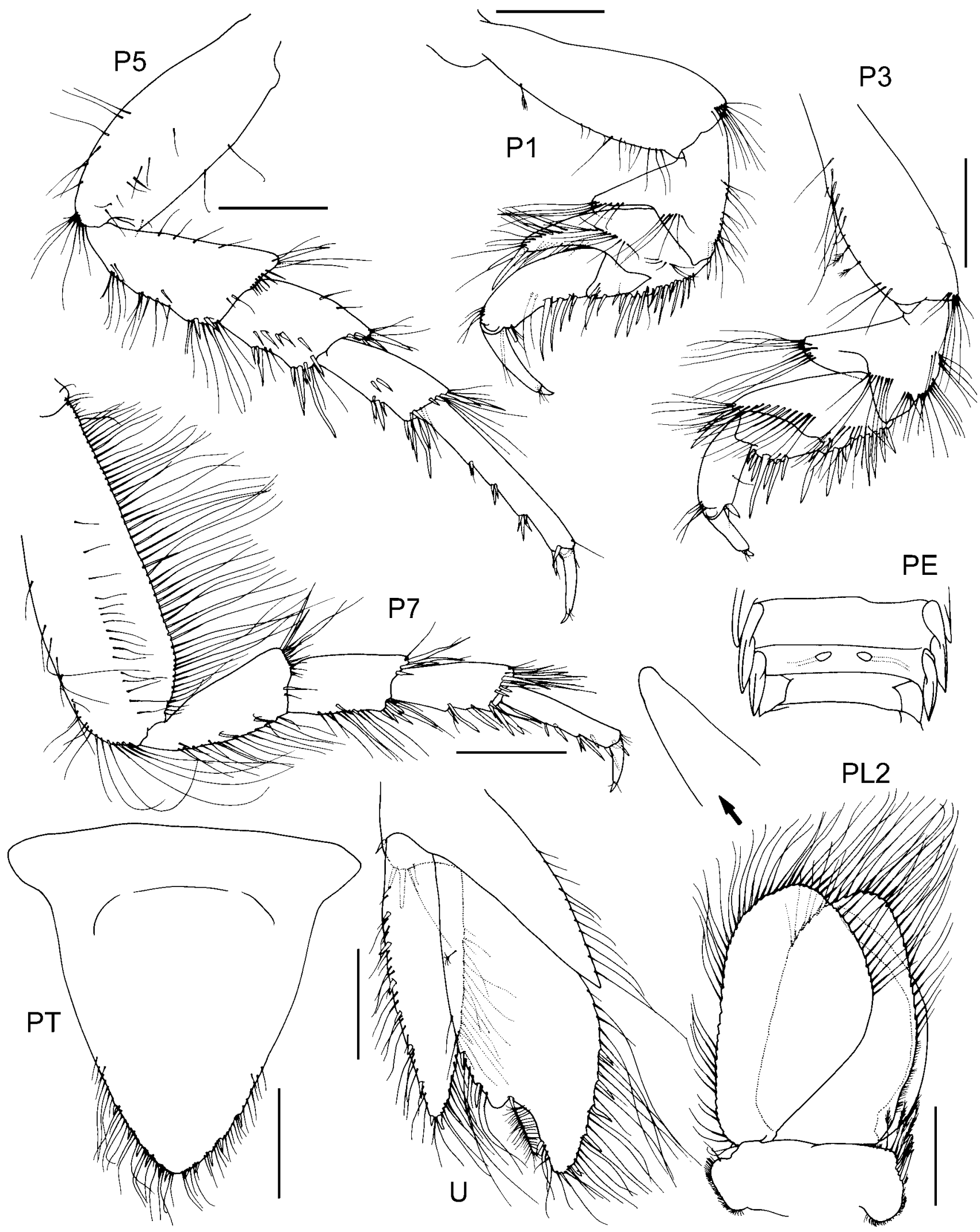

Fig. 30. Natatolana honu, n.sp., holotype. Scales $=0.5 \mathrm{~mm}$.

SS. Pereon: ornamentation absent, all pereonites smooth; pereonite 1 longest, 2-6 subequal, 7 shortest. Coxae: pereonite 1 , coxae $2-3$ with rounded posteroventral corners, coxae 4-7 with increasingly produced, broad, acute posteroventral corners. Pleonite 2: dorsal posterolateral margin clearly projecting posterior to ventral posterolateral margin. Pereopod 7: basis anterior margin straight; medial carina with SS (on distal three quarters); posterior margin convex, SS present. Ischium anterior margin with non-RS absent; posterior margin with 2 RS (submarginal), PS 
present. Merus posterior margin with 1 RS (submarginal), SS present. Carpus posterior margin with 4 RS, SS present. Propodus longer than carpus; posterior margin with $6 \mathrm{RS}$, SS absent. Penes: forming well separated flattened lobes. Pleopod 2 appendix masculina: arising basally. Pleopods 1-5: exopod suture strongly developed on pleopods 3-5; endopod PS on most of margins on pleopods 1-4, absent on pleopod 5. Uropods: endopod lanceolate; medial margin convex, with 5 RS, PS along entire length; apex with 2 RS; lateral margin slightly convex with a prominent lateral excision near apex, with 3 RS, 1 conspicuous penicillate seta in excision, PS on distal third (but absent from proximal part of excision). Exopod medial margin convex, with 3 RS, PS on distal three quarters; apex acute, with 2 RS; lateral margin convex, with $6 \mathrm{RS}$, PS on distal three quarters.

Variation. The holotype has 11 robust setae on the pleotelson. It is difficult to ascertain the usual number of robust setae present on the pleotelson, as these have been rubbed off most of the material available, but it appears to range between 10 and 14. In some specimens, the interocular furrow is indistinct and incomplete.

Size. Adults to $16.5 \mathrm{~mm}$.

Etymology. From the Maori for deep, in reference to the depths the type specimens have been recorded from.

Remarks. Natatolana honu and $N$. variguberna are the only species of Natatolana with a prominent excision near the apex of the uropod endopod lateral margin. Natatolana honu most noticeably differs from $N$. variguberna in having vestigial rather than well-developed eyes, coxal furrows only on the posterior coxae, penes in males, and a greater number of robust setae on the pleotelson margins.

Distribution. New Zealand: west coast of North and South islands. At depths of 1120-1313 m.

\section{Natatolana imicola (Dollfus, 1903)}

Synonymy in Keable \& Bruce, 1997: 688, figs. 13-15.

Type material of $\boldsymbol{N}$. imicola. Syntypes: all IOM; unknown number of specimens, Station 209; 7 ô $\widehat{o}, 11$ ㅇ $ᄋ, 360257$, Station 228 (cited as 238); ㅇ, 360252 , Station 553; 2 के के (mature), male (immature), 3 우, 36 0256, Station 846. All examined except those from station 209. - Type locality of $N$. imicola: Atlantique, $39^{\circ} 18.08^{\prime} \mathrm{N} 33^{\circ} 32.25^{\prime} \mathrm{W}, 1372 \mathrm{~m}$, [Campagnes de l'Hirondelle et de la Princesse Alice Station 209]; Atlantique, $38^{\circ} 22.38^{\prime} \mathrm{N}$ $30^{\circ} 42.78^{\prime} \mathrm{W}, 1924 \mathrm{~m}$, [Campagnes de l'Hirondelle et de la Princesse Alice Station 228 (cited as 238)]; Atlantique, $37^{\circ} 42.67^{\prime} \mathrm{N}$ $27^{\circ} 25.5^{\prime} \mathrm{W}, 1385 \mathrm{~m}$, [Campagnes de l'Hirondelle et de la Princesse Alice Station 553]; Atlantique, $30^{\circ} 01.5^{\prime} \mathrm{N} 27^{\circ} 46^{\prime} \mathrm{W}, 1638$ $\mathrm{m}$, [Campagnes de l'Hirondelle et de la Princesse Alice Station 846].

Type material of $\boldsymbol{N}$. schmidti. Syntypes: ovigerous 우 13.5 $\mathrm{mm}$, male $11 \mathrm{~mm}$, manca $7 \mathrm{~mm}$, ZMUC CRU150, Ingolf $\mathrm{stn} 25$; +, $12.5 \mathrm{~mm}$, manca $4.75 \mathrm{~mm}$, ZMUC CRU151, Thor stn 99. All examined. - Type locality of N. schmidti: Davis Strait, $63^{\circ} 30^{\prime} \mathrm{N}$ $54^{\circ} 25^{\prime} \mathrm{W}, 1064 \mathrm{~m}$, [Danish Ingolf Expedition Station 25]; west of the most southern of the Färoe Islands, $61^{\circ} 15^{\prime} \mathrm{N} 9^{\circ} 35^{\prime} \mathrm{W}, 872-$ $970 \mathrm{~m}$, [Thor $\operatorname{stn}$ 99].

Material examined. Listed by Keable \& Bruce (1997).

Diagnosis. Eyes: vestigial, or absent (there is a very slight indication of ommatidia, possibly these become less distinct with preservation). Interocular furrow: moderately developed, distinct but not extending across the cephalon. Frontal lamina: lateral margins straight, narrowing posteriorly. Antenna: c. $0.37 \times$ as long as body, reaching to between approximately half way along pereonite 3 and posterior of pereonite 4. Coxal plates: furrows moderately developed, on all coxae. Pleonite 4: apex slightly rounded. Pleotelson: broad, length $0.9 \times$ basal width; anterodorsal depression absent (although there is a slight depression it is not equivalent to the distinct and abrupt depression found in species such as $N$. pellucida); anterolateral margins convex; posterolateral margins convex; apex not produced, lateral margins converging smoothly to a point; with 8-12 RS. Pereopod 2: propodus with 2 RS on palm. Pereopod 3: ischium anterodistal angle produced, but not as produced as on pereopods 1 and 2, similar to pereopod 4. Propodus with 2 RS on palm. Pereopod 7: basis narrow, width $0.4 \times$ length; distance between anterior margin and medial carina less than between posterior margin and medial carina; posterior margin with setae completely absent along entire length. Penes: present. Pleopod 2 appendix masculina: extending subequal with tip of endopod, $1 \times$ length of endopod; margins very strongly curved laterally; broad; apex not at angle to adjacent margins, club shaped with a lateral notch. Uropods: exopod slightly shorter than endopod, $0.82 \times$ the length of the endopod.

Variation. The development of penes and the appendix masculina varies in male specimens, with the appendix masculina relatively straight and the vasa deferentia opening flush to the surface of the sternite. This variation does not appear to be correlated with size of the individual although it probably represents changes associated with maturity (Keable \& Bruce, 1997).

Size. Smallest manca $4.75 \mathrm{~mm}$ and largest specimen (ovigerous female) $13.5 \mathrm{~mm}$.

Remarks. Natatolana imicola was originally described as a subspecies of $N$. neglecta, Keable \& Bruce (1997) redescribed it, elevated it to species rank and synonymized N. schmidti with it.

Characters that distinguish $N$. imicola from similar species are noted in the remarks for $N$. rekohu.

Distribution. northeastern Atlantic, Davis Strait and Färoe Islands, south to $30^{\circ} \mathrm{N}$, westwards to $54^{\circ} \mathrm{W}$. At depths of 872-2450 m.

\section{Natatolana insignis Hobbins \& Jones, 1993}

Natatolana insignis Hobbins \& Jones, 1993: 124, figs. 7-10.Brusca et al., 1995: 80.-Kensley, 2001: 230.

Cirolana albicaudata.-Barnard, 1936: 152, fig. 2a-c [misidentification, not Natatolana albicaudata (Stebbing, 1900)].

Type material. Holotype: $\widehat{\sigma}$, SIF 19041. Paratypes: $q$, SIF 19042; 7 ㅇ 9 SIF 19043. None examined. • Type locality: Central Red Sea, $21^{\circ} 28.97^{\prime} \mathrm{N} 38^{\circ} 15.55^{\prime} \mathrm{E}, 740-785$ m, [R. V. VALDIVIA, Station Va22-111 ST-235, 12 April 1979].

Material examined. India: 18, ZMUC CRU105, off Tranquebar, $11^{\circ} 6^{\prime} \mathrm{N} 80^{\circ} 5^{\prime} \mathrm{E}$, coarse sand and mud, $148 \mathrm{~m}$, Galathea stn 288, 21 Apr. 1951. Thailand: ${ }^{\star}, \mathrm{PMBC}$, Phuket Bay, c. $7^{\circ} 52^{\prime} \mathrm{N} 98^{\circ} 22^{\prime} \mathrm{E}, 10$ Jul. 1981.

Diagnosis. Interocular furrow: well developed, extending across the cephalon; smoothly convex. Frontal lamina: 
lateral margins medially constricted. Antenna: c. $0.42 \times$ as long as body, reaching to approximately half way along pereonite 4. Flagellum digitate processes present in males. Coxal plates: furrows moderately developed, on all coxae (although only shown on coxae 4-7 in original description). Pleonite 4: apex forming a broad acute point. Pleotelson: broad, length $0.79 \times$ basal width; anterodorsal depression absent (although a depression is apparent it is not equivalent to the distinct and abrupt depression found in species such as $N$. pellucida); anterolateral margins convex; posterolateral margins broadly rounded; lateral margins converging smoothly to a point; with 6-8 RS (8 in description but only 6 figured, 8 in material examined). Pereopod 2: propodus with $2 \mathrm{RS}$ on palm. Pereopod 3: propodus with $1 \mathrm{RS}$ on palm. Pereopod 7: basis broad, width $0.54 \times$ length; distance between anterior margin and medial carina less than between posterior margin and medial carina; posterior margin with setae on proximal threequarters. Penes: absent. Pleopod 2 appendix masculina: just shorter than endopod, $0.75 \times$ length of endopod; margins very slightly curved laterally; slender; apex not at angle to adjacent margins, bluntly rounded. Uropods: exopod short, $0.63-0.75 \times$ the length of the endopod.

Sexual dimorphism. Females lack the digitate processes on the articles of the antennal flagellum.

Size. Adults to c. $10 \mathrm{~mm}$.

Remarks. The presence of digitate processes on the articles of the antennal flagella in males of Natatolana insignis distinguish this species from all others in the genus. The shape of the uropod endopod is also highly distinctive, with a broadly rounded medial margin and distinct notch on the lateral margin.

Distribution and ecology. Red Sea; Arabian Sea; Gulf of Oman; India: Bombay and Tranquebar; Thailand: Phuket. At depths of 148-1825 m. Scavenger.

\section{Natatolana intermedia (Vanhöffen, 1914)}

Cirolana intermedia Vanhöffen, 1914: 500, fig. 37.-Tattersall, 1921: 205.-Hale, 1937: 17.-1952: 27.-Kussakin, 1967: 224. Natatolana intermedia.-Bruce, 1981: 958.-1986: 222.-Brandt, 1988: 113, figs. 51-55.-Brusca et al., 1995: 80.

Type material. Lectotype designated by Brandt (1988): $\widehat{\jmath}, 15.5$ $\mathrm{mm}$, originally ZMG but now in SIF ZMG 260 (not examined). Paralectotypes: o, $17 \mathrm{~mm}, 4$ ㅇ $, 13 \mathrm{~mm}, 14 \mathrm{~mm}, 15 \mathrm{~mm}, 16$ $\mathrm{mm}$, SIF ZMG 261 (not examined). Also, $2 \hat{\jmath} \widehat{0}$, ZMUC CRU158; $2 q$ \& , ZMUC CRU159; apparently part of original syntype series from the type locality donated by the ZMB in 1926 (examined). Other possible paralectotypes are ZMB 17618 (male and $2 q$ q $)$ ZMB 17620 (male and $6 \%$ o ); all from type locality (Brandt, 1988) (not examined). $\cdot$ Type locality: off Gauss Station, Posadowsky

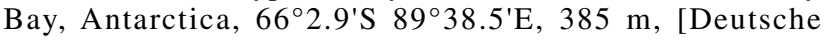
Sudpolarexpedition 1901-1903].

Diagnosis. Eyes: well developed; elongate, length c. $2 \times$ height. Interocular furrow: weakly developed, indistinct and not extending across the cephalon. Frontal lamina: lateral margins straight, narrowing anteriorly. Antenna: c. 0.33$0.4 \times$ as long as body, reaching to between the posterior of pereonite 3 and 4. Coxal plates: furrows strongly developed, on all coxae. Pleonite 4: posterodorsal margin strongly concave proximal to meeting posteroventral margin at apex; apex forming a narrow acute point. Pleotelson: broad, length $0.92 \times$ basal width; anterodorsal depression absent (there is an indistinct depression but this is not as distinct and abrupt as in species such as $N$. pellucida); anterolateral margins convex; posterolateral margins convex; apex produced into a small point; with 10-16 RS. Pereopod 2: propodus with 3-4 RS on palm. Pereopod 3: propodus with 3-6 RS on palm. Pereopod 7: basis narrow, width $0.45 \times$ length; distance between anterior margin and medial carina less than between posterior margin and medial carina; posterior margin with setae along entire length. Penes: present. Pleopod 2 appendix masculina: extending subequal with tip of endopod, $1 \times$ length of endopod; margins very strongly curved laterally; slender; apex not at angle to adjacent margins, bluntly rounded. Uropods: exopod slightly shorter than endopod, $0.81 \times$ the length of the endopod.

Size. Females to $23 \mathrm{~mm}$, males to $24 \mathrm{~mm}$.

Remarks. Natatolana intermedia is most similar to N. nitida but has a rounded anteroventral corner on coxa 2 , a pleotelson with convex posterolateral margins and a slender and strongly curved appendix masculina. Natatolana obtusata is also similar but has pleonite 4 with a sinuate posterodorsal margin.

Distribution. Antarctica: Gauss Station; McMurdo Sound; Banzare Coast; Kemp Coast; Davis Sea; Enderby Land; Lars Christensen Coast; Antarctic Peninsula; Weddell Sea (Brandt, 1988). At depths of 163-560 m (Kussakin, 1967).

\section{Natatolana japonensis (Richardson, 1904)}

Synonymy in Keable, 1996a: 8, figs. 1-3. Additional listings and records of this species are those of Nierstrasz (1931, p. 158), Brusca et al. (1995, p. 80), Saito et al. (2000, p. 64), Yu \& Li (2001, p. 263), Nunomura (2004, p. 356).

Type material of $\boldsymbol{N}$. japonensis. Holotype: $₫, 18 \mathrm{~mm}$, USNM 29085 (examined). - Type locality of $N$. japonensis: Yokkaichi Light, Japan, [c. $35^{\circ} 02^{\prime} \mathrm{N} 136^{\circ} 40^{\prime} \mathrm{E}$ ].

Type material of $\boldsymbol{N}$. miyamotoi. Holotype: $\widehat{\alpha}$, TSM TOYA Cr10793 (not examined). Allotype: o, TSM TOYA Cr-10794 (not examined). Paratypes: 2, TSM TOYA Cr-10795-10796 (examined). - Type locality of N. miyamotoi: Off Iwase, Toyama City, Japan [36 $43.6^{\prime} \mathrm{N} 137^{\circ} 14.7^{\prime} \mathrm{E}$ ], $20 \mathrm{~m}$.

\section{Material examined. Listed by Keable (1996a).}

Diagnosis. Interocular furrow: well developed, forming a ridge that extends across the cephalon; smoothly convex. Frontal lamina: lateral margins medially constricted. Antenna: c. 0.3-0.46× as long as body, reaching to between the posterior of pereonite 3 and 4. Coxal plates: furrows variously developed, complete but faint on coxae 2-5 and 7 , very faint and incomplete or absent on coxa 6. Pleonite 4: apex forming a broad acute point. Pleotelson: broad, length $0.81-0.85 \times$ basal width; anterodorsal depression absent; anterolateral margins almost straight and angling posteriorly toward the midline; posterolateral margins straight, markedly angled to anterolateral margins and meeting at an acute angle or convex; apex not produced, lateral margins converging smoothly to a point; with 10-12 RS. Pereopod 2: propodus with 1 RS on palm. Pereopod 3: ischium anterodistal angle produced, but not as produced as on pereopods 1 and 2, similar to pereopod 4. Propodus with 1 RS on palm (and apparently a socket for another 1). Pereopod 7: basis of medium breadth, or broad, width 0.5 $0.56 \times$ length; distance between anterior margin and medial 
carina less than between posterior margin and medial carina; posterior margin with setae on proximal quarter. Penes: absent. Pleopod 2 appendix masculina: extending beyond tip of endopod, $1.04 \times$ length of endopod; margins very slightly curved laterally; slender; apex not at angle to adjacent margins, bluntly rounded. Uropods: exopod subequal to endopod, $0.93 \times$ the length of the endopod.

Variation. The posterior of the pleotelson appears to become broader as individuals increase in size. Of the material examined one specimen from off Iwase (TSM Cr 10796), $14 \mathrm{~mm}$ long, has the posterior margins of the pleotelson less distinctly angled to the anterolateral margins and has a more acute apex than in the holotype of $N$. japonensis. Another specimen from the same locality (TSM $\mathrm{Cr}$ 10795) is, however, $23 \mathrm{~mm}$ long and has a pleotelson identical in shape to that of $N$. japonensis. The holotype (USNM 29085 ) is the only specimen examined that has 10 robust setae on the pleotelson, other specimens have either 11 or 12 .

Size. Adult specimens examined range from $12 \mathrm{~mm}$ to $26 \mathrm{~mm}$.

Remarks. Natatolana japonensis was redescribed by Keable (1996). It can most readily be distinguished from other species of Natatolana by the following characters: size and shape of the eyes, length of the antenna, shape of the lateral margins of pleonite 4, shape, size and setation of the pleotelson and uropods and absence of penes.

Distribution. Japan, Korea and China. At depths of 6-439 m (Iwasa, 1965; Nunomura, 2004).

\section{Natatolana kahiba Bruce, 1986}

Natatolana kahiba Bruce, 1986: 111, fig. 76.-Springthorpe \& Lowry, 1994: 48.-Brusca et al., 1995: 80.-Bruce et al., 2002: 150.

Type material. Holotype: $\uparrow, 8.2 \mathrm{~mm}$, ZMUC CRU1693. Paratype: AM P32175. All examined. - Type locality: $5 \mathrm{~km}$ south of North Solitary Island [originally cited as off Cape Byron, corrected by Springthorpe \& Lowry (1994)], NSW, Australia, $29^{\circ} 57^{\prime} \mathrm{S} 153^{\circ} 24^{\prime} \mathrm{E}, 75 \mathrm{~m}$.

Material examined. New South Wales: 37, AM P47283, east of Coffs Harbour, $30^{\circ} 17.49^{\prime} \mathrm{S} 153^{\circ} 13.90^{\prime} \mathrm{E}, 45.4 \mathrm{~m}, 11-12$ Aug. 1993, SEAS NSW-873; 7, AM P47284, off Rosherville Beach, Port Jackson, $33^{\circ} 48.9^{\prime} \mathrm{S} 151^{\circ} 15.0^{\prime} \mathrm{E}$, baited trap, $10 \mathrm{~m}$, S. Keable \& J. Lowry, 8-9 May 1988, stn 10. Tasmania: many, AM P47285, mouth of Fortescue Bay, $43^{\circ} 07.77$ 'S $145^{\circ} 59.47^{\prime} \mathrm{E}$, baited trap, 50 m, 17-18 April 1993, SEAS TAS-368.

Diagnosis. Interocular furrow: moderately developed, distinct but not extending across the cephalon. Frontal lamina: lateral margins medially constricted. Antenna: c. $0.2-0.25 \times$ as long as body, reaching to between the posterior of pereonites 1-2 (holotype pereonite 1, paratype pereonite 2). Coxal plates: furrows moderately developed, on all coxae. Pleonite 4: apex rounded. Pleotelson: broad, length $0.9 \times$ basal width; anterodorsal depression absent; anterolateral margins convex; posterolateral margins convex; apex produced into a small point; with 4 RS. Pereopods 2-3: propodus without RS on palm. Pereopod 7: basis broad, width $0.66 \times$ length; distance between anterior margin and medial carina greater than between posterior margin and medial carina; posterior margin with setae along entire length. Penes: absent. Pleopod 2 appendix masculina: extending subequal with tip of endopod, $0.94 \times$ length of endopod; margins straight or very slightly curved laterally; slender; apex recurved, bent slightly medially, bluntly rounded. Uropods: exopod short, $0.71 \times$ the length of the endopod.

Variation. The antennal flagellum of the holotype and paratype has 12 and 15 articles, respectively. In material examined from Coffs Harbour (AM P47283) near the type locality and in Port Jackson (AM P47284) there are up to 18 articles in the antennal flagellum.

Size. Adults to c. $25 \mathrm{~mm}$.

Remarks. This is the first record of a male specimen of Natatolana kahiba. This species is most similar to N. bulba, $N$. arrama and $N$. woodjonesi. It can be most easily separated from these species by the presence of two to three robust setae on the lateral margin of the uropod exopod.

Bruce (1986, p. 111) described small spines (= robust setae) on the palm of the propodus of pereopods 2 and 3 of this species. Absence of these robust setae is, however, regarded by Bruce (1986) as a diagnostic character of species in the Natatolana woodjonesi group, into which he places $N$. kahiba, and in his key to species $N$. kahiba can only be reached if it is assumed that these robust setae are absent. Examination of these setae in N. kahiba indicates they are minute and easily overlooked. They do not appear to be homologous to the robust setae found in this position in other species because in N. kahiba they are slender and flexible and appear to have their base on the lateral margin of the pereopod rather than the palm itself. This observation is consistent with the placement of $N$. kahiba in the $N$. woodjonesi group and key to species by Bruce (1986).

Distribution and ecology. Australia: northern and central New South Wales; Tasmania. At depths of 10-75 m. Scavenger.

\section{Natatolana karkarook Bruce, 1986}

Natatolana karkarook Bruce, 1986: 69, figs. 44, 45.Springthorpe \& Lowry, 1994: 49.-Brusca et al., 1995: 80.Bruce et al., 2002: 151.

Type material. Holotype: + , 20.8 mm, AM P30335. Paratype: + , AM P30336. All examined. - Type locality: Cairns Reef, Cooktown, Queensland, Australia, $15^{\circ} 42^{\prime} \mathrm{S} 145^{\circ} 33^{\prime} \mathrm{E}$.

Material examined. Northern Territory: $\widehat{\delta}$, NTM Cr009861, Gove, $12^{\circ} 12^{\prime} \mathrm{S} 136^{\circ} 43^{\prime} \mathrm{E}, 0$ m, R. Hanley et al., 20 Nov. 1991, RH91115. Queensland: manca, QM W18886, Gulf of Carpentaria, $15^{\circ} 57^{\prime} \mathrm{S}$ 138 41.8'E, grab, 25 m, CSIRO, 11 Dec. 1990.

Diagnosis. Interocular furrow: weakly developed, indistinct and not extending across the cephalon. Frontal lamina: lateral margins straight, parallel. Labrum: with acute laminar projection. Antenna: c. $0.16-0.22 \times$ as long as body, reaching to between the posterior of pereonite 1 and the posterior of pereonite 2. Coxal plates: furrows variously developed, incomplete and on coxae 2-3 only. Pleonite 4: apex rounded. Pleotelson: broad, length $0.76 \times$ basal width; anterodorsal depression absent; anterolateral margins almost straight and angling posteriorly toward the midline; posterolateral margins straight, markedly angled to anterolateral margins and meeting at an obtuse angle or convex; apex not produced, lateral margins converging smoothly to a point; with 8-12 RS. Pereopod 2: propodus with $1 \mathrm{RS}$ on palm. Pereopod 3: propodus without RS on palm. Pereopods 57: propodus short and robust on each pereopod. Pereopod 7: basis broad, width $0.55 \times$ length; distance between anterior 
margin and medial carina greater than between posterior margin and medial carina; posterior margin with setae on proximal half. Penes: absent, vasa deferentia opening flush to surface of sternite 7 (area around openings slightly raised but not forming flexible processes). Pleopod 2 appendix masculina: extending subequal with tip of endopod, $0.94 \times$ length of endopod; slender; margins bent slightly medially; apex not at angle to adjacent margins, bluntly rounded. Uropods: exopod slightly shorter than endopod, $0.85 \times$ the length of the endopod.

Variation. The holotype has 12 robust setae on the pleotelson margin, the paratype has nine and the male from Gove (NTM Cr009861) has eight.

Size. Adults to $20.8 \mathrm{~mm}$.

Remarks. This is the first record of a male specimen of Natatolana karkarook. This species is unique in having an acute laminar projection on the labrum, the shape of the pleotelson coupled with the relatively short antennae are also distinctive and the mouthparts are unusual (as discussed in remarks for $N$. buzwilsoni).

Distribution. Australia: Gove, Northern Territory; Gulf of Carpentaria; Cooktown, Queensland. Intertidal to $25 \mathrm{~m}$ depth.

\section{Natatolana laewilla Bruce, 1986}

Natatolana laewilla Bruce, 1986: 85, figs. 56, 57.-Brusca et al., 1995: 80.-Bruce et al., 2002: 151.

Natatolana leawilla.-Springthorpe \& Lowry, 1994: 51 [lapsus].

Type material. Holotype: + , AM P33551. Paratypes: AM P33550, P33552. All examined. - Type locality: east of Port

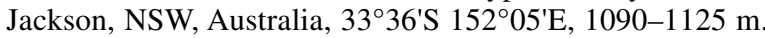

Material examined. Queensland: series from off Flynn Reef, 16³7.81'S 146²3.08'E, 1000m, 6-8 Jun. 1993: 1, AM P47300, SEAS QLD-932; 6, AM P47301, SEAS QLD-950. New South Wales: series from northeast of Coffs Harbour, 1000m, 11-13 Aug. 1993; 15, AM P47302, $30^{\circ} 10.88^{\prime} \mathrm{S} 153^{\circ} 32.21^{\prime} \mathrm{E}, \mathrm{SEAS}$ NSW-877; 7, AM P47303, 30¹0.94'S 15332.27'E, SEAS NSW862. Tasmania: 8 , AM P47304, east of Fortescue Bay, $43^{\circ} 08.96$ 'S $145^{\circ} 15.36 ' \mathrm{E}, 1000 \mathrm{~m}, 8-9$ April 1994, SEAS TAS-403.

Diagnosis. Eyes: vestigial. Interocular furrow: moderately developed, distinct but not extending across the cephalon. Frontal lamina: lateral margins sinuate. Antenna: c. $0.35 \times$ as long as body, reaching to posterior of pereonite 3. Coxal plates: furrows variously developed or completely absent on all coxae, if present may be weakly developed on all or only some coxae. Pleonite 4: apex forming a broad acute point. Pleotelson: broad, length $0.81 \times$ basal width; anterodorsal depression present; anterolateral margins convex; posterolateral margins convex; apex not produced, lateral margins converging smoothly to a point; with $10 \mathrm{RS}$. Pereopods 1-6: males with conspicuous elongated RS subequal to propodus on the merus of pereopods $1-3$ and extending from the carpus to dactylus of pereopods 4-6. Pereopod 2: propodus with $0-1 \mathrm{RS}$ on palm (the holotype has one robust seta on one side, in the other material examined these setae may be present or absent). Pereopod 3: propodus without RS on palm. Pereopod 7: basis narrow, width $0.46 \times$ length; distance between anterior margin and medial carina less than between posterior margin and medial carina; posterior margin with setae along entire length. Penes: present. Pleopod 2 appendix masculina: extending subequal with tip of endopod; slender; margins strongly or very strongly curved laterally; apex not at angle to adjacent margins, bluntly rounded. Uropods: exopod slightly shorter than endopod, $0.82 \times$ the length of the endopod.

Variation. Indistinct to well-developed coxal furrows are apparent on all coxae in some type material and the material examined from Queensland. The holotype and some material examined from Queensland has a robust seta on the propodal palm of pereopod 2. Conspicuously elongated robust setae were only present on the merus of pereopods 1-3 and on the carpus of pereopods 4-6 of adult males from Queensland. None of the male specimens in the non-type material examined had the appendix masculina as strongly curved as in the type material.

Sexual dimorphism. Females lack the conspicuously elongated robust setae that may be present on the merus of pereopods 1-3 and on the carpus of pereopods 4-6 of adult males.

Size. In type material females to $9.5 \mathrm{~mm}$, males to $7.5 \mathrm{~mm}$. Non-type material to c. $15 \mathrm{~mm}$.

Remarks. Natatolana laewilla can be separated from all other species in the genus by the reduced eyes and the presence of a distinct dorsal depression on the pleotelson.

Distribution and ecology. Australia: Cairns, Queensland to Tasmania. At depths of 880-1125 m. Scavenger.

\section{Natatolana lilliput n.sp.}

Figs. 31-32

Type material. HolotyPe: $\widehat{\jmath}, 12 \mathrm{~mm}$, AM P47237. PARATYPE: ơ, TM. Type locality: about $0.5 \mathrm{~km}$ east of shore, Garretts Bight, Tasmania, Australia, $43^{\circ} 22.2^{\prime} \mathrm{S} 147^{\circ} 3.6^{\prime} \mathrm{E}$, [baited trap], $25 \mathrm{~m}$, [J.K. Lowry \& S.J. Keable, 20-21 April 1991, TAS-228].

Additional material. Tasmania: 32, AM P47238, about $50 \mathrm{~m}$ off

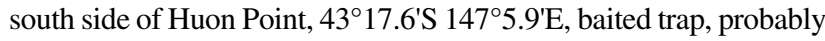
sandy bottom, 13 m, J.K. Lowry \& S.J. Keable, 18-19 April 1991, TAS-188; 7, AM P47239, in the middle of the cove on the south side of Huon Point, $43^{\circ} 17.8^{\prime} \mathrm{S} 147^{\circ} 5.2^{\prime} \mathrm{E}$, baited trap, probably muddy substrate, 18 m, J.K. Lowry \& S.J. Keable, 18-19 April 1991, TAS191; 1, AM P47240, in small cove just north of Esperance Point, $43^{\circ} 19.5^{\prime} \mathrm{S} 147^{\circ} 4.1^{\prime} \mathrm{E}$, baited trap, probably rocky substrate, $3 \mathrm{~m}, \mathrm{~J} . \mathrm{K}$. Lowry \& S.J. Keable, 18-19 April 1991, TAS-196.

Diagnosis. Interocular furrow: well developed, extending across the cephalon; smoothly convex. Frontal lamina: lateral margins medially constricted. Antenna: c. $0.17 \times$ as long as body, reaching to approximately one third of the way along pereonite 2. Coxal plates: furrows strongly developed, on all coxae. Pleonite 4: apex rounded. Pleotelson: broad, length $0.89 \times$ basal width; anterodorsal depression absent; anterolateral margins convex; posterolateral margins convex; apex produced into a small point; with 4-6 RS. Pereopods 2-3: propodus without RS on palm. Pereopods 5-7: propodus short and robust on each pereopod. Pereopod 7: basis broad, width $0.71 \times$ length; distance between anterior margin and medial carina greater than between posterior margin and medial carina; posterior margin with setae on proximal two-thirds. Penes: absent. Pleopod 2 appendix masculina: just shorter than endopod, $0.94 \times$ length of endopod; margins bent slightly medially; slender; apex not at angle to adjacent margins, bluntly rounded. Uropods: exopod short, $0.76 \times$ the length of the endopod. 


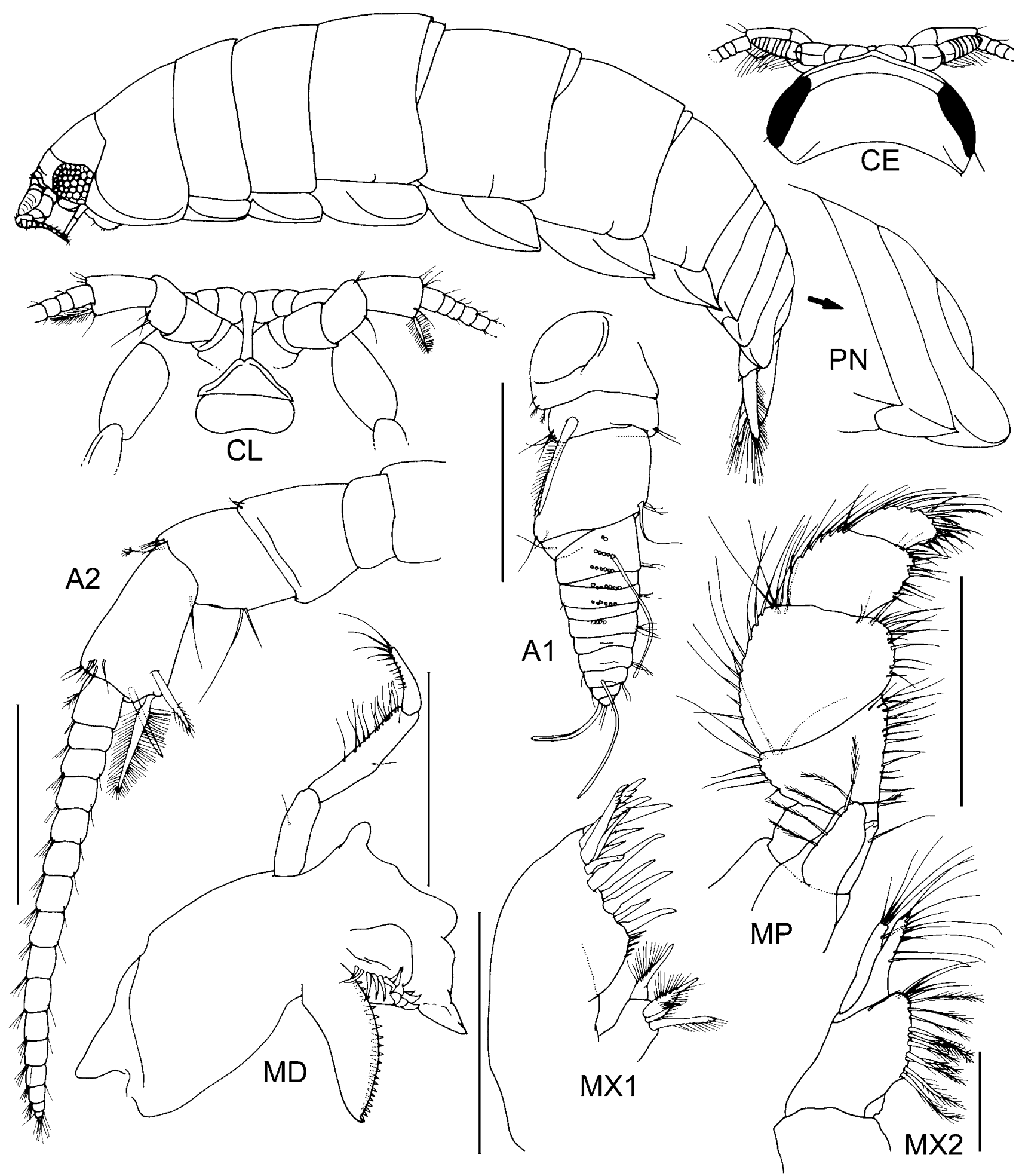

Fig. 31. Natatolana lilliput $\mathrm{n} . \mathrm{sp}$, , holotype. Scales $=0.5 \mathrm{~mm}$, except MX2 $=0.2 \mathrm{~mm}$.

Additional descriptive characters. Based on holotype. Body: length c. $4 \times$ width. Colour cream/tan in alcohol. Chromatophores absent. Eyes: with 8 ommatidia in horizontal diameter; with 7 ommatidia in vertical diameter; round with upper margin flat; colour tan in alcohol. Frontal lamina: length c. $5 \times$ basal width; apex expanded, anterior margin rounded. Antennule: peduncular article 1 longer than article 2; article 2 with 1 large pappose seta; article 3 long, larger than article 1 or 2 but shorter than their combined lengths. Flagellum 10-articulate. Antenna: peduncular article 4 with 2 SS medially on posterolateral margin, $1 \mathrm{SS}$ at posterodistal angle, $4 \mathrm{SS}$ and 1 penicillate seta at anterodistal angle; article 5 with 2 conspicuous pappose setae and $1 \mathrm{SS}$ at posterodistal angle, $5 \mathrm{SS}$ and 1 penicillate seta at anterodistal angle. Flagellum 17-articulate. Mandible: setal row with 13 RS. Maxillule: medial lobe with 3 large and 1 smaller robust pappose setae (left side) or with 3 large robust pappose setae (right side); lateral lobe with $13 \mathrm{RS}$ on distal surface. Maxilla: lateral lobe with $5 \mathrm{SS}$; medial lobe with $6 \mathrm{SS}$ and $10 \mathrm{PS}$; middle lobe with $10 \mathrm{SS}$. 


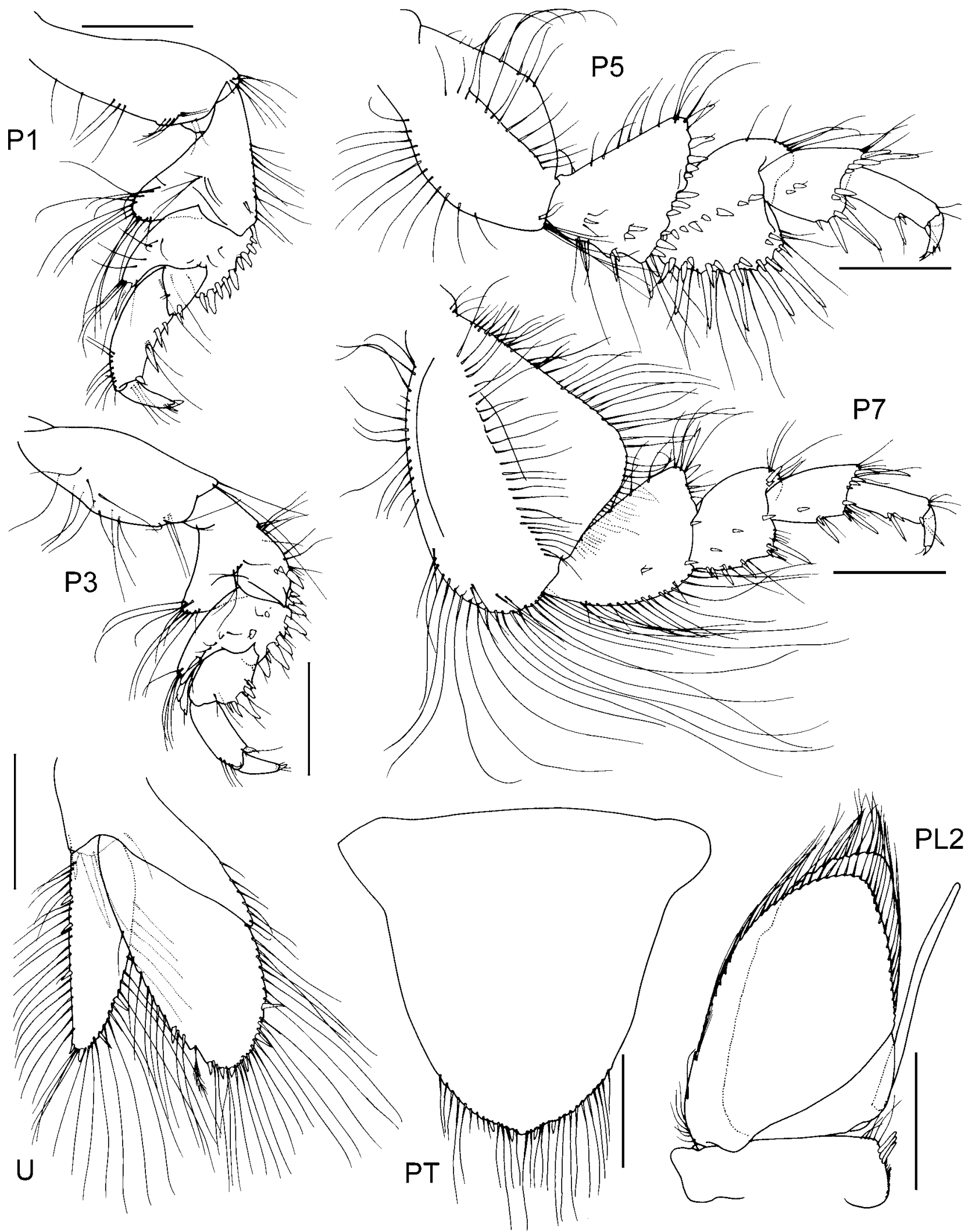

Fig. 32. Natatolana lilliput n.sp., holotype. Scales $=0.5 \mathrm{~mm}$.

Maxilliped: endite with 1 coupling hook, and 6 PS. Pereon: ornamentation consists of 1 strongly developed furrow on lateral margin of pereonite 1 and 1 short, medial furrow on lateral margins of pereonites 4-7; pereonites 4-6 subequal and longer than 1 and 7 which are subequal and longer than 2-3. Coxae: pereonite 1, coxae 2-4 with rounded posteroventral corners, coxae 5-7 with increasingly produced, broad, acute posteroventral corners. Pleonite 2: dorsal posterolateral margin subequal with ventral posterolateral margin. Pereopod 7: basis anterior margin slightly convex; medial carina with PS along entire length; posterior margin convex, PS present. Ischium anterior margin 
with SS; posterior margin without RS (1 submarginally), PS present. Merus posterior margin with $6 \mathrm{RS}, \mathrm{SS}$ present. Carpus posterior margin with $2 \mathrm{RS}$ (and 1 submarginally), $1 \mathrm{SS}$. Propodus subequal to carpus; posterior margin with $3 \mathrm{RS}, \mathrm{SS}$ absent. Pleopod 2 appendix masculina: arising sub-basally. Pleopods 1-5: exopod suture strongly developed on pleopods 3-5; endopod PS on most of margins on pleopods 1-4, absent on pleopod 5. Uropods: endopod lanceolate; medial margin convex, with 3 RS, PS along entire length; apex with 2 RS; lateral margin slightly convex, with 2 RS and 1 penicillate seta, PS on distal two-thirds. Exopod medial margin convex, with 2 RS, PS on distal three-quarters; apex acute, with 2 $\mathrm{RS}$; lateral margin straight, with $3 \mathrm{RS}$, PS along entire length.

Variation. The holotype has four robust setae on the pleotelson. Of 42 additional specimens examined five (12\%) have a damaged pleotelson, two $(5 \%)$ have six robust setae on the pleotelson, eight (19\%) have five robust setae on the pleotelson and $27(64 \%)$ have four. Some of the specimens from Huon Point (AM P47239) have orange pigment on the posterolateral margins of pleonite 4 and on the uropod peduncle.

Size. Adults to $14 \mathrm{~mm}$.

Etymology. Derived from Lilliput, a place in the novel Gulliver's Travels by Jonathan Swift where everything is reduced in size, in reference to the short nature of the antennae.

Remarks. Natatolana lilliput can be most readily separated from similar species by the following characters: the short antennae that reach just beyond the posterior margin of pereonite 1 and have relatively few flagellar articles; the complete interocular furrow; the rounded apices and posterior margins of the uropod endopod and pleotelson. Natatolana kahiba is most similar but has an incomplete interocular furrow. Natatolana rusteni n.sp. is also similar but differs in having a narrow and more acute pleotelson, usually with six robust setae on the posterolateral margins, an incomplete interocular furrow and slightly shorter antennae with fewer articles in the flagella.

Distribution and ecology. Australia: known only from the east coast of Tasmania. At depths of 3-25 m. Scavenger.

\section{Natatolana longispina Bruce, 1986}

Natatolana longispina Bruce, 1986: 82, figs. 54, 55.Springthorpe \& Lowry, 1994: 51.-Brusca et al., 1995: 80.Bruce et al., 2002: 151.

Cirolana corpulenta.-Hale, 1940: 289 (part) [mis-identification, not Natatolana corpulenta (Hale, 1925)].

Natatolana corpulenta.-Bruce, 1986: 79, figs. 51-53 (part) [misidentification, not Natatolana corpulenta (Hale, 1925)].

Type material. Holotype: $\widehat{\delta}, 8.8 \mathrm{~mm}$, NMV J1770 (not examined). Paratypes: NMV J1771-1783 (not examined); AM P32371-32374 (examined); USNM (not examined). - Type locality: Western Port, Victoria, Australia, $38^{\circ} 27^{\prime} \mathrm{S} 145^{\circ} 14^{\prime} \mathrm{E}$.

Material examined. New South Wales: series from $1.5 \mathrm{~km}$ east of Belmont Beach, near Newcastle, $33^{\circ} 02.36{ }^{\prime} \mathrm{S} 151^{\circ} 41^{\prime} \mathrm{E}$, shipek [grab], AM Hunter District Water Board Survey (reported by Bruce [1986]); 1, AM P23035, 23 m, 16 Dec. 1975; manca, AM P23042, 20 Sep. 1975; 1, AM P23047, 22 m, 10 Jun. 1975; ․, AM P47153, between Merimbula Point and Haystack Rock, Merimbula, $36^{\circ} 56.4^{\prime} \mathrm{S} 149^{\circ} 56.9^{\prime} \mathrm{E}$, baited trap, sand, J. Lowry \& S. Keable, 1-2 Dec. 1988, NSW-406; 3, AM P47154, off Wattamolla, $34^{\circ} 44^{\prime} \mathrm{S} 150^{\circ} 39^{\prime} \mathrm{E}$, baited trap, unknown substrate,
40 m, J. Lowry, 13-14 Nov. 1990, NSW-431; 220, AM P47157, off Providential Head, $34^{\circ} 44^{\prime} \mathrm{S} 150^{\circ} 39^{\prime} \mathrm{E}$, baited trap, 25-30 m, S. Keable, A. Parker \& J. Lowry, 14-15 Jan. 1991, PIO-103. Victoria: paratype + , AM P32372, Crib Point, Western Port, $38^{\circ} 22^{\prime} \mathrm{S} 145^{\circ} 12^{\prime} \mathrm{E}, 8 \mathrm{~m}$, Victorian Fisheries and Wildlife Department, 14 Jul. 1964, sample A1/2 no. 53588; 7 paratypes, AM P32373, Crib Point, Western Port, $38^{\circ} 22^{\prime}$ S $145^{\circ} 12^{\prime} \mathrm{E}$, sand, $11 \mathrm{~m}$, Victorian Fisheries and Wildlife Department 10 Mar. 1965, CPBS no. 53611. Bass Strait: $\delta^{\star}$, ㅇ, NMV J1107, $39^{\circ} 02^{\prime} \mathrm{S}$ $143^{\circ} 14^{\prime} \mathrm{E}$, grab, medium carbonate sand, $79 \mathrm{~m}$, G. Poore, 8 Oct. 1980; 15, J1329, fine sand, 95 m, G. Gomon et al., 31 Jan. 1981. Tasmania: + , AM E6757, Elliott Cove, west coast, [presumably 42 59 'S 145³3'E], 9 m, FIS Endeavour Expedition 1909-14 (reported by Hale [1940]); series from baited traps, J. Lowry and S. Keable: 3, AM P47139, due north of Lomas Point, Port Esperance, $43^{\circ} 20.8^{\prime} \mathrm{S} 147^{\circ} 3.3^{\prime} \mathrm{E}$, probably sandy bottom, $10 \mathrm{~m}, 19-20$ April 1991, TAS-201; D'Entrecasteaux Channel: 47, AM P47140, $43^{\circ} 22.2^{\circ} \mathrm{S}$ $147^{\circ} 3.2^{\prime} \mathrm{E}, 13 \mathrm{~m}, 20-21$ April 1991, TAS-226; 20, AM P47147, $43^{\circ} 22.2147^{\circ} 3.4^{\prime} \mathrm{E}, 21 \mathrm{~m}, 20-21$ April 1991, TAS-227; 23, AM P47142, $43^{\circ} 22.2147^{\circ} 3.6^{\prime} \mathrm{E}, 25 \mathrm{~m}, 20-21$ April 1991, TAS-228; Bruny Island: 9, AM P47143, 43 $21.5^{\prime} \mathrm{S} 147^{\circ} 22.2^{\prime} \mathrm{E}$, sandy bottom, $25 \mathrm{~m}$, 24-25 April 1991, TAS-267; 3, AM P47144, 43ํ⒉.5'S 147²2.3'E, sandy bottom, 28 m, 24-25 April 1991, TAS-268; 1, AM P47145, $43^{\circ} 21.3^{\prime} \mathrm{S} 147^{\circ} 22.4^{\prime} \mathrm{E}$, sandy bottom, $28 \mathrm{~m}, 24-25$ April 1991, TAS269; 12, AM P47146, $43^{\circ} 21.5^{\prime} \mathrm{S} 147^{\circ} 22.2^{\prime} \mathrm{E}$, sandy bottom, $24 \mathrm{~m}$, 24-25 April 1991, TAS-271; 2, AM P47147, 4321.1'S 147²2.4'E, sandy bottom, 28 m, 24-25 April 1991, TAS-272; Cape Sorell: 6, AM P47148, $42^{\circ} 11.5^{\prime} \mathrm{S} 145^{\circ} 11^{\prime} \mathrm{E}$, sand and detritus, $18 \mathrm{~m}, 26-27$ April 1991, TAS-277; 10, AM P47149, 42 ${ }^{\circ} 11.5^{\prime} \mathrm{S} 145^{\circ} 11^{\prime} \mathrm{E}$, sand and detritus, $25 \mathrm{~m}, 26-27$ April 1991, TAS-278; ð, AM P47150, $42^{\circ} 11.5^{\prime} \mathrm{S} 145^{\circ} 11.4^{\prime} \mathrm{E}$, sand, $25 \mathrm{~m}, 26-27$ April 1991, TAS-282; 2 , AM P47151, 42 ${ }^{\circ} 09.4^{\prime} \mathrm{S} 145^{\circ} 15^{\prime} \mathrm{E}$, sandy bottom, $16 \mathrm{~m}, 27-28$ April 1991, TAS-304; Freycinet Peninsula: 146, AM P47152, 42 17 'S $148^{\circ} 18.8^{\prime} \mathrm{E}, 45$ m, 30 April-1 May 1991, TAS-337.

Diagnosis. Interocular furrow: absent. Frontal lamina: lateral margins straight, narrowing anteriorly. Antenna: c. $0.35 \times$ as long as body, reaching to posterior of pereonite 3 . Coxal plates: furrows strongly developed, on coxae 2-7. Pereonite 1, coxa 2 posterior margins sinuate, posteroventral corners developed into weak coxal points. Pleonite 4: apex forming a broad acute point. Pleotelson: broad, length $0.73 \times$ basal width; anterodorsal depression present; anterolateral margins convex; posterolateral margins convex; apex produced into a small point; with $10 \mathrm{RS}$. Pereopods 1-6: males with conspicuous elongated RS subequal to propodus on the merus of pereopods $1-3$ and extending from the carpus to dactylus of pereopods 4-6. Pereopods 2-3: propodus without RS on palm. Pereopod 7: basis narrow, width $0.47 \times$ length; distance between anterior margin and medial carina less than between posterior margin and medial carina; posterior margin with setae along entire length. Penes: present. Pleopod 2 appendix masculina: extending beyond tip of endopod; slender; margins sinuate; apex recurved, bent slightly medially, acute. Uropods: exopod slightly shorter than endopod.

Variation. In the material examined, there is a slight variation in the production of the pleotelson apex. The specimens from near Cape Sorell (AM P47148-47151) have the apex more produced than the other specimens identified as Natatolana longispina.

Sexual dimorphism. Females lack the conspicuously elongated robust setae present on the merus of pereopods 1-3 and on the carpus of pereopods 4-6 of adult males.

Size. Females to $12.7 \mathrm{~mm}$, males to $8.8 \mathrm{~mm}$, mancas to $5.6 \mathrm{~mm}$. 
Remarks. Bruce (1986) noted that Natatolana longispina is similar to $N$. corpulenta. These two species can be easily separated by the anteroventral corner of coxa 2 , it is rounded in N. longispina and produced into an acute tooth in $N$. corpulenta.

Distribution. Australia: southern and central New South Wales; Port Phillip Bay and Western Port, Victoria; Bass Strait; east and west coasts of Tasmania. At depths of 9-95 m.

\section{Natatolana lowryi Keable, 1997}

Natatolana lowryi Keable, 1997: 256, figs. 2-4.-Bruce et al., 2002: 151 .

Type material. Holotype: $\widehat{\delta}, 15.3 \mathrm{~mm}$, NTM Cr-011523. Paratypes: + , manca, AM P44852; $\widehat{0}$, NTM Cr-011508; 0 , ZMUC CRU1713; §, USNM 264079. All examined. • Type locality: Middle Arm, west of Channel Island, Darwin Harbour, NT, Australia, $12^{\circ} 33.7^{\prime} \mathrm{S} 130^{\circ} 50.7^{\prime} \mathrm{E}$, [baited trap, unknown substrate, probably muddy sediment], 2 m, [S. Keable, 12-13 Jul. 1993, NT-148].

\section{Material examined. Listed by Keable (1997).}

Diagnosis. Interocular furrow: well developed, extending across the cephalon; smoothly convex. Frontal lamina: lateral margins straight, narrowing anteriorly. Antenna: c. $0.2 \times$ as long as body, reaching to posterior of pereonite 1 . Coxal plates: furrows variously developed, incomplete furrows on coxae 3 and 4, absent on other coxae. Pleonite 4: apex forming a broad acute point. Pleotelson: narrow, length $1.01 \times$ basal width; anterodorsal depression absent; anterolateral margins almost straight and angling posteriorly toward the midline; posterolateral margins straight, contiguous with anterolateral margins; apex not produced, lateral margins converging smoothly to a point; with 10-14 RS. Pereopods 2-3: propodus without RS on palm. Pereopod 7: basis of medium breadth, width $0.46 \times$ length; distance between anterior margin and medial carina greater than between posterior margin and medial carina; posterior margin with setae on proximal quarter. Penes: absent. Pleopod 2 appendix masculina: extending beyond tip of endopod, $1.09 \times$ length of endopod; margins very slightly curved laterally; slender; apex not at angle to adjacent margins, acute. Uropods: exopod short, $0.77 \times$ the length of the endopod.

Variation. The holotype specimen has 11 robust setae on the pleotelson margin, the majority of other specimens in the type series have 12 robust setae on the pleotelson and the other material reported by Keable (1997) mostly has 14 robust setae on the pleotelson.

Size. Adults to c. $20 \mathrm{~mm}$.

Remarks. Natatolana lowryi is most similar to N. luticola. It is separated from that species by the posterolateral margins of the pleotelson being less markedly angled to the anterolateral margins and by having a more acute angle at the apex of the pleotelson. The fringe of long slender setae on the posterior margin of the antennal peduncular article 4 is also a distinctive character state for this species.

Distribution and ecology. Australia: Darwin and Gove, Northern Territory; Gulf of Carpentaria. At depths of 2-55 $\mathrm{m}$. Scavenger.

\section{Natatolana luticola (Holdich, Harrison \& Bruce, 1981)}

Cirolana luticola Holdich et al., 1981: 569, fig. 6 (part).

Natatolana luticola.-Bruce, 1981: 958.-1986: 101, fig. 69.Brusca et al., 1995: 80.-Keable, 1997: 261.-Bruce et al., 2002: 151.

Type material. Holotype: $\widehat{\jmath}, 10.4 \mathrm{~mm}, \mathrm{QM}$ W6339. Paratypes: +, QM W6340 (mis-identification = Natatolana angula Bruce, 1986 according to Bruce [1986]); lots of 1 manca, 10े, $1 \hat{\sigma}^{\hat{0}}, 1$ ㅇ and $7 \hat{\delta} \widehat{\delta}, 6+q$ and 9 mancas, recorded by Holdich et al. (1981) but institution where deposited not stated, possibly in Nottingham University. According to Bruce (1986) the adult male paratype shown by Holdich et al. (1981) in figs. a-c,h,j,l is N. angula not $N$. luticola. None examined. - Type locality: Halifax Bay, Queensland, Australia [c. $19^{\circ} 05^{\prime} \mathrm{S} 146^{\circ} 40^{\prime} \mathrm{E}$ ], $14.5 \mathrm{~m}$.

Material examined. Listed by Keable (1997).

Diagnosis. Interocular furrow: moderately developed, distinct but not extending across the cephalon. Frontal lamina: lateral margins straight, narrowing anteriorly. Antenna: c. $0.21-0.3 \times$ as long as body, reaching to posterior of pereonite 2. Coxal plates: furrows moderately developed, on all coxae. Pleonite 4: apex slightly rounded. Pleotelson: broad, length $0.75 \times$ basal width; anterodorsal depression absent; anterolateral margins almost straight and angling posteriorly toward the midline; posterolateral margins straight, markedly angled to anterolateral margins and meeting at an acute angle; apex not produced, lateral margins converging smoothly to a point; with 12 RS. Pereopods 2 3: propodus without RS on palm. Pereopod 7: basis broad, width $0.53 \times$ length; distance between anterior margin and medial carina greater than between posterior margin and medial carina; posterior margin with setae along entire length. Penes: absent. Pleopod 2 appendix masculina: just shorter than endopod; margins very slightly curved laterally; slender; apex not at angle to adjacent margins, bluntly rounded. Uropods: exopod short, $0.76 \times$ the length of the endopod.

Size. Adults to $13.6 \mathrm{~mm}$.

Remarks. The angular pleotelson with a relatively high number of robust setae, well-developed rounded eye, incomplete interocular furrow and relatively narrow basis on pereopod 7 are sufficient characters to distinguish Natatolana luticola from all other species in the genus.

Distribution and ecology. Australia: Darwin Harbour and Gove, Northern Territory; northern Queensland south to Halifax Bay. At depths of 1.9-49 m. Scavenger.

\section{Natatolana matong Bruce, 1986}

Natatolana matong Bruce, 1986: 93, figs. 62, 63.-Springthorpe \& Lowry, 1994: 52.-Brusca et al., 1995: 80.-Bruce et al., 2002: 151 .

Cirolana rossi.-Hale, 1952: 24 [mis-identification, not Natatolana rossi (Miers, 1876)].

Type material. Holotype: $\delta$, TM G2543 (not examined). Paratypes: TM G2193; NMV J920, J1733; SAMA C3277, C3921; USNM 109986; BMNH (not examined); AM P33546 (examined). - Type locality: off King Island, northwest Tasmania, Australia, c. $40^{\circ} 00^{\prime} \mathrm{S} 144^{\circ} 00^{\prime} \mathrm{E}$.

Material examined. New South Wales: series from off Wollongong: 6, AM P46924, 34³2.02'S 151 ${ }^{\circ} 13.00^{\prime} \mathrm{E}, 200 \mathrm{~m}, 6$ 7 May 1993, SEAS NSW-780; 5, AM P44415, 34³3.01'S 
$151^{\circ} 16.54 ' E, 400$ m, 7-8 May 1993, SEAS NSW-803. Tasmania: 9, AM P47453, east of Fortescue Bay, 4309.37'S $145^{\circ} 13.6^{\prime} \mathrm{E}$, baited trap, 300 m, 16-17 April 1993, SEAS TAS-361.

Diagnosis. Eyes: well developed; elongate, length c. $2 \times$ height. Interocular furrow: well developed, extending across the cephalon (the feeble trace of a furrow that curves anteriorly from the point of termination of the distinct furrow, described by Bruce (1986), appears in the paratype material to be equivalent to the complete interocular furrow of other taxa examined [e.g., N. rossi]); produced medially. Frontal lamina: lateral margins medially constricted. Antenna: c. $0.33 \times$ as long as body, reaching to just beyond the posterior of pereonite 3. Coxal plates: furrows variously developed, coxae 2-3 with faint but complete furrows, coxa 4 with a faint partial furrow, coxae 5-6 without furrows and coxa 7 with a feeble trace of a furrow (on some specimens examined (AM P46924) nearly complete coxal furrows are present on all coxae). Pleonite 4: apex forming a narrow acute point. Pleotelson: broad, length $0.76 \times$ basal width; anterodorsal depression absent; anterolateral margins almost straight and angling posteriorly toward the midline; posterolateral margins straight, markedly angled to anterolateral margins and meeting at an acute or obtuse angle (angle about $90^{\circ}$ ); apex not produced, lateral margins converging smoothly to a point; with 12 RS. Pereopod 2: propodus with $3 \mathrm{RS}$ on palm. Pereopod 3: propodus with $3 \mathrm{RS}$ on palm. Pereopod 7: basis of medium breadth, width $0.5 \times$ length; distance between anterior margin and medial carina less than between posterior margin and medial carina; posterior margin with setae completely absent along entire length. Penes: absent. Pleopod 2 appendix masculina: extending subequal with tip of endopod; margins straight; slender; apex not at angle to adjacent margins, bluntly rounded. Uropods: exopod subequal to endopod, $0.9 \times$ the length of the endopod.

Size. Adults to c. $40 \mathrm{~mm}$.

Remarks. Natatolana matong is extremely similar to $N$. rossi. The development of the interocular and coxal furrows does not reliably separate the two species as suggested by Bruce (1986). The shape of pleonite 4, however, is consistently different between the two species, $N$. rossi having a more sinuate posterodorsal margin. Natatolana hirtipes is also similar but has a smoothly convex interocular furrow (sinuate in $N$. matong), a broader basis of pereopod 7 and pleonite 4 with a more strongly sinuate posterodorsal margin.

Distribution and ecology. Australia: off Wollongong, New South Wales; off east and northwest Tasmania At depths of 155-400 m. Scavenger.

\section{Natatolana meridionalis (Hodgson, 1910)}

Cirolana meridionalis Hodgson, 1910: 20, pl. 3.-?Stephensen, 1947: 24, fig. 7.

Natatolana meridionalis.-Bruce 1981: 958.-1986: 218, 222.Brandt 1988: 102.-Brusca et al., 1995: 80.-Castelló, 1999: 278.-Takeuchi et al., 2001: 624.

Cirolana albinota Vanhöffen, 1914: 497, fig. 35.-Monod, 1931: 22.-Hale, 1952: 26.-?Menzies 1962: 126, fig. 41, F-G.Kussakin, 1967: 223.-Carvacho 1977: 40.

Natatolana albinota.-Bruce, 1981: 958.-1986: 218, 222.-Brandt, 1988: 105, figs. 45-50.

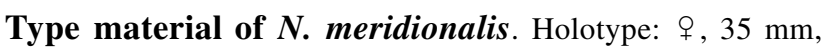
BMNH 1910.3.18:39-40 (examined). - Type locality of $N$. meridionalis: Winter Quarters, National Antarctic Expedition
1901-1904, Antarctica, [ $78^{\circ} \mathrm{S} 165^{\circ} \mathrm{E}$, fide Stephensen (1947), 29 Aug. 1903, trap], 25 fathoms. Hodgson (1910) mentions another mutilated specimen found in a seal's stomach. The description, however, appears to have been based entirely on the intact specimen taken in the trap. There are two specimens in the type lot, the larger female specimen is the holotype. The smaller female specimen appears to be the specimen from the seal's stomach. A note with the smaller specimen reads "The damaged specimen, with eyes, is probably $C$. [Natatolana] intermedia, Vanhöffen (note by W.M. Tattersall)"; this identification by Tattersall appears to be correct.

Type material of $\boldsymbol{N}$. albinota. Lectotype designated by Brandt (1988): ๙, $40.5 \mathrm{~mm}$, originally ZMG but now in SIF, ZMG 259. Paralectotypes: 3 ô $\widehat{0}, 37 \mathrm{~mm}, 40 \mathrm{~mm}, 42 \mathrm{~mm}, 3$ ㅇ 우, $35 \mathrm{~mm}, 35$ $\mathrm{mm}$ (ovigerous), $43 \mathrm{~mm}$ (ovigerous), SIF, ZMG 258. None examined.

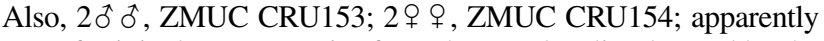
part of original syntype series from the type locality donated by the ZMB in 1926 (examined). - Type locality of N. albinota: Gauss Station, Posadowsky Bay, Antarctica, 66 $2.9^{\circ} \mathrm{S} 89^{\circ} 38.5^{\prime} \mathrm{E}, 385 \mathrm{~m}$, [Deutsche Sudpolarexpedition 1901-1903].

Diagnosis. Eyes: well developed or vestigial (apparently fading with preservation). Interocular furrow: moderately developed, distinct but not extending across the cephalon. Frontal lamina: lateral margins straight, parallel. Antenna: c. $0.33 \times$ as long as body, reaching to posterior of pereonite 3 or half way along pereonite 4 . Coxal plates: furrows moderately developed or strongly developed, on all coxae. Pereonite 1, coxa 2 posterior margins straight or slightly convex, or sinuate. Pleonite 4: posterodorsal margin strongly concave proximal to meeting posteroventral margin at apex; apex forming a narrow acute point. Pleotelson: broad, length $0.9 \times$ basal width; anterodorsal depression absent; anterolateral margins convex; posterolateral margins convex; apex produced into a small point; with 12-18 RS. Pereopod 2: propodus with $4 \mathrm{RS}$ on palm. Pereopod 3: propodus with 5 RS on palm. Pereopod 7: basis narrow, width $0.44 \times$ length; distance between anterior margin and medial carina less than between posterior margin and medial carina; posterior margin with sparse setae proximally and distally but not medially, or completely absent. Penes: present. Pleopod 2 appendix masculina: extending beyond tip of endopod, 1.16-1.27× length of endopod; margins very slightly curved laterally; slender; apex not at angle to adjacent margins, bluntly rounded. Uropods: exopod subequal to endopod, $0.91 \times$ the length of the endopod.

Size. Males to $42 \mathrm{~mm}$, females to $43 \mathrm{~mm}$ (Brandt, 1988).

Remarks. Bruce (1986, p. 222) regarded Natatolana albinota to be a junior synonym of $N$. meridionalis. This synonymy was overlooked by Brandt (1988) as noted by Brusca et al. (1995, p. 80). Comparison of type specimens, of the two nominal taxa, supports the synonymy of Bruce (1986). Brandt (1988) used the absence of well-developed eyes in N. meridionalis to separate it from other Antarctic species of Natatolana, including $N$. albinota which was described as having small, light red eyes. Although the eyes of the holotype of $N$. meridionalis were described as absent (Hodgson, 1910), they are actually present with indistinct ommatidia that lack pigment. In other characters $N$. meridionalis resembles $N$. albinota, the difference in the appearance of the eyes is probably due to initial and subsequent preservation of the material examined by Brandt (1988) because the type material of $N$. albinota examined in this study also has indistinct weakly pigmented eyes. 
Brandt (1988) discussed the records by Schultz (1977) of Natatolana oculata from southern Argentina, intimating that they were of $N$. meridionalis $(=N$. albinota $)$. His illustrations, however, showing the posterior margins of the pleotelson and a relatively short appendix masculina, with a tapered apex, indicate he may have been describing another species, possibly $N$. pastorei. Schultz $(1977,1978)$ indicated that the record of $N$. meridionalis by Menzies (1962) from Chile may be $N$. oculata. Both of these records require verification by examination of the specimens.

Distribution and ecology. Antarctica: Discovery Bay, Davis Sea (Vanhöffen, 1914); Enderby Land and Pzydz Bay (Hale, 1952; Takeuchi et al., 2001); Banzare Coast; Lars Christensen Coast; Ross Sea (Monod, 1931); Antarctic Peninsula; Weddell Sea; Scotia Sea. At depths of 35-670 m (Brandt, 1988). The records of Menzies (1962) from southern Chile require verification. Scavenger.

\section{Natatolana nammuldi Bruce, 1986}

Natatolana nammuldi Bruce, 1986: 113, figs. 77, $78 .-$ Springthorpe \& Lowry, 1994: 53.-Brusca et al., 1995: 82.Bruce et al., 2002: 152 .

Natatolana wullunya Bruce, 1986: 120, fig. 83.-Springthorpe \& Lowry, 1994: 66.-Brusca et al., 1995: 82.

Type material of Natatolana nammuldi. Holotype: $q$, 20.2 mm, NMV J1718 (not examined). Paratypes: NMV J1719-1722, J1753 (not examined); AM P32363-32365 (examined); USNM 190722 (not examined). $\bullet$ Type locality of Natatolana nammuldi: Western Port, Victoria, Australia, $38^{\circ} 27^{\prime} \mathrm{S} 145^{\circ} 14^{\prime} \mathrm{E}$.

Type material of Natatolana wullunya. Holotype: $\odot, 11.3 \mathrm{~mm}$, AM P30364 (examined). Type locality of Natatolana wullunya:

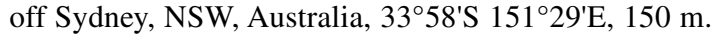

Material examined. New South Wales: 7, AM P47287, east of Coffs Harbour, $30^{\circ} 17.49^{\prime} \mathrm{S} 153^{\circ} 13.90^{\prime} \mathrm{E}, 45.4 \mathrm{~m}, 11-12$ Aug. 1993, SEAS NSW-873; 53, AM P47288, between Lookout Point and Seahorse Shoals, Twofold Bay, 37 ${ }^{\circ} 5.6^{\prime} \mathrm{S} 149^{\circ} 56.6^{\prime} \mathrm{E}$, baited trap, unknown substrate, probably sediment, $30 \mathrm{~m}$, J. Lowry \& S. Keable, 28-29 Nov. 1988, NSW-392. Tasmania: series from east of Fortescue Bay, $43^{\circ} 09.37^{\prime} \mathrm{S} 145^{\circ} 13.6^{\prime} \mathrm{E}, 300 \mathrm{~m}, 16-18$ April 1993; 8, AM P47289, SEAS TAS-361; 28, AM P47290, SEAS TAS-361; 24, AM P47291, SEAS TAS-378.

Diagnosis. Interocular furrow: moderately developed, distinct but not extending across the cephalon. Frontal lamina: lateral margins medially constricted. Antenna: c. $0.27-0.3 \times$ as long as body, reaching to posterior of pereonite 2. Coxal plates: furrows moderately developed, on all coxae. Pleonite 4: apex slightly rounded. Pleotelson: broad or narrow, length $0.90-1.00 \times$ basal width; anterodorsal depression absent; anterolateral margins almost straight and angling posteriorly toward the midline, or convex; posterolateral margins straight, markedly angled to anterolateral margins and meeting at an acute angle or convex; apex not produced, lateral margins converging smoothly to a point or produced into a small point; with 68 RS. Pereopods 2-3: propodus without RS on palm. Pereopod 7: basis broad, width $0.58 \times$ length; distance between anterior margin and medial carina greater than between posterior margin and medial carina; posterior margin with setae on entire length. Penes: absent. Pleopod 2 appendix masculina: extending subequal with tip of endopod, $0.99 \times$ length of endopod; margins very slightly curved laterally; slender; apex recurved, bent slightly medially, bluntly rounded. Uropods: exopod slightly shorter than endopod, $0.87-0.9 \times$ the length of the endopod; lateral margin with or without RS (present in type material).

Variation. In all samples specimens with eight robust setae on the pleotelson were most abundant but specimens with six robust setae were also common. In a sample from eastern Tasmania (AM P47291) forty percent of the specimens have four robust setae on the uropod endopod medial margin and the remainder has five. Two specimens from this sample were found to have three robust setae on the lateral margin of the uropod endopod as in the type material of $N$. nammuldi, whereas all other specimens examined have only two. The specimens in another sample from the same locality in eastern Tasmania (AM P47290) lack robust setae on the uropod exopod lateral margin, however, these could not be otherwise distinguished from specimens in the same sample (AM P47289, eight specimens) that have two to four robust setae on this margin.

Size. Adults from c. $11.3 \mathrm{~mm}$ to c. $27 \mathrm{~mm}$, largest manca $7 \mathrm{~mm}$.

Remarks. Bruce (1986) discussed the differences between Natatolana nammuldi and $N$. woodjonesi and $N$. wowine. Differences between $N$. nammuldi and $N$. wullunya, however, were not discussed. Bruce (1986) separated $N$. wullunya from all other species principally by its narrow frontal lamina. He also discussed other differences between $N$. wullunya, $N$. arrama and $N$. woodjonesi, including the shape of the frontal lamina, clypeus, pereopod 7, and number of robust setae on the pleotelson and lateral margin of the uropod exopod. Both $N$. nammuldi and $N$. wullunya were originally reported only from female specimens and single localities. For $N$. wullunya only a single specimen was recorded.

Comparison of type material of Natatolana nammuldi and $N$. wullunya indicates that any difference in the shape of the frontal lamina is relatively minor. The only other differences that could be found between the two nominal taxa are that the type material of $N$. nammuldi has eight robust setae on the pleotelson (except AM P32365 which has seven [six in $N$. wullunya]); five robust setae on the uropod endopod medial margin (four in $N$. wullunya); three robust setae on the uropod endopod lateral margin (two in $N$. wullunya); and four robust setae on the uropod exopod lateral margin (three in N. wullunya). The lateral margin of the uropod endopod is also slightly sinuate in the types of $N$. nammuldi (convex in $N$. wullunya) but this appears to be related to the larger size of the specimens. In the other material examined here, variations between the two extremes were found within samples, although most material had only two robust setae on the uropod endopod lateral margin.

Therefore, Natatolana nammuldi and $N$. wullunya appear to be synonymous as reported in Bruce et al. (2002) based on the unpublished thesis of Keable (1996). Natatolana nammuldi is recognized as the objective senior synonym because it has page precedence, a more accessible type locality and more type specimens than $N$. wullunya. Further material from the type localities of $N$. nammuldi and N.wullunya would help to confirm that the variation noted here is intra-specific.

Distribution and ecology. Australia: off Coffs Harbour/off Sydney/in Twofold Bay, New South Wales; Western Port, 
Victoria; off the east coast of Tasmania. At depths of 8.1-300 $\mathrm{m}$ (the holotype of $N$. wullunya was collected from $150 \mathrm{~m}$ and the type material of $N$. nammuldi from c. $8.1 \mathrm{~m}$ ). Scavenger.

\section{Natatolana narica (Bowman, 1971)}

Cirolana narica Bowman, 1971: 107, figs. 1-22.

Natatolana narica.-Bruce, 1981: 958.-1986: 64, 222.-Brusca et al., 1995: 82.

Type material. Holotype: $\widehat{\jmath}, 21.8 \mathrm{~mm}$, ZMUA Is. 100.527. Paratypes: $\delta, 21.9 \mathrm{~mm}$, USNM 139048; ?,$+ 17.3 \mathrm{~mm}$, ZMUA Is. 100.528. None examined. - Type locality: Banks Peninsula,

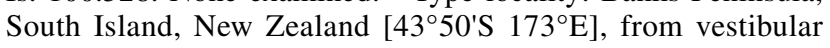
diverticulum of Cephalorhynchus hectori.

Material examined. New Zealand: $\widehat{o}, 3 q q$, QM W18895, [Tasman Bay], $41.18^{\circ} \mathrm{S}, 173.16^{\circ} \mathrm{E}, 0 \mathrm{~m}$, isopod trap, ex New Zealand Oceanographic Institute, K225A; ${ }^{\star}$, + , NMNZ Cr 4434, Otago Harbour, 20.3 m, 23 Feb. 1962, loc. 10520.

Diagnosis. Eyes: vestigial (ommatidia are indistinct and lack pigment). Interocular furrow: well developed, forming a ridge that extends across the cephalon; smoothly convex. Frontal lamina: lateral margins medially constricted. Antenna: c. $0.3-0.4 \times$ as long as body, reaching to threequarters of the way along pereonite 4. Coxal plates: furrows variously developed, incomplete and indistinct on coxae 2-4, 7. Pleonite 4: posterodorsal margin strongly concave proximal to meeting posteroventral margin at apex; apex forming a narrow acute point. Pleotelson: broad, length $0.75 \times$ basal width; anterodorsal depression absent; anterolateral margins almost straight and angling posteriorly toward the midline, or convex; posterolateral margins broadly rounded; apex not produced, truncate with a small medial point; with 8-12 RS (material examined 8-10, types described as having about 12). Pereopod 2: propodus with 0-1 RS on palm. Pereopod 3: propodus without RS on palm. Pereopod 7: basis broad, width $0.56 \times$ length; distance between anterior margin and medial carina less than between posterior margin and medial carina; posterior margin with setae on proximal third. Penes: absent. Pleopod 2 appendix masculina: extending beyond tip of endopod, $1.06 \times$ length of endopod; margins straight or very slightly curved laterally; slender; apex not at angle to adjacent margins, bluntly rounded. Uropods: exopod longer than endopod, $1.15 \times$ the length of the endopod.

Size. Adults to c. $21 \mathrm{~mm}$.

Remarks. Natatolana narica and $N$. paranarica n.sp. are the only species of Natatolana in which the uropod exopod is distinctly longer than the endopod. Natatolana paranarica is almost identical to $N$. narica but differs in that the posterolateral margins of the pleotelson meet at an acute angle, rather than being broadly rounded; the uropod endopod medial margin is smoothly convex, not sinuate; the ventral margin of the posterior coxae is straight not sinuate; there are slender setae at the uropod endopod and exopod apices that are shorter than the length of these rami, rather than being as long as them.

Distribution and ecology. New Zealand. Intertidal to $20.3 \mathrm{~m}$ depth. Natatolana narica has been collected from nasal tract of a dolphin, it is unlikely to be a parasite as entry probably occurred while the dolphin was dead or dying (Bowman, 1971) and the species is likely to be a scavenger.

\section{Natatolana natalensis (Barnard, 1940)}

Figs. 33-35

Cirolana natalensis Barnard, 1940: 393.-Roman, 1970: 167.Kensley, 1978: 69, fig. 28D.

Natatolana natalensis.-Bruce 1981: 958.-1986: 222.-Brusca et al., 1995: 82.-Kensley, 2001: 230.

Type material. Lectotype: designated here, $\widehat{\jmath}, 12 \mathrm{~mm}, \mathrm{SAM}-$ A8183 (examined). Paralectotypes:,$+ 16 \mathrm{~mm}$ (examined) and 2 others (not examined) SAM A-8183; 3 specimens, BMNH 1937.11.10.68 (examined). • Type locality: Illovo, Natal, South Africa, [30 $066^{\prime} \mathrm{S} 30^{\circ} 51^{\prime} \mathrm{E}$ ].

Diagnosis. Interocular furrow: absent. Frontal lamina: lateral margins straight, narrowing anteriorly. Antenna: c. $0.3 \times$ as long as body, reaching to posterior of pereonite 3 . Coxal plates: furrows moderately developed on all coxae, difficult to see on coxae 2-4 and becoming increasingly weak on coxae 5-7. Pleonite 4: apex forming a broad acute point. Pleotelson: narrow, length $1 \times$ basal width; anterodorsal depression present; anterolateral margins convex; posterolateral margins convex; apex not produced, lateral margins converging smoothly to a point; with $12 \mathrm{RS}$. Pereopod 2: propodus with $4 \mathrm{RS}$ on palm. Pereopod 3: propodus with $4 \mathrm{RS}$ on palm. Pereopod 7: basis broad, width $0.53 \times$ length; distance between anterior margin and medial carina less than between posterior margin and medial carina; posterior margin with setae on proximal third. Penes: absent. Pleopod 2 appendix masculina: extending beyond tip of endopod, $1.2 \times$ length of endopod; margins sinuate; slender; apex recurved, bent slightly medially, bluntly rounded. Uropods: exopod slightly shorter than endopod, $0.85 \times$ the length of the endopod.

Additional descriptive characters. Based on lectotype. Body: length c. $2.5 \times$ width. Colour cream to white in alcohol. Chromatophores present, or absent (these are not obvious and appear to have faded after preservation). Eyes: with 9 ommatidia in horizontal diameter; with 9 ommatidia in vertical diameter; round; colour red in alcohol. Frontal lamina: length c. $3.4 \times$ basal width; apex expanded, anterior margin angled. Antennule: peduncular article 1 longer than article 2; article 2 with 1 large pappose seta and several smaller penicillate and SS; article 3 short, subequal to article 1. Flagellum 14-articulate. Antenna: peduncular article 4 with a group of 8 long SS and 1 penicillate seta on posterolateral margin; article 5 with 2 conspicuous pappose setae on posterolateral margin. Flagellum 23-articulate. Mandible: setal row with 14 RS. Maxillule: medial lobe with 3 large and 1 smaller robust pappose setae and $1 \mathrm{SS}$; lateral lobe with $13 \mathrm{RS}$ on distal surface. Maxilla: lateral lobe with $6 \mathrm{SS}$; medial lobe with $3 \mathrm{SS}$ and $15 \mathrm{PS}$; middle lobe with 14 long SS on outer row and 3 short SS on inner row. Maxilliped: endite with 1 coupling hook, 6 PS and 1 SS. Pereon: ornamentation consists of 1 strongly developed furrow on lateral margins of all pereonites, oblique on pereonites $1-3$, short straight and medial on pereonites 47; pereonites 1, 4-6 subequal and longest, 2-3 and 7 subequal. Coxae: pereonite 1, coxae 2-4 with rounded posteroventral corners, coxae 5-7 with sinuate posterior margins formed into moderately large coxal points. Pleonite 2: dorsal posterolateral margin subequal with ventral posterolateral margin. Pereopod 7: basis anterior margin convex; medial carina with PS along entire length; posterior 


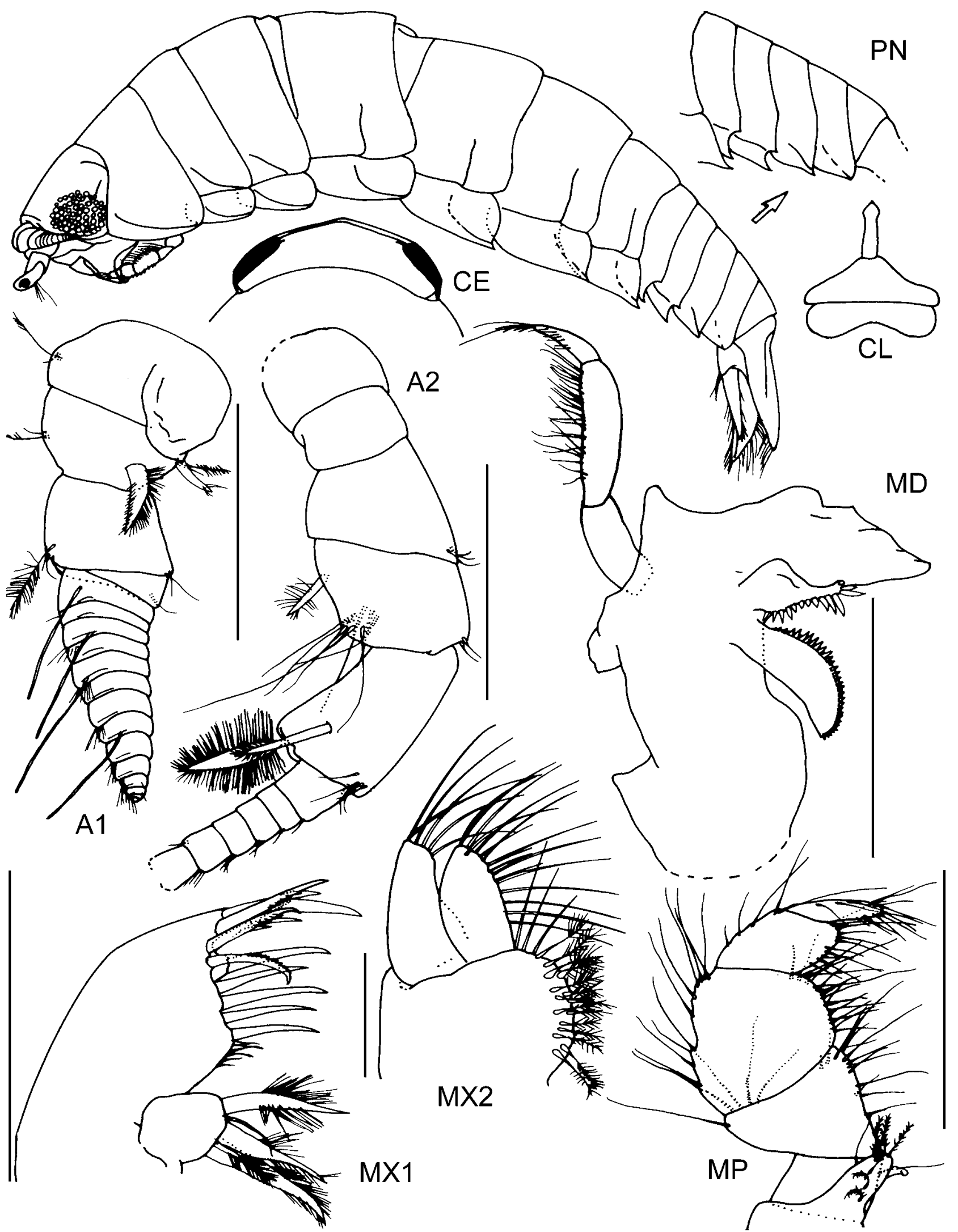

Fig. 33. Natatolana natalensis. Whole animal = paralectotype female, all other parts $=$ lectotype male. Scales $=0.5 \mathrm{~mm}$, except $\mathrm{MX} 2=0.2 \mathrm{~mm}$.

margin convex, SS present. Ischium anterior margin with $\mathrm{SS}$; posterior margin with $3 \mathrm{RS}$ (submarginal). Merus anterior margin with SS; posterior margin with $7 \mathrm{RS}, \mathrm{SS}$ present. Carpus posterior margin with $3 \mathrm{RS}$, SS present.
Propodus subequal to carpus; posterior margin with 3 RS, SS present. Pleopod 2 appendix masculina: arising subbasally. Pleopods 1-5: exopod suture feebly developed on pleopods 3-5; endopod PS on most of margins of pleopods 

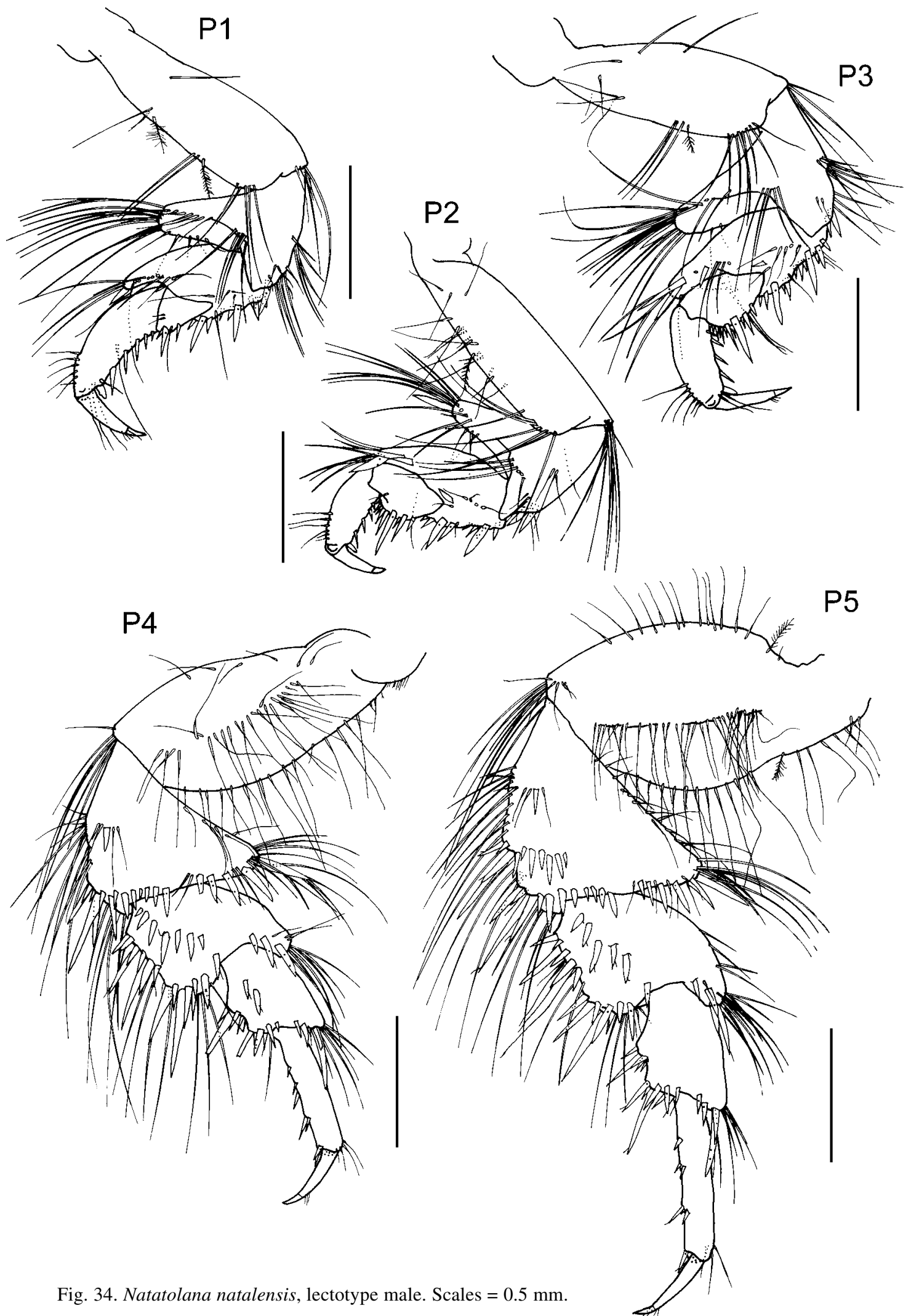

1-4, only 1 seta on pleopod 5. Uropods: endopod lanceolate; medial margin convex, with 3 RS, PS along entire length; apex with $2 \mathrm{RS}$; lateral margin angled close to midpoint, each half approximately straight, with $1 \mathrm{RS}, \mathrm{PS}$ along entire length. Exopod medial margin convex, with 2 RS, PS along entire length; apex acute, with 2 RS; lateral margin straight, with 5 RS, PS along entire length.
Size. Adults to 13 mm (Barnard, 1940; Kensley, 1978), but a female paralectotype in SAM A-8183 (newly measured) is $16 \mathrm{~mm}$.

Remarks. It is unclear how many specimens were in the original type series of Natatolana natalensis but there were several and "no adult males or ovigerous females" (Barnard 


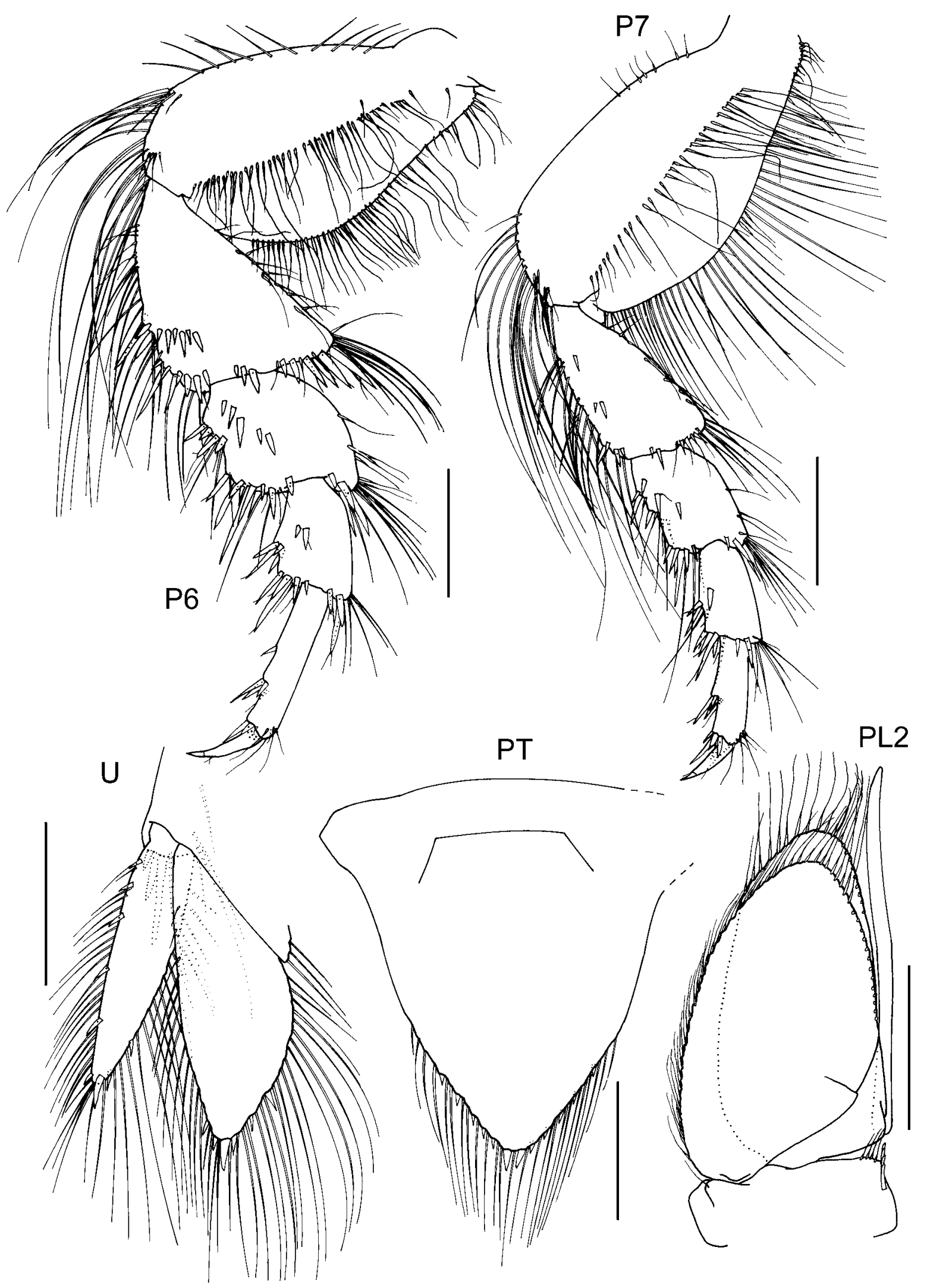

Fig. 35. Natatolana natalensis, lectotype male. Scales $=0.5 \mathrm{~mm}$.

1940). Seven specimens were initially registered as types at the SAM but only four of these remain (L. Hoenson, SAM, in litteris), three apparently being transferred to the BMNH. The collection data on the label of the SAM type material (Illovo Beach, Natal. 1934. Det. Barnard) matches that given in the original description but contrary to the description the sample contains a well-developed male. Barnard did not illustrate the type material and the original description consists largely of a comparison to $N$. hirtipes, apparently based on the description of that species by 
Hansen (1890). Because N. natalensis is difficult to identify from the original description, and from female specimens, the male is designated here as a lectotype to avoid future taxonomic confusion regarding identification of this species. The remaining type specimens become paralectotypes. The lectotype is consistent with Barnard's description and important characters, such as the 12 robust setae on the pleotelson, lack of an interocular furrow, rounded posterolateral margins of coxa 4 and shape of the pereopod 7 basis, match perfectly.

The distinct dorsal depression on the pleotelson, the presence of robust setae on the propodal palm of pereopods 2 and 3 , the broad basis of pereopod 7 and the absence of penes in adult males, distinguish $N$. natalensis from all other species.

Distribution and ecology. South Africa: Natal. Madagascar. Shallow, infratidal-subtidal (Kensley, 1978; Bruce, 1986). Scavenger, "An enemy of fishes, and anglers' bête noire" (Barnard, 1940).

\section{Natatolana natalis (Menzies \& George, 1972)}

Cirolana natalis Menzies \& George, 1972: 24, figs. 14-15. Natatolana natalis.-Bruce, 1981: 958.-1986: 222.-Brusca et al., 1995: 82.

Type material. Holotype: ๙ิ, 17 mm, USNM 121737 (examined). - Type locality: off Peru, Peru-Chile Trench, 08 23 'S $80^{\circ} 25^{\prime} \mathrm{W}, 2966-2945 \mathrm{~m}$, [ANTON BRUUN Sta. 161].

Diagnosis. Eyes: vestigial. Interocular furrow: moderately developed, distinct but not extending across the cephalon. Frontal lamina: lateral margins medially constricted. Antenna: c. $0.39 \times$ as long as body, reaching to posterior of pereonite 3. Coxal plates: furrows strongly developed, on all coxae. Pleonite 4: apex slightly rounded. Pleotelson: broad (original description states that the pleotelson is longer than wide but this does not appear to be measured using the basal width), length $0.89 \times$ basal width; anterodorsal depression absent; anterolateral margins almost straight and angling posteriorly toward the midline; posterolateral margins convex; apex not produced, lateral margins converging smoothly to a point; RS present (these setae appear to have been rubbed off this margin but there seem to be sockets indicating the presence of at least 10). Pereopod 2: propodus with 6 RS on palm. Pereopod 3: propodus with 4 RS on palm. Pereopod 7: basis narrow, width $0.48 \times$ length; distance between anterior margin and medial carina less than between posterior margin and medial carina; posterior margin with sparse setae on distal half. Penes: present. Pleopod 2 appendix masculina: extending subequal with tip of endopod, $1 \times$ length of endopod; margins very strongly curved laterally; broad; apex not at angle to adjacent margins, with lateral projection forming a Y shape with acute apex. Uropods: exopod slightly shorter than endopod, $0.86 \times$ the length of the endopod; lateral margin RS unknown (originally illustrated as absent, uropod exopods are now missing from the holotype).

Size. Adults to $17 \mathrm{~mm}$.

Remarks. The holotype is the only specimen recorded of Natatolana natalis. The original illustrations and description differ markedly in several respects to the specimen registered as the holotype, although there is no strong reason to doubt that this is the specimen originally described. The original description of the appendix masculina indicates that it has two or three tubercules- this is an artefact, the margins are smooth. The original description of the pleotelson is misleading because it indicates a far more rounded apex and a lack of setae. Plumose setae and sockets are, however, apparent on the margins of the pleotelson, the sockets indicate the former presence of robust setae.

Natatolana natalis is extremely similar to N. imicola and $N$. rekohu but has a slightly different morphology of the appendix masculina - the apex is more acute and the notch adjacent to the apex is deeper so that an acute projection occurs proximal to the notch. Because the only specimen of $N$. natalis is in poor condition, further specimens from near the type locality are needed to fully characterize the species and to identify further differences to these species.

Distribution. Off Peru: Peru-Chile Trench. At depths of 2966-2945 m.

\section{Natatolana neglecta (Hansen, 1890)}

Synonymy in Keable \& Bruce, 1997: 695, figs. 16-18. Additional listings and records of this species are those of Zavodnik \& Kovacic (2000, p. 337).

Type material. Syntypes: $\widehat{0}, 2 \% q$, ZMUC CRU148, Gulf of Naples; 9 , ZMUC CRU149, Nice. All examined. • Type locality: Gulf of Naples [as Neapels Golf-c. $40^{\circ} 42^{\prime} \mathrm{N} 14^{\circ} 16^{\prime} \mathrm{E}$ ]; probably Nice (Hansen, 1905) [presumably France, originally as Nizzac. $\left.43^{\circ} 42^{\prime} \mathrm{N} 7^{\circ} 15 \cdot 4^{\prime} \mathrm{E}\right]$. All examined.

Material examined. Listed by Keable \& Bruce (1997).

Diagnosis. Interocular furrow: moderately developed, distinct but not extending across the cephalon. Frontal lamina: lateral margins straight, parallel. Antenna: c. $0.35 \times$ as long as body, reaching to three-quarters of the way along pereonite 3. Coxal plates: furrows strongly developed, on all coxae. Pleonite 4: apex forming a broad acute point. Pleotelson: broad, length $0.84 \times$ basal width; anterodorsal depression absent (although in some specimens there is a slight depression this is not equivalent to the distinct and abrupt depression found in species such as N. pellucida); anterolateral margins almost straight and angling posteriorly toward the midline; posterolateral margins straight, markedly angled to anterolateral margins and meeting at an obtuse angle; apex not produced, lateral margins converging smoothly to a point; with 10-14 RS. Pereopods 2-3: propodus without RS on palm. Pereopod 7: basis of medium breadth, width $0.5 \times$ length; distance between anterior margin and medial carina less than between posterior margin and medial carina; posterior margin with setae completely absent along entire length. Penes: absent. Pleopod 2 appendix masculina: extending beyond tip of endopod, $1.09 \times$ length of endopod; margins very slightly curved laterally; slender; apex not at angle to adjacent margins, bluntly rounded. Uropods: exopod slightly shorter than endopod, $0.83 \times$ the length of the endopod.

Variation. The type specimens have nine to ten robust setae on the pleotelson but other the specimens examined have eight.

Size. Adults to $16 \mathrm{~mm}$.

Remarks. Keable \& Bruce (1997) redescribe Natatolana neglecta. Hansen (1905) regarded the records of N. neglecta by Dollfus (1903), from the mid north Atlantic Ocean and depths of c. 1000-2000 m, as dubious. Keable \& Bruce (1997) established the validity of Natatolana imicola 
(Dollfus) as a distinct species based on the same material. The specimens Dollfus (1903) reported from shallower depths are either $N$. neglecta (IOM 360250 ) or are damaged and mixed with other taxa (IOM 36 0254, Campagnes de l'Hirondelle et de la Princesse Alice Station 323) and cannot be accurately identified.

The straight posterolateral margins of the pleotelson, markedly angled to the straight anterolateral margins, is a distinctive feature of Natatolana neglecta. This coupled with the well-developed eyes, an incomplete interocular furrow, well-developed coxal furrows on all coxae, absence of penes, appendix masculina morphology, setation and shape of the uropods and setation of the pleotelson, distinguishes this species from all other species of Natatolana.

Distribution. Natatolana neglecta is known from the west coast of France, the vicinity of Nice and Naples in the Mediterranean and Tyrrhenian Seas, the Atlantic coast of northwestern Africa at about $28^{\circ} \mathrm{N}$, and also the Adriatic Sea. At depths of 19-188 m.

The tentative record of Müller (1989), if confirmed, would extend the range of $N$. neglecta to the Levantine Basin of the Mediterranean Sea, $\left(32^{\circ} 0.53^{\prime} \mathrm{N} 34^{\circ} 33.98^{\prime} \mathrm{E}\right)$. It has not been possible to locate the specimens and confirm the records of Larwood (1940) from off Egypt, at depths of 42-73 m.

\section{Natatolana nitida (Hale, 1952)}

Cirolana nitida Hale, 1952: 25, fig. 1.-Kussakin, 1967: 224.Carvacho, 1977: 176.-Kensley, 1980: 159.-Kussakin \& Vasina, 1982a: 261.-1982b: 329, 335-336.

Natatolana nitida.-Bruce 1981: 958.-1986: 222.-Brandt, 1988: 102.-Brusca et al., 1995: 82.-Kensley, 2001: 230.

Type material. Holotype: $\widehat{o}, 22 \mathrm{~mm}$, SAMA C3279. Allotype: ,$+ 24 \mathrm{~mm}$, SAMA C3281. Paratypes: 11, SAMA C3280. All examined. - Type locality: just south of Kerguelen, $49^{\circ} 50^{\prime} \mathrm{S}$ 69 $33^{\prime}$ E, [B.A.N.Z.A.R.E. Station 47 First Cruise, 7 Feb. 1930, large rectangular dredge], $150 \mathrm{~m}$.

Diagnosis. Eyes: well developed; elongate, length c. $2 \times$ height. Interocular furrow: weakly developed, indistinct and not extending across the cephalon. Frontal lamina: lateral margins sinuate. Antenna: c. $0.35 \times$ as long as body, reaching to three quarters of the way along pereonite 3. Coxal plates: furrows strongly developed, on all coxae. Coxa 2 with anteroventral corner produced into an acute tooth. Pleonite 4: posterodorsal margin strongly concave proximal to meeting posteroventral margin at apex; apex forming a narrow acute point. Pleotelson: broad, length $0.89 \times$ basal width; anterodorsal depression absent; anterolateral margins almost straight and angling posteriorly toward the midline; posterolateral margins straight, markedly angled to anterolateral margins and meeting at an obtuse angle or concave; apex produced into a large point; with 8-10 RS. Pereopod 2: propodus with $3 \mathrm{RS}$ on palm. Pereopod 3: propodus with 2 RS on palm. Pereopod 7: basis of medium breadth, width $0.47-0.52 \times$ length; distance between anterior margin and medial carina less than between posterior margin and medial carina; posterior margin with setae along entire length. Penes: present. Pleopod 2 appendix masculina: extending subequal with tip of endopod, 0.96-0.98× length of endopod; margins twisted; broad; apex not at angle to adjacent margins, acute or bluntly rounded. Uropods: exopod subequal to endopod, $0.91 \times$ the length of the endopod.

Size. Adults to just over $30 \mathrm{~mm}$.
Remarks. Natatolana nitida and N. obtusata are the only species of Natatolana in which males have an excavate medial margin on the endopod of pleopod 2 and a distinctly twisted appendix masculina. Natatolana nitida also has a distinct acute tooth on the anteroventral corner of coxa 2 that is otherwise known only in $N$. corpulenta. These characters distinguish $N$. nitida from all other species in the genus. Natatolana obtusata is most similar but has the posterodorsal margin of pleonite 4 sinuate, as well as lacking the acute tooth on the anteroventral corner of coxa 2 . Natatolana intermedia is also similar but has the pleotelson with convex posterodorsal margins and a slender, strongly curved appendix masculina, as well as lacking the acute tooth on the anteroventral corner of coxa 2.

Distribution. Kerguelen Islands, Crozet Islands, Southern Ocean. At depths of 40-334 m (Kussakin \& Vasina, 1982b).

\section{Natatolana nukumbutho Bruce \& Olesen, 1995}

Natatolana nukumbutho Bruce \& Olesen, 1995: 212, figs. 1-4.

Type material. Holotype: $\widehat{\jmath}, 12.3 \mathrm{~mm}$, ZMUC CRU580 (not examined). Paratypes: $\hat{\sigma}, 13.2 \mathrm{~mm}$, ZMUC CRU581; 9, ZMUC CRU582 (Bruce \& Olesen (1995) list 13 specimens: 20 t and 11 우 ) (not examined); 3, AM P43423, (Bruce \& Olesen (1995) list one male and one female) (examined). - Type locality: off Lauthala Bay, Suva, Fiji, $18^{\circ} 13^{\prime} \mathrm{S} 178^{\circ} 29^{\prime} \mathrm{E}$, [baited trap], $470 \mathrm{~m}$, [Institute of Marine Research, University of the South Pacific, 23 Jan. 1981].

Diagnosis. Eyes: well developed; elongate, length c. $2 \times$ height. Interocular furrow: well developed, extending across the cephalon. Frontal lamina: lateral margins medially constricted. Antenna: c. 0.4-0.43× as long as body, reaching to between the posterior of pereonite 3 and three quarters of the way along pereonite 4. Coxal plates: furrows strongly developed, on all coxae. Pleonite 4: apex forming a broad acute point. Pleotelson: broad, length $0.89 \times$ basal width; anterodorsal depression absent; anterolateral margins convex; posterolateral margins straight, markedly angled to anterolateral margins and meeting at an acute angle; apex not produced, lateral margins converging smoothly to a point; with 10-12 RS. Pereopod 2: propodus with $2 \mathrm{RS}$ on palm. Pereopod 3: propodus with 2 RS on palm. Pereopod 7: basis of medium breadth, width $0.5 \times$ length; distance between anterior margin and medial carina less than between posterior margin and medial carina; posterior margin with setae completely absent along entire length. Penes: absent, vasa deferentia opening flush to surface of sternite 7 (Bruce \& Olesen (1995) were unable to discern the openings of the vas deferentia as the internal structure of the specimens appeared somewhat decomposed but distinct penes are absent). Pleopod 2 appendix masculina: much shorter than endopod, 0.7-0.87× length of endopod; margins straight; slender; apex not at angle to adjacent margins, bluntly rounded. Uropods: exopod slightly shorter than endopod, $0.86 \times$ the length of the endopod.

Variation. The illustration of pereopod 7, provided by Bruce \& Olesen (1995), indicates the setae on the anterior margin of the ischium are plumose. Examination of paratype specimens (AM P43423), however, indicates that these setae are slender, without setules. Bruce \& Olesen (1995) stated that pleonite 3 does not extend posteriorly beyond the posterior margin of pleonite 5 . In the paratype material examined here, however, the posterodistal margin of pleonite 3 does extend beyond the posterior margin of pleonite 5 . 
Size. Males 11.2 to $13.4 \mathrm{~mm}$, non-ovigerous females 12.2 to $17 \mathrm{~mm}$.

Remarks. Natatolana nukumbutho is very similar to $N$. carlenae but differs in having complete coxal furrows on all coxae, a slightly narrower basis on pereopod 7 and slightly narrower posterolateral margins on pleonite 4 .

Distribution and ecology. Fiji at a depth of $470 \mathrm{~m}$. Scavenger.

\section{Natatolana obtusata (Vanhöffen, 1914)}

Cirolana obtusata Vanhöffen, 1914: 496, fig. 34.-Tattersall 1921: 205.-?Stephensen, 1947: 496, fig. 8.

Natatolana obtusata.-Bruce, 1981: 958.-1986: 222.-Brandt, 1988: 120, figs. 56-60.-Brusca et al., 1995: 82.

Type material. Lectotype designated by Brandt (1988): ^ð, 38 $\mathrm{mm}$, originally ZMG but now in SIF ZMG 262 (not examined). Paralectotypes: đo, $27 \mathrm{~mm}, 5$ ㅇ $, 19 \mathrm{~mm}, 20 \mathrm{~mm}, 27 \mathrm{~mm}, 28$ $\mathrm{mm}, 30 \mathrm{~mm}$, SIF ZMG 263; 20 ơ, ZMUC CRU155; 2 우, ZMUC CRU156 - apparently part of original syntype series from the type locality donated by the Zoological Museum, Berlin, in 1926 (examined). Other possible paralectotypes are: $3 q q, \mathrm{ZMB}$ 17605; 2 우, ZMB 17607-all from type locality (Brandt, 1988) (not examined). - Type locality: off Gauss Station, Posadowsky Bay, Antarctica, $66^{\circ} 2.9^{\prime} \mathrm{S} 89^{\circ} 38.5^{\prime} \mathrm{E}, 385 \mathrm{~m}$, [Deutsche Sudpolarexpedition 1901-1903].

Diagnosis. Eyes: well developed; elongate, length c. $2 \times$ height. Interocular furrow: moderately developed, distinct but not extending across the cephalon. Frontal lamina: lateral margins straight, parallel. Antenna: c. $0.3 \times$ as long as body, reaching to posterior of pereonite 3. Coxal plates: furrows strongly developed, on all coxae. Pleonite 4: apex rounded. Pleotelson: broad, length $0.75 \times$ basal width; anterodorsal depression absent; anterolateral margins almost straight and angling posteriorly toward the midline; posterolateral margins straight, markedly angled to anterolateral margins and meeting at an obtuse angle; apex produced into a small point; with 10-14 RS. Pereopod 2: propodus with 3-5 RS on palm. Pereopod 3: propodus with 4 RS on palm. Pereopod 7: basis of medium breadth, width $0.49 \times$ length; distance between anterior margin and medial carina less than between posterior margin and medial carina; posterior margin with setae along entire length. Penes: present. Pleopod 2 appendix masculina: extending subequal with tip of endopod or just shorter than endopod, 0.9-1x length of endopod; twisted; broad; apex bent laterally slightly, bluntly rounded. Uropods: exopod subequal to endopod, $1 \times$ the length of the endopod.

Sexual dimorphism. Females may be larger than males.

Size. Females to $37 \mathrm{~mm}$, males to $27 \mathrm{~mm}$.

Remarks. Natatolana obtusata and $N$. nitida are the only species of Natatolana in which males have an excavate medial margin on the endopod of pleopod 2 and a distinctly twisted appendix masculina. Natatolana obtusata most noticeably differs from $N$. nitida in having the anteroventral corner of coxa 2 rounded, not produced into an acute tooth, and in having the posterodorsal margin of pleonite 4 sinuate, not concave. Natatolana intermedia is also similar but has a concave posterodorsal margin on pleonite 4 .

Distribution and ecology. Antarctica: Gauss Station, Posadowsky Bay, 385 m; Visikoi, S. Sandwich 10-17 m;
Bridgeman, S. Sandwich, Antarctic Peninsula, Weddell Sea, $750 \mathrm{~m}$ (Brandt, 1988). Scavenger. The anatomy and ultrastructure of the digestive system of this species has been studied by Storch et al. (2002).

\section{Natatolana oculata (Vanhöffen, 1914)}

Cirolana oculata Vanhöffen, 1914: 499, fig. 36.-Hale, 1937: 17.1952: 26.-Kussakin, 1967: 224.-?Schultz, 1977: 72, figs. 34 [figures labelled C. albinota]; 1978: 32.

Natatolana oculata.-Bruce, 1986: 222.-Brandt, 1988: 129, figs. 61-65.-Brusca et al., 1995: 82.

Type material. Lectotype designated by Brandt (1988): đิ, 21 mm, ZMB 17617 (not examined). Paralectotypes: $ᄋ, 34 \mathrm{~mm}$, ZMB 17617 (not examined); 2 q \&, ZMUC CRU157-apparently part of the original syntype series from the type locality donated by the ZMB in 1926 (examined). • Type locality: off Gauss Station, Posadowsky Bay, Antarctica, 66 2.9'S 89 $38.5^{\prime} \mathrm{E}, 385 \mathrm{~m}$, [Deutsche Sudpolarexpedition 1901-1903].

Material examined. Antarctica: $29 q$, USNM Acc. No. 247268, Palmer Peninsula, 64 $466^{\prime} \mathrm{S} 64^{\circ} 04^{\prime} \mathrm{W}$, fish traps, $47.5 \mathrm{~m}$, 5 April, 1963, Staten Island Expedition.

Diagnosis. Interocular furrow: moderately developed, distinct but not extending across the cephalon. Frontal lamina: lateral margins straight, narrowing posteriorly, or lateral margins straight, parallel. Antenna: c. $0.3 \times$ as long as body, reaching to half way along pereonite 3 . Coxal plates: furrows moderately developed, on all coxae. Pereonite 1, coxa 2 posterior margins straight or slightly convex, or sinuate. Pleonite 4: posterodorsal margin strongly concave proximal to meeting posteroventral margin at apex; apex forming a narrow acute point. Pleotelson: broad, length $0.84 \times$ basal width; anterodorsal depression absent; anterolateral margins convex; posterolateral margins concave; apex produced into a small point; with 8-12 RS. Pereopod 2: propodus with 6 RS on palm. Pereopod 3: propodus with 4 RS on palm. Pereopod 7: basis narrow, width $0.46 \times$ length; distance between anterior margin and medial carina less than between posterior margin and medial carina; posterior margin with setae along entire length. Penes: present. Pleopod 2 appendix masculina: extending beyond tip of endopod; margins very slightly curved laterally; slender; apex not at angle to adjacent margins, bluntly rounded. Uropods: exopod subequal to endopod, $0.96 \times$ the length of the endopod.

Size. Brandt (1988) states that the maximum length of males is $35 \mathrm{~mm}$ and of females $28 \mathrm{~mm}$ but also mentions that a paralectotype female is $34 \mathrm{~mm}$.

Remarks. Natatolana oculata is similar to $N$. meridionalis and $N$. pastorei. It differs most noticeably from $N$. meridionalis in having the posterolateral margins of the pleotelson distinctly concave and markedly angled to the anterolateral margins (not convex and joining smoothly with anterolateral margins). Natatolana oculata differs most noticeably from $N$. pastorei in having the dorsal posterolateral margin of pleonite 2 projecting posterior to the ventral posterolateral margin (not projecting subequal to the ventral margin).

The material of Schultz (1977) from southern Argentina is discussed under remarks for $N$. meridionalis.

Distribution and ecology. Magellan Strait, South Shetland Islands, Antarctic Peninsula and Weddell Sea (Brandt, 1988); possibly southern Argentina. At depths of 43.5-385 $\mathrm{m}$. Scavenger. 


\section{Natatolana pallidocula (Kussakin \& Vasina, 1982)}

Cirolana pallidocula Kussakin \& Vasina, 1982a: 262, figs. 1, 2.1982b: 329, 334.

Natatolana pallidocula.-Bruce, 1986: 222.-Brusca et al., 1995: 82.-Kensley, 2001: 230.

Type material. Holotype: $\widehat{\jmath}, 10.8 \mathrm{~mm}$, ZIAS 1/71 227 (not examined, an attempt to obtain the only known specimen, from the Zoological Institute of the Academy of Science, St. Petersburg, was unsuccessful). - Type locality: Kerguelen Islands, $49^{\circ} 18^{\prime} \mathrm{S}$ $71^{\circ} 12^{\prime} \mathrm{E}, 310 \mathrm{~m}$.

Diagnosis. Details regarding the interocular furrow, labrum, coxa 2 , number of robust setae on the pleotelson, setation and size of the pereopod articles, and penes are unknown. Eyes: well developed (although described as hardly distinguishable because they lack pigment, this may be due to preservation as the ommatidia are apparently well developed). Antenna: c. $0.35 \times$ as long as body, reaching to middle of pereonite 3 . Coxal plates: furrows variously developed, coxa 2 with a short straight furrow, coxae 3-6 with strongly developed furrows and coxa 7 apparently without furrows. Pleonite 4: apex forming a broad acute point. Pleotelson: broad; anterolateral margins almost straight and angling posteriorly toward the midline; posterolateral margins straight, markedly angled to anterolateral margins and meeting at an acute angle or concave; apex produced into a large point; RS present. Pereopod 7: basis narrow; posterior margin with setae on distal two-thirds. Pleopod 2 appendix masculina: just shorter than endopod; margins straight; slender; apex not at angle to adjacent margins, bluntly rounded. Uropods: exopod slightly shorter than endopod, $0.9 \times$ the length of the endopod.

Size. The only known specimen is a male of $10.8 \mathrm{~mm}$.

Remarks. Natatolana pallidocula is known only from the holotype. This species appears to be very similar to $N$. corpulenta. The eyes in $N$. pallidocula are, however, apparently longer, with more ommatidia in the horizontal row, than those of $N$. corpulenta. It is unclear from the original illustrations but the ventral anterior tooth on coxa 2 , characteristic of $N$. corpulenta, may also be present in $N$. pallidocula.

Distribution. Kerguelen Islands, Southern Ocean. At a depth of $310 \mathrm{~m}$.

\section{Natatolana paranarica n.sp.}

Figs. 36-37

Type material. HolOTYPE: $\widehat{\delta}, 31 \mathrm{~mm}$, NMNZ. PARATYPES:

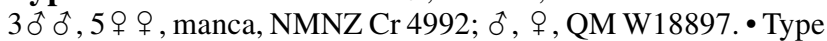
locality: Palliser Bay, off Carls Beach, North Island, New Zealand, [c. $41^{\circ} \mathrm{S} 175^{\circ} \mathrm{E}$ ], 5.5m, [14 Jan. 1986].

Diagnosis. Eyes: vestigial. Interocular furrow: well developed, forming a ridge that extends across the cephalon; smoothly convex. Frontal lamina: lateral margins straight, narrowing anteriorly. Antenna: c. $0.48 \times$ as long as body, reaching to posterior of pereonite 4. Coxal plates: furrows variously developed, incomplete on coxae 2-3, absent on coxae 4-7. Pleonite 4: posterodorsal margin strongly concave proximal to meeting posteroventral margin at apex; apex forming a narrow acute point. Pleotelson: broad, length $0.9 \times$ basal width; anterodorsal depression absent; anterolateral margins convex; posterolateral margins convex; apex not produced, lateral margins converging smoothly to a point; with 10-14 RS. Pereopod 2: propodus with 0-2 RS on palm. Pereopod 3: propodus without RS on palm. Pereopod 7: basis of medium breadth, width $0.5 \times$ length; distance between anterior margin and medial carina less than between posterior margin and medial carina; posterior margin with setae on proximal third. Penes: absent. Pleopod 2 appendix masculina: just shorter than endopod, $0.92 \times$ length of endopod; margins very slightly curved laterally; slender; apex not at angle to adjacent margins, bluntly rounded. Uropods: exopod longer than endopod, 1.08x the length of the endopod.

Additional descriptive characters. Based on holotype. Body: length c. $2.8 \times$ width. Colour cream/yellow in alcohol. Chromatophores absent. Eyes: with 14 ommatidia in horizontal diameter; with 11 ommatidia in vertical diameter; round; lacking pigment in alcohol. Frontal lamina: length c. $3.9 \times$ basal width; apex expanded, anterior margin angled. Antennule: peduncular article 1 longer than article 2 ; article 2 with 1 large pappose seta and 3 penicillate setae; article 3 short, subequal to article 1. Flagellum 16-articulate. Antenna: peduncular article 4 with 6 SS medially on posterolateral margin, 2 SS near posterodistal angle and 4 SS at anterodistal angle; article 5 with 2 pappose setae at posterodistal angle, 4 SS and 1 penicillate seta at anterodistal angle. Flagellum 28-articulate. Mandible: setal row with 21 RS. Maxillule: medial lobe with 3 large and 1 smaller robust pappose setae; lateral lobe with 13 RS on distal surface. Maxilla: lateral lobe with 4 SS; medial lobe with 15 SS and 8 PS; middle lobe with 18 SS. Maxilliped: endite with 2 coupling hooks, 1 PS and 2 SS. Pereon: ornamentation consists of 1 strongly developed furrow on lateral margin of pereonite 1, 1 short curved furrow on lateral margin of pereonites $2-3,1$ short medial furrow on lateral margins of pereonites 4-7; pereonite 1 longest, 2-6 subequal, 7 shortest. Coxae: pereonite 1 and coxa 2 with rounded posteroventral corners, coxa 3 with square posteroventral corner, coxae 4-7 with increasingly produced, broad, acute posteroventral corners. Pleonite 2: dorsal posterolateral margin subequal with ventral posterolateral margin. Pereopod 7: basis anterior margin slightly convex; medial carina with PS along entire length; posterior margin convex, PS present. Ischium anterior margin with SS; posterior margin without RS, PS present. Merus anterior margin with SS; posterior margin without RS (9 submarginally), SS present. Carpus posterior margin without RS, SS present. Propodus longer than carpus; posterior margin with 5 RS, SS present. Pleopod 2 appendix masculina: arising sub-basally. Pleopods 1-5: exopod suture strongly developed on pleopods 3-5; endopod PS on most of margins of pleopods 1-4, only a few setae on pleopod 5. Uropods: endopod lanceolate; medial margin convex, with 5 RS, PS along entire length; apex with $2 \mathrm{RS}$; lateral margin slightly convex, with 4 RS, PS on distal three-quarters. Exopod medial margin convex, with 4 RS, PS along entire length; apex acute, with 2 RS; lateral margin convex, with $8 \mathrm{RS}$, PS along entire length.

Variation. Several of the paratypes have one or two robust setae on the palm of pereopod 2 but this is not a consistent feature. The holotype has 11 robust setae on the pleotelson. Robust setal counts from margins of paratypes $(n=10)$ : pleotelson: damaged (20\%); 5:6 (20\%); 6:6 (30\%); 6:7 (30\%). Endopod, medial: $6(70 \%), 5(30 \%)$; lateral: $2(10 \%)$, 3 (30\%), 4 (60\%). Exopod medial: 3 (20\%), $4(60 \%), 5$ (20\%); lateral: 7 (10\%), 8 (30\%), $9(40 \%), 10(20 \%)$. 


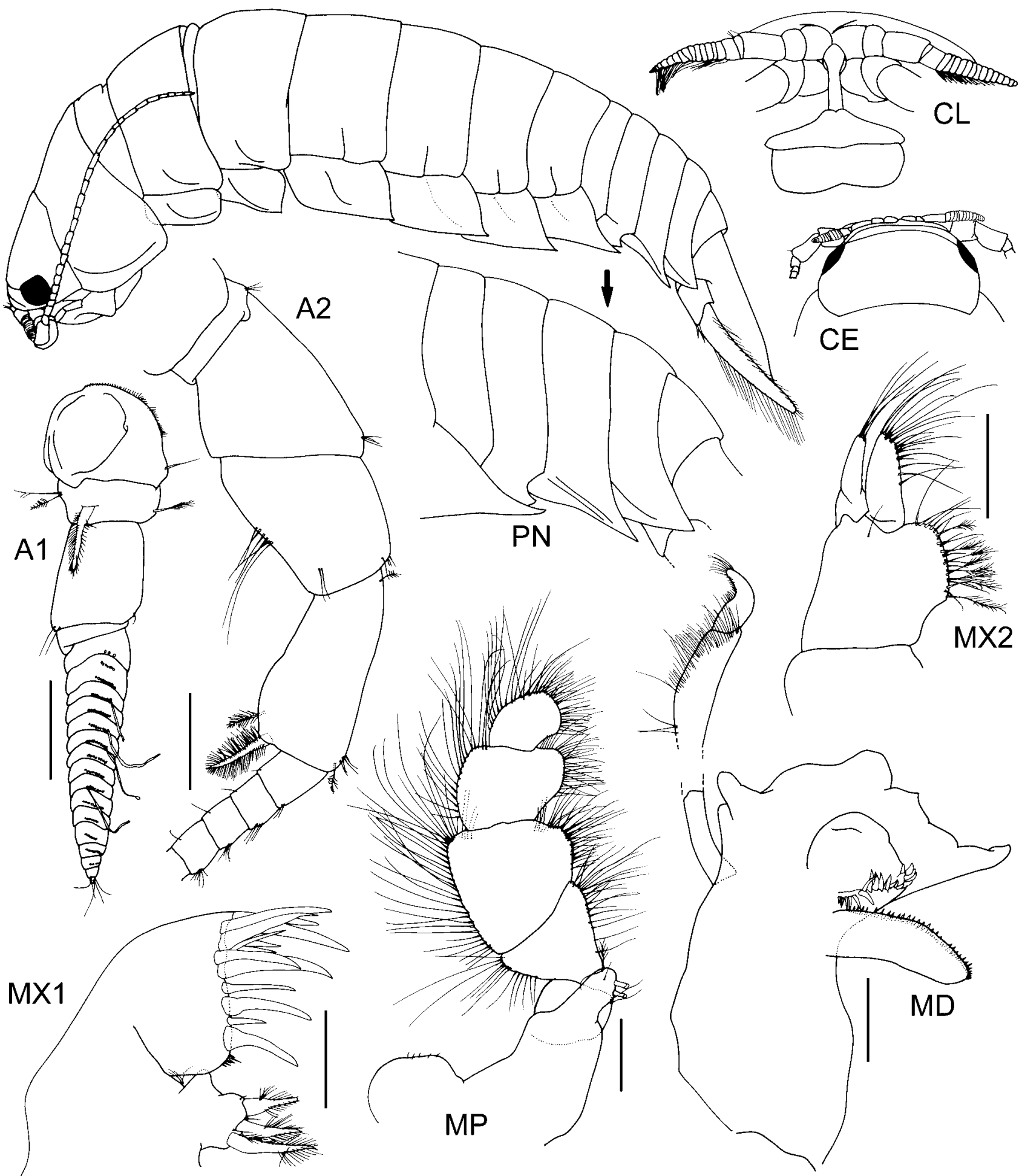

Fig. 36. Natatolana paranarica, n.sp., holotype. Scales $=0.5 \mathrm{~mm}$.

Size. Adults to $31 \mathrm{~mm}$.

Etymology. Refers to the similarity this species has to Natatolana narica.

Remarks. Natatolana paranarica is almost identical to $N$. narica but differs in that the posterolateral margins of the pleotelson meet at an acute angle, rather than being broadly rounded; the uropod endopod medial margin is smoothly convex, not sinuate; the ventral margin of the posterior coxae is straight not sinuate; there are slender setae at the uropod endopod and exopod apices that are shorter than the length of these rami, rather than being as long as them. Natatolana paranarica and N. narica are the only species of Natatolana in which the uropod exopod is distinctly longer than the endopod. The uropod exopod is as long as the endopod in $N$. endota but that species differs in many characters, including having only four robust setae on the pleotelson and antennae that are longer than the body.

Distribution. New Zealand: known only from the type locality. At a depth of $5.5 \mathrm{~m}$. 


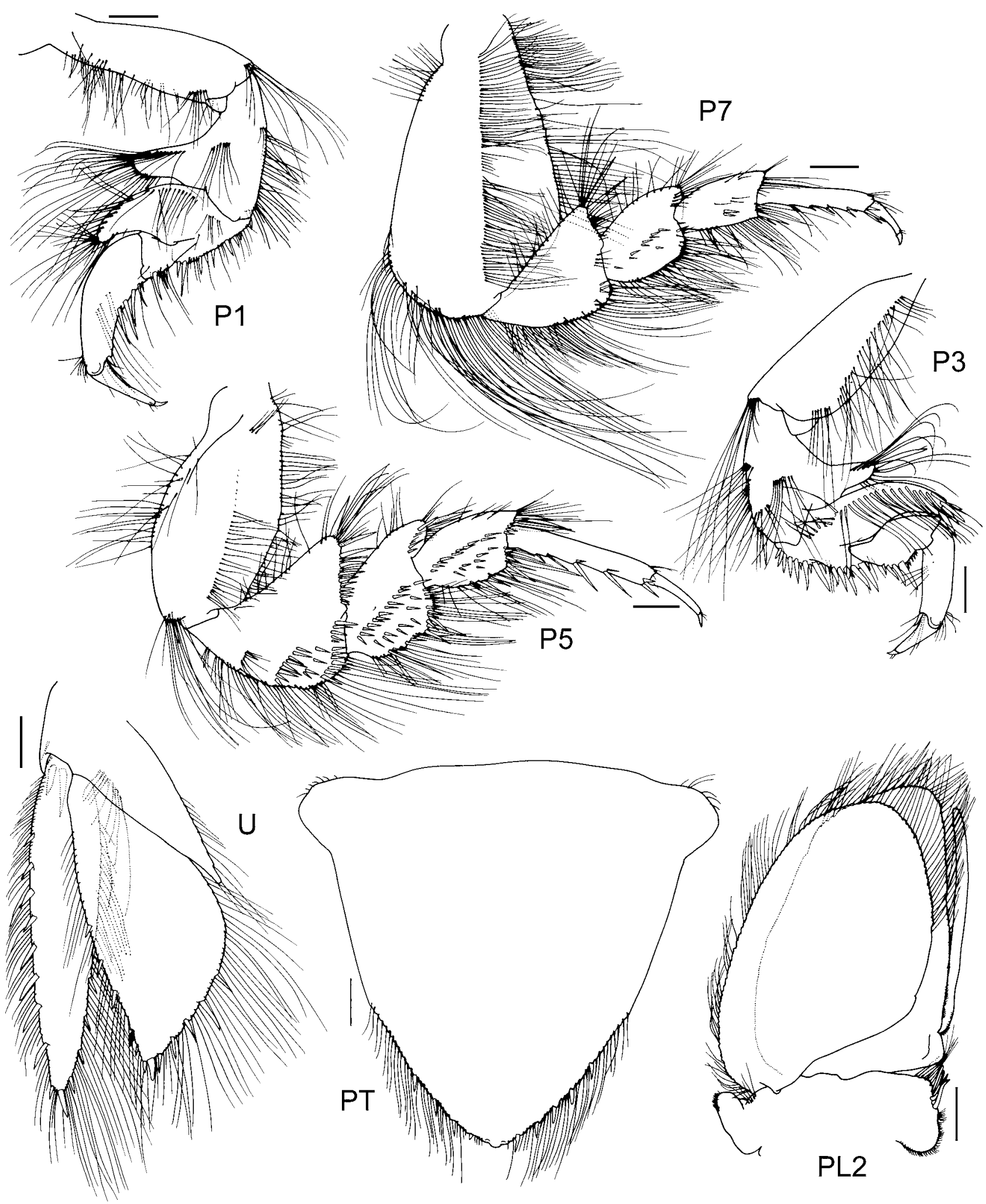

Fig. 37. Natatolana paranarica, n.sp., holotype. Scales $=0.5 \mathrm{~mm}$. 


\section{Natatolana pastorei (Giambiagi, 1925)}

Cirolana magellanica Pfeffer, 1887: 58, nomen nudum.-Hansen, 1890: 357.-Bruce, 1986: 218.-Wägele \& Bruce, 1989: 95

Cirolana pastorei Giambiagi, 1925: 4, pl. 1, pl. 3, fig. 3.

Natatolana pastorei.-Bruce, 1981: 958.-1986: 97, 222.-Wägele \& Bruce, 1989: 95.-Brusca et al., 1995: 82.-Lorenti \& Mariani, 1997: 255

?Cirolana oculata.-Schultz, 1977: 72, figs. 3-4 [figures labelled C. albinota]. [possible mis-identification of Natatolana oculata Vanhöffen, 1914].

Not Cirolana pastorei.-Monod, 1931: 22 [mis-identification = Natatolana sp.].

Type material. Syntypes: 9, Museo Argentino de Ciencias Naturales "Bernardino Rivadavia", Buenos Aires Nr 12690 (not examined). - Type locality: San Sebástian, Tierra del Fuego [c. $\left.53^{\circ} 9^{\prime} \mathrm{S} 68^{\circ} 18^{\prime} \mathrm{W}\right]$

Material examined. Chile: $q$, ô, AM P47134, Fiordo Quintupeu, $42^{\circ} 10^{\prime} \mathrm{S} 72^{\circ} 25^{\prime} \mathrm{W}$, A. Carvacho; ${ }^{\circ}$, USNM Acc. No. 288382 , off south tip of Vancouver Island, $51^{\circ} 27.5^{\prime} \mathrm{S} 74^{\circ} 03^{\prime} \mathrm{W}$, epibenthic dredge, 700-920 m, D.L. Pawson, 10 Oct. 1969, HERO Cruise 69-5 stn 213; ${ }^{\star}$, USNM Acc. No. 288382, 5331'S $70^{\circ} 33^{\prime} \mathrm{W}, 270 \mathrm{~m}$. South Georgia: $20^{\hat{\jmath}} \mathrm{o}^{\circ}$, 오, ZMUC CRU132, $54^{\circ} 27.3^{\prime} \mathrm{S} 35^{\circ} 47.5^{\prime} \mathrm{W}, 50 \mathrm{~m}$.

Diagnosis. Interocular furrow: moderately developed, distinct but not extending across the cephalon. Frontal lamina: lateral margins medially constricted. Antenna: c. $0.4 \times$ as long as body, reaching to posterior of pereonite 4 . Coxal plates: furrows strongly developed, on all coxae. Pleonite 4: posterodorsal margin strongly concave proximal to meeting posteroventral margin at apex; apex forming a narrow acute point. Pleotelson: broad, length $0.92 \times$ basal width; anterodorsal depression absent; anterolateral margins convex; posterolateral margins convex; apex produced into a small point; with 10-16 RS. Pereopod 2: propodus with 3 RS on palm. Pereopod 3: propodus with 2 RS on palm. Pereopod 7: basis broad, width $0.54 \times$ length; distance between anterior margin and medial carina less than between posterior margin and medial carina; posterior margin with setae on distal half. Penes: present. Pleopod 2 appendix masculina: extending beyond tip of endopod; margins straight; slender; apex recurved, bent slightly medially, tapered to a finely acute point. Uropods: exopod subequal to endopod, $1 \times$ length of endopod.

Variation. Wägele \& Bruce (1989) state that the antennule flagellum is not much longer than the peduncle. Their illustration, however, shows the peduncle longer than the flagellum and this is the case in the material examined. The specimens from southern Chile (AM P47134) have the apex of the pleotelson less produced than in other material examined. One specimen from southern Chile (USNM Acc. No. 288382) has only 10 robust setae on the pleotelson rather than the 12-16 recorded by Wägele \& Bruce (1989).

Size. Immature adults $27-34 \mathrm{~mm}$, males $30.5-33 \mathrm{~mm}$ (Wägele \& Bruce, 1989).

Remarks. Natatolana pastorei is similar to N. meridionalis and $N$. oculata but differs most noticeably in having the dorsal posterolateral margin of pleonite 2 projecting subequal to the ventral posterolateral margin (not projecting posterior to the ventral margin), pereonite 1 and coxa 2 with straight or slightly convex posterior margins (never sinuate) and the appendix masculina tapered to a finely acute point (not bluntly rounded).
The possible record from southern Argentina by Schultz (1977) (as Cirolana oculata, figures labelled C. albinota) is discussed under remarks for $N$. meridionalis.

Distribution and ecology. Straits of Magellan; South America: between Hale Cove, Argentina to Punta Arenas, Chile and from San Sebastián, Argentina. In shallow sublittoral sediments (Wägele \& Bruce, 1989). New records reported here are from the vicinity of South Georgia and to depths of $920 \mathrm{~m}$. Scavenger.

\section{Natatolana pellucida (Tattersall, 1921)}

Cirolana pellucida Tattersall, 1921: 206, pl. II figs. 4-10.Nierstrasz, 1931: 158.-Hurley, 1957: 11.-1961: 267.

Natatolana pellucida.-Bruce, 1981: 958.-1986: 76, figs. 49, 50.Brusca et al., 1995: 82.-Bruce et al., 2002: 152.

Type material. Syntypes: $\delta, 7.5 \mathrm{~mm}, 2 q q, 11.3,12.0 \mathrm{~mm}$, BMNH 1921.11.29.22-24 (measurements of Bruce (1986), examined and newly measured here as-undissected female, 11 $\mathrm{mm}$, partially dissected $\widehat{\delta}, 9.5 \mathrm{~mm}$ and fully dissected female, 12 $\mathrm{mm}$ ); many specimens, BMNH 1921.11.29.25-44. All examined. - Type locality: off Three Kings Island, New Zealand [c. $34^{\circ} 14$ 'S $172^{\circ} 12^{\prime}$ E, British Antarctic (Terra Nova) Expedition Station 130], surface.

Material examined. Queensland: series from off East Fitzroy Reef, AM P47619-47622; 29, 2334.92'S 152 ${ }^{\circ} 11.76^{\prime} \mathrm{E}, 58 \mathrm{~m}$, 16-17 Jun. 1993, SEAS QLD-952; 1, 2332.53'S 152 16.45'E, $105 \mathrm{~m}, 16-17$ Jun. 1993, SEAS QLD-956; 8, 2332.16'S $152^{\circ} 17.98^{\prime} \mathrm{E}, 203 \mathrm{~m}, 16-17$ Jun. 1993 SEAS QLD-959; 7, due east of Mooloolaba, $26^{\circ} 36.21^{\prime} \mathrm{S} 153^{\circ} 34.90^{\prime} \mathrm{E}, 116 \mathrm{~m}, 2-3 \mathrm{Aug}$. 1994, SEAS QLD-1126.

Diagnosis. Interocular furrow: moderately developed, distinct but not extending across the cephalon. Frontal lamina: lateral margins straight, narrowing anteriorly. Antenna: c. $0.3 \times$ as long as body, reaching to between the posterior of pereonite 2 and half way along pereonite 3 . Coxal plates: furrows strongly developed, on all coxae. Pleonite 4: apex forming a broad acute point. Pleotelson: broad, length $0.8 \times$ basal width; anterodorsal depression present; anterolateral margins convex; posterolateral margins convex; apex produced into a small point; with 8 12 RS. Pereopods 1-6: males with conspicuous elongated RS subequal to propodus on the merus of pereopods $1-3$ and extending from the carpus to dactylus of pereopods 4 6. Pereopods 2-3: propodus without RS on palm. Pereopod 7: basis of medium breadth (Bruce (1986) describes it and illustrates it (from a topotype male) as relatively narrow. In the syntype female examined here it is broader), width 0.48 $0.53 \times$ length; distance between anterior margin and medial carina less than between posterior margin and medial carina; posterior margin with sparse setae along entire length. Penes: present. Pleopod 2 appendix masculina: extending beyond tip of endopod, 1.06× length of endopod; slender; margins sinuate; apex recurved, bent slightly medially, acute. Uropods: exopod slightly shorter than endopod, $0.87 \times$ the length of the endopod.

Variation. There is a variation in the number of robust setae found on the pleotelson margins. For the syntypes Tattersall (1921) describes and illustrates 12 robust setae while Bruce (1986) describes and illustrates only 10. In BMNH 1921.11.29.22-24 the undissected female syntype has 11 robust setae, the male has nine (and appears damaged on side with only three) and the fully dissected female has 10 . 
In a subsample of ten syntype specimens from BMNH $1921.11 .29 .22-24,30 \%$ had 10 robust setae, $60 \%$ had 11 and $10 \%$ had 12 . The material from off East Fitzroy Reef, Australia (AM P47619-47622) consistently had only eight robust setae on the margins of the pleotelson. Male syntype specimens in BMNH 1921.11.29.22-24, 25-44, have conspicuously elongated robust setae on the merus of pereopods $4-6$ but do not have the elongated robust setae on the merus of pereopods 1-3 that are illustrated by Bruce (1986) from Australian material.

Sexual dimorphism. Females lack the conspicuously elongated robust setae present on the merus of pereopods 1-3 and on the carpus of pereopods 4-6 of adult males.

Size. Largest female $12.0 \mathrm{~mm}$, largest male $8.7 \mathrm{~mm}$, largest manca $5.1 \mathrm{~mm}$, smallest adult female $4.1 \mathrm{~mm}$.

Remarks. Natatolana pellucida is most readily distinguished from similar species by details of the pleotelson and uropods, presence of well-developed eyes, rounded posteroventral margins of pereonite 1 and coxa 2 and relatively short propodus of pereopod 5. This species is most similar to $N$. galathea but has a relatively narrow pleotelson and uropod endopod compared to it.

Distribution and ecology. Australia: Moreton Bay north to Gladstone Queensland, New South Wales, Bass Strait, Tasmania. New Zealand, Campbell Island. Recorded from surface plankton to a depth of $450 \mathrm{~m}$. Scavenger.

\section{Natatolana pilula (Barnard, 1955)}

Figs. 38-40

Cirolana pilula Barnard, 1955: 54, fig. 26a-c.-Kensley, 1975: 39.-1978: 69, fig. $28 \mathrm{H}$.

Natatolana pilula.-Bruce 1981: 958.-1986: 8, 222.-Brusca et al., 1995: 82.-Kensley, 2001: 230.

Type material. Syntypes: 3 specimens, SAM A-43144. According to Barnard (1955) "including male but no ovigerous female". All examined. The material registered as the types has been largely dismembered. One specimen (including pereonites $2-7$, pleon and pleotelson), however, has ooestegites and developing embryos. The remaining specimens cannot be sexed. The pleopod 2 with the appendix masculina figured by Barnard (1955) is not present. None of the type material is in good enough condition to use for a full redescription. - Type locality: False Bay, South Africa, 34 $14^{\circ} 06^{\prime \prime S} 18^{\circ} 39^{\prime} 02^{\prime \prime E}$ and $34^{\circ} 12^{\prime} 08^{\prime \prime S}$ $18^{\circ} 36^{\prime} 05 " \mathrm{E}, 46-62 \mathrm{~m}$.

Material examined. South Africa: $\widehat{\delta}, 10 \mathrm{~mm}, \mathrm{SAM}-\mathrm{A} 14532$, False Bay, 34⒓5'S 18³7'E, 15 May 1961, Sta No: FAL 414V.

Diagnosis. Interocular furrow: well developed, extending across the cephalon; smoothly convex. Frontal lamina: lateral margins straight, parallel. Antenna: c. $0.2 \times$ as long as body, reaching to just posterior of pereonite 1. Coxal plates: furrows variously developed, strong but incomplete on coxae 2-4, complete on coxae 5-7. Pleonite 4: apex broadly rounded. Pleotelson: broad, length $0.67 \times$ basal width; anterodorsal depression absent; anterolateral margins convex; posterolateral margins broadly rounded; apex truncate; RS absent. Pereopods 2-3: propodus without RS on palm. Pereopods 5-7: propodus short and robust on each pereopod. Pereopod 7: basis broad, width $0.58 \times$ length; distance between anterior margin and medial carina less than between posterior margin and medial carina; posterior margin with setae along entire length. Penes: absent. Pleopod 2 appendix masculina: extending subequal with tip of endopod, $0.99 \times$ length of endopod; margins straight or sinuate; slender; apex bent laterally slightly, serrulate with a minute digitiform process. Uropods: exopod slightly shorter than endopod, $0.8 \times$ the length of the endopod.

Additional descriptive characters. Body: length c. $2.5 \times$ width. Colour cream to white in alcohol. Chromatophores absent. Cephalon: submarginal cephalic furrow moderately developed, does not run entire length of anterior margin. Eyes: with 7 ommatidia in horizontal diameter; with 9 ommatidia in vertical diameter; ovate; colour deep red in alcohol. Frontal lamina: length c. $3 \times$ basal width; apex expanded, anterior margin angled. Antennule: short, just reaching pereonite 1. Peduncular article 1 longer than article 2; article 2 with 1 large pappose seta; article 3 very long, subequal to or longer than the combined lengths of articles 1 and 2. Flagellum 10-articulate. Antenna: peduncular article 4 with long SS projecting from posterolateral margin; article 5 with 2 conspicuous pappose setae at posterodistal angle. Flagellum 15-articulate. Mandible: setal row with 13 RS. Maxillule: medial lobe with 3 large robust pappose setae; lateral lobe with 13 RS on distal surface. Maxilla: lateral lobe with $6 \mathrm{SS}$; medial lobe with $5 \mathrm{SS}$ and 6 PS; middle lobe with 15 SS. Maxilliped: endite with 2 coupling hooks, and 5 PS. Pereon: ornamentation consists of 1 strongly developed furrow on the lateral margins of pereonite 1 and 1 weakly developed furrow on lateral margins of pereonites 2 7; pereonite 1 longest, 2-5 subequal, 6-7 progressively shorter. Coxae: pereonite 1, coxae 2-4 with rounded posteroventral corners, coxa 5 with a short square corner, coxae 6 and 7 with broad, acute, posteroventral corners. Pleonites: 1 concealed by pereonite 7,2-5 visible. Pleonite 2: not produced. Pleonite 3: subacute. Pleotelson: PS restricted to apex. Pereopod 7: basis anterior margin straight; medial carina with PS along entire length; posterior margin convex, posterior margin SS present. Ischium anterior margin with non-RS absent; posterior margin with 2 RS (submarginal), PS present. Merus posterior margin with 8 RS, SS present. Carpus posterior margin with 1 RS, SS absent. Propodus subequal to carpus; posterior margin with 3 RS, SS present. Pleopod 2 appendix masculina: arising basally. Pleopods 1-5: exopod suture absent on pleopods 3-5; endopod PS on most of margins on pleopods 1-4, absent on pleopod 5. Uropods: endopod subcircular; medial margin rounded, with 3 RS, PS along entire length; apex with 3 RS; lateral margin straight, with 1 RS, PS on distal three-quarters. Exopod medial margin convex, with 1 RS, PS present on distal half; apex rounded, with $3 \mathrm{RS}$; lateral margin convex, with $2 \mathrm{RS}$, PS on distal quarter.

Size. 10-11 mm (Barnard, 1955; Kensley, 1978; this study).

Remarks. The material examined matches the original description and illustrations of Natatolana pilula by Barnard (1955) except that chromatophores are absent, whereas the original description mentions pinkish or greyish speckles.

The following characters are most useful in distinguishing Natatolana pilula from other species within the genus; the short antenna, the shape of the posterolateral margins of pleonites 3 and 4, the shape and setation of the pleotelson and uropods; and the morphology of the appendix masculina apex.

Distribution. South Africa: Lambert's Bay to Natal. At depths of 18-66 m (Barnard, 1955; Kensley, 1978; Bruce, 1986). 


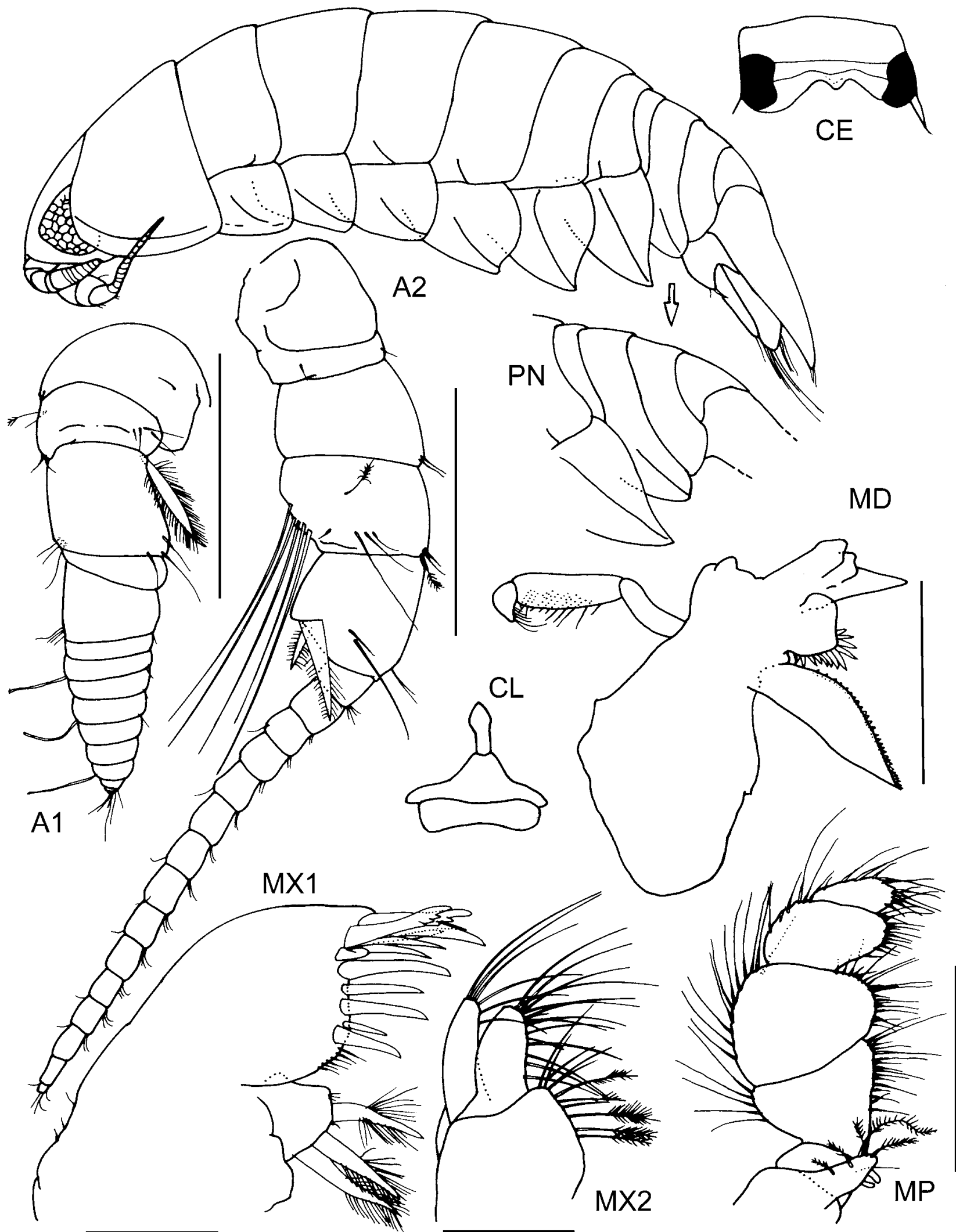

Fig. 38. Natatolana pilula, male SAM A-14532. Scales for MD, MP $=0.5 \mathrm{~mm}$, for MX1, MX2 $=0.2 \mathrm{~mm}$, for A1, A2 = $0.5 \mathrm{~mm}$.

Natatolana prolixa Bruce, 1986

Natatolana prolixa Bruce, 1986: 64, figs. 40, 41.-Brusca et al., 1995: 82.-Bruce et al., 2002: 152.

Type material. Holotype: ô, $21.0 \mathrm{~mm}, \mathrm{QM}$ W6738 (examined). - Type locality: off Hay Point, Mackay, Queensland, Australia, $21^{\circ} 17^{\prime} \mathrm{S} 149^{\circ} 18^{\prime} \mathrm{E}$.
Diagnosis. Interocular furrow: moderately developed, distinct but not extending across the cephalon. Frontal lamina: lateral margins straight, parallel. Antenna: c. $1.5 \times$ as long as body, reaching to beyond pleotelson. Coxal plates: furrows variously developed, indistinct furrows on coxae 2-3 only. Pleonite 2: ventral posterolateral margin acute, 


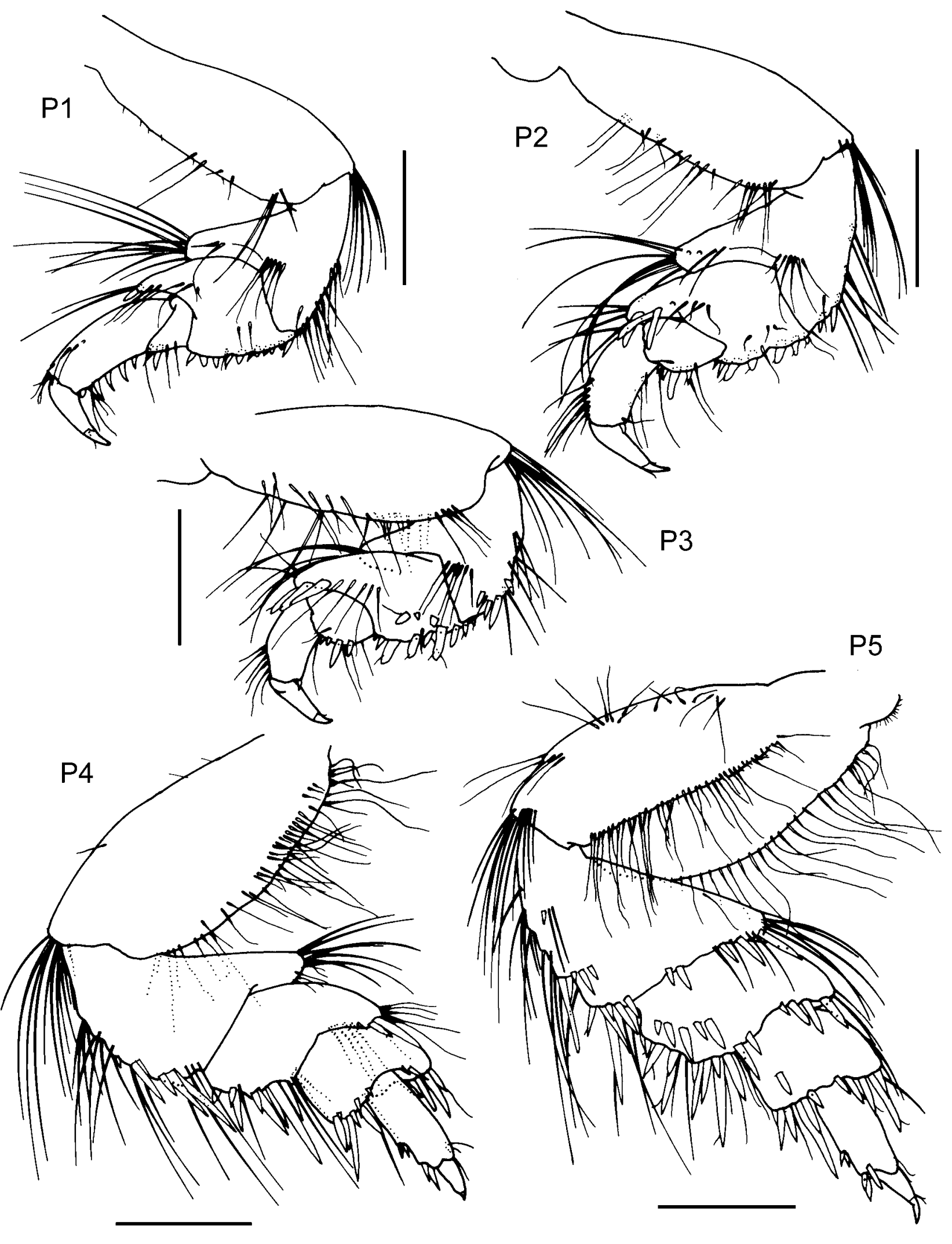

Fig. 39. Natatolana pilula, male SAM A-14532. Scales $=0.5 \mathrm{~mm}$. 


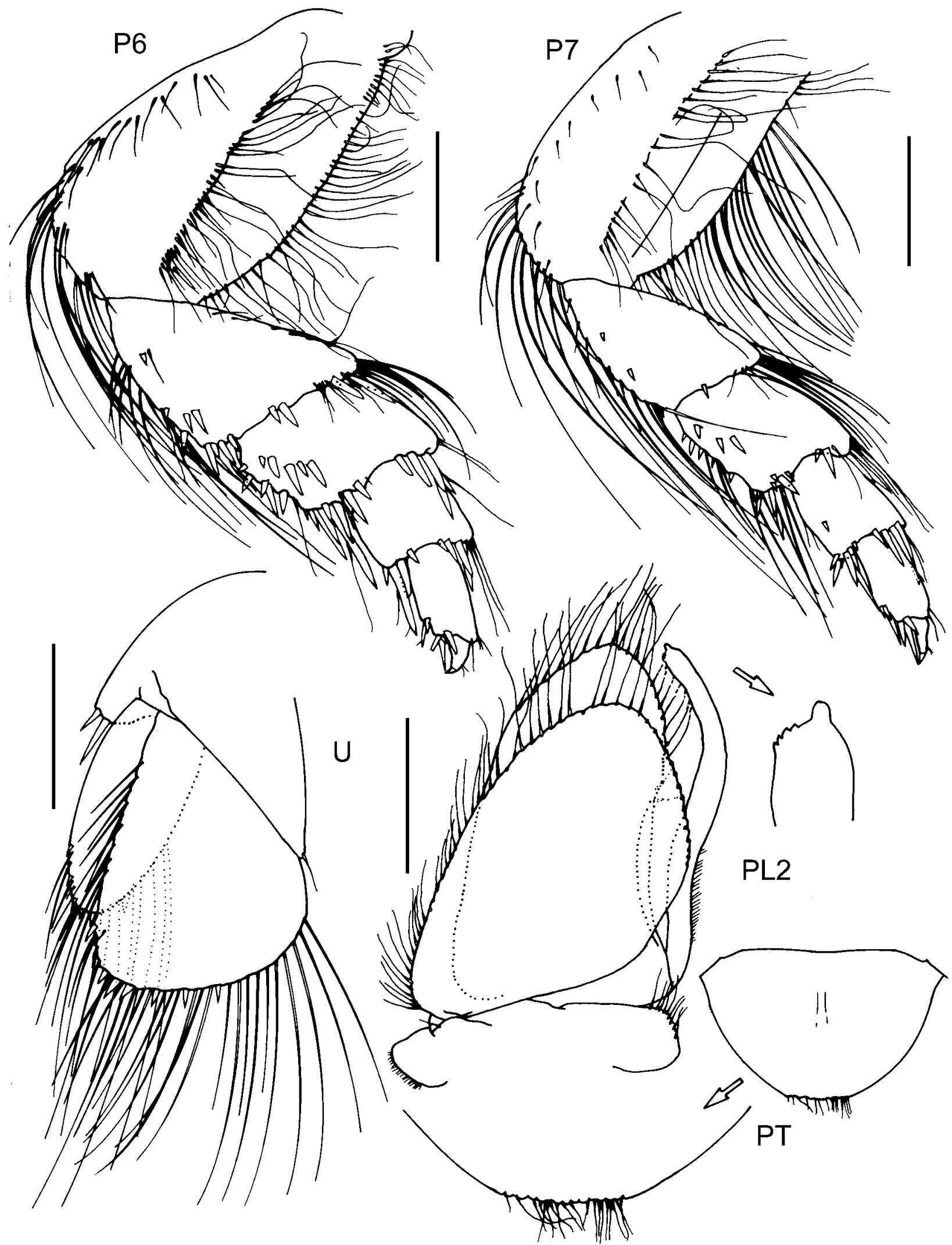

Fig. 40. Natatolana pilula, male SAM A-14532. Scales $=0.5 \mathrm{~mm}$ 
formed into long curved process. Pleonite 4: posterodorsal margin strongly concave proximal to meeting posteroventral margin at apex; apex forming a narrow acute point. Pleotelson: broad, length $0.75 \times$ basal width; anterodorsal depression absent; anterolateral margins convex; posterolateral margins concave; apex produced into a large point; RS absent. Pereopod 2: propodus with 2 RS on palm. Pereopod 3: propodus with 2 RS on palm. Pereopod 7: basis of medium breadth, width $0.5 \times$ length; distance between anterior margin and medial carina less than between posterior margin and medial carina; posterior margin with setae along entire length. Penes: present (although the vas deferens are described as opening flush to the sternite surface by Bruce (1986), distinct penial processes are evident in the type material). Pleopod 2 appendix masculina: extending subequal with tip of endopod; slender; margins straight; apex not at angle to adjacent margins, acute. Uropods: exopod subequal to endopod, $0.95 \times$ the length of the endopod.

Sexual dimorphism. Unknown.

Size. Adults to $21 \mathrm{~mm}$.

Remarks. The long antennae and sinuate margins of the pleotelson that lack robust setae separate Natatolana prolixa from all other species in the genus.

Distribution. Australia: Hay Point, Mackay, Queensland. At depths of 15-21 m.

\section{Natatolana rekohu Bruce, 2003}

Natatolana rekohu Bruce, 2003: 4, figs. 1-4.

Type material. Holotype, NIWA H831, male (19.5 mm). Paratypes, NIWA P1380, 5 ô $\widehat{o}(18.5,20.0,20.5,23.3,24.0$ [dissected] mm), 13 우 (non-ovigerous 17.5-26.5 mm), 3 mancas $(8.5,9.1,12.0 \mathrm{~mm})$. None examined. - Type locality: Chatham Rise, $46^{\circ} 38.24^{\prime} \mathrm{S} 178^{\circ} 31.39^{\prime} \mathrm{E}, 2769 \mathrm{~m}$.

Material examined. 10, AM P65202, from type locality.

Diagnosis. Eyes: vestigial. Interocular furrow: moderately developed, distinct but not extending across the cephalon. Frontal lamina: lateral margins concave but not medially constricted, narrowing toward apex. Antenna: c. $0.19 \times$ as long as body, reaching to middle of pereonite 3. Coxal plates: furrows strongly developed, on all coxae. Pleonite 2: ventral posterolateral margin not produced. Pleonite 4: apex slightly rounded. Pleotelson: broad, length $0.7 \times$ basal width; anterodorsal depression absent; anterolateral margins convex; posterolateral margins convex; apex not produced, lateral margins converging smoothly to a point, or rounded; with 12-18 RS. Pereopod 2: propodus with 3-7 RS on palm. Pereopod 3: propodus with 4 RS on palm. Pereopod 7: basis narrow, width $0.39 \times$ length; distance between anterior margin and medial carina less than between posterior margin and medial carina; posterior margin with setae on more than proximal half. Penes: present. Pleopod 2 appendix masculina: just shorter than endopod, $0.9 \times$ length of endopod; margins very strongly curved laterally; broad; apex not at angle to adjacent margins, club shaped with a lateral notch. Uropods: exopod slightly shorter than endopod, $0.87 \times$ the length of the endopod.

Size. Males 18.5-24.0mm, females 17.5-24.5mm, both with a mean of $21 \mathrm{~mm}$; mancas $8.5-12.0 \mathrm{~mm}$.
Remarks. Natatolana rekohu is most similar to N. imicola. It can be distinguished from that species by (in N. rekohu) the greater number of robust setae on the propodal palm of pereopods 1-3 and the (generally) greater number of robust setae on the margins of the pleotelson and uropods. These two species can be separated from other species of Natatolana in which the eyes are vestigial or absent by: the presence of coxal furrows on all coxae; the distinctive club shaped appendix masculina of male specimens; and the ischium of pereopod 3 having the anterodistal angle not weakly produced relative to that of pereopods $1-2$.

Distribution and ecology. Chatham Rise, southeast of New Zealand. At a depth of $2799 \mathrm{~m}$. Scavenger.

\section{Natatolana rossi (Miers, 1876)}

Figs. 41-42

Cirolana rossi Miers, 1876a: 228.-1876b: 109. pl. 3, fig. 3.Hutton, 1879: 340.-Filhol, 1885: 453, 499.-Hansen, 1890: 355.-Thomson \& Chilton, 1886: 154.-Chilton, 1909: 606, 651.-Nierstrasz, 1917: 91, pl. 13, figs. 11-17.-1931: 158.Stephensen, 1927: 361.-Hurley, 1961: 267.-Kussakin, 1967: 223.-Ellis, 1981: 123.

Natatolana rossi.-Bruce, 1981: 958.-1986: 53, 93, 97, 222.Brusca et al., 1995: 82.

Cirolana hirtipes.-Filhol, 1885: 455, 499, pl. 53 fig. 6.-Nierstrasz, 1931: 158.-Hurley, 1961: 267 [mis-identification, not $N$. hirtipes (Milne Edwards, 1840)].

Not Cirolana rossi.-Hale, 1952: 24 [mis-identification $=N$. matong Bruce, 1986].

Type material. Lectotype: designated here, $ぇ, 18 \mathrm{~mm}, \mathrm{BMNH}$ 1844:3. Paralectotypes: all BMNH, 2, 1843: 70; 6, 1844: 3; 1, 1848: 80; 2, 1856: 33. Details as per the list of Ellis (1981) except the material presented by Lieut. A. Smith has the label: "Rendezvous Cove, Auckland Island, 'Erebus'-Antarctic Expedition" and has registration number: 1843:70, not 1856:33. All examined. - Type locality: originally New Zealand, [c. $40^{\circ} \mathrm{S}$ $\left.175^{\circ} \mathrm{E}\right]$ and Auckland Islands, New Zealand, [50 $\left.35^{\circ} \mathrm{S} 166^{\circ} \mathrm{E}\right]$, now restricted to Auckland Islands, New Zealand.

Material examined. New Zealand: 4, NMNZ Cr 9199, west of Rangitikei River mouth, $40^{\circ} 16^{\prime} \mathrm{S} 174^{\circ} 58.5^{\prime} \mathrm{E}, 75 \mathrm{~m}$, RV Acheron, 2 Mar. 1976; 1, NMNZ Cr 9197, between West Entry Point and Duffers Reef, Pelorus South, 40 $57.5^{\prime} \mathrm{S} 174^{\circ} 01.5^{\prime} \mathrm{E}, 29$ m, RV Acheron, 5 Mar. 1976; 4, NMNZ Cr 9201, south of Mana Island, $41^{\circ} 10^{\prime} \mathrm{S} 177^{\circ} 43^{\prime} \mathrm{E}, 37-53 \mathrm{~m}, 21$ Oct. 1969; many, QM W10261, Tasman Bay, $41^{\circ} 17.55^{\prime} \mathrm{S} 173^{\circ} 16.97^{\prime} \mathrm{E}$, trap, $14 \mathrm{~m}, 2$ May 1971, NIWA stn K179(4); 36, NMNZ Cr 4997, Kaikoura, [42 $\left.23^{\circ} \mathrm{S} 173^{\circ} 41^{\prime} \mathrm{E}\right]$, feeding on crayfish bodies in hagfish trap, Jul. 1987; 20, NMNZ 4998, Kaikoura, baited trap, 10 Sep. 1974. 10, NMNZ 9200, North Otago, on Squalus acanthus, 27-33 m, J. Graham, Oct. 1961; 10, NMNZ Cr 4999, Auckland Island, [50 $35^{\prime} \mathrm{S} 166^{\circ} \mathrm{E}$ ], in crab pots, $55 \mathrm{~m}$, L.D. Ritchie, 11 Feb. 1970.

Diagnosis. Eyes: well developed; elongate, length c. $2 \times$ height. Interocular furrow: well developed, extending across the cephalon; produced medially. Frontal lamina: lateral margins straight, narrowing anteriorly, or medially constricted. Antenna: c. $0.35-0.5 \times$ as long as body, reaching to between the posterior of pereonite 3 and pereonite 4. Coxal plates: furrows strongly developed, on all coxae. Pleonite 4: apex forming a broad acute point, or slightly rounded. Pleotelson: broad, length $0.8 \times$ basal width; anterodorsal depression absent; anterolateral margins almost straight and angling posteriorly toward the midline, or convex; posterolateral margins straight, markedly angled to anterolateral margins and meeting at an acute angle or convex; 


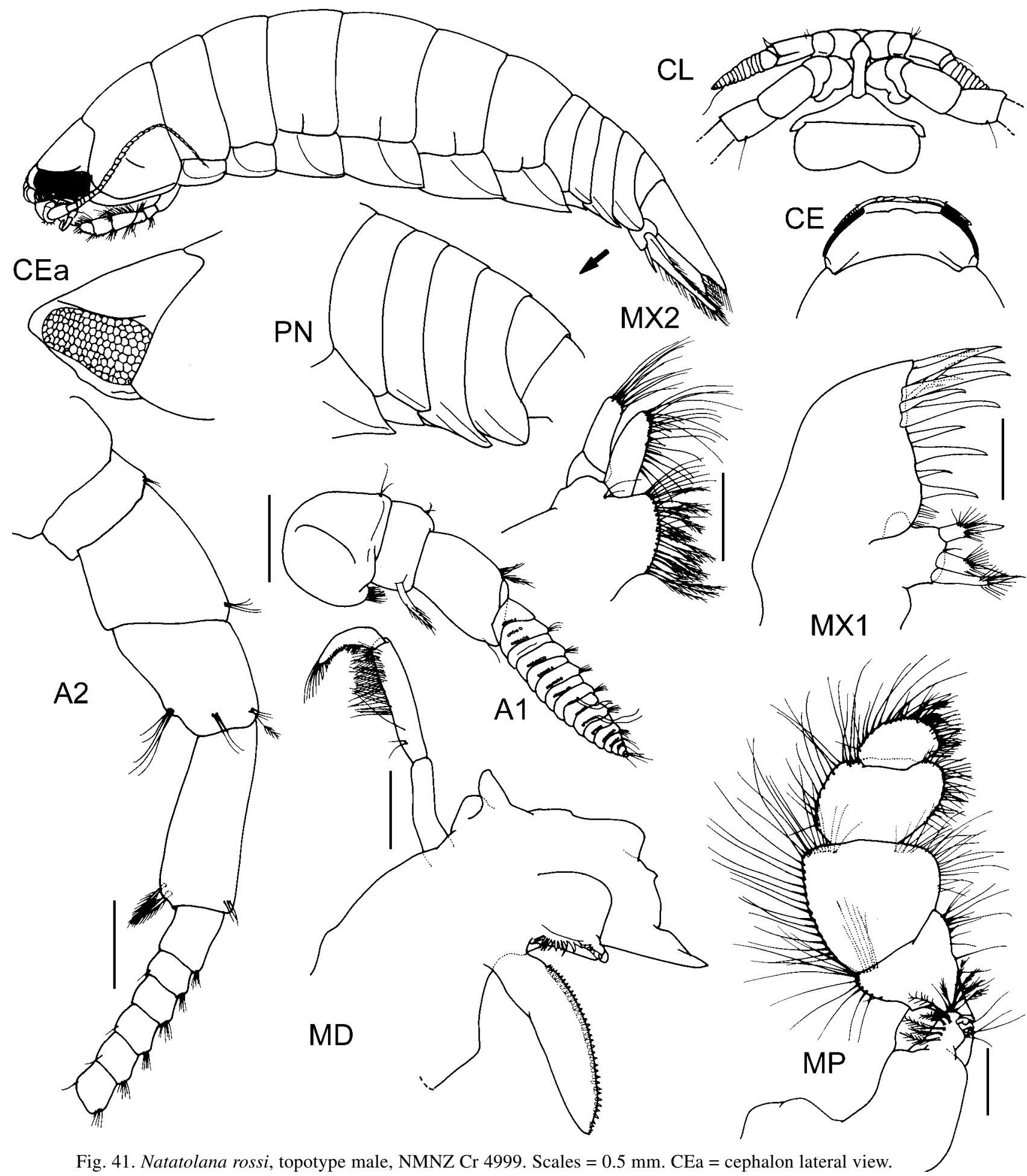

apex not produced, lateral margins converging smoothly to a point; with 10-16 RS. Pereopod 2: propodus with 3 RS on palm. Pereopod 3: propodus with 2 RS on palm. Pereopod 7: basis broad, width $0.64 \times$ length; distance between anterior margin and medial carina less than between posterior margin and medial carina; posterior margin with setae completely absent along entire length. Penes: absent. Pleopod 2 appendix masculina: extending subequal with tip of endopod, 0.96x length of endopod; margins very slightly curved laterally; slender; apex not at angle to adjacent margins, bluntly rounded. Uropods: exopod subequal to endopod, $0.94 \times$ the length of the endopod.
Additional descriptive characters. Based on a topotype, male, 36 mm, NMNZ Cr.4999. Body: length c. 2.7× width. Colour yellow or salmon-pink in alcohol. Chromatophores absent. Eyes: with 18 ommatidia in horizontal diameter; with 8 ommatidia in vertical diameter; rectangular; colour tan in alcohol. Frontal lamina: length c. $4.2 \times$ basal width; apex expanded, anterior margin angled. Antennule: peduncular article 1 longer than article 2; article 2 with 1 large pappose seta; article 3 short, subequal to article 1 . Flagellum 16-articulate. Antenna: peduncular article 4 with 1 patch of $6 \mathrm{SS}$ on posterolateral margin, $2 \mathrm{SS}$ distomedially, 3 PS and 1 penicillate setae at anterodistal angle; article 5 


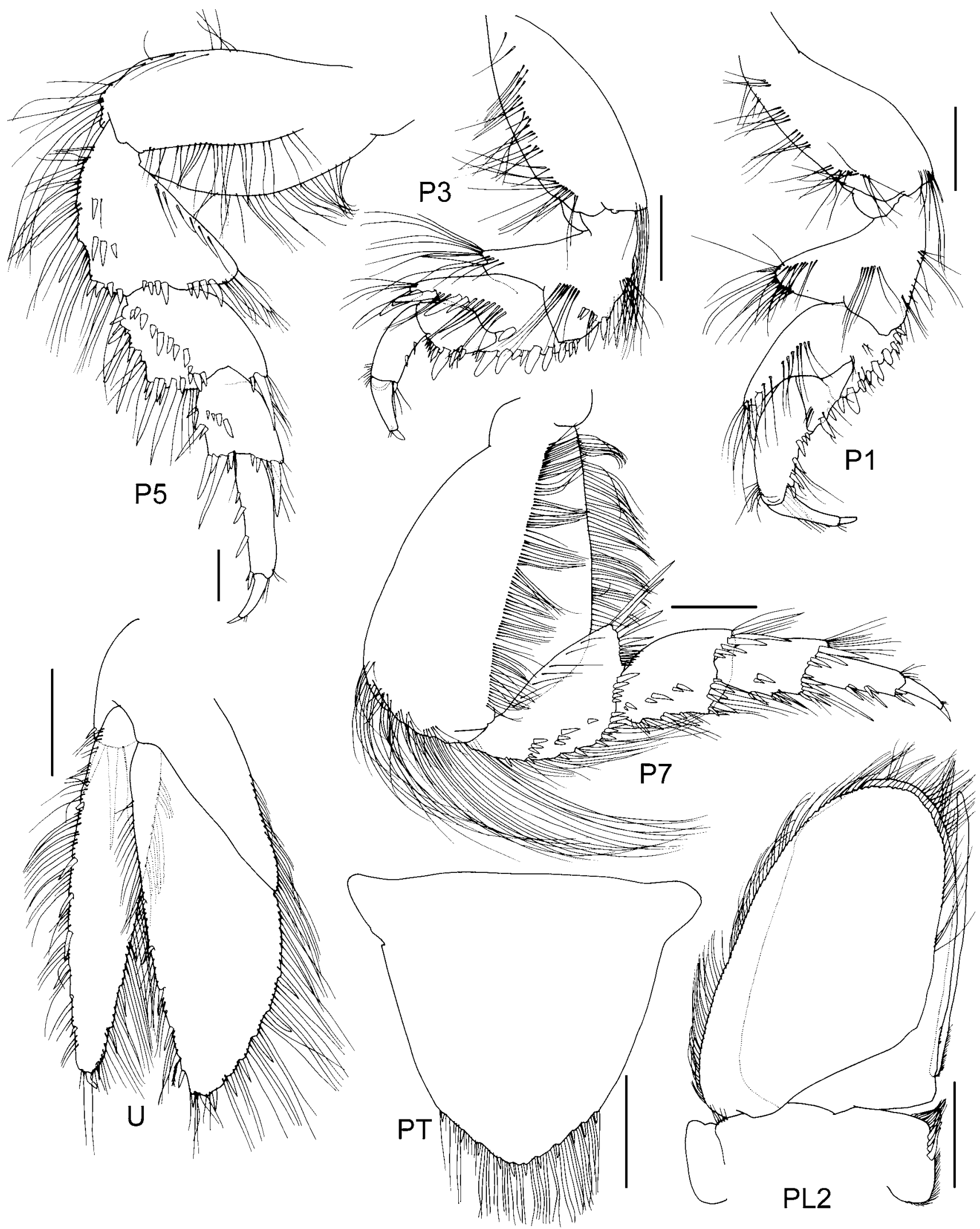

Fig. 42. Natatolana rossi, topotype male, NMNZ Cr 4999. Scales $=1.0 \mathrm{~mm}$.

with 2 pappose at posterodistal angle, $3 \mathrm{SS}$ at anterodistal angle. Flagellum 34-articulate. Mandible: setal row with 19 RS. Maxillule: medial lobe with 3 large robust pappose setae; lateral lobe with 13 RS on distal surface. Maxilla: lateral lobe with $12 \mathrm{SS}$; medial lobe with c. $12 \mathrm{SS}$ and 23
PS; middle lobe with 26 SS. Maxilliped: endite with 5 coupling hooks, 1 SS and 12 PS. Pereon: ornamentation consists of 1 strongly developed furrow on lateral margin of pereonite 1 and 1 short, medial furrow on lateral margins of 4-7; pereonites 1 and 5 subequal in length and longest, 
pereonites 4, 6-7 subequal and longer than 2-3 which are subequal. Coxae: pereonite 1 and coxae $2-3$ with rounded posteroventral corners, coxae 4-7 with increasingly produced, broad, acute posteroventral corners. Pleonite 2: dorsal posterolateral margin subequal with ventral posterolateral margin. Pereopod 7: basis anterior margin convex; medial carina with PS along entire length; posterior margin convex. Ischium anterior margin with SS; posterior margin with 4 RS (and 8 submarginally), PS present. Merus posterior margin with $5 \mathrm{RS}$ (and 6 submarginally), SS present. Carpus posterior margin with 6 RS (and 2 submarginally), SS present. Propodus subequal to carpus; posterior margin with $6 \mathrm{RS}$, SS present. Pleopod 2 appendix masculina: arising sub-basally. Pleopods 1-5: exopod suture feebly developed (sutures present at margins but not medially) on pleopods 3-5; endopod PS on most of margins of pleopods 1-4, only a few setae on pleopod 5. Uropods: endopod lanceolate; medial margin convex, with 5 RS, PS along entire length; apex with 2 RS; lateral margin slightly convex, with 5 RS, PS on distal three-quarters. Exopod medial margin convex, with 3 RS, PS on distal threequarters; apex acute, with $2 \mathrm{RS}$; lateral margin convex, with 8 RS, PS along entire length.

Variation. There is considerable variation in the number of robust setae on the pleotelson and uropods of individuals within all samples examined. There are also some differences between samples; specimens in BMNH 1856:33 (New Zealand), QM W10261 (Tasman Bay), NMNZ Cr 9197, 9199, 9200 and 9201 (Pelorus South, Rangitikei River, Otago, Mana Island, respectively), tend to have a greater number of robust setae on the pleotelson and uropods than specimens in other samples. A comparison (below) of 10 specimens from each of the samples NMNZ Cr 4999 (Auckland Island) and 9200 (Otago) indicates this, figures for $\mathrm{Cr} 9200$ are in square brackets. Pleotelson: 11 (20\%), $12(60 \%), 13(20 \%),[14(100 \%)]$. Endopod, medial: 5 (30\%), 6 (60\%) [20\%], [7 (80\%)], 8 (10\%); lateral: $4(20 \%)$, $5(40 \%), 6(40 \%)$ [60\%], [7 (30\%)], [8 (10\%)]. Exopod, medial: $3(20 \%), 4(80 \%)$ [10\%], [5 (70\%)], [6 (20\%)]; lateral: $8(30 \%), 10(10 \%)$ [20\%], $11(50 \%)$ [40\%], [12 $(40 \%)]$. Because the ranges tend to overlap and no other consistent feature (such as the variation in pleotelson shape as noted in the diagnosis and below) could be found to correlate with these variations, and separate the specimens in these samples, it was concluded that a single variable species is represented. The full variation in setal counts is as follows; pleotelson 10-16, uropod endopod medial margin 5-8, lateral margin 4-8, uropod exopod medial margin 3-6, lateral margin 8-12.

The length of the antenna also varies, on some specimens it reaches to the posterior of pereonite 4 and is $0.5 \times$ the length of the body, while in the material described and the lectotype selected here (see below) it reaches to the posterior of pereonite 3 and is c. $0.35 \times$ the length of the body. The number of flagella articles in the antennae also ranges from 26-36. Furthermore, in some specimens the anterolateral and posterolateral margins of the pleotelson are relatively straight compared to the material illustrated here. In the material examined the number of coupling hooks on the maxilliped endites ranged from two to five. Smaller specimens have fewer articles in the antennular and antennal flagella, and fewer coupling hooks on the maxilliped endite.

The lectotype has 11 robust setae on the pleotelson, six on the uropod endopod medial margin, 6 on the uropod endopod lateral margin, four on the uropod exopod medial margin and 12 on the uropod exopod lateral margin. In the lectotype the antennae extend to just beyond pereonite 3 and the posterolateral margins of the pleotelson are only slightly convex and distinctly angled to the anterolateral margins, which are relatively straight.

Size. Lengths of $25 \mathrm{~mm}, 26 \mathrm{~mm}$ and $21 \mathrm{~mm}$ have previously been recorded (Miers, 1876a, b; Nierstrasz, 1917; Kussakin, 1967). In the material examined here adults ranged from $18 \mathrm{~mm}$ up to $36 \mathrm{~mm}$.

Remarks. Because of the large number of syntypes and the variation among them, a male (BMNH 1844:3, Auckland Is., Antarctic Expedition, Presented by Capt. James Clarke Ross) is selected here as a lectotype for Natatolana rossi to avoid future taxonomic confusion when identifying this species. The remaining type specimens become paralectotypes. A topotype that has been closely compared to the types is illustrated here, and used for the description of characters additional to the diagnosis, because the type specimens are fragile and are damaged so that they lack many setae.

Natatolana rossi is extremely similar to $N$. hirtipes in most features, as noted by Chilton (1909). Miers (1876a) distinguished $N$. rossi from $N$. hirtipes because Milne Edwards (1840) described the length of the cephalon of that species to be equal to the width. This description is incorrect, however, consistent differences between $N$. rossi and $N$. hirtipes include a medially produced interocular furrow (smoothly convex in $N$. hirtipes), a convex anterior margin to the eye (angled in $N$. hirtipes), a concave ventral margin to the cephalon (convex in $N$. hirtipes) and a slightly more sinuate anterior margin of the basis of pereopod 7 in $N$. hirtipes. Large males of $N$. hirtipes may develop indistinct tubercles on the dorsal surface of pereonite 2, these are not apparent in material identified as $N$. rossi.

Natatolana rossi is also extremely similar to $N$. matong. The development of the interocular and coxal furrows does not reliably separate the two species as suggested by Bruce (1986). The shape of pleonite 4 is, however, consistently different between the two species, $N$. rossi having a more sinuate posterodorsal margin.

Distribution and ecology. New Zealand and southern Pacific Ocean south of New Zealand. In depths to $260 \mathrm{~m}$ (Kussakin, 1967). Marsden (1999) has measured the feeding rate, oxygen consumption and effects of aerial exposure for this species, concluding it is a predator/scavenger capable of long periods of fasting.

\section{Natatolana rusteni n.sp.}

Figs. 43-44

Type material. HOLOTYPE: $\widehat{\jmath}, 8 \mathrm{~mm}$, AM P47158. PARATYPES: 576 specimens AM P38672; 0 , 9 , in BMNH, USNM, ZMUC. • Type locality: off Dobroyd Head, Port Jackson, NSW, Australia, $33^{\circ} 48.7^{\prime} \mathrm{S} 151^{\circ} 16.4^{\prime} \mathrm{E}$, [baited trap, unknown substrate, probably sediment], 15 m, [S. Keable, D. Townsend, J. Lowry, 3-4 Jul. 1988, Site 30].

Additional material. New South Wales: $q$, ZMUC CRU122, near Solitary Islands, $2^{\circ} 57^{\prime} \mathrm{S} 153^{\circ} 22^{\prime} \mathrm{E}, 50 \mathrm{~m}, 11$ Nov. 1951, Galathea stn 544; series of 224 specimens, AM P47159-47165, Port Jackson, $33^{\circ} 48.3-50.3^{\prime} \mathrm{S} 151^{\circ} 15.2-16.6^{\prime} \mathrm{E}$, baited trap, sediments, 8-13 m, S. Keable et al., 1988; series of 254 specimens, 


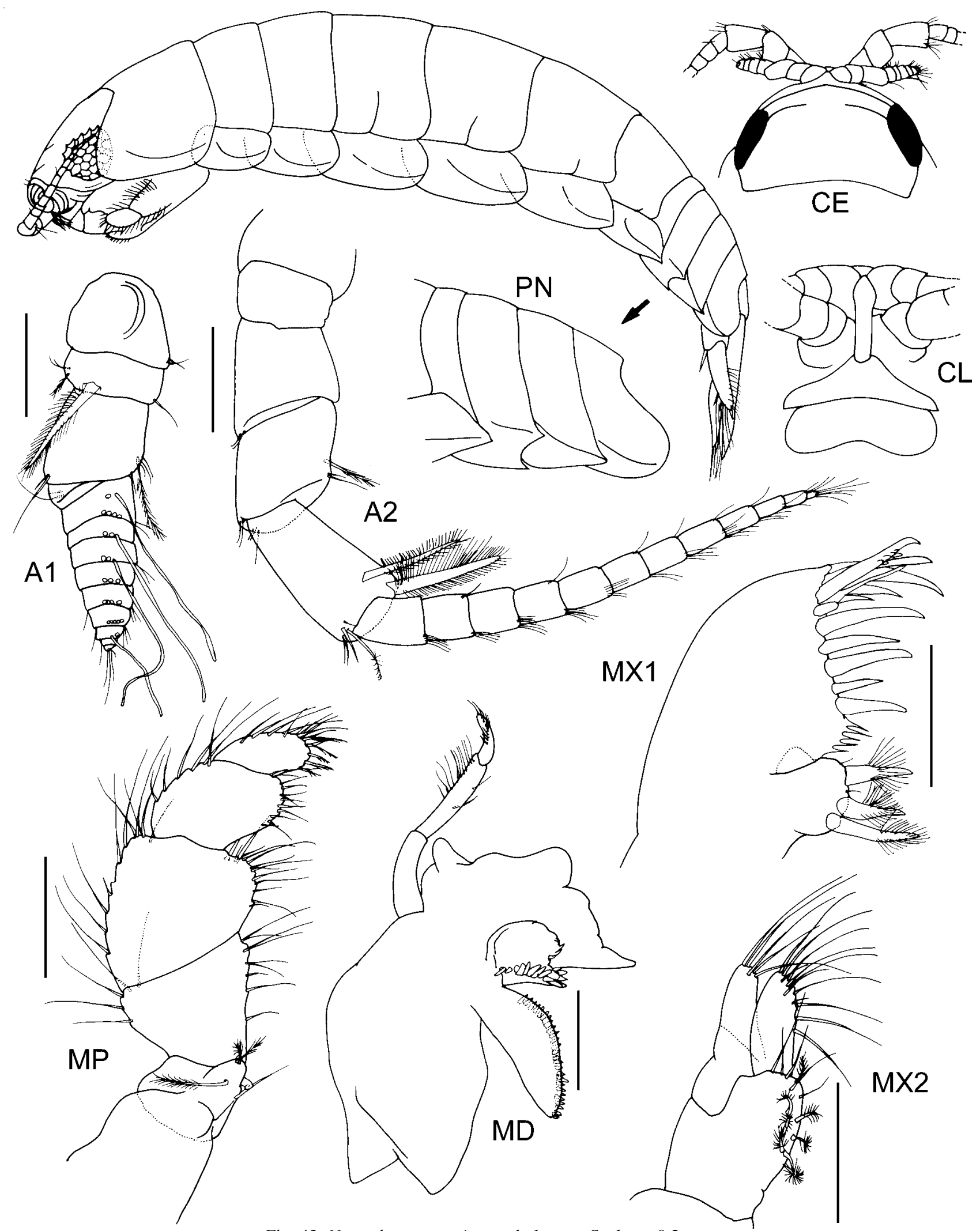

Fig. 43. Natatolana rusteni $\mathrm{n} . \mathrm{sp}$., holotype. Scales $=0.2 \mathrm{~mm}$.

AM P47166-47172, off Bate Bay/Port Hacking, $34^{\circ} 07.00^{\prime} S$ $151^{\circ} 10.00^{\prime} \mathrm{E}$, baited trap, sediments, $25-40 \mathrm{~m}$, AM/The Ecology Lab Pty. Ltd. Pioneer Consultation Project 1991; series of 18 specimens, AM P47173-47184, Botany Bay, 3358.25-59.31'S $151^{\circ} 09.91-$ 11.92'S, baited traps, sediments, 5-7 m, S. Keable \& R. Springthorpe 1992, AM/Federal Airports Corporation Consultation Project.
Diagnosis. Interocular furrow: moderately developed, distinct but not extending across the cephalon. Frontal lamina: lateral margins straight, parallel. Antenna: c. $0.23 \times$ as long as body, reaching to posterior of pereonite 2. Coxal plates: furrows moderately developed, on all coxae. Pleonite 4: apex broadly rounded. Pleotelson: narrow, length $1.05 \times$ basal width; 


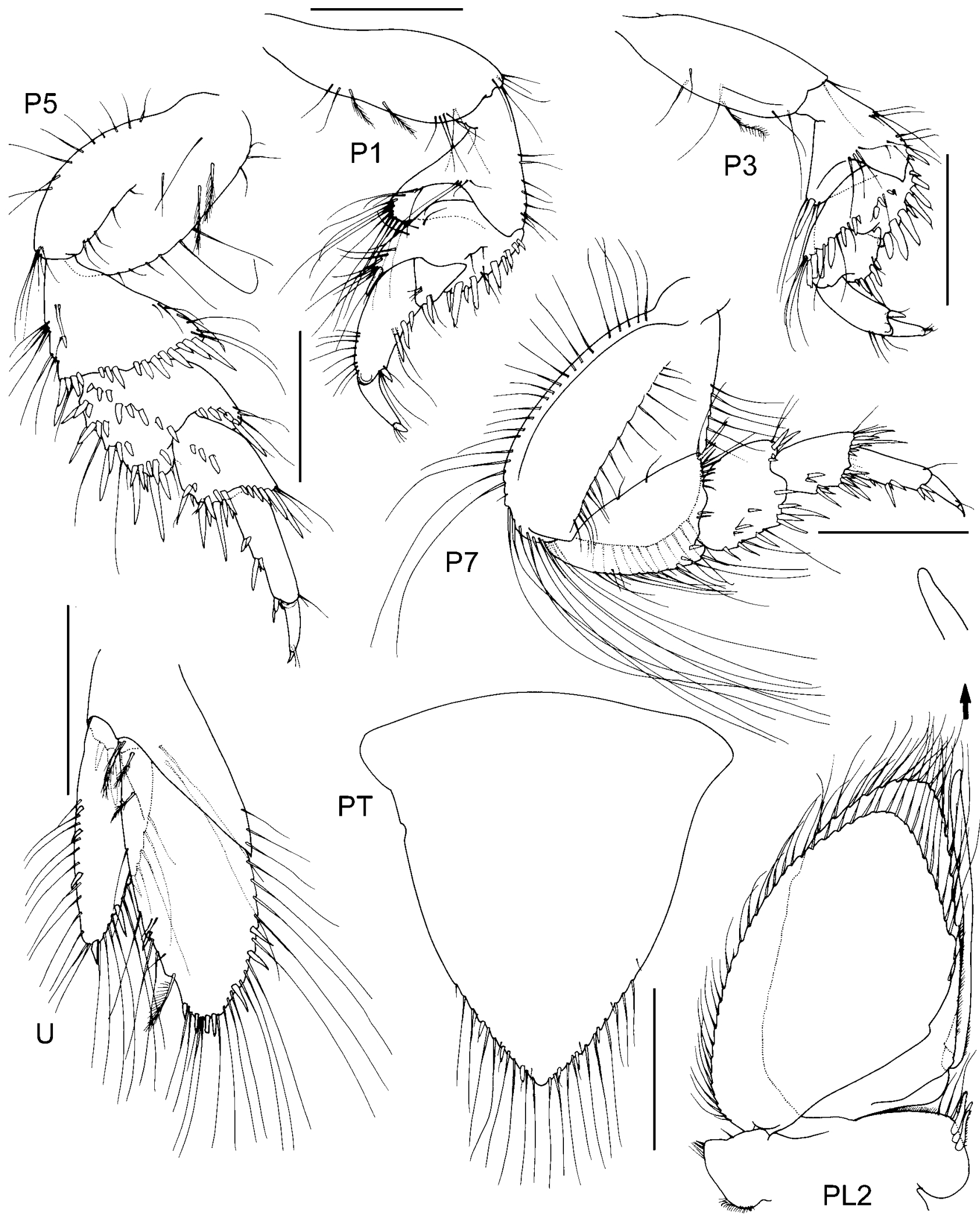

Fig. 44. Natatolana rusteni n.sp., holotype. Scales $=0.5 \mathrm{~mm}$, except for MX2 and U = $0.2 \mathrm{~mm}$.

anterodorsal depression absent; anterolateral margins convex; posterolateral margins convex; apex not produced, lateral margins converging smoothly to a point; with 6-7 RS. Pereopods 2-3: propodus without RS on palm. Pereopod 7: basis broad, width $0.63 \times$ length; distance between anterior margin and medial carina greater than between posterior margin and medial carina; posterior margin with setae along entire length. Penes: absent. Pleopod 2 appendix masculina: extending beyond tip of endopod, $1.04 \times$ length of endopod; margins very slightly curved laterally; slender; apex recurved, bent slightly medially, bluntly rounded. Uropods: exopod short, $0.72 \times$ the length of the endopod. 
Additional descriptive characters. Based on holotype. Body: length c. $3.48 \times$ width. Colour cream in alcohol. In freshly preserved material there is often an orange or red/ brown colouring on the posterolateral margins of pleonite 4. Chromatophores absent. Eyes: with 6 ommatidia in horizontal diameter; with 8 ommatidia in vertical diameter; round; colour red/brown in alcohol. Frontal lamina: length c. $5 \times$ basal width; apex expanded, anterior margin angled. Antennule: peduncular article 1 longer than article 2; article 2 with 1 large pappose seta; article 3 long, larger than article 1 or 2 but shorter than their combined lengths. Flagellum 9-articulate. Antenna: peduncular article 4 with 1 penicillate seta and 2 SS on posterolateral margin, several PS at anterodistal angle; article 5 with 2 conspicuous pappose setae at posterodistal angle, 1 penicillate seta and $5 \mathrm{SS}$ at anterodistal angle. Flagellum 12-articulate. Mandible: setal row with 15 RS. Maxillule: medial lobe with 3 large robust pappose setae; lateral lobe with $13 \mathrm{RS}$ on distal surface. Maxilla: lateral lobe with $5 \mathrm{SS}$; medial lobe with $5 \mathrm{SS}$ and 7 PS; middle lobe with 12 SS. Maxilliped: endite with 1 coupling hook, and 3 PS. Pereon: ornamentation consists of 1 weakly developed furrow on lateral margin of pereonite 1 and 1 short, medial furrow on lateral margins of pereonites 4-6; pereonites 1, 4-6 subequal and longest, 2-3 and 7 subequal. Coxae: pereonite 1 and coxae 2-5 with rounded posteroventral corners, coxae 6-7 with increasingly produced, broad, acute posteroventral corners. Pleonite 2: dorsal posterolateral margin subequal with ventral posterolateral margin. Pereopod 7: basis anterior margin slightly convex; medial carina with PS along entire length; posterior margin convex, PS present. Ischium anterior margin with SS (sparse); posterior margin without RS, PS present. Merus posterior margin with 3 RS (and 3 submarginally), 1 SS. Carpus posterior margin with 3 RS (and 2 submarginally), SS absent. Propodus subequal to carpus; posterior margin with 4 RS, SS absent. Pleopod 2 appendix masculina: arising sub-basally. Pleopods 1-5: exopod suture strongly developed on pleopods $3-5$; endopod PS on most of margins of pleopods 1-4, only a few setae on pleopod 5. Uropods: endopod lanceolate; medial margin convex, with 3 RS, PS along entire length; apex with $3 \mathrm{RS}$; lateral margin slightly convex, with $2 \mathrm{RS}$ and 1 penicillate seta, PS on distal two-thirds. Exopod medial margin convex, with 2 RS, PS on distal two-thirds; apex acute, with 2 RS (1 missing on side illustrated but socket present and setae present on other side); lateral margin convex, with 3 RS, PS on distal two thirds.

Variation. One paratype specimen has seven robust setae on the pleotelson margin.

\section{Size. Adults to c. $8 \mathrm{~mm}$.}

Etymology. Named after Mr Jim Rusten, former storeman at the Australian Museum, in recognition of his help with boats and other field equipment that made collection of the type specimens possible.

Remarks. Natatolana rusteni is separated from nearly all other species within the genus by its relatively short antennae that have few flagellar articles. This character, in combination with the number of robust setae on the pleotelson and the shape of the pleotelson, identifies this species as distinct. Natatolana kahiba is most similar but has a shorter, less acute pleotelson with four robust setae. Natatolana lilliput n.sp. is also extremely similar but also has a shorter, less acute pleotelson and a complete interocular furrow.
Distribution and ecology. Australia: within and off Port Jackson and Botany Bay, and off Solitary Islands, New South Wales. At depths of 5-50 m. Scavenger.

\section{Natatolana sinuosa n.sp.}

Figs. $45-47$

Cirolana corpulenta.-Hale, 1940: 289 (part) [mis-identification, not Natatolana corpulenta (Hale, 1925)].

Natatolana corpulenta.-Bruce 1986: 79, figs. 51-53 (part) [misidentification, not Natatolana corpulenta (Hale, 1925)].

Type material. Holotype: $\delta, 14.5 \mathrm{~mm}$, AM P47214. PARATYPE: + , $16.5 \mathrm{~mm}$, TM, same collection data as holotype only $100 \mathrm{~m}$ off Pilot Beach, $3 \mathrm{~m}$, TAS-285. - Type locality: between breakwater and Prater Rock, Pilot Bay, Tasmania, Australia, $42^{\circ} 12^{\prime} \mathrm{S} 145^{\circ} 12^{\prime} \mathrm{E}$, [baited trap, probably sand bottom], 10 m, [J. Lowry \& S. Keable, 26-27 April 1991, TAS-284].

Additional material. New South Wales: series from near Newcastle, AM Hunter District Water Board Survey, Shipek [grab] (reported by Bruce [1986]): 1, AM P23034, $1 \mathrm{~km}$ east of Belmont Beach, $33^{\circ} 02.36^{\prime} \mathrm{S} 151^{\circ} 41^{\prime} \mathrm{E}, 18 \mathrm{~m}$; 1, AM P23036, $500 \mathrm{~m}$ east of Belmont Beach, 330. $2.5^{\prime} \mathrm{S} 151^{\circ} 41^{\prime} \mathrm{E}, 14 \mathrm{~m} ; 2$, AM P23037, 500 $\mathrm{m}$ east of Stockton Beach, $32^{\circ} 54^{\prime} \mathrm{S} 151^{\circ} 47.5^{\prime} \mathrm{E}, 6 \mathrm{~m}$; 2 , AM P23038, $1 \mathrm{~km}$ east of Stockton Beach, 32 $54^{\circ} \mathrm{S} 151^{\circ} 47.5^{\prime} \mathrm{E}, 15$ $\mathrm{m} ; 1$, AM P23039, $500 \mathrm{~m}$ east of Dudley Beach, 32 $2^{\circ} 59^{\prime} \mathrm{S} 151^{\circ} 44^{\prime} \mathrm{E}$, 16 m; 37, SAMA C5640, Newcastle, NSW, [32 ${ }^{\circ} 56^{\prime} \mathrm{S} 151^{\circ} 46^{\prime} \mathrm{E}$ ], from shark liver, T.C. Roughley (reported by Hale [1940]); 156, AM P47221, off Providential Head, $34^{\circ} 44^{\prime}$ S $150^{\circ} 39^{\prime}$ E, baited trap, 25-30 m, S. Keable \& A. Parker 14-15 Jan. 1991, PIO-103. Tasmania: series from off Maurouard Beach, St Helens Point, all c. $41^{\circ} 17.3^{\prime} \mathrm{S} 148^{\circ} 21^{\prime} \mathrm{E}$, baited trap, J. Lowry, S. Keable \& C. McCormick, 13-14 April 1991; 40 o o, 3 우 o, 31 mancas, AM P47215, sandy bottom, $15 \mathrm{~m}$, TAS-124; $\delta$, AM P47216, sandy bottom, 5 m, TAS-125; 3 o $~$, 23 mancas, AM P47217, sandy bottom, 10 m, TAS-126; 64 mancas, AM P47218, sandy bottom, 15 m, TAS139; 9 , manca, AM P47219, off Binalong Beach, Binalong Bay, $41^{\circ} 14.7^{\prime} \mathrm{S} 148^{\circ} 17.6^{\prime} \mathrm{E}$, baited trap, on sand, $8 \mathrm{~m}$, J. Lowry, S. Keable \& C. McCormick, 14-15 April 1991, TAS-144; 21 ơ ô, 17 ㅇ 9,15 mancas, AM P47220, about $100 \mathrm{~m}$ off Nine Mile Beach near Point Bagot, Freycinet Peninsula, $42^{\circ} 06.2^{\prime} \mathrm{S} 148^{\circ} 13.8^{\prime} \mathrm{E}$, baited trap, J. Lowry \& S. Keable, 30 April-1 May 1991, TAS-344. South Australia: ${ }^{\top}$, SAMA C5641, Christies Beach [ $\left.35^{\circ} 08^{\prime} \mathrm{S} 138^{\circ} 28^{\prime} \mathrm{E}\right]$, seaweed on beach, T. Castle, 29 Jan. 1959; 6 paratypes of $N$. corpulenta, SAMA C276, Port Willunga [ $\left.35^{\circ} 16^{\prime} \mathrm{S} 138^{\circ} 28^{\prime} \mathrm{E}\right]$.

Diagnosis. Interocular furrow: absent. Frontal lamina: lateral margins straight, narrowing anteriorly. Antenna: c. $0.5 \times$ as long as body, reaching to posterior of pereonite 4 . Coxal plates: furrows moderately developed, on all coxae but indistinct, particularly on coxa 2 . Pereonite 1 , coxa 2 posterior margins sinuate, posteroventral corners developed into strong coxal points. Pleonite 4: posterodorsal margin distinctly concave proximal to meeting posteroventral margin at apex; apex forming a broad acute point. Pleotelson: broad, length $0.88 \times$ basal width; anterodorsal depression present; anterolateral margins convex; posterolateral margins concave; apex produced into a large point; with 10 RS. Pereopods 1-6: males with conspicuous elongated RS subequal to propodus on the merus of pereopods $1-3$ and extending from the carpus to dactylus of pereopods 4-6. Pereopods 2-3: propodus without RS on palm. Pereopod 7: basis narrow, width $0.42 \times$ length; distance between anterior margin and medial carina less than between posterior margin and medial carina; posterior margin with 


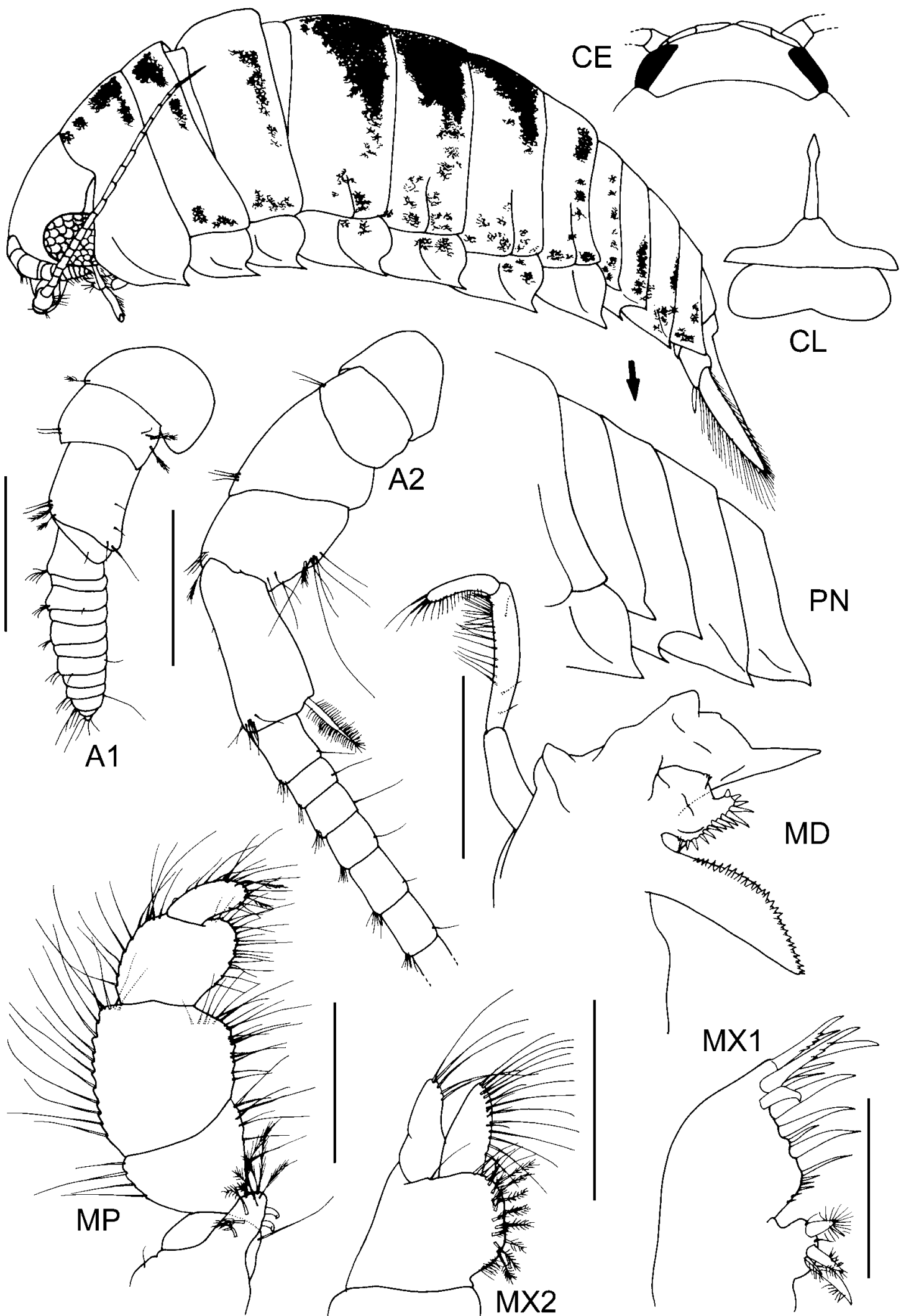

Fig. 45. Natatolana sinuosa n.sp., holotype. Scales $=0.5 \mathrm{~mm}$.

setae along entire length. Penes: present. Pleopod 2 appendix masculina: extending beyond tip of endopod, $1.07 \times$ length of endopod; margins very slightly curved laterally; slender; apex not at angle to adjacent margins, bluntly rounded. Uropods: exopod subequal to endopod, $0.93 \times$ the length of the endopod.
Additional descriptive characters. Based on holotype. Body: length c. 2.26x width. Colour yellow in alcohol. Chromatophores present; large; black in alcohol; arranged in bands. Eyes: with 7 ommatidia in horizontal diameter; with 7 ommatidia in vertical diameter; round; colour redbrown in alcohol. Frontal lamina: length c. $5 \times$ basal width; 

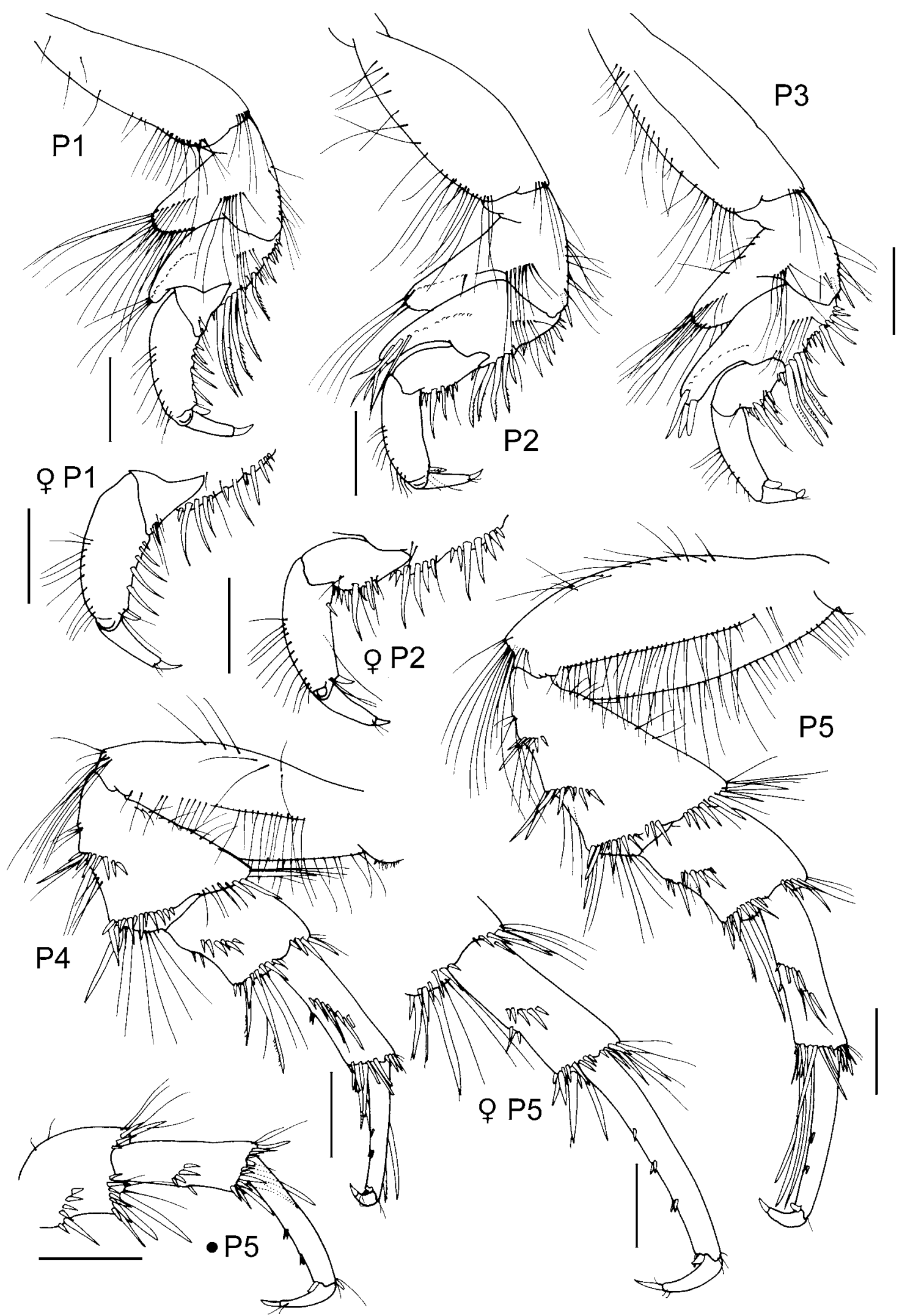

Fig. 46. Natatolana sinuosa n.sp., holotype, except; $\bullet P 5=$ male (immature) AM P47215; female $=$ paratype female TM. Scales $=0.5$ mm.

apex expanded, anterior margin angled. Antennule: peduncular article 1 longer than article 2; article 2 with 1 large pappose and several small penicillate setae; article 3 long, larger than article 1 or 2 but shorter than their combined lengths. Flagellum 12-articulate. Antenna: peduncular article 4 with $6 \mathrm{SS}$ and 1 penicillate seta medially and 3 SS at posterodistal angle, 5 SS and 1 penicillate seta at anterodistal angle; article 5 with 1 large pappose seta at posterodistal angle and $8 \mathrm{SS}$ at anterodistal angle. Flagellum 23-articulate. Mandible: setal row with 15 RS. Maxillule: 


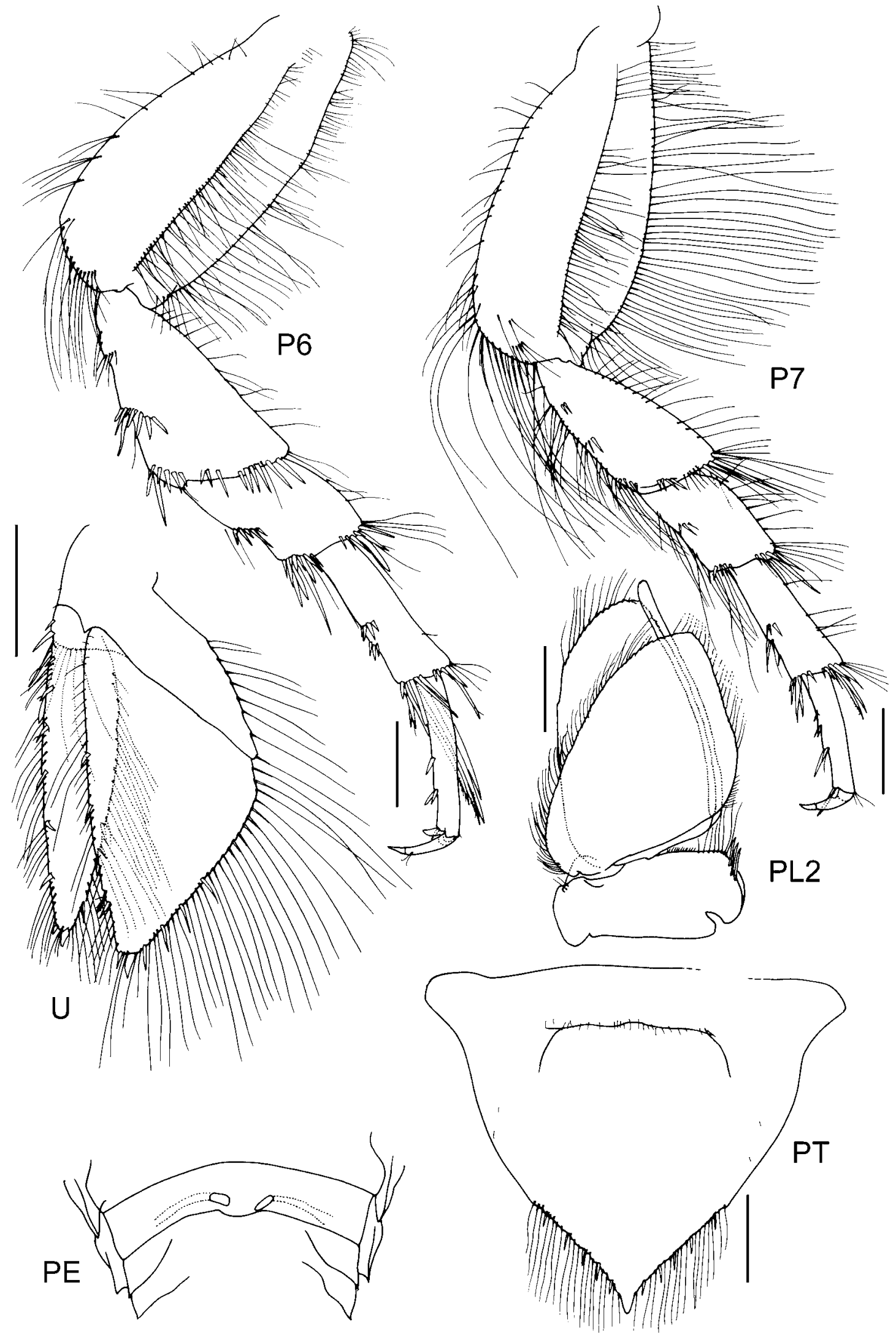

Fig. 47. Natatolana sinuosa n.sp., holotype. Scales $=0.5 \mathrm{~mm}$.

medial lobe with 3 large and 1 smaller robust pappose setae and 2 small SS; lateral lobe with 13 RS on distal surface. Maxilla: lateral lobe with $5 \mathrm{SS}$; medial lobe with $4 \mathrm{SS}$ and 15 PS; middle lobe with 12 long SS on outer row and 7 shorter SS on inner row. Maxilliped: endite with 2 coupling hooks, and 9
PS. Pereon: ornamentation consists of 1 weakly developed furrow on lateral margin of pereonite 1; pereonites 1, 4-6 subequal and longest, 2-3 and 7 subequal. Coxae: coxal points strongly developed on posteroventral corners, on all coxae. Pleonite 2: dorsal posterolateral margin subequal with ventral 
posterolateral margin. Pereopod 7: basis anterior margin convex; medial carina with PS and SS present (plumose proximally, mostly slender distally but with a few plumose setae also); posterior margin convex, SS present. Ischium anterior margin with SS; posterior margin with groups of RS present, PS present. Merus anterior margin with SS; posterior margin with 2 RS, SS present. Carpus posterior margin with 6 RS, 1 SS. Propodus subequal to carpus; posterior margin with 6 RS, SS absent. Penes: forming well separated flattened lobes. Pleopod 2 appendix masculina: arising basally. Pleopods 1-5: exopod suture strongly developed on pleopods 3-5; endopod PS on most of margins on pleopods 1-4, absent on pleopod 5. Uropods: endopod triangular; medial margin slightly convex and obtusely angled proximal to peduncle, with 4 RS, PS along entire length; apex with $2 \mathrm{RS}$; lateral margin slightly convex, with 4 RS and 1 penicillate seta, PS along entire length. Exopod medial margin convex, with 3 RS, PS along entire length; apex acute, with 2 RS; lateral margin convex, with 6 RS, PS along entire length.

Variation. Small males (to $10.5 \mathrm{~mm}$ ) are apparently immature and do not have conspicuously elongated robust setae on pereopods $1-6$, they also have the appendix masculina shorter than the pleopod endopod. There is also a mixture of specimens both with and without obvious chromatophores in the additional material examined.

Sexual dimorphism. Females lack the conspicuously elongated robust setae present on the merus of pereopods 1-3 and on the carpus of pereopods 4-6 of adult males.

Size. Adults to $16.5 \mathrm{~mm}$.

Etymology. From the Latin "sinuosus" (full of windings) in reference to the sinuate posterior margins of the coxae.

Remarks. Natatolana sinuosa is most similar to $N$. corpulenta, $N$. debrae n.sp. and $N$. femina $\mathrm{n}$.sp. Natatolana sinuosa can be distinguished from these species because it has strongly developed coxal points on the posterolateral margins of pereonite 1 and coxae $2-7$. It also lacks an acute tooth at the anteroventral corner of coxa 2 that is found in $N$. corpulenta. Natatolana longispina is also very similar but is distinguished from $N$. sinuosa by having less strongly developed coxal points and the pleotelson with convex posterolateral margins.

Distribution and ecology. Australia: New South Wales, east and west coast of Tasmania, and South Australia. Intertidal to $30 \mathrm{~m}$ depth.

\section{Natatolana taiti Keable, 1997}

Natatolana taiti Keable, 1997: 261, figs. 5-7.-Bruce et al., 2002: 152.

Type material. Holotype: $₫$, 8.5 mm, NTM Cr-011524. Paratypes: 12 specimens, AM P44854; 11 specimens, NTM Cr011516; 11 specimens, BMNH 1995.732-741; 11 specimens, USNM 264080; 11 specimens, ZMUC CRU1714. All examined. - Type locality: between North Shell and South Shell Islands, Darwin Harbour, NT, Australia, 12 29.7'S 130 52.9'E, [baited trap, unknown substrate, probably rocks and muddy sand], $7 \mathrm{~m}$, [S. Keable, 14-15 Jul. 1993, NT-157].

Material examined. Listed by Keable (1997).
Diagnosis. Interocular furrow: moderately developed, distinct but not extending across the cephalon. Frontal lamina: lateral margins straight, parallel. Antenna: c. $0.3 \times$ as long as body, reaching to posterior of pereonite 3. Coxal plates: furrows moderately developed, on all coxae. Pleonite 4: apex rounded. Pleotelson: broad, length $0.95 \times$ basal width; anterodorsal depression absent; anterolateral margins convex; posterolateral margins convex; apex produced into a small point; with 4-6 RS. Pereopods 2-3: propodus without RS on palm. Pereopod 7: basis broad, width $0.53 \times$ length; distance between anterior margin and medial carina greater than between posterior margin and medial carina; posterior margin with setae on proximal third. Penes: absent. Pleopod 2 appendix masculina: extending subequal with tip of endopod, $0.99 \times$ length of endopod; margins very slightly curved laterally; slender; apex not at angle to adjacent margins, bluntly rounded. Uropods: exopod short, $0.79 \times$ the length of the endopod.

Variation. The holotype has four robust setae on the pleotelson margins, a subsample of paratype specimens showed $85 \%$ have four robust setae, $2 \%$ have three, $4 \%$ have five and $9 \%$ have six. In other material from Shadwell Reef, Queensland, most of the adult specimens have six robust setae on the pleotelson.

Size. Adults to c. $12 \mathrm{~mm}$.

Remarks. Natatolana taiti is similar to both $N$. woodjonesi and $N$. kahiba. It differs from adult specimens of these species in having longer antennae, reaching to the posterior of pereonite 3 and $0.3 \times$ as long as the body when extended along it (reaching to the posterior of pereonite 2 with 18 21 articles in the flagellum and $0.25 \times$ as long as the body in $N$. woodjonesi; reaching to the posterior of pereonite 2 , with c. $12-18$ articles and $0.25 \times$ as long as the body in N. kahiba). Other differences include the less acute posterior margins of the pleotelson and uropod endopod apex in $N$. taiti. Natatolana arrama and N. bulba are also similar to N. taiti. Using the key provided by Bruce (1986) these species can only be reached if it is assumed in couplet 21 that they have six or more robust setae on the pleotelson, whereas they only have four, as in N. taiti. Natatolana arrama differs from $N$. taiti in having a frontal lamina with the apex not expanded; the antennae with c. 18 articles in the flagellum, reaching to the middle of pereonite $2,0.24 \times$ the length of the body; the uropod exopod lateral margin lacking robust setae and the endopod narrower and more lanceolate; and the posterolateral margins of the pleotelson are less convex. Natatolana bulba differs in that the uropod endopod is narrower and more lanceolate; the uropod exopod lateral margin lacks robust setae; and the posterolateral margins of the pleotelson are less convex.

Distribution and ecology. Australia: Darwin, Northern Territory; northern Queensland. At depths of 5-35 m. Scavenger.

\section{Natatolana tenuistylis (Miers, 1884)}

Cirolana tenuistylis Miers, 1884: 303, pl. 33B.-Hansen, 1890: 356.-Hale, 1925: 136, fig. 4.-Nierstrasz, 1931: 157.-Holdich et al., 1981: 572, fig. 7.-Ellis, 1981: 123.

Natatolana tenuistylis.-Bruce, 1981: 958.-1986: 103, figs. 70, 71.-Keable, 1995: 43.-Brusca et al., 1995: 82.-Bruce et al., 2002: 152. 
Type material. Lectotype designated by Holdich et al. (1981): 13.9 mm, BMNH 1882:7 (Bruce (1986) has 1882:1). Paralectotypes: 2, BMNH 1882:53 (Ellis (1981) has 1856:33 for the syntypes). Holdich et al. (1981) question the conspecific status of these specimens with the lectotype. Bruce (1986) regards one paralectotype as Natatolana vieta and the other as too badly damaged to be identified but most likely to be $N$. matong. None examined. - Type locality: Prince of Wales Channel, Queensland, Australia [10 $\left.32^{\prime} \mathrm{S} 142^{\circ} 10^{\prime} \mathrm{E}\right]$.

Material examined. Listed by Keable (1997).

Diagnosis. Interocular furrow: well developed, extending across the cephalon (not illustrated by Holdich et al. (1981) but present according to Bruce (1986) and in material examined); smoothly convex. Frontal lamina: lateral margins medially constricted. Antenna: c. $0.6 \times$ as long as body, reaching to posterior of pereonite 5. Coxal plates: furrows moderately developed, on all coxae. Pleonite 2: ventral posterolateral margin acute, formed into long curved process. Pleonite 4: apex broadly rounded dorsally, but meeting convex ventral margin at a point. Pleotelson: broad, length $0.94 \times$ basal width; anterodorsal depression absent; anterolateral margins convex; posterolateral margins convex; apex not produced, lateral margins converging smoothly to a point; with 8-12 RS. Pereopods 2-3: propodus without RS on palm. Pereopod 7: basis broad, width $0.6 \times$ length; distance between anterior margin and medial carina greater than between posterior margin and medial carina; posterior margin with setae on proximal half. Penes: absent. Pleopod 2 appendix masculina: just shorter than endopod; margins very slightly curved laterally; slender; apex not at angle to adjacent margins, with a distinct acute projection. Uropods: exopod slightly shorter than endopod, $0.88 \times$ the length of the endopod.

Variation. The lectotype is damaged and has only four robust setae present on one side of the pleotelson apex, Keable (1997) discusses the variation in the total number of robust setae occurring on the pleotelson.

Size. Adults to c. $17.5 \mathrm{~mm}$.

Remarks. Characters that are particularly useful for identifying Natatolana tenuistylis are: the complete interocular furrow; the ventral posterolateral margin of pleonite 2 (produced and formed into an acute process); the acute projection on the apex of the appendix masculina; the long antennae, reaching to the posterior of pereonite 5 (c. $0.6 \times$ the length of the body); and the unusual shape of the posterolateral margin of pleonite 4 (rounded dorsally and meeting the ventral margin at a point) (Bruce, 1986; Keable, 1997).

Distribution and ecology. Australia: northern Western Australia, Northern Territory, northern Queensland. Papua New Guinea: Daru. At depths of 3-62 m. Scavenger.

\section{Natatolana thalme Bruce, 1986}

Natatolana thalme Bruce, 1986: 113, figs. 79, 80.-Springthorpe \& Lowry, 1994: 62.-Keable, 1995: 43.-Brusca et al., 1995: 82.-Keable, 1997: 268.-Bruce et al., 2002: 153.

Type material. Holotype: $\widehat{\delta}$, QM W6292 (not examined). Paratypes: QM W6288, W6291-6293, W9848-9852 (not examined); AM P32382 (examined). - Type locality: Middle Banks, Moreton Bay, Queensland, Australia, 27 $06^{\prime} \mathrm{S} 153^{\circ} 16^{\prime} \mathrm{E}$.

Material examined. Listed by Keable (1997).
Diagnosis. Interocular furrow: moderately developed, distinct but not extending across the cephalon. Frontal lamina: lateral margins medially constricted. Antenna: c. $0.34 \times$ as long as body, reaching to posterior of pereonite 3 (not pereonite 2 as described by Bruce [1986]). Coxal plates: furrows moderately developed, on all coxae. Pleonite 4: apex rounded. Pleotelson: narrow, length $1.05 \times$ basal width; anterodorsal depression absent; anterolateral margins almost straight and angling posteriorly toward the midline, or convex; posterolateral margins straight, markedly angled to anterolateral margins and meeting at an acute angle or convex; apex produced into a small point; with 4-6 RS. Pereopods 2-3: propodus without RS on palm. Pereopod 7: basis of medium breadth, width 0.49 $0.52 \times$ length; distance between anterior margin and medial carina greater than between posterior margin and medial carina; posterior margin with sparse setae along entire length. Penes: absent. Pleopod 2 appendix masculina: extending subequal with tip of endopod; margins very slightly curved laterally; slender; apex not at angle to adjacent margins, with a distinct acute projection. Uropods: exopod slightly shorter than endopod, $0.84 \times$ the length of the endopod.

Variation. Type material of Natatolana thalme has four robust setae on the margins of the pleotelson, Keable (1997) reported that this was the most common number of robust setae but that some specimens may have six.

Sexual dimorphism. Bruce (1986) reported that males have fewer robust setae on the pereopods than females. This may reflect the difference in size of the material examined.

Size. Males to c. $6.9 \mathrm{~mm}$, females to c. $9.5 \mathrm{~mm}$, mancas to c. $6.0 \mathrm{~mm}$ (Bruce, 1986).

Remarks. Natatolana thalme is most similar to N. gallica. It differs most noticeably from that species in having the posterolateral margins of the pleotelson noticeably angled to the anterolateral margins (convex and smoothly continuous with the anterolateral margins in N. gallica), incomplete coxal furrows, sparse setae along the length of the posterior margin of the basis of pereopod 7 (dense in $N$. gallica) and in lacking robust setae on the palm of the propodus of pereopods 2 and 3 (often present in N. gallica).

Distribution and ecology. Australia: northern Western Australia, Northern Territory, northern Queensland south to Moreton Bay. Intertidal to $83 \mathrm{~m}$ depth. Scavenger.

\section{Natatolana thurar Bruce, 1986}

Natatolana thurar Bruce, 1986: 97, figs. 64, 65.-Springthorpe \& Lowry, 1994: 62.-Brusca et al., 1995: 82.-Bruce et al., 2002: 153.

Type material. Holotype: $\stackrel{+}{1} 15.8 \mathrm{~mm}$, AM P32171. Paratypes: AM P30350. All examined. - Type locality: $10 \mathrm{~km}$ southeast of Lakes Entrance, Victoria, Australia, 30³5'S 14906'E, $149 \mathrm{~m}$ [originally cited as Eastern Bass Strait, Australia, 38 $35^{\prime} \mathrm{S}$ $149^{\circ} 06^{\prime} \mathrm{E}$, corrected by Springthorpe \& Lowry (1994)].

Material examined. New South Wales: $8 \widehat{\delta} \widehat{\delta}, 4 q q+$, manca, AM P47269, east of Coffs Harbour, 30 $14.63^{\prime}$ S 153 $27.68^{\prime} \mathrm{E}, 199$ m, 12-13 Aug. 1993, SEAS NSW-883.

Diagnosis. Eyes: vestigial. Interocular furrow: well developed, forming a ridge that runs across the cephalon. Frontal lamina: lateral margins straight, parallel. Antenna: c. $0.35 \times$ as long as body, reaching to posterior of pereonite 3. Coxal plates: furrows variously developed, coxae 2,3 
and 7 with complete furrows, furrows absent on coxae 4-6. Pleonite 4: posterodorsal margin strongly concave proximal to meeting posteroventral margin at apex; apex forming a narrow acute point. Pleotelson: broad, length $0.76 \times$ basal width; anterodorsal depression absent; anterolateral margins almost straight and angling posteriorly toward the midline, or convex; posterolateral margins straight, markedly angled to anterolateral margins and meeting at an obtuse angle or convex; apex not produced, lateral margins converging smoothly to a point; with 8-10 RS. Pereopod 2: propodus with 2 RS on palm. Pereopod 3: propodus with 2 RS on palm. Pereopod 7: basis narrow, width $0.44 \times$ length; distance between anterior margin and medial carina less than between posterior margin and medial carina; posterior margin with setae on proximal quarter. Penes: absent. Pleopod 2 appendix masculina: extending subequal with tip of endopod; margins very slightly curved laterally; slender; apex not at angle to adjacent margins, bluntly rounded. Uropods: exopod subequal to endopod, $0.93 \times$ the length of the endopod.

Variation. This species was originally described as having eight robust setae on the pleotelson. In the material examined from Coffs Harbour there were specimens with either eight or 10 robust setae on the pleotelson.

Size. $12.6-32 \mathrm{~mm}$.

Remarks. This is the first record of a male specimen of Natatolana thurar. This species is best identified using the characters discussed under remarks for $N$. aotearoa.

Distribution and ecology. Australia: off Coffs Harbour, New South Wales; off eastern Victoria. At depths of 149$200 \mathrm{~m}$. Scavenger.

\section{Natatolana valida (Hale, 1940)}

Cirolana valida Hale, 1940: 290, fig. 2.-Springthorpe \& Lowry, 1994: 64.

Natatolana valida.-Bruce, 1981: 958.-1986: 89, fig. 60.-Brusca et al., 1995: 82.-Bruce et al., 2002: 153.

Type material. Holotype: $ᄋ$, $31.0 \mathrm{~mm}$, AM E4814 (examined). - Type locality: east of Flinders Island, Bass Strait [Springthorpe \& Lowry (1994) give c. $40^{\circ} \mathrm{S} 148^{\circ} 30^{\prime} \mathrm{E}, 366-549 \mathrm{~m}$ ].

Material examined. New South Wales: 76 including numerous ô ô (2 dissected), AM P44412, off Wollongong, 34 33.01'S $151^{\circ} 16.54^{\prime} \mathrm{E}, 400 \mathrm{~m}, 7-8$ May 1993, SEAS NSW-803. Western Australia: $6 \circ+$, NTM Cr 007337, NW of Shark Bay, 262 $28^{\prime} \mathrm{S}$ $112^{\circ} 31^{\prime} \mathrm{E}$, pot caught, 400 m, CSIRO Fisheries, 28 April 1990.

Diagnosis. Eyes: well developed; elongate, length c. $2 \times$ height. Interocular furrow: well developed, extending across the cephalon. Frontal lamina: lateral margins straight, parallel. Antenna: c. $0.4 \times$ as long as body, reaching to posterior of pereonite 3. Coxal plates: furrows variously developed, coxa 2 and 3 with a strongly developed furrow along ventral margin, coxae 4-7 without furrows. Pleonite 4: posterodorsal margin strongly concave proximal to meeting posteroventral margin at apex; apex forming a narrow acute point, or apex slightly rounded. Pleotelson: broad; anterodorsal depression absent; anterolateral margins almost straight and angling posteriorly toward the midline; posterolateral margins straight, markedly angled to anterolateral margins and meeting at an obtuse angle or convex; apex not produced, lateral margins converging smoothly to a point; with 14-20 RS (Hale (1940) records 20 on the holotype but Bruce (1986) notes that some may have rubbed off since the original description and records 16; in the material examined a total of 14 was most common but this ranged up to 20). Pereopod 2: propodus with $4 \mathrm{RS}$ on palm. Pereopod 3: propodus with 3 RS on palm. Pereopod 7: basis of medium breadth, width $0.5 \times$ length; distance between anterior margin and medial carina less than between posterior margin and medial carina; posterior margin with setae completely absent along entire length. Penes: absent. Pleopod 2 appendix masculina: extending beyond tip of endopod; margins very slightly curved laterally; slender; apex not at angle to adjacent margins, bluntly rounded. Uropods: exopod subequal to endopod, $0.91 \times$ the length of the endopod.

Variation. In the material from New South Wales (AM $\mathrm{P} 44412$ ) the median downbent process at the anterior of the cephalon is more obvious than in the type specimen. Although Bruce (1986) regarded this process as not constituting the rostral process found in other members of the genus it does appear to be homologous to it. Therefore, the anterior margin of the cephalon is not medially recessed as in other genera, such as Aatolana Bruce, 1993.

Size. Adults to c. $40 \mathrm{~mm}$.

Remarks. This is the first record of a male specimen of Natatolana valida. This species is most readily recognized by the elongate eyes, lack of penes, morphology of the appendix masculina and frontal lamina with a strongly expanded apex.

Distribution and ecology. Australia: off Shark Bay, Western Australia; off Wollongong, New South Wales; off Flinders Island, Bass Strait. At depths of 400-600 m. Scavenger.

\section{Natatolana variguberna (Holdich, Harrison \& Bruce, 1981)}

Cirolana variguberna Holdich et al., 1981: 566, fig. 5.Springthorpe \& Lowry, 1994: 64.

Natatolana variguberna.-Bruce, 1981: 958.-1986: 105, fig. 72.1995a: 409, fig. 19A-E.-Keable, 1995: 43.-Brusca et al., 1995: 82.-Keable, 1997: 269.-Bruce et al., 2002: 153.

Type material. Holotype: ๙ึ, $6.17 \mathrm{~mm}$, QM W6337 (not examined). Paratypes: QM W6338 (not examined); lots of 15, 7 and 207 specimens, institution where deposited not stated, possibly in Nottingham University (not examined); 8, AM P32109-32114, not noted in original description but cited by Springthorpe \& Lowry (1994) (examined). $\bullet$ Type locality: Halifax Bay, Queensland, Australia, $19^{\circ} 07^{\prime} \mathrm{S} 146^{\circ} 36^{\prime} \mathrm{E}$.

Material examined. Listed by Keable (1997).

Diagnosis. Interocular furrow: well developed, extending across the cephalon; smoothly convex. Frontal lamina: lateral margins medially constricted, or straight, parallel. Antenna: c. $0.4 \times$ as long as body, reaching to between the posterior of pereonite 3 to the posterior of pereonite 5. Coxal plates: furrows moderately developed, on all coxae. Pleonite 4: apex forming a broad acute point, or slightly rounded. Pleotelson: broad, length $0.7 \times$ basal width, anterodorsal depression absent; anterolateral margins almost straight and angling posteriorly toward the midline, or convex (original illustration shows almost straight or concave anterolateral margins, material examined has slightly convex anterolateral margins); posterolateral margins convex; apex produced into a small point; with 4-6 RS. Pereopod 2: propodus with 0$1 \mathrm{RS}$ on palm. Pereopod 3: propodus without RS on palm. Pereopod 7: basis of medium breadth, width $0.5 \times$ length; distance between anterior margin and medial carina greater 
than between posterior margin and medial carina; posterior margin with setae along entire length or on proximal quarter. Penes: absent. Pleopod 2 appendix masculina: extending beyond tip of endopod; margins very slightly curved laterally; slender; apex not at angle to adjacent margins, bluntly rounded. Uropods: endopod lateral margin with prominent excision. Exopod short, $0.75 \times$ the length of the endopod.

Variation. Type material of this species has six robust setae on the pleotelson margin. Additional material from the type locality and other locations, however, has four robust setae.

Sexual dimorphism. Females may have slightly shorter antennae that extend to the posterior of pereonite 3 whereas in males they extend to the posterior of pereonite 5 (Keable, 1997).

Size. Adults to $10.7 \mathrm{~mm}$ (Bruce, 1986) and $11.5 \mathrm{~mm}$ (Bruce, 1995a).

Remarks. Natatolana variguberna and $N$. honu are the only species of Natatolana with a prominent excision near the apex of the uropod endopod lateral margin. Natatolana variguberna most noticeably differs from $N$. honu in having well-developed eyes, coxal furrows on all coxae, lacking penes and having fewer robust setae on the pleotelson margins.

Distribution and ecology. Australia: Darwin Harbour and Cobourg Peninsula, Northern Territory; northern Queensland south to Moreton Bay. Papua New Guinea: Madang Lagoon. At depths of 2.7-63 m. Scavenger.

\section{Natatolana vieta (Hale, 1925)}

Cirolana vieta Hale, 1925: 150, fig. 11.-1929: 249, fig. 242.1940: 288, fig. 1.-Nierstrasz, 1931: 157.

Natatolana vieta.-Bruce 1981: 958.-1986: 55 figs. 33, 34.-Jones \& Morgan, 1993: 142.-Brusca et al., 1995: 82.-Kensley, 2001: 230.-Bruce et al., 2002: 153.

Type material. Holotype: $\uparrow, 13$ mm, SAMA C278 (examined). - Type locality: Encounter Bay, South Australia, Australia [35 $35^{\circ} \mathrm{S}$ $\left.138^{\circ} 45^{\prime} \mathrm{E}\right]$.

Material examined. Queensland: 3, AM P47268, off East Fitzroy Reef, $23^{\circ} 32.53$ 'S $152^{\circ} 16.45^{\prime} \mathrm{E}, 105$ m, 16-17 Jun. 1993, SEAS QLD-956. New South Wales: 2, AM P47267, east of Coffs Harbour, $30^{\circ} 17.49^{\prime} \mathrm{S} 153^{\circ} 13.90^{\prime} \mathrm{E}, 45.4 \mathrm{~m}, 11-12$ Aug. 1993, SEAS NSW-873; series from off Providential Head, c. $34^{\circ} 44^{\prime} \mathrm{S}$ $150^{\circ} 39^{\prime}$ E, baited traps, $25-38$ m, S. Keable, A. Parker \& J. Lowry on MV Krista, 14-15 Jan. 1991, Australian Museum/The Ecology Lab Pty. Ltd. Pioneer Consultation Project 1991: AM P4724747254. Tasmania: 1, AM P47264, east of Fortescue Bay, $43^{\circ} 06.70$ 'S $148^{\circ} 03.45^{\prime} \mathrm{E}, 100 \mathrm{~m}, 16-17$ April 1993, SEAS TAS354. South Australia: series from Upper Spencer Gulf, $32^{\circ} 42.2^{\prime}-$ $33^{\circ} 5^{\prime} \mathrm{S} 137^{\circ} 47.26^{\prime}-57.44^{\prime} \mathrm{E}, 5-17 \mathrm{~m}$, Fisheries Department Survey, SAMA C5642-5648. Western Australia: series from North-West Shelf, $19^{\circ} 3.5-5.4^{\prime}$ 'S $118^{\circ} 50.8-119^{\circ} 3.1^{\prime} \mathrm{E}, 81-84 \mathrm{~m}$, sled, CSIRO 1983; 5, AM P47259-47263.

Diagnosis. Interocular furrow: absent. Frontal lamina: lateral margins concave but not medially constricted, narrowing toward apex. Antenna: c. $0.8-1.05 \times$ as long as body, reaching to between pleonite 4 and just beyond the pleotelson. Coxal plates: furrows strongly developed, on all coxae. Pleonite 4: posterodorsal margin strongly concave proximal to meeting posteroventral margin at apex; apex acute and slightly produced. Pleotelson: narrow, length $0.91 \times$ basal width; anterodorsal depression present; anterolateral margins convex; posterolateral margins convex; apex produced into a large point; with 4-8 RS. Pereopod 2: propodus with $6 \mathrm{RS}$ on palm. Pereopod 3: propodus with $5 \mathrm{RS}$ on palm. Pereopod 7: basis narrow, width $0.38 \times$ length; distance between anterior margin and medial carina less than between posterior margin and medial carina; posterior margin with sparse setae proximally and distally but not medially. Penes: present. Pleopod 2 appendix masculina: extending beyond tip of endopod; margins moderately curved laterally; apex not at angle to adjacent margins, blunt with a minute spiniform process or bluntly rounded. Uropods: exopod slightly shorter than endopod, $0.85 \times$ the length of the endopod.

Variation. Bruce (1986) noted that the scattered furrows, giving a "wrinkled" appearance to the dorsal surfaces of the various body segments that is characteristic of Natatolana vieta, tend to be more developed in larger specimens. This is not the case in the material examined, specimens from Upper Spencer Gulf have clearly developed furrows while specimens of a similar size (or larger) from other localities do not have well-developed furrows. Bruce (1986) illustrated a complete interocular furrow for this species. This appears to be formed from the scattered wrinkle like furrows occurring elsewhere on the body and is not apparent in specimens lacking wrinkles.

The specimens from the North-West Shelf of Western Australia have six to eight robust setae on the pleotelson rather than the usual four found in the other material examined. In material with scattered furrows, the geniculate appearance of the antennular peduncle is more strongly developed. In material examined from Queensland and New South Wales, the spiniform process on the apex of the appendix masculina is not developed.

Sexual dimorphism. Females may have shorter antennae (c. $0.8 \times$ body length) than males (c. $1.05 \times$ body length) (Hale, 1940). This is not, however, a constant feature, some males having the antennae only as long as females.

Size. Females to $27.7 \mathrm{~mm}$, mancas to $8.5 \mathrm{~mm}$.

Remarks. Characters that separate Natatolana vieta from all other species, when used in combination, are the long antennae and the presence of a distinct dorsal depression on the pleotelson.

Distribution and ecology. Australia: northwestern Western Australia, south to Rottnest Island; Queensland, north to Gladstone; New South Wales; Victoria; Tasmania; South Australia. At depths of 5-156 m. Scavenger.

\section{Natatolana virilis (Barnard, 1940)}

Figs. 48-50

Cirolana virilis Barnard, 1940: 393 fig. 7d.-Kensley, 1975: 39 (part, specimen from SST.101.D).-1978: 72, fig. 29I.-1984: 215.

Natatolana virilis.-Bruce, 1981: 958.-1986: 222.-Brusca et al., 1995: 82.-Kensley, 2001: 230.

Not Cirolana virilis.-Kensley, 1975: 39 (part, specimen from SST.54.N) [mis-identification $=$ Natatolana n.sp.].

Type material. Holotype: $\delta$, 13.5 mm, SAM-A150997 (examined). - Type locality: Algoa Bay, South Africa, 3359'S $25^{\circ} 43^{\prime} \mathrm{E}, 60 \mathrm{~m}$. 


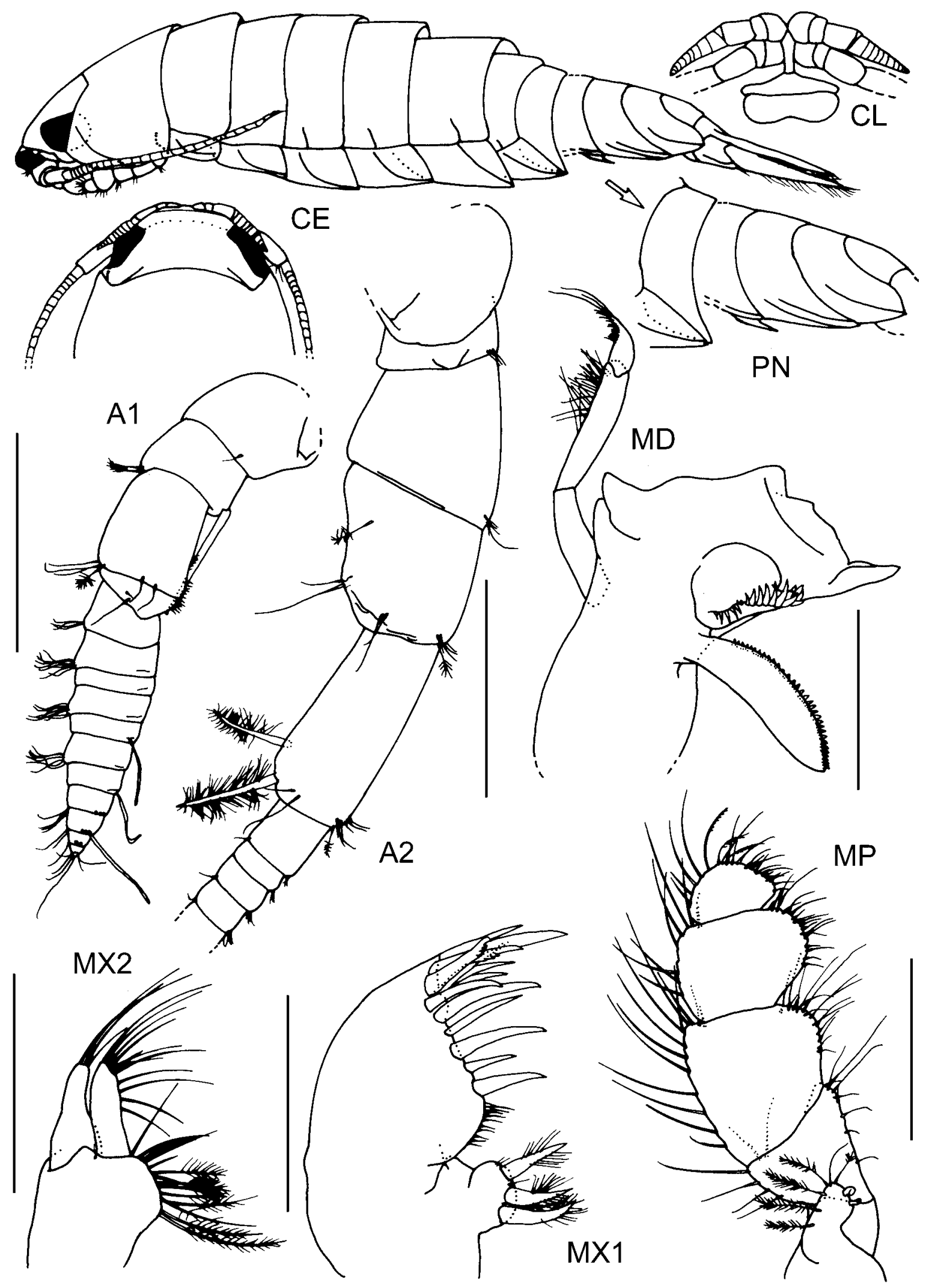

Fig. 48. Natatolana virilis holotype male. Scales $=0.5 \mathrm{~mm}$.

Material examined. South Africa:,$+ 10.5 \mathrm{~mm}$, SAM A$19334,31^{\circ} 59.3$ 'S $29^{\circ} 22.5^{\prime} \mathrm{E}$, dredge, RV Meiring Naude, 150200 m, 25 Jun. 1979, Sta No:SM 250.

Diagnosis. Eyes: well developed; elongate, length c. $2 \times$ height. Interocular furrow: moderately developed, distinct but not extending across the cephalon (but very faint partial furrow medially). Frontal lamina: lateral margins medially constricted. Antenna: c. $0.4 \times$ as long as body, reaching to between the posterior of pereonite 3 and three-quarters of the way along pereonite 4. Coxal plates: furrows moderately 


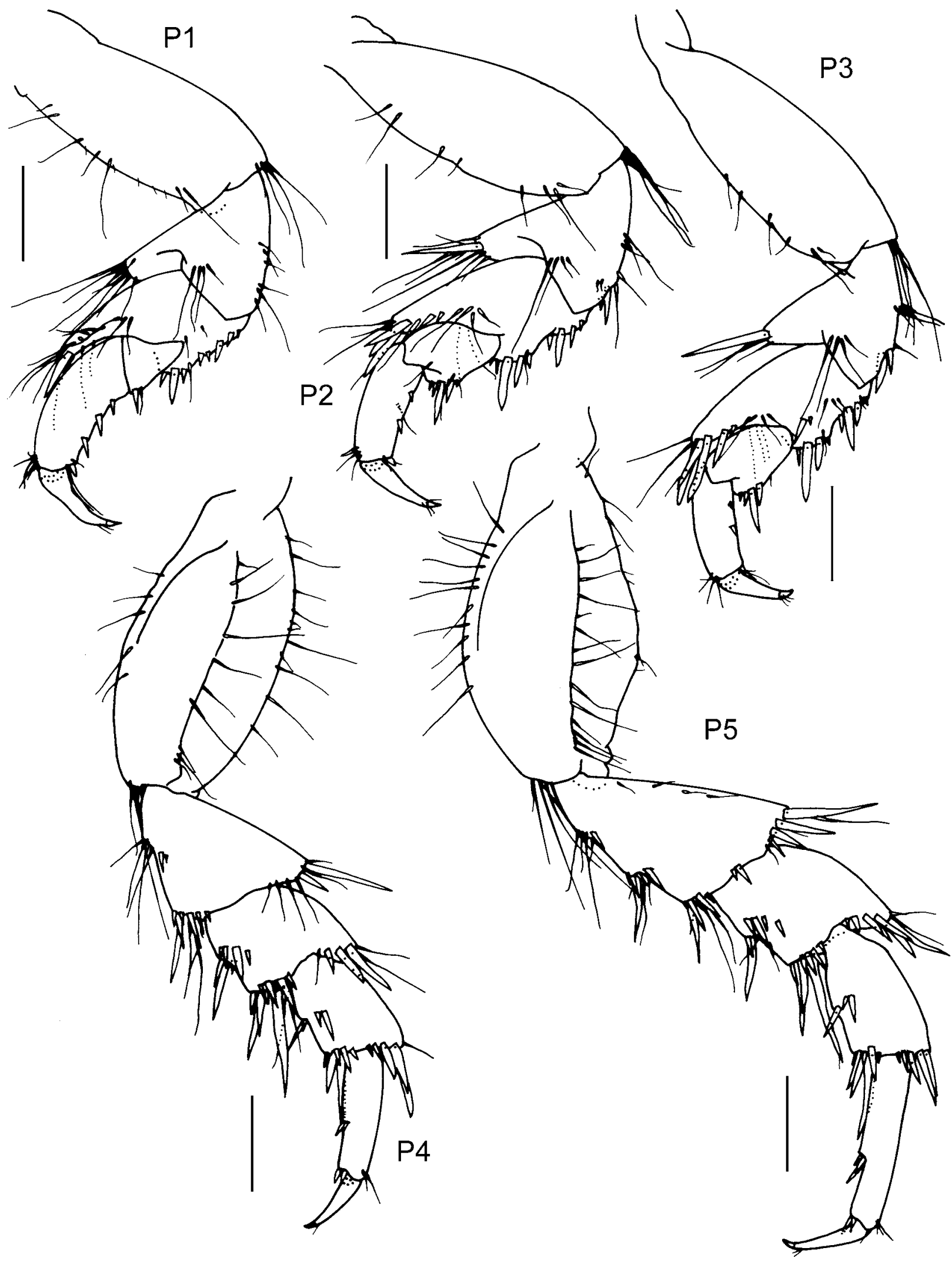

Fig. 49. Natatolana virilis holotype male. Scales $=0.5 \mathrm{~mm}$.

developed, on all coxae. Pleonite 4: apex forming a broad acute point. Pleotelson: broad, length $0.89 \times$ basal width; anterodorsal depression absent; anterolateral margins convex; posterolateral margins convex; apex not produced, lateral margins converging smoothly to a point; with 14-16
RS. Pereopod 2: propodus with 1-2 RS on palm. Pereopod 3: propodus with 1-2 RS on palm. Pereopods 5-7: propodus long, but on pereopod 5 less than $2 \times$ the length of that of pereopod 7 (apparently, but uncertain because the distal articles of pereopod 7 are missing in the material examined). 


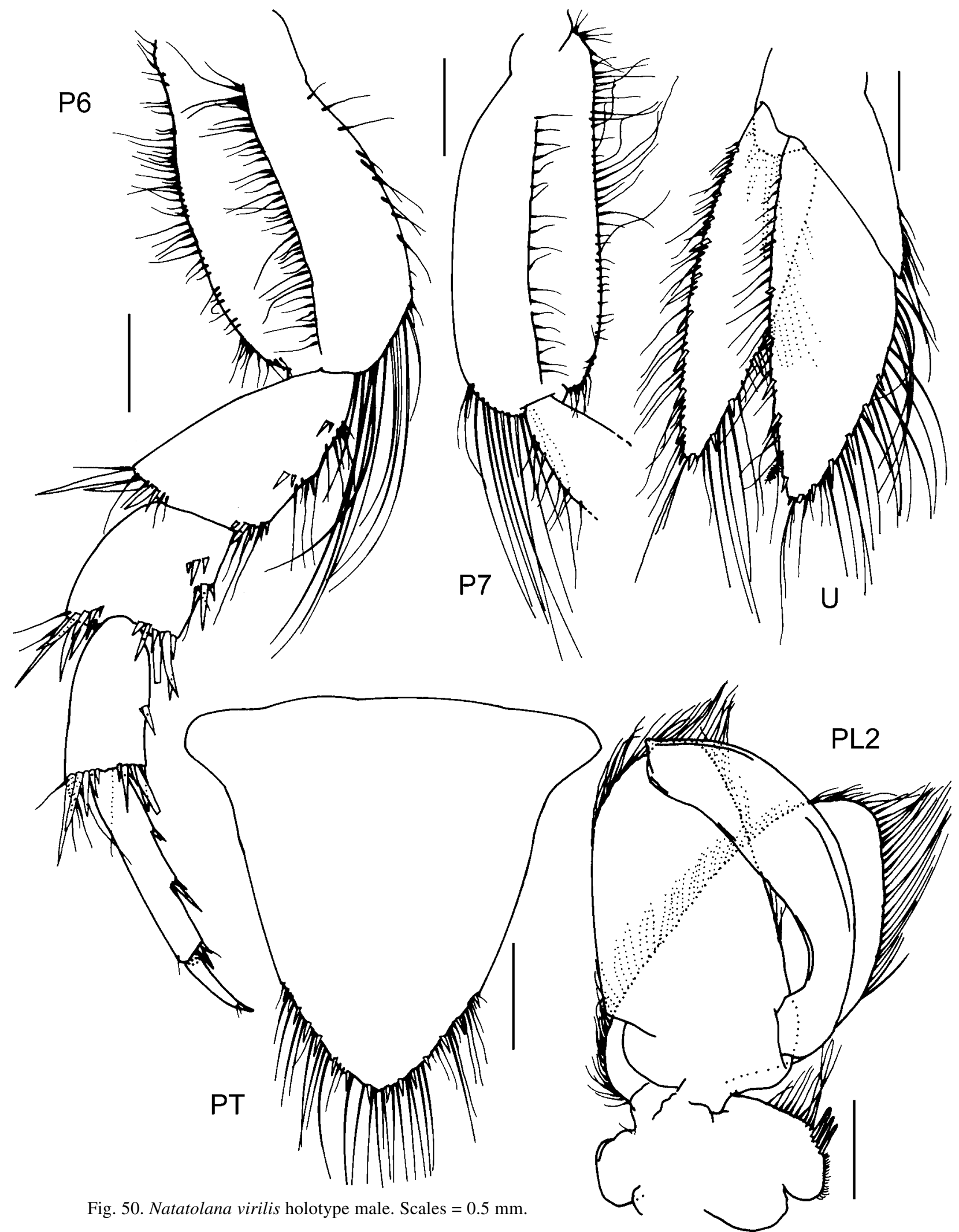

Pereopod 7: basis narrow, width $0.37 \times$ length; distance between anterior margin and medial carina less than between posterior margin and medial carina; posterior margin with setae completely absent along entire length. Penes: absent. Pleopod 2 appendix masculina: extending subequal with tip of endopod, $1.03 \times$ length of endopod; margins very strongly curved laterally; broad; apex not at angle to adjacent margins, truncate. Uropods: exopod subequal to endopod, $0.93 \times$ the length of the endopod.

Additional descriptive characters. Based on holotype. Body: length c. $3 \times$ width. Colour cream to white in alcohol. Chromatophores absent. Eyes: with c. 16 ommatidia in horizontal diameter; with c. 9 ommatidia in vertical 
diameter; narrower anteriorly; colour burgundy red in alcohol. Frontal lamina: length c. $4 \times$ basal width; apex expanded, anterior margin angled. Antennule: peduncular article 1 longer than article 2; article 2 with 1 large pappose seta; article 3 long, larger than article 1 or 2 but shorter than their combined lengths. Flagellum 12-articulate. Antenna: peduncular article 4 with 1 penicillate seta medially on posterolateral margin, $2 \mathrm{SS}$ at posterodistal angle, 2 penicillate setae and 1 SS at anterodistal angle; article 5 with 2 large pappose setae at posterodistal angle. Flagellum 29-articulate. Mandible: setal row with 17 RS. Maxillule: medial lobe with 3 large and 1 smaller robust pappose setae; lateral lobe with 13 RS on distal surface. Maxilla: lateral lobe with 4 SS; medial lobe with 6 SS and 8 PS; middle lobe with 12 SS. Maxilliped: endite with 2 coupling hooks, and 6 PS. Pereon: ornamentation consists of 1 weakly developed furrow on lateral margins of pereonites 1 and 4-7; pereonites 1 and 6 subequal in length and longest, 2-5 subequal and longer than 7. Coxae: pleonite 1, coxae 2-3 with rounded posteroventral corners, coxae 4-7 with increasingly produced, broad, acute posteroventral corners. Pleonite 2: dorsal posterolateral margin subequal with ventral posterolateral margin. Pereopod 7: basis anterior margin straight; medial carina with SS; posterior margin convex. Ischium damaged and other distal articles missing. Pleopod 2 appendix masculina: arising sub-basally. Pleopod 5: exopod suture strongly developed; only a few endopod PS present. Uropods: endopod lanceolate; medial margin convex, with 5 RS, PS along entire length; apex with 2 RS; lateral margin slightly convex, with $5 \mathrm{RS}$ and 1 penicillate seta, PS along entire length. Exopod medial margin convex, with 4 RS, PS along entire length; apex acute, with 2 RS; lateral margin straight, with $10 \mathrm{RS}$, PS along entire length.

Size. Adults to $13.5 \mathrm{~mm}$ (Barnard, 1940; Kensley, 1978).

Remarks. Barnard (1940) stated that he only had a single male specimen of Natatolana virilis (i.e., the holotype). The material described here is registered as the holotype but this status is questionable because of differences to the original description and because of the presence of body parts from more than one individual as noted below. In this material a previous dissection has separated pleonites $2-5$, the pleotelson and uropods from the rest of the body, pleopods $1-5$ have also been removed from the left side and pleopods 1-3 (and part of pleopod 4) from the right side. Pereopods 1 and 7 from the left side and pereopod 6 from the right side have also been previously removed. Both the dissected pereopod 7 and that still attached to the body are incomplete. There is also an additional pereopod 6 or 7 from a larger specimen and a single pleopod 2 that has the appendix masculina straight and slender, not very stout and strongly curved as described and illustrated by Barnard (1940). These additional parts have not been used in the redescription of the species.

The body in the type material matches the brief description of Barnard (1940) reasonably well, although he described the interocular furrow as confined to the hind margins of the eyes and not continuous across the median area. A faint discontinuous furrow can, however, be traced between the eyes. Barnard also indicated that the pleotelson has 16 robust setae but in this material there are only 14 and no sockets to indicate there may have been more.

Among the parts that appear to have been dissected from the apparent holotype, there is a pair of second pleopods with appendix masculina that match the original description and illustration perfectly. This distinguishes $N$. virilis from all other species of Natatolana. Unfortunately, because these pleopods cannot be conclusively linked with the material with which they are registered, some doubt must remain as to the validity of the parts described here as type material. No further male specimens identified as $N$. virilis are available in SAM collections to help resolve this question. A female specimen examined (SAM A-19334), however, matches the assumed type material in diagnostic features other than the sexual characters. This indicates that the parts identified as type material are unlikely to have been mixed together from more than one species or individual.

A female specimen from off Still Bay (Kensley, 1975; SAM A-14593) was also examined. This specimen is similar to the material identified here as Natatolana virilis but has sinuate, rather than straight, posterior margins on coxae 36 with their posteroventral margins formed into notched coxal points rather than being rounded or broadly acute. The antennae of this specimen reach to the posterior of pereonite 5 rather than to the anterior of pereonite 4 as described by Barnard (1940) and also found in the other material examined in this study. This specimen is from a new species but the material is inadequate to describe.

Distribution. South Africa: Port Elizabeth to Natal. At depths of 60-200 m (Barnard, 1940; Kensley, 1975, 1978; Bruce, 1986; this study).

\section{Natatolana woodjonesi (Hale, 1924)}

Cirolana woodjonesi Hale, 1924: 71, fig. 2, pl. 2.-1925: 137, fig. 5 (part).-1929: 248, figs. 232, 233, 240.-Nierstrasz, 1931: 157.-Naylor, 1966: 184.-Poore et al., 1975: 33.-Holdich et al., 1981: 575, fig. 9.

Cirolana woodjonsoni.-Roman, 1970: 167, 192, 195, 197 [lapsus].

Natatolana woodjonesi.-Bruce, 1981: 958, figs. 1d-e, 2c-d, 3ef, 4c, 5c-d.-1986: 98, figs. 66, 68.-Brusca et al., 1995: 82.Bruce et al., 2002: 154

Not Cirolana woodjonesi.-Hale, 1940: 288 [mis-identification = Natatolana bulba Bruce, 1986; Natatolana arcicauda (Holdich, Harrison \& Bruce, 1981)].

Type material. Hale (1924) did not designate type specimens, instead the description "is based upon a series taken from body cavity of a Port Jackson shark... collected by Mr Collyer". Specimens from several other locations and variation within the species were also mentioned in the original description. Therefore, there was originally a syntype series and all the material initially mentioned by Hale (1924) is accordingly registered as syntypes in the SAMA: 3 specimens, C230, Beachport, South Australia, 3-4 fm, H.M. Hale (examined, re-identified as N. wowine Bruce, 1986); 21 specimens, C231, Elliston, Eyre Peninsula, South Australia, on bait when line fishing, H.M. Hale (examined, re-identified as N. wowine Bruce, 1986); 0 , C228, Gulf St. Vincent, from body cavity of Heterodontus phillipi (Port Jackson shark), H. Collyer (examined); 36 specimens, C160, Gulf St. Vincent, from body cavity of Heterodontus phillipi (Port Jackson shark), H. Collyer (examined). Hale (1925) illustrated a "type male" and gave Gulf St. Vincent as "type loc.". Under ICZN article 74.5 this qualifies as a lectotype designation. Unfortunately, Hale did not clearly indicate which specimen from the Gulf St. Vincent material this male was. Holdich et al. (1981) 
recognized a male specimen (SAMA C228), previously noted by Hale (1924) as the largest specimen, as the "Type" and St. Vincent Gulf as the type locality. Bruce (1986) under the heading material examined noted "Holotype, male" and under the heading "Types" noted "Held by the South Australian Museum, Adelaide, C228", it was also stated that the type locality is Port Willunga, South Australia. The male C228, however, should be regarded as a lectotype, the other material registered as syntypes are paralectotypes and the exact type locality is not known more precisely than Gulf St. Vincent, South Australia. - Type locality: Gulf St. Vincent, South Australia, [Australia].

Material examined. New South Wales: 195, AM P38676, off Grotto Point, Port Jackson, $33^{\circ} 49.2^{\prime} \mathrm{S} 151^{\circ} 15.75 ' \mathrm{E}$, baited trap, unknown substrate, probably sediment, 10 m, S. Keable, J. Lowry \& D. Townsend, 16-17 Jul. 1988. Tasmania: 169, AM P47246, about $1 \mathrm{~km}$ off steps at south end of Ocean Beach on a line towards Cape Sorell Lighthouse, $42^{\circ} 09.4^{\prime} \mathrm{S} 145^{\circ} 15^{\prime} \mathrm{E}$, baited trap, sand, 16 m, J. Lowry \& S. Keable, 27-28 April 1991, TAS-305.

Diagnosis. Interocular furrow: moderately developed, distinct but not extending across the cephalon. Frontal lamina: lateral margins medially constricted. Antenna: c. $0.26 \times$ as long as body, reaching to posterior of pereonite 2 . Coxal plates: furrows moderately developed, on all coxae. Pleonite 4: apex slightly rounded. Pleotelson: broad or narrow, length $0.96-1.01 \times$ basal width; anterodorsal depression absent; anterolateral margins convex; posterolateral margins convex; apex produced into a small point; with 3-6 RS. Pereopods 2-3: propodus without RS on palm. Pereopod 7: basis broad, width $0.7-0.8 \times$ length; distance between anterior margin and medial carina greater than between posterior margin and medial carina; posterior margin with setae along entire length. Penes: absent, vasa deferentia opening flush to surface of sternite 7 (although Bruce (1986) indicates the penes to be present as small papillae). Pleopod 2 appendix masculina: extending beyond tip of endopod, 1.04$1.06 \times$ length of endopod; margins very slightly curved laterally or straight; slender; apex recurved, bent slightly medially, bluntly rounded. Uropods: exopod slightly shorter than endopod, $0.84-0.87 \times$ the length of the endopod.

Variation. Pleotelson and uropod robust setal counts from margins $(\mathrm{n}=10)$, paralectotypes SAMA C160: Pleotelson: 2:2 (100\%). Endopod, medial: 3 (10\%), 4 (90\%); lateral: 2 (90\%), 3 (10\%). Exopod, medial: 1 (10\%), 2 (90\%); lateral: $4(60 \%), 5(40 \%)$. Pleotelson and uropod robust setal counts from margins $(\mathrm{n}=10)$, non type material AM P38676. Pleotelson: 2:1 (10\%), 2:2 (50\%), 2:3 (10\%), 3:3 (30\%). Endopod, medial: 4 (90\%), 5 (10\%); lateral: 2 (100\%). Exopod, medial: 2 (100\%); lateral: 5 (100\%). Specimens from Port Jackson (AM P38676) have a narrower pleotelson than the type material.

Sexual dimorphism. Females may be larger than males.

Size. Largest female $19.9 \mathrm{~mm}$.

Remarks. Hale (1924) mentions variation in the number of articles present in the antennal flagellum of Natatolana woodjonesi. This is probably because there are two species in the original syntype series. The specimens from Beachport (SAMA C230) and those from Elliston (SAMA C231) appear to be $N$. wowine, a species that has longer a antennal flagellum containing more articles than are found in $N$. woodjonesi. In Natatolana woodjonesi the antenna reach to the posterior of pereonite 2 and there are up to c. 21 articles in the flagella. In $N$. wowine the antenna extend to the posterior or pereonite 3 and the flagella contain up to c. 28 articles.

Figures of the lectotype of Natatolana woodjonesi in Holdich et al. (1981) have two omissions. The uropod exopod is shown and described as having two robust setae on the lateral margin. There are actually four to five robust setae on this margin, some of which are flattened and difficult to see. The illustration of pereopod 7 lacks the slender setae along the anterior margin of the ischium as shown by Hale (1924), Hale (1925) and Bruce (1986).

Distribution and ecology. Australia: New South Wales, Victoria, Tasmania, South Australia. In depths to $82 \mathrm{~m}$. Scavenger.

\section{Natatolana wowine Bruce, 1986}

Natatolana wowine Bruce, 1986: 118, figs. 81, 82.-Hutchings et al., 1993: 13.-Springthorpe \& Lowry, 1994: 65.-Brusca et al., 1995: 82.-Bruce et al., 2002: 154.

Cirolana woodjonesi.-Hale, 1924: 71-72 (part).-1925: 137 (part) [mis-identification, not Natatolana woodjonesi (Hale, 1924)].

Type material. Holotype: $\widehat{0}$, NMV J1723 (not examined). Paratypes: NMV J1724-1731 (not examined); AM P9592, P9594, P32366-32370 (examined); WAM 18-80 (examined). - Type locality: Crib Point, Western Port, Victoria, Australia, $8^{\circ} 23^{\prime} \mathrm{S} 145^{\circ} 14^{\prime} \mathrm{E}$.

Material examined. Queensland: series from due east of Mooloolaba, $26^{\circ} 35.42 ' S 153^{\circ} 41.50^{\prime} \mathrm{E}, 206$ m, 2-4 Aug. 1994: ㅇ, AM P47606, SEAS QLD-1128; 2 우, AM P47607, SEAS QLD-1148. New South Wales: series from northeast and north of Coffs Harbour, 11-13 Aug. 1993; đิ, AM P47608, 30¹5.86'S $153^{\circ} 21.90^{\prime} \mathrm{E}, 92.7 \mathrm{~m}$, SEAS NSW-870; 0 , AM P47609, $30^{\circ} 14.63^{\prime} \mathrm{S} 153^{\circ} 27.68^{\prime} \mathrm{E}, 199 \mathrm{~m}$, SEAS NSW-883; 우, AM $\mathrm{P} 47610,30^{\circ} 14.84^{\prime} \mathrm{S} 153^{\circ} 27.69^{\prime} \mathrm{E}, 182.9 \mathrm{~m}$, SEAS NSW-867; series from off Wollongong: 35, AM P47611, 34 $32.02^{\prime} \mathrm{S}$ $151^{\circ} 13.00 ' \mathrm{E}, 200 \mathrm{~m}, 6-7$ May 1993, SEAS NSW-780; 52, AM P47612, 34을 $32.53^{\prime} \mathrm{S} 151^{\circ} 17.07^{\prime} \mathrm{E}, 400 \mathrm{~m}, 6-7$ May 1993, SEAS NSW-787. Victoria: 95, AM P47613, southeast of Bastion Point, Mallacoota, $37^{\circ} 36.6^{\prime} \mathrm{S} 149^{\circ} 48.3^{\prime} \mathrm{E}$, baited trap, ?bottom, $30 \mathrm{~m}$, J. Lowry \& S. Keable, 29-30 Nov. 1988, NSW-398. Tasmania: many, AM P47614, $100 \mathrm{~m}$ off south side Esperance Point, Port Esperance, $43^{\circ} 19.8^{\prime} \mathrm{S} 147^{\circ} 3.8^{\prime} \mathrm{E}$, baited trap, ?bottom, $24 \mathrm{~m}$, J. Lowry \& S. Keable, 19-20 April 1991, TAS-205; 12, AM P47615, mouth of Fortescue Bay, 430.77'S $145^{\circ} 59.47$ 'E, 50 m, 17-18 April 1993, SEAS TAS-368. South Australia: 3 paralectotypes of Natatolana woodjonesi, SAMA C230, Beachport; 21 paralectotypes of Natatolana woodjonesi, SAMA C231, Elliston, Eyre Peninsula; series from Upper Spencer Gulf: SAMA C56175639, $32^{\circ}-33^{\circ} 5^{\prime} \mathrm{S} 137^{\circ} 37.38-57.4^{\prime} \mathrm{E}, 7-22 \mathrm{~m}$, South Australia Fisheries Department Survey, Feb. 1987.

Diagnosis. Interocular furrow: moderately developed, distinct but not extending across the cephalon. Frontal lamina: lateral margins medially constricted. Antenna: c. $0.39 \times$ as long as body, reaching to posterior of pereonite 3 . Coxal plates: furrows moderately developed, on all coxae. Pleonite 4: apex broadly rounded. Pleotelson: broad, length 0.77-0.92× basal width; anterodorsal depression absent; anterolateral margins almost straight and angling posteriorly 
toward the midline, or convex; posterolateral margins convex or broadly rounded; apex not produced, lateral margins converging smoothly to a point; with 6-8 RS. Pereopods 2-3: propodus without RS on palm. Pereopod 7: basis broad, width $0.64 \times$ length; distance between anterior margin and medial carina greater than between posterior margin and medial carina; posterior margin with setae on proximal two-thirds. Penes: absent. Pleopod 2 appendix masculina: extending beyond tip of endopod; margins very slightly curved laterally; slender; apex recurved, bent slightly medially, acute. Uropods: exopod slightly shorter than endopod, $0.87 \times$ the length of the endopod; lateral margin with or without RS.

Variation. Bruce (1986) recorded a variation in the "roundness of the pleotelson," i.e., the posterolateral margins of the pleotelson may be convex converging smoothly to a point or broadly rounded. Bruce (1986) also recorded variation in the number of robust setae on the margins of the pleotelson, from seven or eight in material from Victoria, to six in specimens from Tasmania and Western Australia. In the material examined here in samples from New South Wales (Coffs Harbour: AM P47608, AM P47609; Wollongong: AM P47611, AM P47612) and eastern Tasmania (AM P47614, AM P47615), specimens had both six and eight robust setae on the pleotelson margins. The most common number of robust setae on the pleotelson margins was six, in all samples, except for AM P47615 (eastern Tasmania) where 10 specimens had eight and only two had six. Variation was also found in the number of robust setae on the lateral margins of the uropod exopod, ranging from none to five but most commonly five. All of the material from the South Australia Fisheries Department Upper Spencer Gulf Survey lack robust setae on the uropod exopod lateral margin, as do specimens from eastern Victoria (AM P47613). Most of the specimens in AM P47614 (eastern Tasmania) also lack these setae although they are present on five specimens from this sample. Examination of the paratypes in AM P9592 (17 specimens, not two as recorded by Springthorpe \& Lowry [1994]) and P9594 (18 specimens) (material recorded by Hale (1925) as "Tasmania: off Cape Portland" and "New South Wales: 'From porpoise", respectively) shows that they also lack robust setae on the uropod exopod lateral margin.

Sexual dimorphism. Females tend to be larger than males and ovigerous females may be slightly broader.

Size. Adults to $35 \mathrm{~mm}$ (Bruce (1986) records largest male $19.0 \mathrm{~mm}$, largest female $17.6 \mathrm{~mm})$, largest manca to c. 8 $\mathrm{mm}$.

Remarks. Examination of the paralectotypes of Natatolana woodjonesi show that they include specimens of $N$. wowine. The falcate apex of the appendix masculina of specimens of $N$. wowine is distinctive. This combined with details of the frontal lamina, length of the antennae, pleonite 4 , pleotelson and uropods are the most useful features in separating this species from similar species.

Distribution and ecology. Australia: southern Queensland; New South Wales; Tasmania; Mallacoota, Western Port, Port Phillip Bay, in Victoria; Upper Spencer Gulf, Beachport, Elliston, Eyre Peninsula, in South Australia; Recherche Archipelago, in Western Australia. At depths of 6-400 m. Scavenger.

\section{Natatolana zebra n.sp.}

Figs. 51-53

Type material. HolOTYPE: $\delta, 11 \mathrm{~mm}$, AM P47225. PARATYPES: 562 specimens, AM P47226; $\uparrow$, AM P47227; subadult ô, AM

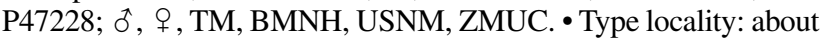
$25 \mathrm{~m}$ off middle of breakwater, Pilot Bay, Tasmania, Australia, $42^{\circ} 12.4^{\prime} \mathrm{S} 145^{\circ} 12.4^{\prime} \mathrm{E}$, [baited trap, unknown substrate, probably sand], 6 m, [J. Lowry \& S. Keable, 26-27 April 1991, TAS-286].

Additional material. Tasmania: 2, AM P47229, about $250 \mathrm{~m}$ offshore, and just to the east of Hannants Bight on a line toward large bluff of Ocean Beach north side of Cape Sorell, $42^{\circ} 11.5^{\prime} \mathrm{S}$ $145^{\circ} 11.4^{\prime} \mathrm{E}$, baited trap, sand, $25 \mathrm{~m}$, J. Lowry \& S. Keable, 2627 April 1991, TAS-282; 16, AM P47230, between breakwater and Prater Rock, Pilot Bay, $42^{\circ} 12^{\prime} \mathrm{S} 145^{\circ} 12^{\prime} \mathrm{E}$, baited trap, probably sand bottom, 10 m, J. Lowry \& S. Keable, 26-27 April 1991, TAS-284; 59, AM P47231, same data as holotype, except 100 m off Pilot Beach, 3 m, TAS-285.

Diagnosis. Interocular furrow: absent. Frontal lamina: lateral margins medially constricted. Antenna: c. $0.4 \times$ as long as body, reaching to posterior of pereonite 4. Coxal plates: furrows strongly developed, on all coxae. Pleonite 4: apex slightly rounded. Pleotelson: broad, length $0.95 \times$ basal width; anterodorsal depression present; anterolateral margins convex; posterolateral margins convex; apex produced into a small point; with $10 \mathrm{RS}$. Pereopods 1-6: males with conspicuous elongated RS subequal to propodus on the merus of pereopods $1-3$ and extending from the carpus to dactylus of pereopods 4-6. Pereopods 2-3: propodus without RS on palm. Pereopods 5-7: propodus long, on pereopod 5 greatly elongate, $2 \times$ that of pereopod 7. Pereopod 7: basis narrow, width $0.35 \times$ length; distance between anterior margin and medial carina less than between posterior margin and medial carina; posterior margin with sparse setae on distal half. Penes: present. Pleopod 2 appendix masculina: extending beyond tip of endopod, $1.17 \times$ length of endopod; margins sinuate; slender; apex not at angle to adjacent margins, bluntly rounded. Uropods: exopod subequal to endopod, $0.91 \times$ the length of the endopod.

Additional descriptive characters. Based on holotype. Body: length c. $2.6 \times$ width. Colour translucent white to yellow in alcohol. Chromatophores present; large; greyblack in alcohol; arranged in bands. Eyes: with 7 ommatidia in horizontal diameter; with 7 ommatidia in vertical diameter; round; colour tan in alcohol. Frontal lamina: length c. $3.75 \times$ basal width; apex expanded, anterior margin angled. Antennule: peduncular article 1 longer than article 2 ; article 2 with 1 large pappose seta; article 3 short, subequal to article 1. Flagellum 10-articulate. Antenna: peduncular article 4 with $5 \mathrm{SS}$ on posterolateral margin and $1 \mathrm{SS}$ at anterodistal angle; article 5 with 2 pappose setae and 3 SS at posterodistal angle, c. $5 \mathrm{SS}$ and 1 penicillate seta at anterodistal angle. Flagellum 21-articulate. Mandible: setal row with 16 RS. Maxillule: medial lobe with 3 large robust pappose setae and 2 small SS; lateral lobe with $12 \mathrm{RS}$ on distal surface. Maxilla: lateral lobe with 4 SS; medial lobe with 5 SS and 10 PS; middle lobe with 12 long and 3 short SS. Maxilliped: endite with 1 coupling hook, and 5 PS. Pereon: ornamentation consists of 1 strongly developed furrow on lateral margin of pereonite 1 ; pereonites 1, 4-6 subequal and longest, $2-3$ and 7 subequal. Coxae: pereonite 1 , coxae 2-3 with rounded posteroventral corners, coxae 4-7 with increasingly produced, broad, acute posteroventral 


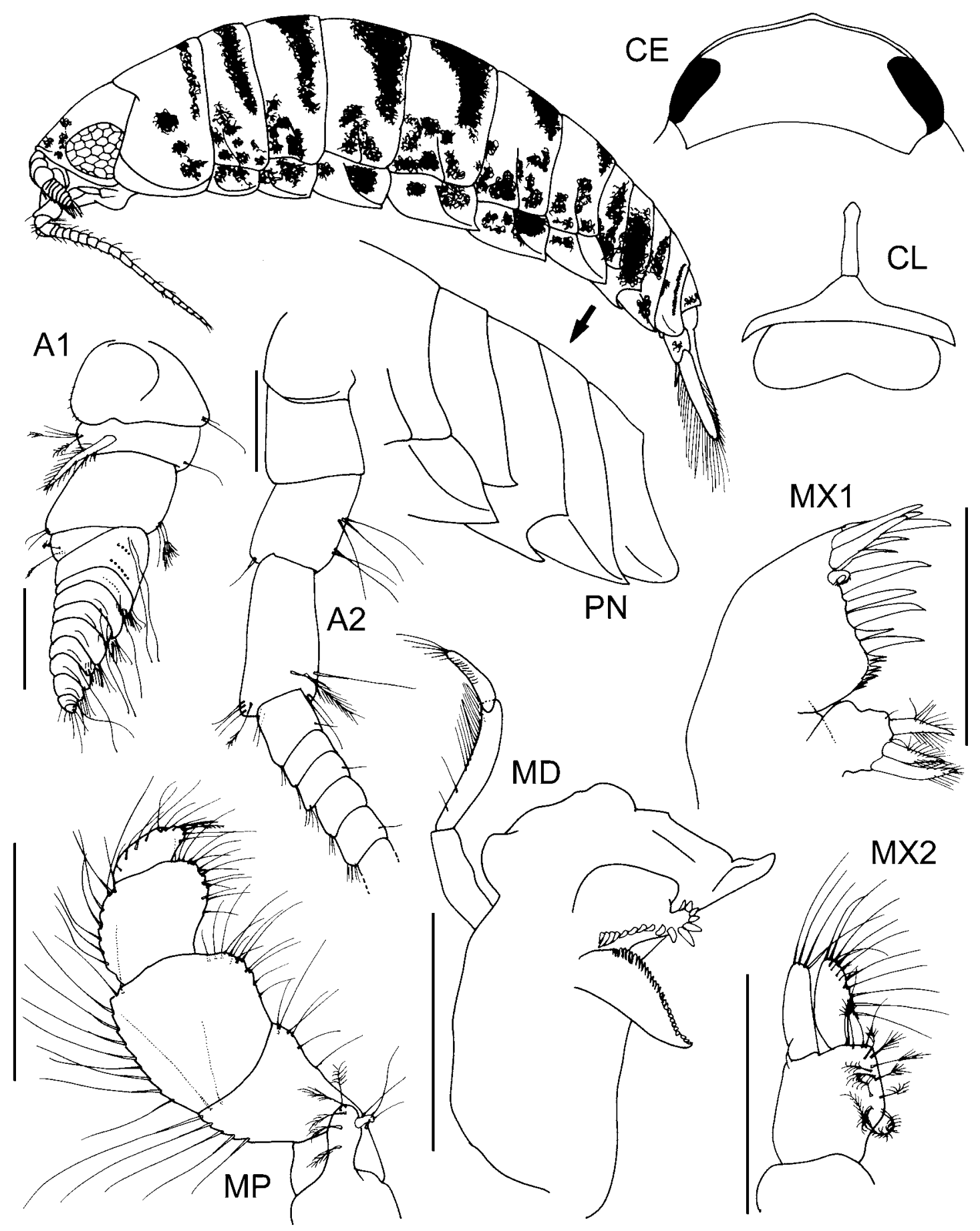

Fig. 51. Natatolana zebra n.sp., holotype. Scales $=0.5 \mathrm{~mm}$.

corners. Pleonite 2: dorsal posterolateral margin subequal with ventral posterolateral margin. Pereopod 7: basis anterior margin straight; medial carina with PS along entire length; posterior margin convex, SS present. Ischium anterior margin with SS; posterior margin with groups of RS present, PS present. Merus anterior margin with $1 \mathrm{SS}$; posterior margin with $2 \mathrm{RS}, \mathrm{SS}$ present. Carpus posterior margin with 2 RS, SS absent. Propodus subequal to carpus; posterior margin with 2 RS, SS absent. Penes: forming well separated flattened lobes. Pleopod
2 appendix masculina: arising basally. Pleopods 1-5: exopod suture strongly developed on pleopods 1-5; endopod PS on most of margins on pleopods 1-4, absent on pleopod 5 . Uropods: endopod triangular; medial margin convex, with 3 RS, PS along entire length; apex with 2 RS; lateral margin slightly convex, with 2 RS and 1 penicillate seta, PS along entire length. Exopod medial margin convex, with 3 RS, PS along entire length; apex acute, with $2 \mathrm{RS}$; lateral margin convex, with 6 RS, PS along entire length. 


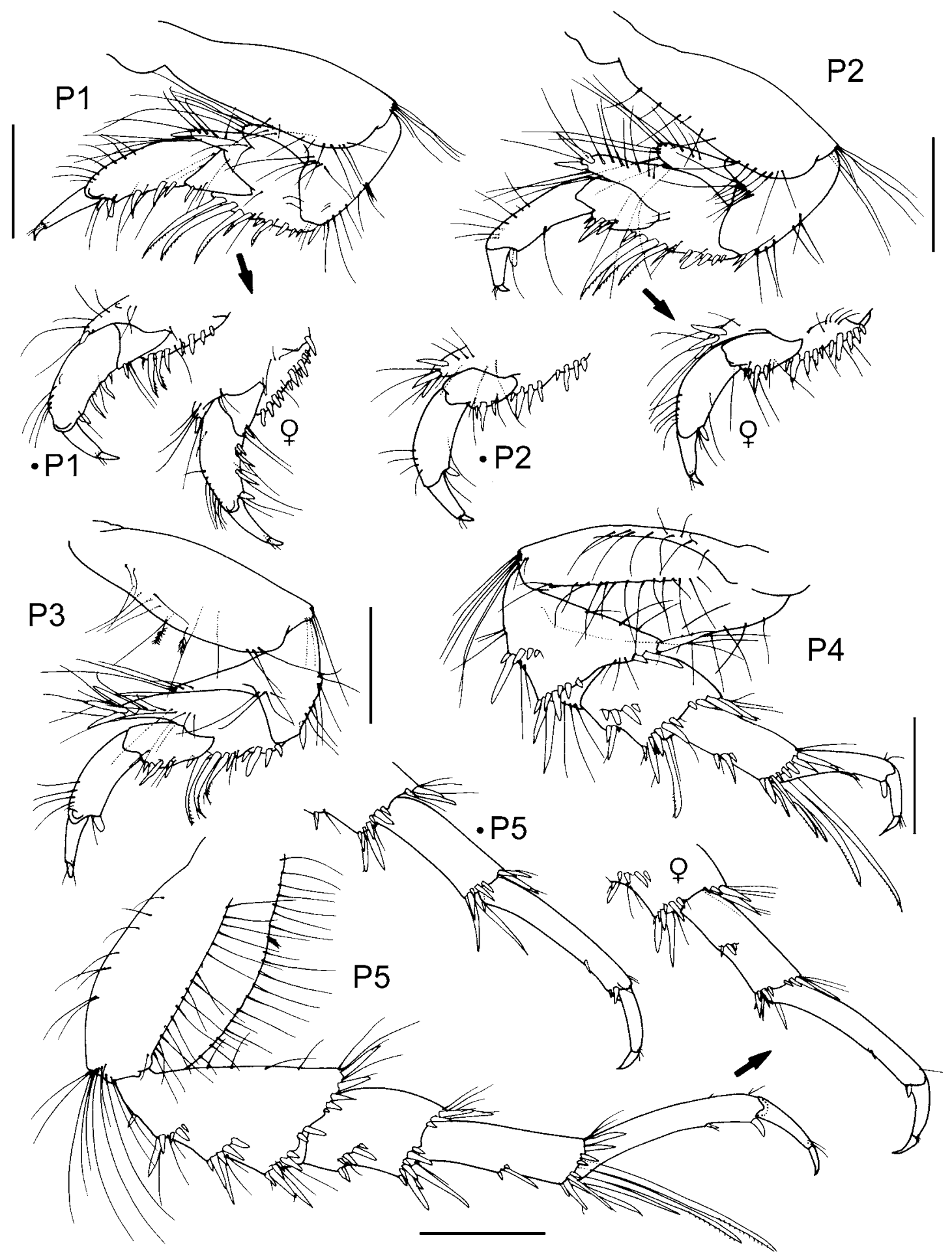

Fig. 52. Natatolana zebra $\mathrm{n} . \mathrm{sp}$., holotype, male, $11 \mathrm{~mm}$ except; $\bullet P 5 .=$ paratype male (immature) AM P47228; female $=$ paratype female AM P47277. Scales $=0.5 \mathrm{~mm}$.

Variation. Immature males lack the conspicuously elongate robust setae on pereopods 1-6.

Sexual dimorphism. Females lack the conspicuously elongated robust setae present on the merus of pereopods 1-3 and on the carpus of pereopods 4-6 of adult males.

Size. Up to c. $13.5 \mathrm{~mm}$.

Etymology. Named after the equine quadruped, the zebra, in reference to the striped pattern of chromatophores.
Remarks. The most distinctive character that separates Natatolana zebra from other species of Natatolana is the elongate propodus of pereopod 5 (longer than that of pereopod 6 and twice as long as that of pereopod 7). The distinct dorsal depression on the pleotelson, presence of penes, lack of robust setae on the propodal palm of pereopod 2 , relatively narrow basis of pereopod 7 and conspicuously long robust setae on pereopods 1-6 of males also help to distinguish this species from all others in the genus. 


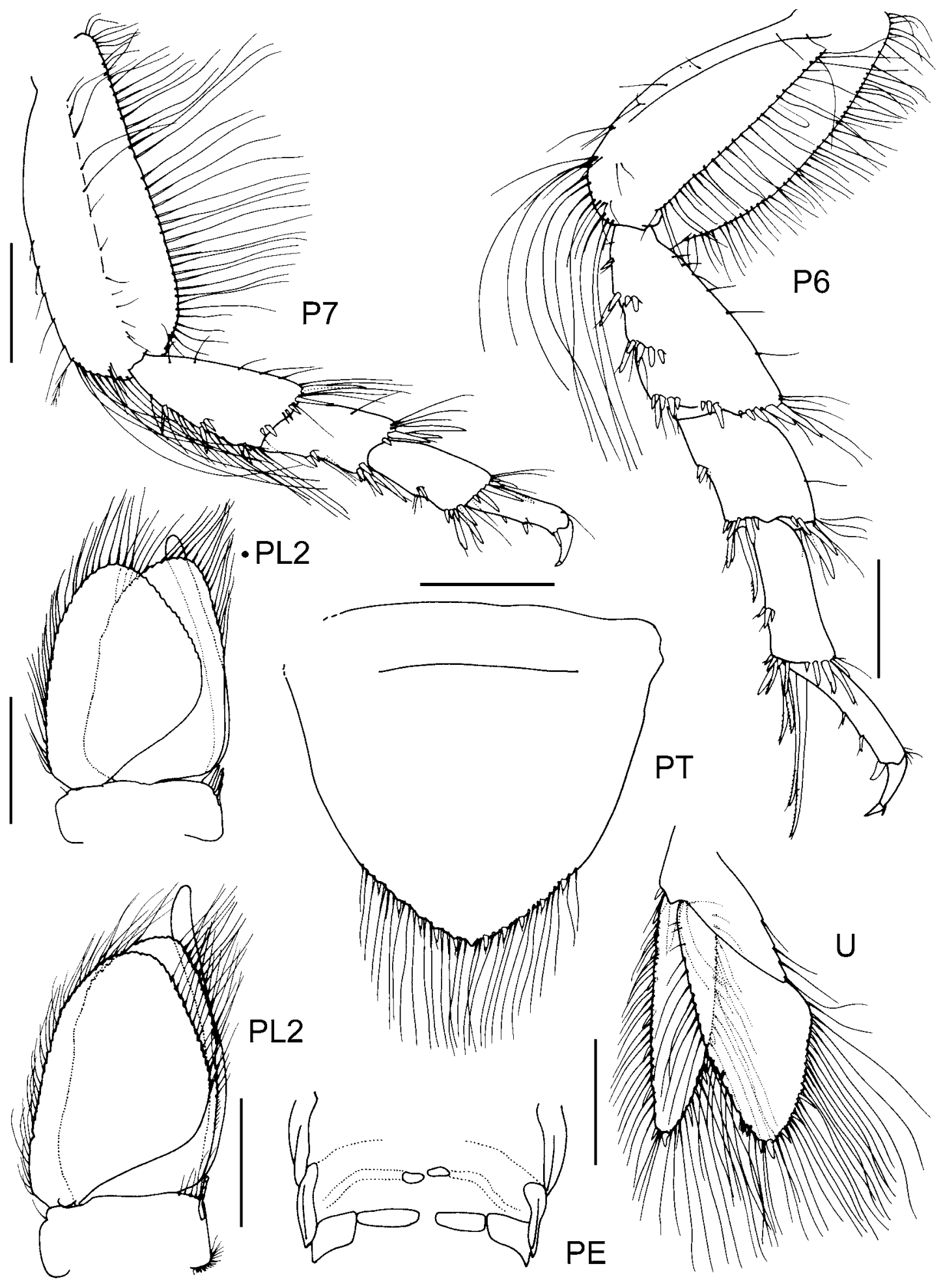

Fig. 53. Natatolana zebra n.sp., holotype, except; $\bullet P L 2=$ paratype male (immature) AM P47228. Scales $=0.5 \mathrm{~mm}$.

Distribution and ecology. Australia: known only from southwest Tasmania in the vicinity of the type locality. At depths of 3-25 m. Scavenger.
ACKNOWLEDGMENTS. This study would not have been possible without the support, help and understanding of my wife Debra. It was undertaken in partial fulfilment of a PhD degree, Macquarie University, while in receipt of a Macquarie University Postgraduate Scholarship. Financial assistance was also provided by a grant from the Joyce W. Vickery Research Fund of the Linnean Society of New South Wales. I am grateful for the support of the recent Directors and Trustees of The Australian Museum in allowing me to use the facilities of the museum. 
I would particularly like to thank my supervisors Dr James Lowry and Dr Noel Tait for their assistance, advice and encouragement during the course of this study, and for their constructive criticism of the manuscript. Additionally, Dr George (Buz) Wilson was extremely patient and supportive of my many and varied requests for advice during the course of the study, publication of which would not have occurred without his continual encouragement and generous allowance of research time. I am also indebted to Ms Helen Stoddart for guidance in taxonomic procedures and Dr Penny Berents for allowing me time to edit the manuscript for publication.

Dr Niel Bruce provided much needed encouragement, commented on early species descriptions and through the Zoological Museum, University of Copenhagen, provided funding that made it possible for me to examine material held at the Phuket Marine Biological Centre, Thailand. He also provided references, specimens and notes (including information regarding the species of Natatolana, described in this study, from New Zealand), and added details regarding the distributions and synonymies of the north Atlantic species of Natatolana. I thank him for his contribution and continued interest. Two anonymous referees also provided a wealth of advice for improvement of the manuscript. For assistance in composing and inking many of the final figures I thank Mr Roger Springthorpe.

The following individuals assisted in making specimens from various institutions available to me: Ms M. Lowe (BMNH); $\mathrm{Dr}$ C. Carpine (IOM); L. Cederholm (Lund University, Sweden); Dr D. Defaye (MNHN); Mr R. Webber (NMNZ); Ms K. Coombes (NTM); Mr P. Anderson (NIWA); Mr P. Davie and Mr J. Short (QM); Ms L. Hoenson (SAM); Ms K. Gowlett Holmes (SAMA); Ms K. Sindemark (SMNH); Dr N. Nunomura (TSM); Ms M. Schotte (USNM); Ms J. Griffith (WAM); Dr N. Bruce (ZMUC).

\section{References}

Barnard, K.H., 1936. Isopods collected by the R.I.M.S. “Investigator”. Records of the Indian Museum, Calcutta 38: 147-191.

Barnard, K.H., 1940. Contributions to the Crustacean Fauna of South Africa. XII. Further Additions to the Tanaidacea, Isopoda, and Amphipoda, together with Keys for the Identification of the hitherto Recorded Marine and Fresh-water Species. Annals of the South African Museum 32: 381-515.

Barnard, K.H., 1955. Additions to the Fauna-list of South African Crustacea and Pycnogonida. Annals of the South African Museum 43: 1-107.

Berrow, S., 1994. Fish predation by the marine crustaceans Orchomene nana and Natatolana borealis. Irish Naturalists' Journal 24(12): 514.

Bird, P.M., 1981. The occurrence of Cirolana borealis (Isopoda) in the hearts of sharks from Atlantic coastal waters of Florida. United States Fishery Bulletin 79(2): 376-383.

Botosaneanu, L., N. Bruce \& J. Notenboom, 1986. Isopoda: Cirolanidae. In Stygofauna Mundi. A Faunistic, Distributional and Ecological Synthesis of the World Fauna inhabiting Subterranean Waters (including the Marine Interstitial), ed. L. Botosaneanu, pp. 412-422. Leiden: E.J. Brill/Dr W. Backhuys.

Bowman, T.E., 1971. Cirolana narica n.sp., a New Zealand isopod (Crustacea) found in the nasal tract of the dolphin Cephalorhynchus hectori. Beaufortia 19(252): 107-112.

Bozzano, A., \& F. Sarda, 2002. Fishery discard consumption rate and scavenging activity in the northwestern Mediterranean Sea. Ices Journal of Marine Science 59(1): 15-28.

Brandt, A., 1988. Antarctic Serolidae and Cirolanidae (Crustacea: Isopoda): new genera, new species, and redescriptions. Koeltz Scientific Books [Theses Zoologicae 10], Koenigstein, 143 pp.

Brandt, A., \& G.C.B. Poore, 2003. Higher classification of the flabelliferan and related Isopoda based on a reappraisal of relationships. Invertebrate Systematics 17: 893-923. http://www.publish.csiro.au/?act=view_file\&file_id=IS02032.pdf [accessed 2006]
Bruce, N.L., 1981. Cirolanidae (Crustacea: Isopoda) of Australia: Diagnoses of Cirolana Leach, Metacirolana Nierstrasz, Neocirolana Hale, Anopsilana Paulian \& Debouteville, and Three New Genera-Natatolana, Politolana and Cartetolana. Australian Journal of Marine and Freshwater Research 32: 945-966.

Bruce, N.L., 1986. Cirolanidae (Crustacea: Isopoda) of Australia. Records of the Australian Museum, Supplement 6: 1-239.

Bruce, N.L., 1993a. Two new genera of marine isopod crustaceans (Flabellifera: Sphaeromatidae) from Southern Australia, with a reappraisal of the Sphaeromatidae. Invertebrate Taxonomy 7: $151-171$.

Bruce, N.L., 1993b. Two new genera of marine isopod crustaceans (Cirolanidae) from Madang, Papua New Guinea. Memoirs of the Queensland Museum 33(1): 1-15.

Bruce, N.L., 1995a. Cirolana and related marine isopod crustacean genera (family Cirolanidae) from the coral reefs of Madang, Papua New Guinea. Cahiers de Biologie Marine 35: 375-413.

Bruce, N.L., 1995b. Redescription of the tropical pelagic oceanic cirolanid genus Pontogelos Stebbing, 1910 (Crustacea, Isopoda). Steenstrupia 21: 37-48.

Bruce, N.L., 2003. A new deep-water species of Natatolana (Crustacea: Isopoda: Cirolanidae) from Chatham Rise, eastern New Zealand. Zootaxa 265:1-12. http://www.mapress.com/zootaxa/2003/zt00265.pdf [accessed 25 March 2006]

Bruce, N.L., H.M. Lew Ton \& G.C.B. Poore, 2002. Cirolanidae Dana, 1852. In Zoological Catalogue of Australia: Crustacea: Malacostraca: Syncarida, Peracarida: Isopoda, Tanaidacea, Mictacea, Thermosbaenacea, Spelaeogriphacea, ed. W.W.K. Houston \& P.L. Beesley, pp. 138-157, vol.19.2A. Melbourne, Australia: CSIRO Publishing.

Bruce, N.L., \& J. Olesen, 1995. Natatolana nukumbutho, a new species (Crustacea: Isopoda: Cirolanidae) from deep water off Suva, Fiji. Proceedings of the Biological Society of Washington 108(2): 212-219.

Brusca, R.C., \& E.W. Iverson, 1985. A Guide to the Marine Isopod Crustacea of Pacific Costa Rica. Universidad de Costa Rica. Revista de Biologia Tropical 33 (suppl. 1): 1-77.

Brusca, R.C., \& M. Ninos, 1978. The status of Cirolana californiensis Schultz, and C. deminuta Menzies and George, with a key to the California species of Cirolana (Isopoda: Cirolanidae). Proceedings of the Biological Society of Washington 91(2): 379-385.

Brusca, R.C., R. Wetzer \& S.C. France, 1995. Cirolanidae (Crustacea: Isopoda: Flabellifera) of the Tropical Eastern Pacific. Proceedings of the San Diego Society of Natural History 30: 1-96.

Carvacho, A., 1977. Isopodes intertidaux des côtes du centre et du nord du Chili. 1. Familles des Cirolanidae, Excorallanidae et Corallanidae. Crustaceana 32(1): 27-44.

Carvalho, F.P., \& S.W. Fowler, 1985. Biokinetics of plutonium, americium and californium in the marine isopod Cirolana borealis, with observations on its feeding and molting [sic] behavior. Marine Biology 89: 173-181.

Castelló, J., 1999. Taxonomic study of the isopod crustaceans from the Spanish expedition "Antartida 1986-11" in the Scotia Sea, South Atlantic. Scientia Marina 63: 275-279.

Castelló, J., \& J.L. Carballo, 2001. Isopod fauna, excluding Epicaridea, from the Strait of Gibraltar and nearby areas (Southern Iberian Peninsula). Scientia Marina 65(3): 221-241. http://www.icm.csic.es/scimar/PDFs/sm65n3221.pdf [accessed 11 May 2006]

Castro, M., A. Araujo \& P. Monteiro, 2005. Fate of discards from deep water crustacean trawl fishery off the south coast of Portugal. New Zealand Journal of Marine and Freshwater Research 39(2):437-446.

Chilton, C., 1909. The Crustacea of the Subantarctic Islands of New Zealand. Wellington: Government Printer, pp. 601-671.

Dallwitz, M.J., 1980. A general system for coding taxonomic descriptions. Taxon 29: 41-46. 
Dallwitz, M.J., T.A. Paine \& E.J. Zurcher, 1993. DELTA User's Guide. A General System for Processing Taxonomic Descriptions. CSIRO Australia, Division of Entomology; CSIRO Information Services (Publications), Melbourne, pp. 136.

Dana, J.D., 1853 [dated 1852]. On the classification of the Crustacea Choristopoda or Tetradecapoda. American Journal of Science and Arts Series 2 14(41): 297-316.

Dollfus, A., 1903. Note préliminaire sur les espéces du genre Cirolana recueillies pendant les campagnes de l'Hirondelle et de la Princesse Alice sous la direction de S.A.S. le Prince Albert Ier, de Monaco. Bulletin de la Société Zoologique de France 28: 5-10.

Edmonds, C., 1989. Dangerous Marine Creatures. Sydney: Reed Books, pp. 192

Ellis, J., 1981. Some type specimens of Isopoda (Flabellifera) in the British Museum (Natural History), and the isopods in the Linnaean Collection. Bulletin of the British Museum of Natural History (Zoology) 40(4): 121-128.

Espinosa-Pérez, M.C., \& M.E. Hendrickx, 1997. Isópodos (Crustacea: Isopoda). In Tercer Catálogo de la Colección de Referencia de Invertebrados. Estación Mazatlán, ICML, UNAM. Comisión Nacional para el Conocimiento y Uso de la Biodiversidad e Inst. de Cienc. Mar y Limol., UNAM, Mazatlán, Mexico, ed. M.E. Hendrickx, M.C. Espinosa Pérez, J. Slagado Barragán \& M.N. Méndez Ubach, pp. 27-49.

Espinosa-Pérez, M.C., \& M.E. Hendrickx, 2001. Checklist of isopods (Crustacea: Peracarida: Isopoda) from the Eastern Tropical Pacific. Belgian Journal of Zoology 131(1): 43-55.

Filhol, H., 1885. Crustacés. In Recueil de Mémoires, Rapports et Documents relatifs a l'observation du passage de Vénus sur le soleil du 9 Decembre 1874, vol. 3(2) and atlas of plates, pp. 349-510. Paris: Libraire des Comptes Rendus des Séances de l'Academie des Sciences.

Giambiagi, D., 1925. Resultados de la Primera Expedición a Tierra del Fuego (1921). Crustáceos Isópodos. Anales de la Sociedad Cientifica Argentina, Buenos Aires 1925: 229-245.

Goss, P.H., 1855. A Manual of Marine Zoology for the British Isles. Part I. London: John van Voorst, pp. 203.

Hale, H.M., 1924. The flora and fauna of Nuyts Archipelago and the Investigator Group. No. 16.-The Crustacea. Transactions of the Royal Society of South Australia 48: 67-73.

Hale, H.M., 1925. Review of Australian isopods of the cymothoid group. Part I. Transactions of the Royal Society of South Australia 49: 128-185.

Hale, H.M., 1929. The crustaceans of South Australia. Part II. Handbooks of the Flora and Fauna of South Australia. British Science Guild, Adelaide, pp. 202-308.

Hale, H.M., 1937. Isopoda and Tanaidacea. Australasian Antarctic Expedition 1911-14 2(2): 1-45.

Hale, H.M., 1940. Report on the cymothoid isopoda obtained by the F.I.S. "Endeavour" on the coasts of Queensland, New South Wales, Victoria, Tasmania, and South Australia. Transactions of the Royal Society of South Australia 64(2): 288-304.

Hale, H.M., 1952. Isopoda families Cymothoidae and Serolidae. British Australian and New Zealand Antarctic Research Expedition 1929-1931 under the command of Sir Douglas Mawson. Reports-Series B (Zoology and Botany) 6: 21-36.

Hansen, H.J., 1890. Cirolanidae et familiae nonnulae propinquae Musaei Hauniensis. Det Kongelige Danske Videnskabernes Selskabs Skrifter, Naturvidenskabelig og Mathematisk Afdeling 6(3): 237-426.

Hansen, H.J., 1905. Revision of the European forms of the Cirolaninae, a Subfamily of Crustacea Isopoda. Journal of the Linnean Society, Zoology 29: 337-373.

Hayward, B.W., M.S. Morley, J.J. Hayward, A.B. Stephenson, W.M. Blom, K.A. Hayward \& H.R. Grenfell, 1999. Monitoring studies of the benthic ecology of Waitemata Harbour, New Zealand. Records of the Auckland Museum 36: 95-117.

Hayward, B.W., A.B. Stephenson, M.S. Morley, W.M. Blom, H.R. Grenfell, F.J. Brook, J.L. Riley, F. Thompson \& J.J. Hayward, 2001. Marine biota of Parengarenga Harbour, Northland, New
Zealand. Records of the Auckland Museum 37: 45-80.

Heller, C., 1866. Carcinologische Beiträge zur Fauna des adriatischen Meeres. Verhandlungen der Zoologischbotanischen Gesellschaft in Wien 16: 723-760.

Hobbins, C.St.C., \& D.A. Jones, 1993. New species of deep sea isopods from the Red Sea and North Western Indian Ocean: families Cirolanidae and Corallanidae. Senckenbergiana Maritima 23: 115-134.

Hodgson, T.V., 1910. Crustacea. IX. Isopoda. National Antarctic Expedition 1901-1904, Natural History, vol. 5, Zoology and Botany: 1-77.

Holdich, D.M., K. Harrison \& N.L. Bruce, 1981. Cirolanid isopods from the Townsville region of Queensland, Australia, with descriptions of six new species. Journal of Natural History 15: 555-605.

Huber, B.A., 1992. Frontal heart and arterial system in the head of Isopoda. Crustaceana 63(1): 57-69.

Hurley, D.E., 1957. Some Amphipoda, Isopoda and Tanaidacea from Cook Strait. Zoological Publications of Victoria University Wellington 21: 1-20.

Hurley, D.E., 1961. A Checklist and Key to the Crustacea Isopoda of New Zealand and the Subantarctic Islands. Transactions of the Royal Society of New Zealand 1(20): 239-292.

Hutchings, P.A., T.J. Ward, J.H. Waterhouse \& L. Walker, 1993. Infauna of marine sediments and seagrass beds of Upper Spencer Gulf near Port Pirie, South Australia. Transactions of the Royal Society of South Australia 117(1 \& 2): 1-14.

Hutton, F.W., 1879. Notes on a Collection of Crustacea from the Auckland Islands and Campbell Island. Transactions of the New Zealand Institute (Zoology) 11: 337-343.

Iwasa, M., 1965. Isopod crustaceans collected by the surveying ship Sôyômaru on the continental shelf bordering Japan during the years 1926-1930. Bulletin Seiki University 3: 13-19.

Johansen, P.-O., 1999. Observations on the tolerance of Natatolana borealis (Lilljeborg) (Crustacea, Isopoda) to reduced salinity. Sarsia 84: 169-172.

Johansen, P.-O., 2000a. Contribution to the knowledge of growth and postmarsupial development of Natatolana borealis (Crustacea: Isopoda). Journal of the Marine Biological Association of the United Kingdom 80: 623-632.

Johansen, P.-O., 2000b. Bait attraction studies on the scavenging deep water isopod Natatolana borealis (Crustacea, Isopoda). Ophelia 53(1): 27-35.

Johansen, P.-O. \& T. Brattegard, 1998. Observations on behaviour and distribution of Natatolana borealis (Lilljeborg) (Crustacea, Isopoda). Sarsia 83: 347-360.

Jones, D.S., \& G.J. Morgan, 1993. An annotated checklist of Crustacea from Rottnest Island, Western Australia. In The Marine Flora and Fauna of Rottnest Island, Western Australia, ed. F.E. Wells, D.I. Walker, H. Kirkman \& R. Lethbridge, vol. 1, pp. 135-163. Perth: Western Australian Museum.

Kaïm-Malka, R.A., 1997. Biology and life cycle of Natatolana borealis Lilj. 1851, a scavenging isopod from the continental slope of the Mediterranean. Deep Sea Research 44(12): 2045-2067.

Kaïm-Malka, R.A., S. Maebe, C. Macquart-Moulin \& C. Bezac, 1998. Antennal sense organs of Natatolana borealis (Lilljeborg 1851) (Crustacea: Isopoda). Journal of Natural History 33: 65-88.

Keable, S.J., 1992. The scavenging, small, marine invertebrates of Lizard Island, Queensland, Australia. MSC Thesis, Macquarie University, Sydney, Australia, pp. 206.

Keable, S.J., 1995. Structure of the marine invertebrate scavenging guild of a tropical reef ecosystem: field studies at Lizard Island, Queensland, Australia. Journal of Natural History 29: 27-45.

Keable, S.J., 1996a. The synonymy of Natatolana miyamotoi Nunomura, 1991 with Natatolana japonensis (Richardson, 1904) (Isopoda: Cirolanidae) and a redescription of the species. Crustacean Research 25: 7-15.

Keable, S.J., 1996b. Revision of the taxonomy, systematics and biogeography of Natatolana (Crustacea: Isopoda: Cirolanidae). Ph.D. Thesis, Macquarie University, Sydney, Australia, pp. 751. 
Keable, S.J., 1997. The Cirolanidae (Crustacea: Isopoda) of Darwin Harbour, Northern Territory, with additional records from northern Australia and Papua New Guinea. In The marine flora and fauna of Darwin Harbour, Northern Territory, Australia, ed. Hanley, J.R., Caswell, G., Megirian, D. \& Larson, H.K., pp. 245-278. Proceedings of the Sixth International Marine Biological Workshop. Darwin: Museums and Art Galleries of the Northern Territory and the Australian Marine Sciences Association.

Keable, S.J., 1999. Description of a new species of Dolicholana Bruce, 1986 (Crustacea: Isopoda: Cirolanidae) and a redescription of Dolicholana porcellana (Barnard, 1936) comb. nov. Journal of Natural History 33: 395-414.

Keable, S.J., \& N.L. Bruce, 1997. Redescription of the north Atlantic and Mediterranean species of Natatolana (Crustacea: Isopoda: Cirolanidae). Journal of the Marine Biological Association of the United Kingdom 77(3): 655-706.

Kensley, B., 1975. Marine Isopoda from the continental shelf of South Africa. Annals of the South African Museum 67: 35-89.

Kensley, B., 1978. Guide to the Marine Isopods of Southern Africa. Cape Town: Trustees of the South African Museum, pp. 173.

Kensley, B., 1980. Marine isopods from Marion, Prince Edward, and Crozet Islands (Crustacea, Isopoda). Annals of the South African Museum 85(5): 155-185.

Kensley, B., 1984. The South African Museum's Meiring Naude cruises. Part 15. Marine Isopoda of the 1977, 1978, 1979 cruises. Annals of the South African Museum 93(4): 213-301.

Kensley, B., 1989. Marine isopod crustaceans from the St. Paul and Amsterdam Islands, southern Indian Ocean. Bulletin du Muséum national d'Histoire naturelle série 4 tome 11 section A zoologie biologie et écologie animales (1): 147-164.

Kensley, B., 1998. Estimates of species diversity of free-living marine isopod crustaceans on coral reefs. Coral Reefs 17: 83-88.

Kensley, B., 2001. Biogeography of the marine Isopoda of the Indian Ocean, with a check-list of species and records. In Isopod Systematics and Evolution, Crustacean Issues, ed. B. Kensley \& R.C. Brusca, vol. 13, pp. 205-264. Rotterdam: A.A. Balkema.

Kensley, B., \& M. Schotte, 1989. Guide to the Marine Isopod Crustaceans of the Caribbean. Washington: Smithsonian Institution Press, pp. 308.

Koening, M.L., 1972. Nota sobre ocorréncia de alguns isópodos no norte e nordeste do Brasil. Trabahlos Oceanografia da Universidade Federale Pernambuco, Recife 13: 237-244.

Kussakin, O.G., 1967. Fauna of Isopoda and Tanaidacea in the coastal zones of the Antarctic and subantarctic waters. Biological Reports of The Soviet Antarctic Expedition (19551958) 3: 220-389.

Kussakin, O.G., \& G.S. Vasina, 1982a. Addition to the fauna of benthic Isopoda and Gnathiida (Crustacea) of subantarctic waters of the Indian Ocean 1. Isopoda (Flabellifera and Anthuridea). Tethys 10(3): 261-273.

Kussakin, O.G., \& G.S. Vasina, 1982b. Additions to the fauna of benthic Isopoda and Gnathiida (Crustacea) of subantarctic waters of the Indian Ocean. Tethys 10(4): 315-336.

Kwon, D.H., 1988. A Systematic Study on the Korean Marine Isopod Crustaceans I. Flabellifera Part 1. Family Cirolanidae. Inje Journal 4(2): 353-370.

Larwood, H.J., 1940. The fishery grounds near Alexandria. XXI. Tanaidacea and Isopoda. Notes and Memoirs of the Hydrobiology and Fisheries Division, Cairo 1: 1-92.

Leach, W.E., 1818. Cymothoadées. In Dictionnaire des sciences naturelles, ed. F. Cuvier, vol. 12, pp. 338-354. Paris and Strasbourg.

Liljeborg, W., 1851. Norges Crustacéer. Ofversigt af Konglinga Vetenskapsakademiens Forhandlingar, Stockholm 8: 19-25.

Lorenti, M., \& S. Mariani, 1997. Isopoda assemblages in the Straits of Magellan: Structural and functional aspects. Polar Biology 18(4): 254-259.

Lo Bianco, S., 1903. Le pesche abissali eseguite da F. A. Krupp col Yacht Puritan nelle adiacenze di Capri ed in altre località del Mediterraneo. Mittheilungen aus der Zoologischen Station zu Neapel 16: 109-279.

Macquart-Moulin, C., \& R. Kaïm-Malka, 1994. Endogenous circadian rhythm of emergence and swimming activity of the deep water isopod Cirolana borealis Lilljeborg. Marine Behaviour and Physiology 24(3): 151-164.

Marsden, I.D., 1999. Feeding, respiration, and aerial exposure in a scavenging cirolanid isopod from New Zealand. Journal of Crustacean Biology 19(3): 459-466.

Menzies, R.J., 1962. The zoogeography, ecology, and systematics of the Chilean marine isopods. Reports of the Lund University Chile Expedition 1948-49. 42. Lunds Universitets Årsskrifter Avd. 2. Bd 57. Nr 11: 1-162.

Menzies, R.J., \& R.Y. George, 1972. Isopod Crustacea of the PeruChile Trench. Anton Bruun Report 9. Scientific Results of the Southeast Pacific Expedition. Texas A \& M Press, College Station Texas, pp. 124.

Miers, E.J., 1876a. Descriptions of some new Species of Crustacea, chiefly from New Zealand. Annals and Magazine of Natural History 17: 218-229.

Miers, E.J., 1876b. Catalogue of the stalk- and sessile-eyed Crustacea of New Zealand. Colonial Museum and Geological Survey Department of New Zealand, Natural History Publication 10: i-xii, 1-136, pls. 1-3.

Miers, E.J., 1884. Crustacea. In Report on the Zoological Collections Made in the Indo-Pacific Ocean During the Voyage of H.M.S. "Alert” 1881-2, pp. 178-322, 513-575, pls 18-34, 46-52. London: Trustees of the British Museum.

Milne Edwards, H., 1836-1849 (exact date of publication unknown, see Sherborn (1922) but refers to Milne Edwards [1840]). Les crustacés. In Le Règne animal distribue d'après son organisation, pour servir de base a l'histoire naturelle des animaux, et d'introduction a l'anatomie comparee, ed. G.L.C.F.D. Cuvier, vol. 8. Paris: Deterville.

Milne Edwards, H., 1840. Histoire naturelle des Crustacés, comprenant l'anatomie, la physiologie et la classification de ces animaux. Roret, Paris, pp. 638, pls 1-42.

Mizzan, L., 1995. Cirolana cfr. neglecta Hansen, 1890 (Crustacea, Isopoda, Cirolanidae) nelle coste del Veneziano: note su di un attacco ad una postazione di pesca. Bolletino del civico di Storia naturale, Venezia 44: 145-151.

Monod, T., 1930. Contribution a l'étude des Cirolanidae. Annales des Sciences Naturelles Zoologie 13: 129-183.

Monod, T., 1931. Tanaidaces et isopodes sub-antarctiques de la collection Kohl-Larsen du Senckenberg Museum. Senckenbergiana 13(1): 10-30.

Müller, H.-G., 1989. Marine Isopoda from the Levantine Basin of the Mediterranean Sea (Crustacea). Seckenbergiana Maritima 20: 237-240.

Naylor, E., 1966. Port Phillip Survey 1957-1963. Isopoda. Memoirs of the National Museum of Victoria 27: 183-198.

Nierstrasz, H.F., 1917. II.-Die isopoden-sammlung im Naturhistorischen Reichsmuseum zu Leiden.-II. Cymothoidae, Sphaeromidae, Serolidae, Anthuridae, Idotheidae, Asellidae, Janiridae, Munnopside. Zoologische Mededeelingen 3(2-3): 87-120.

Nierstrasz, H.F., 1931. Die Isopoden der Siboga-Expedition. 3. Isopoda Genuina. 2. Flabellifera. Siboga-Expeditie Monographs 32c: 123-233.

Nunomura, N., 1985. Cirolana albicauda, a New Cirolanid Isopod from the Sea of Owase, Middle Japan. Bulletin of the Toyama Science Museum 7: 73-76.

Nunomura, N., 1991. A New Species of the Genus Natatolana off the Coast of Toyama City. Bulletin of the Toyama Science Museum 14: 45-48.

Nunomura, N., 2004. Isopod crustaceans collected from Aomori Prefecture Northern Japan. Contribution of the Biological Laboratory of Kyoto University 29: 351-360.

Pfeffer, G., 1887. Die Krebse von Süd-Georgiea nach der Ausbeute der Deutschen Station 1882-83. Jahurbuch der Hamburgischen 
Wissenschaftlichen Anstalten 4: 41-150.

Pires-Vanin, A.-M.S., 1998. Malacostraca-Peracarida. Marine Isopoda. Anthuridea, Asellota (pars), Flabellifera (pars), and Valvifera. In Catalogue of Crustacea of Brazil, ed. P.S. Young, vol. 6, pp. 605-624. Rio de Janeiro: Museu Nacional.

Poore, G.C.B., S.F. Rainer, R.B. Spies \& E. Ward, 1975. The Zoobenthos program in Port Phillip Bay, 1969-73. Fisheries and Wildlife Paper 7: 1-78.

Ramsay, K., M.J. Kaiser, P.G. Moore \& R.N. Hughes, 1997. Consumption of fisheries discards by benthic scavengers: utilization of energy subsidies in different marine habitats. Journal of Animal Ecology 66: 884-896.

Richardson, H., 1904. Contributions to the natural history of the Isopoda. Proceedings of the United States National Museum 27: $1-89$.

Richardson, H., 1910. Marine Isopods collected in the Philippines by U.S. Fisheries steamer Albatross in 19071908. Department of Commerce and Labor, Bureau of Fisheries Document 736: 1-44.

Ríos, C., E. Mutschke \& E. Morrison, 2003. Biodiversidad bentónica sublitoral en el estrecho de Magallanes, Chile. Revista de Biología Marina y Oceanografía 38(1): 1-12. http://www.revbiolmar.cl/resumenes/v381/381-1.pdf [accessed 11 May 2006]

Riseman, S.F., \& R.C. Brusca, 2002. Taxonomy, phylogeny and biogeography of Politolana Bruce, 1981 (Crustacea: Isopoda: Cirolanidae). Zoological Journal of the Linnean Society 134(1): 57-140.

Roman, M.-L., 1970. Écologie et répartition de certaines groupes d'Isopodes dans les divers biotopes de la région de Tulear (Sudouest de Madagascar). Recueil des travaux de la Station marine d'Endoume, Faculte des sciences de Marseille. Fascicule hors série supplement 10: 163-208.

Saito, N., G. Itani \& N. Nunomura, 2000. A Preliminary Check List of Isopod Crustaceans in Japan. Bulletin of the Toyama Science Museum 23: 11-107.

Schultz, G.A., 1966. Submarine canyons of southern California. Part 4. Systematics: Isopoda. Allan Hancock Pacific Expeditions 27: 1-56.

Schultz, G.A., 1969. How to Know the Marine Isopod Crustaceans. Iowa: Wm. C. Brown, pp. 359.

Schultz, G.A., 1977. Bathypelagic isopod Crustacea from the Antarctic and Southern Seas. Antarctic Research Series, American Geophysical Union 23: 69-128.

Schultz, G.A., 1978. Nonasellote Isopod Crustaceans From Anvers Island and other Antarctic Locations. Antarctic Research Series, American Geophysical Union 28: 21-41.

Sherborn, C.D., 1922. On the dates of Cuvier, "Le Règne Animal", etc. (Disciples Edition). Annals and Magazine of Natural History 9, 10: 555-556.

Springthorpe, R.T., \& J.K. Lowry, 1994. Catalogue of Crustacean Type Specimens in the Australian Museum: Malacostraca. Technical Reports of the Australian Museum 11: 1-134.

Stalio, L., 1877. Catalogo metodico e descrittivo dei crostacei dell'Adriatico. Atti del Reale, Instituto Veneto di Scienze, Lettere ed Arti 3: 1345-1420.

Stebbing, T.R.R., 1900. On Crustacea brought by Dr. Willey from the South Seas. In Zoological Results Based on Material from New Britain, New Guinea, Loyalty Islands, and Elsewhere, Collected During the Years of 1895, 1896 and 1897, ed. A. Willey, vol. 5(33), pp. 605-690 pls 64-74. Cambridge: University Press.

Stebbing, T.R.R., 1910. General Catalogue of South African Crustacea (Part V. of S. A. Crustacea for the Marine Investigations in South Africa). Annals of the South African Museum 6(4): 281-593 pls 15-22b (Crustacea plates 41-48b).

Stephensen, K., 1927. Papers from Dr. Th. Mortensen's Pacific Expedition, 1914-16. XL. Crustacea from the Auckland and Campbell Islands. Videnskabelige Meddelelser fra Dansk Naturhistorisk Forening i Københaven 83: 289-390.
Stephensen, K., 1947. Tanaidacea, Isopoda, Amphipoda and Pycnogonida. Scientific Results of the Norwegian Antarctic Expedition, Oslo 27: 1-90.

Storch, V., J. Strus \& A. Brandt, 2002. Microscopic anatomy and ultrastructure of the digestive system of Natatolana obtusata (Vanhöffen, 1914) (Crustacea, Isopoda). Acta Zoologica 83(1): 1-14.

Stossich, M., 1880. Prospetto della Fauna del mare Adriatico. Bolletino della Societa Adriatica di Scienze in Trieste 6: 178-271.

Takeuchi, I., K. Watanabe, A. Tanimura \& M. Fukuchi, 2001. Assemblages of necrophagous animals off Enderby Land, East Antarctica. Polar Biology 24: 650-656.

Tattersall, W.M., 1913. The Schizopoda, Stomatopoda, and NonAntarctic Isopoda of the Scottish National Antarctic Expedition. Transactions of the Royal Society of Edinburgh 49: 865-894.

Tattersall, W.M., 1921. Crustacea. Part VI.-Tanaidacea and Isopoda. British Antarctic ("Terra Nova") Expedition, 1910. Natural History Report. Zoology 3(8): 191-258.

Taylor, A.C., \& P.G. Moore, 1995. The burrows and physiological adaptations to a burrowing lifestyle of Natatolana borealis (Isopoda: Cirolanidae). Marine Biology 123: 805-814.

Thielemann, M., 1910. Beiträge zur kenntnis der isopodenfauna Ostasiens. Beiträge zur Naturgeschichte Ostasiens. Abhandlungen det Mathematisch-Physikalischen Klasse der Koeniglich Bayerische Akademie der Wissenschaften 2(3): 1-110.

Thomson, G.M., \& C. Chilton, 1886. Critical list of the Crustacea Malacostraca of New Zealand. Transactions and Proceedings of the New Zealand Institute 18: 141-159.

Vanhöffen, E., 1914. Die isopoden der Deutschen SüdpolarExpedition 1901-1903. Deutsche Südpolar Expedition, 19011903 15(Zoology 7): 447-598.

Wägele, J.-W., 1989. Evolution und phylogenetisches System der Isopoda. Zoologica 140: 1-262.

Wägele, J.-W., \& N.L. Bruce, 1989. Natatolana pastorei (Giambiagi, 1925) (Crustacea, Isopoda, Cirolanidae) from the Straits of Magellan, South America: redescription and notes on functional morphology. Proceedings of the Biological Society of Washington 102(1): 95-105.

Watson, L., G.E. Gibbs Russell \& M.J. Dallwitz, 1989. Grass genera of southern Africa: Interactive identification and information retrieval from an automated data bank. South African Journal of Botany 55(4): 452-463.

Wetzer, R., P. Delaney \& R. Brusca, 1987. Politolana wickstenae new species, a new cirolanid isopod from the Gulf of Mexico, and a review of the "Conilera genus-group" of Bruce (1986). Contributions in Science, Natural History Museum of Los Angeles County 392: 1-10.

Wetzer, R., H.G. Kuck, P.R. Baéz, R.C. Brusca \& L.M. Jurkevics, 1991. Catalog of the isopod Crustacea type collection of the Natural History Museum of Los Angeles County. Los Angeles Natural History Museum Technical Reports 3: 1-59.

White, A., 1857. A Popular History of British Crustacea. London: Lovell Reeve, pp. 357.

Wong, Y.M., \& P.G. Moore, 1995. Biology of feeding in the scavenging isopod Natatolana borealis (Isopoda: Cirolanidae). Ophelia 43: 181-196.

Yu, H., \& X. Li, 2001. Record on the species of Cirolanidae (Crustacea Isopoda) from Chinese waters. Studia Marina Sinica 43: 240-269.

Zavodnik, D., \& M. Kovacic, 2000. Index of marine fauna in Rijeka Bay (Adriatic Sea, Croatia). Natura Croatica 9(4): 297379 .

Manuscript submitted 10 November 2004, revised 16 August 2005 and accepted 15 March 2006.

Associate Editor: George D.F. Wilson. 